Universidade de São Paulo

Faculdade de Filosofia, Ciências e Letras de Ribeirão Preto

\title{
Modelos aplicados ao crescimento e tratamento de tumores e à disseminação da dengue e tuberculose
}

\author{
Brenno Caetano Troca Cabella
}

Tese apresentada à Faculdade de Filosofia, Ciências e Letras de Ribeirão Preto da Universidade de São Paulo como parte das exigências para a obtenção do título de Doutor em Ciências. Área: Física Aplicada à Medicina e Biologia.

Ribeirão Preto

2012 


\section{BRENNO CAETANO TROCA CABELLA}

Modelos aplicados ao crescimento e tratamento de tumores e à disseminação da dengue e tuberculose

Tese apresentada à Faculdade de Filosofia, Ciências e Letras de Ribeirão Preto da Universidade de São Paulo como parte das exigências para a obtenção do título de Doutor em Ciências.

Área de Concentração:

Física Aplicada à Medicina e Biologia.

Orientador:

Prof. Dr. Alexandre Souto Martinez.

Versão corrigida

Versão original disponível na FFCLRP-USP

Ribeirão Preto

2012 
Autorizo a reprodução e divulgação total ou parcial deste trabalho, por qualquer meio convencional ou eletrônico, para fins de estudo e pesquisa, desde que citada a fonte.

\section{FICHA CATALOGRÁFICA}

Cabella, Brenno Caetano Troca.

Modelos aplicados ao crescimento e tratamento de tumores e à disseminação da dengue e tuberculose / Brenno Caetano Troca Cabella; orientador: Prof. Dr. Alexandre Souto Martinez. - - Ribeirão Preto, 2012.

182 p. : il.

Tese (Doutorado) - - Faculdade de Filosofia, Ciências e Letras de Ribeirão Preto da Universidade de São Paulo, 2012.

Inclui Bibliografia.

1. Modelos de crescimento. 2. Modelos epidemiológicos. 3. Modelos baseados em agentes. 4. Modelos analíticos. 5. Transições de fase. 6. Funções logaritmo e exponencial generalizadas. 7. Câncer 8. Dengue 9. Tuberculose 
Nome: CABella, Brenno Caetano Troca

Título: Modelos aplicados ao crescimento e tratamento de tumores e à disseminação da dengue e tuberculose

Tese apresentada à Faculdade de Filosofia, Ciências e Letras de Ribeirão Preto da Universidade de São Paulo como parte das exigências para a obtenção do título de Doutor em Ciências.

Aprovado em:

\section{Banca Examinadora}

Prof. Dr. :

Instituição:

Julgamento:

Assinatura:

Prof. Dr. :

Instituição:

Julgamento:

Assinatura:

Prof. Dr. :

Instituição:

Julgamento:

Assinatura:

Prof. Dr. :

Instituição:

Julgamento:

Assinatura:

Prof. Dr. :

Instituição:

Julgamento:

Assinatura: 
À Daniela 


\section{Agradecimentos}

Ao Prof. Alexandre Souto Martinez pela orientação e amizade. Sua dedicação, empenho e ética não só tornaram esse trabalho possível como também me serviram de exemplo de responsabilidade e caráter.

Ao Prof. Marcelo Mulato pelo apoio durante a coordenação do programa de Física Aplicada à Medicina e Biologia. Aos Profs. Fabiano Lemes Ribeiro, Aquino Lauri de Espíndola e César Augusto Sangaletti Terçariol pela amizade e colaborações nos artigos e trabalhos desenvolvidos ao longo do meu doutorado.

Ao Prof. Roberto André Kraenkel pela oportunidade de cursar e de monitorar os cursos de verão em biologia de populações que foram tão essenciais para minha formação.

À Profa. Gail S. K. Wolkowicz por me receber e me orientar durante o estágio de seis meses o qual realizei em seu grupo de pesquisa no Department of Mathematics and Statistics McMaster University ON-Canadá.

Aos demais Profs. que contribuíram para minha formação acadêmica: Ubiraci Pereira da Costa Neves, Draulio Barros de Araujo e Oswaldo Baffa Filho.

Aos Profs.: Evandro Marcos Saidel Ribeiro, Vanessa Rolnik Artioli, Nelson Augusto Alves e Domingos Alves, pelo engajamento demonstrado nas disciplinas que cursei.

Aos membros da minha banca de qualificação, Antonio Carlos Roque da Silva Filho, Jair Lício Ferreira Santos, Marco Antônio Alves da Silva. As sugestões e críticas levantadas foram fundamentais para o bom desenvolvimento desse trabalho.

Ao Prof. Sérgio Mascarenhas de Oliveira por me dar a oportunidade de desenvolver trabalhos tão relevantes na área de saúde. Sua paixão pela ciência é uma inspiração para qualquer pessoa que queria se tornar um pesquisador.

Ao Prof. Antonio Carlos Roque da Silva Filho por manter o cineclube da física funcionando e com isso complementar minha formação como doutor por meio da cultura.

Às secretárias Nilza Marina Leone Marino e Sonia Aparecida Nali de Paula pelo apoio e atenção dispensadas aos longo de todo o processo de pós-graduação. 
Aos "coleguinhas" de laboratório: Natália Destefano, Marcelo Alves Pereira, Lindomar Soares dos Santos, Olavo Henrique Menin, Tiago José Arruda, Fernanda Miranda de Oliveira, Cristiano Roberto Fabri Granzotti, Enock de Almeida Andrade Neto, Rodrigo Silva González , Juliana Militão da Silva Berbert e Bobby Pelas discussões durante os seminários, conversas nos almoços e corridas no fim de tarde. Valeu Oreia! Obrigado por ajudarem a manter minha sanidade no dia-a-dia de trabalho.

Aos colegas da McMaster University: Stephen Murray, Mudassar Imran, Mehbuba Rehim, Teja Voruganti e Catharina Jager Pelas colaborações e amizade.

À minha família pela força, incentivo e apoio incondicional para seguir na carreira acadêmica.

À minha querida namorada Daniela, que com seu carinho, amor e compreensão me apoiou nos momentos difíceis transformando cada brasa em uma brisa, cada adversidade em um sorriso, e cada tormenta em uma oportunidade de demonstrar seu amor.

Às demais pessoas que fizeram parte da minha vida e a quem devo parte deste trabalho: Louise Chui Florencio, Márcio Júnior Sturzbecher, Leandro Gutierrez Rizzi, Rafael Bertolini Frigori e Shirlei Nabarrete Dezidério.

À CAPES pelo suporte financeiro, possibilitando dedicação exclusiva a esse trabalho.

Ao governo Canadense por fornecer uma bolsa de seis meses por meio do Graduate Student Exchange program (GSEP).

Agradeço a Deus pela oportunidade de ter contato com todas essas pessoas e outras que eventualmente não citei aqui. Todas elas contribuíram para que eu me tornasse a pessoa que sou hoje, feliz e eternamente grato. 
"Le véritable voyage de découverte ne consiste pas à chercher de nouvelles terres, mais de voir avec des yeux nouveaux." 


\section{Resumo}

CABELLA, B. C. T. Modelos aplicados ao crescimento e tratamento de tumores e à disseminação da dengue e tuberculose. 2012. 182 p. Tese (Doutorado - Programa de Pós-Graduação em Física Aplicada à Medicina e Biologia) Faculdade de Filosofia, Ciências e Letras de Ribeirão Preto da Universidade de São Paulo. 2012.

A generalização de modelos de crescimento por meio de um parâmetro de controle foi primeiramente proposta por Richards, em 1959. Em nosso trabalho, propomos uma forma alternativa de generalização obtendo uma interpretação empírica e outra microscópica do parâmetro de controle. Mais especificamente, quando consideramos a proliferação de células, o parâmetro está relacionado ao alcance da interação e à dimensão fractal da estrutura celular. Obtemos a solução analítica para esta equação diferencial. Mostramos que, através da escolha apropriada da escala conseguimos o colapso de dados representando a independência em relação aos parâmetros e às condições iniciais. Além disso, ao considerarmos a taxa de esforço como a retirada de indivíduos de uma população, podemos associá-la ao tratamento visando extinguir uma população de células cancerosas. Em modelos epidemiológicos, propomos modelar a dinâmica de transmissão da dengue utilizando equações diferenciais ordinárias. Em nosso modelo, levamos em conta tanto a dinâmica do hospedeiro quanto a do vetor, assim temos o controle da dinâmica de ambas as populações. Incluímos também no modelo o efeito enhancing com intuito de verificar sua influência na dinâmica de disseminação da doença. O efeito enhancing é considerada uma das principais hipóteses para explicar a dengue hemorrágica que pode levar à morte. Fizemos o estudo de um modelo epidemiológico da dengue com o objetivo de revelar quais são os fatores que levam à disseminação desse caso mais severo da doença e, possivelmente, sugerir políticas públicas de saúde para evitá-lo. Implementamos também um modelo de transmissão da tuberculose fazendo uso da modelagem computacional baseada em agentes, que oferece a possibilidade de representar explicitamente heterogeneidades em nível individual.

Palavras-chave: 1. Modelos de crescimento. 2. Modelos epidemiológicos. 3. Modelos baseados em agentes. 4. Modelos analíticos. 5. Transições de fase. 6. Funções logaritmo e exponencial generalizadas. 7. Câncer 8. Dengue 9. Tuberculose 


\section{Abstract}

CABELLA, B. C. T. Models applied to tumors growth and treatment and the spread of dengue and tuberculosis. 2012. 182 p. Thesis (Ph.D. - Postgraduate program in Physics Applied to Medicine and Biology) - University of São Paulo Faculty of Philosophy, Sciences and Letters. 2012.

The generalization of growth models by means of a control parameter was first proposed by Richards in 1959. In our work, we propose an alternative way to obtainin an empirical and microscopic interpretation of control parameter. More specifically, when considering the proliferation of cells, the parameter is related to the range of interaction and the fractal dimension of the cell structure. We obtain the analytical solution for this differential equation. We show that, by appropriate choice of scale we have data collapse, representing the independence on parameters and initial conditions. Furthermore, when considering the effort as rate the removal of individuals from a population, we can associate it with the treatment to extinguish cancer cells population. In epidemiological models, we propose to model the dynamics of dengue transmission using ordinary differential equations. In our model, we take into account both the dynamics of the host and the vector, so we have control of the dynamics of both populations. We also included in the model the effect of Enhancing in order to verify their influence on the dynamics of disease spread. The effect of Enhancing is considered one of the main hypotheses to explain the hemorrhagic fever that can lead to death. We study a model of epidemiology of dengue in order to reveal what are the factors that lead to the dissemination of this more severe case of the disease and, possibly suggesting public health policies to prevent it. We also implemented a model of tuberculosis transmission making use of agent-based computational modeling, which offers the possibility to explicitly represent heterogeneity at the individual level.

Key-words: 1. Growth models. 2. Epidemiological models. 3. Agent-based models. 4. Analitical models. 5. Phase transitions. 6. Generalized exponential and logarithmic function. 7. Cancer 8. Dengue 9. Tuberculosis 


\section{Lista de Figuras}

2.1 Representação das relações entre os modelos de dinâmica populacional de uma espécie. A partir do modelo de Tsoularis-Wallace todos os demais modelos podem ser obtidos com a escolha apropriada dos parâmetros. .......................... 16

3.2 Gráfico da população $p(\tau)$ [Eqs. 3.4 e 3.22] como função de $\tau$, com: $p_{0}=1 / 10, \epsilon=-3 / 10, \tilde{q}=-1, \tilde{q} \rightarrow 0$ (modelo Gompertz) e $\tilde{q}=1$ (modelo Verhulst). A equivalência completa entre taxa extrínseca de crescimento e capacidade de suporte efetiva é obtida somente para soluções de estado estacionário. No entanto, para $\tilde{q} \rightarrow 0$, a solução transiente também é equivalente.Adaptada da Ref. [23]. . . . . . . . . 28

4.1 A área sob a curva $1 /[p \cdot G(p)]$ cresce linearmente como função de $\tau-\tau_{0}$. Este comportamento não depende do modelo considerado. Extraída da

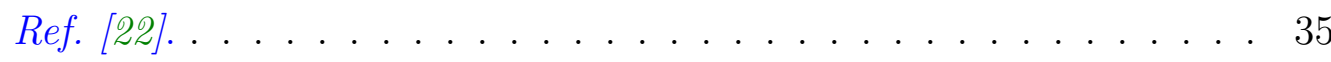

5.1 Diagrama das interações ecológicas entre duas espécies de acordo com parâmetros de interações $\left(\epsilon_{1}, \epsilon_{2}\right)$. Neste diagrama, cada quadrante representa um tipo de interação: I: mutualismo; II e IV: predação; III: competição. A abcissa e a ordenada representam ou amensalismo ou comensalismo. A origem representa neutralidade.Adaptada da Ref. [67] 47 
5.2 Diagrama das interações ecológicas entre duas espécies de acordo com o par $\epsilon_{1}, \epsilon_{2}$. Neste diagrama, cada quadrante representa um tipo de interação. I: Mutualismo; II e IV: Predação; III: Competição. O eixo das abscissas e ordenadas representam amensalismo ou comensalismo. A origem representa neutralismo. As soluções não triviais $\left(\epsilon_{1}>-1, \epsilon_{2}>-1\right.$ e $\left.\epsilon_{1} \epsilon_{2}<1\right)$ correspondem à fase de coexistência. Nesta fase, mutualismo, comensalismo, amensalismo, predação, competição e neutralismo podem ocorrer, por exemplo, dentro do círculo tracejado. A região complementar é caracterizada pela fase de extinção e uma região proibida. A fase de extinção $\left(\epsilon_{1}<-1\right.$ e/ou $\left.\epsilon_{2}<-1\right)$ revela uma região para $\epsilon_{1}<0$ e $\epsilon_{2}<0$ em que, ao contrário dos outros casos, as soluções do estado estacionário dependem das condições iniciais. Para $\epsilon_{1}>1$ e $\epsilon_{2}>0$ e $\epsilon_{2}>1 / \epsilon_{1}$, existe uma região proibida em que não há realidade biológica (número negativo de indivíduos).Adaptado da Ref. [6r] . . . . . . . . . . . . . . . 51

5.3 Gráfico das soluções dos estados estacionários $p_{1, n t}^{*}=\left(1+\epsilon_{1}\right) /\left(1-\epsilon_{1} \epsilon_{2}\right)$ e $p_{2, n t}^{*}=\left(1+\epsilon_{2}\right) /\left(1-\epsilon_{1} \epsilon_{2}\right)$ do modelo da Eq. 5.3 em função de $\epsilon_{1}$, com $\epsilon_{2}=1$. Nestas curvas vemos duas transições de fase. A primeira é a transição coexistência-extinção no regime de predação, que ocorre para $\epsilon_{1}=-1$. Próximo ao ponto crítico $\epsilon_{1}^{c}$, a espécie 1 é extinta de uma forma linear, isto é, $p_{1, n t}^{*} \sim\left(\epsilon_{1}-\epsilon_{1}^{c}\right)$. A segunda é a transição de coexistência (mutualismo) para uma região proibida (sem realidade biológica). Ambas as transições possuem expoente crítico $\beta=1$. Adaptada da Ref. [6r] . . . . . . . . . . . . . 52

5.4 Curvas da solução da Eq. 5.20, dada pela Eq. 5.24, para diferentes valores do parâmetro de interação $\epsilon_{2}$ e $\rho=1$. O regime de comensalismo é obtido para $\epsilon_{2}>0$, em que o valor assintótico, devido à outra espécie, é maior que um. O regime de neutralismo é obtido para $\epsilon_{2}=0$. O regime de amensalismo é obtido para $\epsilon_{2}<0$, em que o valor assintótico não é nulo (coexistência das espécies) para $\epsilon_{2}>-1$ e se torna nulo (extinção da espécie) quando $\epsilon_{2} \leq-1$. Adaptada da

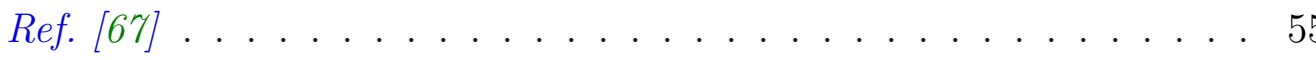


5.5 Gráficos das Eqs. 5.24 e 5.21, que são soluções da Eq. 5.3. A condição inicial é $p_{1,0}=p_{2,0}=1 / 100$ e $\rho=1$. Os parâmetros de interação $\epsilon_{1} \epsilon_{2} \neq 0$ são: para competição, $\epsilon_{1}=-1 / 2$ e $\epsilon_{2}=-1 / 10$; para mutualismo, $\epsilon_{1}=1 / 2$ e $\epsilon_{2}=1 / 10$; e para predação: $\epsilon_{1}=1 / 2$ e $\epsilon_{2}=-1 / 2$. Adaptada da Ref. [67] . . . . . . . . . . . . . . . . . 57

6.1 Diagrama da interações ecológicas entre duas espécies de acordo com o par $\left(\epsilon_{1}, \epsilon_{2}\right)$. Neste diagrama, cada quadrante representa um tipo de interação (ver Fig. 5.1): I: mutualismo; II e IV: predação e III: competição. A abcissa e a ordenada representam cada uma os regimes de amensalismo $\left(\epsilon_{1}\right.$ ou $\left.\epsilon_{2}<0\right)$ e comensalismo $\epsilon_{1}$ ou $\epsilon_{2}>0$. A origem representa o regime de neutralismo. As soluções não triviais $\left(\epsilon_{1}>\right.$ $\left.-1 / \tilde{q}_{1}, \epsilon_{2}>-1 / \tilde{q}_{2}\right)$ correspondem à coexistência de fases. A fase de extinção $\left(\epsilon_{1}<-1 / \tilde{q}_{1}\right.$ e/ou $\left.\epsilon_{2}<-1 / \tilde{q}_{2}\right)$ revela uma região para $\epsilon_{1}<0$ and $\epsilon_{2}<0$ em que, ao contrário dos outros casos, as soluções de estado estacionário dependem da condição inicial.

6.2 Soluções do estado estacionário para a espécie 2 no regime de amensalismo. Valor de $p_{2}^{*}$ em função de $\epsilon_{2}$, para $\tilde{q_{2}}=-1 ; 0 ; 1 / 2 ; 1 ; 3 / 2$ e 2 . Quando $\tilde{q}_{2} \epsilon_{2}<-1$, então $p_{2}^{*}=0$.

6.3 Soluções do estado estacionário para a espécie 2 no regime de amensalismo. Valor de $p_{2}^{*}$ em função de $\tilde{q}_{2}$ para $\epsilon_{2}=-100 ;-10 ;-15 ;-1 \mathrm{e}$ $-1 / 2$. Quando $\tilde{q}_{2} \epsilon_{2}<-1$, então $p_{2}^{*}=0 \ldots \ldots$. . . . . . 68

6.4 Soluções do estado estacionário para a espécie 2 no regime de comensalismo. Valor de $p_{2}^{*}$ em função de $\epsilon_{2}$, para $\tilde{q_{2}}=-1 ; 0 ; 1 ;$ e 2 .

6.5 Soluções do estado estacionário para a espécie 2 no regime de comensalismo. Valor de $p_{2}^{*}$ em função de $\tilde{q}_{2}$ para $\epsilon_{2}=1 / 10 ; 1 / 2 ; 1$; e 2 . A linha tracejada vertical representa o ponto em que a solução do estado estacionário diverge. 
xviii

6.6 Representação da interação ecológica de amensalismo entre o mofo de pão e a bactéria. Um modelo de duas espécies pode ser simplificado a um modelo de uma espécie com capacidade de suporte efetiva. (a) Bactéria ocupando todo espaço disponível com capacidade de suporte K. (b) Crescimento restrito de bactérias devido à interação com o fungo, capacidade de suporte $K^{\prime}<K$.Adaptada da Ref. [23] . . . . . 71

6.7 Valor da população $p(\tau)$ para o regime de amensalismo. Para $\tilde{q}_{1}=1 / 2$ e para diversos valores de $\tilde{q}_{2}$, gráficos de $p_{1}(\tau)$ (linha grossa), dada pela Eq. 2.13 e de $p_{2}(\tau)$ (linhas finas), dadas pela Eq. 6.30, em que a integral desta equação foi calculada numericamente. Parâmetros: $\rho=1, \epsilon_{1}=0$ e $\epsilon_{2}=1 / 2 \ldots \ldots \ldots \ldots \ldots$

6.8 Valor da população $p(\tau)$ para o regime de amensalismo. Para $\tilde{q}_{1}=2$ e para diversos valores de $\tilde{q}_{2}$, gráficos de $p_{1}(\tau)$ (linha grossa), dada pela Eq. 2.13 e de $p_{2}(\tau)$ (linhas finas), dadas pela Eq. 6.30, em que a integral da Eq. 6.30 foi calculada numericamente. Parâmetros: $\rho=1$,

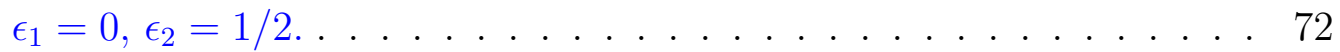

6.9 Isóclinas $1 b$ e $2 b$ com $\epsilon_{1}>0$ e $\epsilon_{2}>0$ (mutualismo); $\tilde{q}_{1}>1$ e $\tilde{q}_{2}>1$. O cruzamento das isóclinas fornece o valor do estado estacionário. . . 73

6.10 Isóclinas $1 b$ e $2 b \operatorname{com} \epsilon_{1}>0$ e $\epsilon_{2}>0$ (mutualismo); $\tilde{q}_{1}<1$ e $\tilde{q}_{2}<1$. As isóclinas nunca interceptam e as populações crescem indefinidamente. 74

6.11 Isóclinas para o regime de competição considerando $\tilde{q}_{1}>1$ e $\tilde{q}_{2}>1$. Quando a solução do estado estacionário está acima da curva $p_{2}=$ $1-p_{1}$ ela é estável. . . . . . . . . . . . . . . . . . . . 74

6.12 Isóclinas para o regime de competição considerando $\tilde{q}_{1}<1$ e $\tilde{q}_{2}<1$. Quando a solução do estado estacionário está acima da curva $p_{2}=$ $1-p_{1}$ ela é estável. . . . . . . . . . . . . . . . . . . 75 
6.13 Representação dos pontos de equilíbrio para o regime de competição. O ponto cheio representa equilíbrio estável e o vazio instável. Quando o ponto fixo da solução não trivial fica abaixo da reta $p_{2}=1-p_{1}$, o ponto se torna instável e as soluções semi triviais passam a ser estáveis. A separatriz demarca o limite que define a partir de qual condição inicial será atingido um ou outro equilíbrio $\left(p_{1}^{*}, p_{2}^{*}\right)=(0,1)$

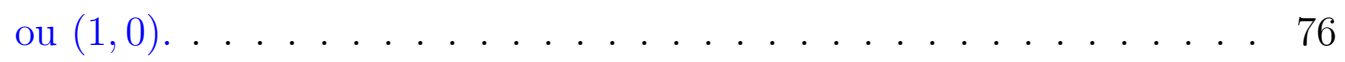

6.14 Regime de predação sendo a espécie 1 a predadora. Para a predação fraca $\tilde{q}_{2}\left|\epsilon_{2}\right|<1$, a solução não trivial é estável e temos coexistência das espécies com $\tilde{q}_{1}>1$ e $\tilde{q}_{2}>1$.

6.15 Regime de predação em que a espécie 1 é a predadora. Para a predação fraca $\tilde{q}_{2}\left|\epsilon_{2}\right|<1$, a solução não trivial é estável e temos coexistência das espécies com $\tilde{q}_{1}<1$ e $\tilde{q}_{2}<1$. . . . . . . . . . . . . . 77

6.16 Regime de predação em que a espécie 1 é a predadora. Neste caso $\tilde{q}_{2}\left|\epsilon_{2}\right|>1$ e a solução semi trivial é estável. Nesse caso não há intersecção entre as isóclinas com $\tilde{q}_{1}>1$ e $\tilde{q}_{2}>1 \ldots$. . . . . . . . . . . 77

6.17 Regime de predação em que a espécie 1 é a predadora. Neste caso $\tilde{q}_{2}\left|\epsilon_{2}\right|>1$ e a solução semi trivial é estável. Nesse caso não há intersecção entre as isóclinas com $\tilde{q}_{1}<1$ e $\tilde{q}_{2}<1 \ldots$. . . . . . . . . 78

6.18 Este esquema nos permite escrever: $d N_{S} / d t=-\beta N_{S} N_{I} / N \ldots \ldots . .79$

7.1 Ilustração esquemática da relação entre o curso da infecção da dengue e a viremia em um hospedeiro. Adaptado da Ref. [101].A infecção inicial leva a uma viremia moderada e a uma produção de anticorpos específicos ao sorotipo. Por um breve período de tempo esses anticorpos podem inibir infecções subsequentes com sorotipos heterólogos (imunidade cruzada) e rapidamente caem de forma a não ter mais impacto contra infecções a outros sorotipos (heterólogos). Se o hospedeiro for infectado com um segundo sorotipo, antes do nível de anticorpos baixar até um segundo limiar, essa quantidade moderada de anticorpos pode favorecer a replicação viral (reforço) [101]. . . . . 86 
7.2 Representação esquemática da dinâmica de transmissão da dengue para dois sorotipos. As transições entre os compartimentos definidos na Tab. 7.1 são regidos por taxas mostradas na Tab. 7.2 . . . . . . . 88

7.3 Número de indivíduos ao longo do tempo para os compartimentos: $I_{1}, I_{2}, V_{I_{1}}, V_{I_{2}}, S, V_{S}, H_{12}$ e $H_{21}$. Um segundo sorotipo é introduzido 300 anos após o primeiro. . . . . . . . . . . . . . . . . . 91

7.4 Número de indivíduos ao longo do tempo para os compartimentos: $I_{1}, I_{2}, V_{I_{1}}, V_{I_{2}}, S, V_{S}, H_{12}$ e $H_{21}$. Um segundo sorotipo é introduzido 1 ano após o primeiro. . . . . . . . . . . . . . . . . . . . . 92

8.1 (a) Possíveis resultados para $b=6$ bolas retiradas de uma urna com $N=2$ bolas. (b) Primeiras 7 linhas do triângulo de Pascal, com a $7^{\mathrm{a}}$ linha em destaque, cuja soma dos elementos é $2^{6}=64$. (c) Possíveis valores assumidos por $b_{1}$ e $b_{2}$ de modo a obedecerem as restrições $b_{1}+b_{2}=b, b_{1} \geq 0$ e $b_{2} \geq 0$. . . . . . . . . . 95

8.2 (a) Possíveis resultados para $b=6$ bolas retiradas de uma urna com $N=3$ bolas. (b) Resultados estão agrupados segundo o número $x$ de cores.

8.3 (a) Pirâmide de Pascal com a $7^{\mathrm{a}}$ camada em destaque, cuja soma dos elementos é $3^{6}=729$. (b) Possíveis valores de $b_{1}, b_{2}$ e $b_{3}$ representados através de um sistema de 3 eixos cartesianos, de modo a obedecer às restrições $b_{1}+b_{2}+b_{3}=b, b_{1} \geq 0, b_{2} \geq 0$ e $b_{3} \geq 0$. . . . . . . 96

8.4 (a) Possíveis resultados para $b=6$ retiradas de uma urna com $N=$ 4 bolas. (b) Resultados estão agrupados segundo o número $x$ de cores. (c) $7^{\mathrm{a}}$ camada da hiper-pirâmide de Pascal, cuja soma de seus elementos é $4^{6}=4096 \ldots \ldots$. . . . . . . . . . . . . . . . 97

8.5 O gráfico para o valor de $\bar{x}(N, b)$ em função de $b$ para diferentes valores de $N \ldots \ldots \ldots \ldots 10 . \ldots \ldots \ldots$

9.1 Representação esquemática da interação entre os cinco estados da tuberculose. Adaptada da Ref. [93] . . . . . . . . . . . . . . . 106 
9.2 Configurações da rede em quatro instantes diferentes. Cada cor representa um estado: verde, $X$; amarelo, $L_{S}$; laranja, $L_{R}$, vermelho, $T_{S}$; e rosa, $T_{R}$. Os parâmetros da simulação são: $L=100, n_{T}=3 / 5$, $n_{L}=1 / 10, \phi=1 / 2, \sigma=1 / 5$ e $r=9 / 10$.Adaptada da Ref. [93] . . . 112

9.3 Evolução de tuberculose em um modelo de rede representando 400 anos, para proporções iniciais diferentes de indivíduos infecciosos com o tipo $s$ de bactéria, $T_{S}(t=0)$. O sistema evolui apenas com interações locais $(\Lambda=1)$. Inset:um zoom para o período do ano 0 até o 100. Tratamento e quimioprofilaxia não são aplicados durante toda a evolução do sistema.Adaptada da Ref. [93] . . . . . . . . . . . . . . 113

9.4 Evolução da tuberculose em um modelo de rede representando 400 anos, para diferentes proporções iniciais de indivíduos infecciosos que possuem o tipo $S$ de bactéria, $T_{S}(t=0)$. O sistema evolui somente com interações globais $(\Lambda=0)$. Inset: ampliação para o período do ano 0 até o 100. Tratamento e quimioprofilaxia não são aplicados durante toda a evolução do sistema.Adaptada da Ref. [93] . . . . . . . 114

9.5 Evolução da tuberculose no modelo de rede, representando 500 anos. Tratamento e quimioprofilaxia começam no ano 200. Inset: Ampliação do período dos anos de 190 a 300. Os parâmetros da simulação são: $n_{T}=3 / 5, n_{L}=1 / 10, \phi=95 / 100, \sigma=58 / 100, r=1 / 10 \mathrm{e}$ $\Lambda=1$. Adaptada da Ref. [93] . . . . . . . . . . . . . . 115

9.6 Evolução da tuberculose durante 300 anos com tratamento e quimioprofilaxia iniciando no ano 200 para dois conjuntos de parâmetros. Conjunto 1: $n_{T}=3 / 5, n_{L}=1 / 10, \phi=95 \%, \sigma=58 \%, r=1 / 10 \mathrm{e}$ $\Lambda=1$. Conjunto $2: n_{T}=3 / 5, n_{L}=1 / 10, \phi=1 / 2, \sigma=1 / 5, r=1 / 2$ e $\Lambda=1$. Adaptada da Ref. [93] . . . . . . . . . . . . . . . . 116 
xxii

9.7 Evolução da tuberculose durante 300 anos com tratamento e quimioprofilaxia começando no ano 200 somente com interações locais, $\Lambda=1$, e somente com interações globais, $\Lambda=0$. A série de tempo a partir do ano 0 até o 299 foi omitida. Somente casos $T_{S}$ são mostrados nessa figura. Inset: estado estacionário para indivíduos $T_{S}$ do $250^{\circ}$ ao $300^{\circ}$ ano. Os parâmetros são: $\phi=1 / 2, \sigma=1 / 5$ e $r=1 / 2$.Adaptada da Ref.[93] . . . . . . . . . . . . . . . . . . 117

9.8 Evolução da tuberculose durante 300 anos com tratamento e quimioprofilaxia iniciando no ano 200 somente com interações locais, $\Lambda=1$, e somente interações globais, $\Lambda=0$. A série de tempo dos anos 0 ao 299 está omitida. Somente casos $T_{R}$ são exibidos nessa figura. Os parâmetros são: $\phi=1 / 2, \sigma=1 / 5, r=1 / 2$.Adaptada da Ref. [93] . . 118

9.9 Evolução no tempo da probabilidade média para interações locais, $P_{\mathcal{L}}$, e globais, $P_{\mathcal{G}}$. Quadrados: média $\left\langle P_{\mathcal{L}}\right\rangle$; triângulos: média $\left\langle P_{\mathcal{G}}\right\rangle$. Os parâmetros usados são: $\phi=1 / 2, \sigma=1 / 5, r=1 / 2$ e $\Lambda=1$.Adaptada da Ref. [93] . . . . . . . . . . . . . . . . . . . . . . 119

9.10 Casos $T_{S}$ e $T_{R}$ como função da proporção de indivíduos infecciosos que recebem tratamento, $n_{T}$. Os valores apresentados na figura são referentes ao $220^{\circ}$ ano. O tratamento e a quimioprofilaxia são iniciados no ano 200. Os parâmetros são: $n_{L}=1 / 5, \phi=1 / 2, \sigma=1 / 5$, $r=1 / 2$ e $\Lambda=1$.Adaptada da Ref. [93] . . . . . . . . . . . 120

9.11 Casos $T_{S}$ e $T_{R}$ como função da proporção de indivíduos latentes que recebem quimioprofilaxia, $n_{L}$. Os valores apresentados na figura são referentes ao $220^{\circ}$ ano. O tratamento e quimioprofilaxia são iniciados no ano 200. Parâmetros usados: $n_{T}=3 / 5, \phi=1 / 2, \sigma=1 / 2, r=1 / 2$ e $\Lambda=1$. Adaptada da Ref. [93] . . . . . . . . . . . . . . . . 120

$9.12 L_{S}$ e $L_{R}$ casos como função de $n_{L}$ para países desenvolvidos $(\phi=95 \%)$ e em desenvolvimento $(\phi=1 / 2)$. Parâmetros: $r=1 / 2, \delta=4 / 5 \mathrm{e}$ $n_{T}=3 / 5 \ldots \ldots \ldots \ldots \ldots \ldots \ldots \ldots$

9.13 Número de casos $T_{S}$ e $T_{R}$ como função de $n_{L}$ para países desenvolvidos $(\phi=95 \%)$ e em desenvolvimento $(\phi=1 / 2)$.Parâmetros usados: $r=$ $1 / 2, \delta=4 / 5, n_{T}=3 / 5 \ldots \ldots \ldots \ldots \ldots \ldots \ldots$ 
9.14 Casos $T_{S}$ e $T_{R}$ em função de $n_{T}$ para diferentes valores de $\phi$. O inset de (b) mostra uma ampliação da região $3 / 5<n_{T}<9 / 10$. Parâmetros: $\delta=4 / 5, \sigma=1 / 5$ e $n_{L}=1 / 10 \ldots \ldots \ldots \ldots \ldots \ldots$

9.15 Casos $T_{R}$ em função de $\Lambda$ para países desenvolvidos $(\phi=95 \%, r=$ 1/10) e em desenvolvimento $(\phi=1 / 2, r=1 / 2)$. Parâmetros: $\sigma=$ $1 / 5, \delta=4 / 5, n_{T}=3 / 5$ e $n_{L}=1 / 10 \ldots \ldots 126$

A.1 Comportamento hiperbólico $(\tilde{q}<1)$, constante $(\tilde{q}=1)$ e lei de potência $(\tilde{q}>1)$ da função $f_{\tilde{q}}(t)=t^{\tilde{q}-1}$ (Eq. A.1) para diversos valores de $\tilde{q}$. Note-se que para $\tilde{q}=2$ (função linear) ocorre uma mudança de concavidade nas leis de potência. . . . . . . . . . . . . . . 150

A.2 Comportamento da função $\tilde{q}$-logarítmica (Eq. A.2) para alguns valores

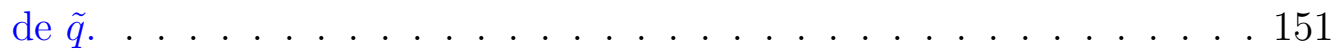

A.3 Comportamento da função $\tilde{q}$-exponencial (Eq A.7) para alguns valores

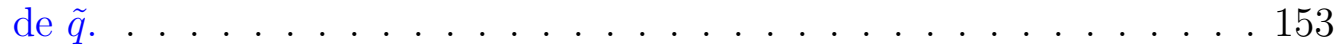




\section{Lista de Tabelas}

4.1 Tabela resumo com as taxas de crescimento per capta dos modelos de uma espécie, reescaladas com a variável independente $\tau=\kappa t$, e suas respectivas soluções e funções de escala. . . . . . . . . . . . . . . . . 40

7.1 Compartimentos do modelo de transmissão da dengue e seus respectivos significados. . . . . . . . . . . . . . . . . . . . . . 89

7.2 Parâmetros do modelo de transmissão da dengue e seus respectivos significados e unidades. A constante $\alpha$ refere-se ao fato de que indivíduos com dengue hemorrágica possuem uma carga viral maior, portanto possuem maior probabilidade de infectar um mosquito. Note também que a princípio utilizamos valores constantes para $r(t), d(t)$ e $\gamma(t) \ldots \ldots \ldots \ldots \ldots \ldots$

8.1 Número de faces de um $n$-simplex. . . . . . . . . . . . . 100

9.1 Descrição dos parâmetros do modelo de disseminação da tuberculose. 106 
xxvi 


\section{Sumário}

$\begin{array}{ll}\text { Lista de Figuras } & \text { XV }\end{array}$

$\begin{array}{ll}\text { Lista de Tabelas } & \text { xxv }\end{array}$

1 Introdução 1

2 Dinâmica populacional de uma espécie $\quad 7$

2.1 Modelo de Malthus . . . . . . . . . . . . . . . . . . . . . . . 8

2.2 Modelo de von Foerster . . . . . . . . . . . . . . . . . . . . . . . . 9

2.3 Modelo de Gompertz . . . . . . . . . . . . . . . . . . . . . . . 10

2.4 Modelo de Verhulst . . . . . . . . . . . . . . . . . . . . . 11

2.5 Modelo de Richards e sua interpretação empírica . . . . . . . . . . . . 11

2.6 Modelo de Hiper-Gompertz ～. . . . . . . . . . . . . . . . . . . . . . 14

2.7 Modelo de Tsoularis-Wallace . . . . . . . . . . . . . . . . . . . . . 15

2.8 Conclusão . . . . . . . . . . . . . . . . . . . . . . . 16

$\begin{array}{lll}3 & \text { Taxa extrínseca de crescimento } & 17\end{array}$

3.1 Modelo de Schaefer . . . . . . . . . . . . . . . . . . . . . . 18

3.2 Taxa extrínseca constante . . . . . . . . . . . . . . . . 18

3.3 Interpretação microscópica do parâmetro $\tilde{q}$. . . . . . . . . . . . . . . 19

3.4 Tratamento de tumores e soluções de estado estacionário . . . . . . . 23

3.5 Capacidade de suporte efetiva . . . . . . . . . . . . 26

3.6 Taxas intrínseca e extrínseca dependentes do tempo . . . . . . . . . . 28

3.7 Conclusão . . . . . . . . . . . . . . . . . . . . . . . . . . . . 30 
xxviii

4 Funções de escala e colapso de dados em modelos de crescimento 33

4.1 Funções de Escala . . . . . . . . . . . . . . . . . . . . . . . . . . 34

4.2 Conclusão . . . . . . . . . . . . . . . . . . . . . . . . . . . 41

5 Modelo de Lotka-Volterra competitivo 43

5.1 Tipos de relações ecológicas . . . . . . . . . . . . . . . . . . 44

5.1 .1 Predação . . . . . . . . . . . . . . . . . 45

5.1 .2 Competição . . . . . . . . . . . . . . . . . . . 45

5.1 .3 Mutualismo .................... 46

5.1 .4 Amensalismo e comensalismo . . . . . . . . . . . . . . 46

5.2 Soluções dos estados estacionários . . . . . . . . . . . . . . . . . 46

5.2.1 Análise de estabilidade . . . . . . . . . . . . . . . . . . 48

5.2.1.1 Soluções triviais . . . . . . . . . . . . . . 48

5.2.1.2 Soluções semi-triviais . . . . . . . . . . . . . . . 49

5.2.1.3 Soluções não-triviais . . . . . . . . . . . . . . . 49

5.2 .2 Diagrama de fases . . . . . . . . . . . . . . . 50

5.3 Soluções analíticas . . . . . . . . . . . . . . . . . . . . . 50

5.3.1 Casos particulares $\left(\epsilon_{1} \epsilon_{2}=0\right) \ldots \ldots \ldots 2$

5.3 .1 .1 Neutralismo . . . . . . . . . . . . 53

5.3.1.2 Comensalismo e amensalismo . . . . . . . . 53

5.3.2 Mutualismo, competição e predação $\left(\epsilon_{1} \epsilon_{2} \neq 0\right) \ldots$. . . . . 54

5.3.3 Tratamento de câncer a partir de vírus replicantes . . . . . . . 57

5.4 Conclusão . . . . . . . . . . . . . . . . . . . . . 58

6 Modelo generalizado de Lotka-Volterra competitivo 61

6.1 Modelo do tipo Richards para duas espécies . . . . . . . . . . . . . . 62

6.2 Estabilidade das soluções dos estados estacionários . . . . . . . . . . 62

6.2.1 Soluções triviais: extinção mútua . . . . . . . . . . . . . . . 64

6.2.2 Soluções semi-triviais: extinção de uma espécie . . . . . . . . . 65

6.2.3 Soluções não-triviais: coexistência das espécies . . . . . . . . . 66

6.3 Regimes ecológicos . . . . . . . . . . . . . . . . . . . . . 67

6.3.1 Neutralismo, amensalismo ou comensalismo $\left(\epsilon_{1} \epsilon_{2}=0\right)$. . . . 67

6.3.2 Casos particulares $\left(\epsilon_{1} \epsilon_{2} \neq 0\right)$. . . . . . . . . 72 
xxix

6.3.2.1 Mutualismo . . . . . . . . . . . . 72

6.3.2.2 Competição . . . . . . . . . . . . . . . . 73

6.3.2.3 Predação . . . . . . . . . . . . . . . 75

6.4 Relações entre modelos de crescimento e epidemiologia . . . . . . . . 78

6.5 Conclusão . . . . . . . . . . . . . . . . . . . . . . . . . 80

7 Modelo de transmissão da dengue hemorrágica $\quad 83$

7.1 Efeito de reforço . . . . . . . . . . . . . . 85

7.2 Transmissão com dois sorotipos . . . . . . . . . . . . 86

7.3 Implementação numérica e resultados . . . . . . . . . . . . . . . . 88

7.4 Conclusão . . . . . . . . . . . . . . . . . . . . . . . . 91

8 Abordagem probabilística em modelos de disseminação de doenças $\begin{array}{ll}\text { transmitidas por vetores } & 93\end{array}$

8.1 Cálculo do número médio de indivíduos infectados . . . . . . . . . . . 94

8.1.1 Urna com duas bolas distintas e seis amostragens . . . . . . . 94

8.1.2 Urna com três bolas distintas e seis amostragens . . . . . . . . 95

8.1.3 Urna com quatro bolas distintas e seis amostragens . . . . . . 97

8.1.4 Urna com $N$ bolas distintas e $b$ amostragens . . . . . . . . . . 98

8.2 Resultados e discussão . . . . . . . . . . . . . . . . . . . . . 100

8.3 Conclusão . . . . . . . . . . . . . . . . . . . . . . . . 101

9 Modelo baseado em agentes para a disseminação da tuberculose. 103

9.1 Modelagem da tuberculose . . . . . . . . . . . . . . . . . . . . 104

9.2 Evolução da doença . . . . . . . . . . . . . . . . . . . . . . 105

9.2.1 Contágio de indivíduos susceptíveis . . . . . . . . . . 107

9.2 .2 Indivíduos latentes . . . . . . . . . . . . . . . . 109

9.2.3 Indivíduos infecciosos . . . . . . . . . . . . . . . . . 110

9.3 Implementação numérica e resultados . . . . . . . . . . . . . . . . . . 111

9.4 Exploração do espaço de parâmetros . . . . . . . . . . . . . . . . . . 121

9.5 Conclusão . . . . . . . . . . . . . . . . . . . . . . 125 
$\mathrm{xxx}$

11 Perspectivas

133

Referências

A Generalização das funções logaritmo e exponencial

A.1 Função logaritmo generalizada . . . . . . . . . . . . . . . . . . . . . . 150

A.2 Função exponencial generalizada . . . . . . . . . . . . . . . . . . 152 


\section{Capítulo}

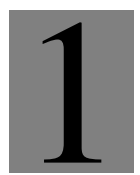

\section{Introdução}

Em nossa vida cotidiana frequentemente nos deparamos com fenômenos, que apesar de parecerem triviais à primeira vista, se revelam extremamente ricos e complexos ao olharmos com mais curiosidade. O crescimento de uma floresta ou das células de uma planta, animais caçando e sendo caçados, pessoas ganhando e perdendo dinheiro no mercado financeiro, doenças que arrasam populações e outras que erradicam pragas de lavouras ou até mesmo atividades cerebrais como raciocínio e memória, são exemplos de processos que consistem de um grande número de elementos que interagem entre si. O estado destes sistemas pode ser descrito por um conjunto de variáveis microscópicas referente a cada um dos elementos de base. A modelagem destes sistemas é obtida pela construção da equação de evolução correspondente à dinâmica de todos os seus elementos.

As equações de evolução estão ligadas entre si pelas interações entre os indivíduos. O primeiro passo conceitual na utilização de modelos é a escolha da escala de representação dos fenômenos observados. Modelos matemáticos podem ser concebidos na escala microscópica, quando a evolução de cada elemento é descrita individualmente, ou em escala macroscópica, quando o modelo refere-se à evolução das grandezas obtidas por médias locais do estado microscópico.

Dados experimentais podem ser organizados em um modelo matemático para obter uma descrição formal do comportamento do sistema observado. As primeiras análises matemáticas deste tipo foram feitas por Graunt e Petty, estudando as London Bills of Mortality ${ }^{1}$ no século XVII. Posteriormente, na segunda metade do

\footnotetext{
${ }^{1}$ A London Bills of Mortality foram a principal fonte de estatísticas de mortalidade, projetados para monitorar as mortes por peste bubônica.
} 
século XVIII, Daniel Bernoulli utilizou métodos matemáticos para avaliar a eficácia da técnica de variolação ${ }^{2}$ contra a varíola [1]. Desde então, muitos modelos têm sido desenvolvidos para estudar diversas doenças, entender sua dinâmica, fazer previsões sobre seu comportamento ou até auxiliar tomadas de decisão relativas à prevenção e erradicação de epidemias. Na sua maioria, tais modelos descrevem a dinâmica dessas doenças por meio de equações diferenciais ordinárias, em que a transição entre os diversos estados de uma doença é regida por taxas médias [2].

Em 1798, foi publicado o artigo An Essay on the Principle of Population, as It Affects the Future Improvement of Society [3] do economista e demógrafo britânico Thomas Robert Malthus. Este estudo foi o primeiro modelo matemático de dinâmica de populações. Os modelos de crescimento populacional são utilizados para prever o tamanho de uma população em um tempo arbitrário sendo conhecido seu tamanho inicial. No modelo de Malthus, o número de indivíduos que cada casal gera é constante, ou seja, independe do número de indivíduos já existentes. Outro parâmetro importante desse modelo é a taxa intrínseca de crescimento, definida como a taxa máxima de crescimento de uma população em um ambiente sem limitações. Isso leva a um crescimento exponencial da população. Nesse caso o número de novos indivíduos gerados, por unidade de tempo, é uma função linear do número de indivíduos existentes. Por isso, a equação diferencial que representa o modelo de Malthus é dita linear. No entanto, Malthus não considerou em seu modelo o fato de que vivemos em um sistema ecológico com recursos limitados e por isso, mais cedo ou mais tarde, toda a população encontraria limitações de alimento, água, espaço físico, etc. Estas limitações mantem estável um limite máximo de sobrevivência. O trabalho de Malthus inspirou Darwin na elaboração da teoria da evolução. Darwin considerou o raciocínio de Malthus de que a população humana aumenta mais rapidamente que a produção de alimentos, levando-a a uma competição.

O modelo de Malthus foi posteriormente ajustado pelos trabalhos de Benjamin Gompertz (1825) e Pierre François Verhulst (1838), que levaram em consideração o efeito do ambiente sobre o crescimento populacional, introduzindo o conceito de capacidade de suporte, definida como o tamanho máximo de uma população que o

\footnotetext{
${ }^{2}$ Nome que designa uma técnica desenvolvida na Ásia em que se provocava deliberadamente a infecção por varíola.
} 
ambiente, com recursos finitos, consegue acomodar. Com essa formulação as equações diferenciais que representam os modelos de Gompertz e Verhulst passam a ser não-lineares, ou seja, o número de novos indivíduos gerados depende de forma nãolinear do número de indivíduos existentes. Isso caracteriza uma dinâmica complexa de interação entre os indivíduos da população. Em 1954, Milner Baily Schaefer formulou um modelo para auxiliar na gestão do mercado de pesca. Neste modelo, um termo extrínseco é acrescido nas equações diferencias para representar a remoção de indivíduos (peixes) da população. Portanto, essa taxa extrínseca de crescimento, representa explicitamente a influência de fatores externos e pode ser relacionada com interações interespecíficas. Um modelo mais genérico foi proposto por F. J. Richards [4] em 1959, do qual os modelos de Gompertz e Verhulst são casos especiais.

Em políticas públicas de saúde, gestão de recursos naturais e manejo de investimentos, se faz necessário um planejamento adequado para atender as demandas da população. Informações a respeito do crescimento populacional são de fundamental importância para que tais medidas sejam apropriadas. Essa necessidade de prever o número de indivíduos de uma dada população levou cientistas a proporem modelos teóricos que pudessem fornecer informações a respeito desse crescimento. No Cap. 2 apresentamos os principais modelos de crescimento que serão utilizados neste trabalho. Neste mesmo capítulo, fornecemos uma interpretação empírica para o parâmetro de controle do modelo de Richards.

No âmbito biológico, os modelos de crescimento podem ser utilizados para descrever a proliferação de células. Isto tem desempenhado papel fundamental na descrição e ajuste de dados referentes a crescimento de tumores. Caracterizar o crescimento de um tumor é o primeiro passo para aplicar métodos e formas de tratamento mais eficazes. No Cap. 3, relacionamos os tipos de crescimento com o meio em que estas células se proliferam e com a forma de como elas interagem. Investigamos também as condições de tratamento necessárias para a eliminação de um tumor. Mostramos ainda que a taxa extrínseca de crescimento pode ser incorporada na capacidade de suporte do modelos. Com isso todas as influências externas podem ser vistas como modificações no ambiente.

Os modelos apresentados, apesar de representarem curvas de crescimento diferentes, revelamos no Cap. 4 que eles podem ser colapsados em uma única curva, 
utilizando uma função de escala apropriada. Revelando com isso um aspecto fundamental dessas curvas de crescimento.

Em ecologia, a influência do homem na natureza ou a forma de interação entre diferentes espécies podem ser caracterizadas pelos modelos de crescimento multiespécies. Nestes, as espécies interagentes são representadas explicitamente revelando a variação no número de indivíduos ao longo do tempo. O quanto uma espécie influencia as demais pode levar a regimes que vão da coexistência à extinção. No Cap. 5, propomos e resolvemos analiticamente um modelo de interação de duas espécies cuja abordagem permite relacionar os diferentes tipos de interações ecológicas com os possíveis regimes. No Cap. 6, estendemos esse estudo ao considerar uma generalização do modelo. Com isso, novos efeitos são obtidos, permitindo uma adequação melhor do modelo ao descrever a dinâmica de interação entre duas espécies. Mostramos que os modelos multi-espécies podem ser relacionados com os de uma única espécie assim como a dinâmica de transmissão de doenças.

O formalismo matemático que descreve o crescimento populacional, também pode ser utilizado para descrever como ocorre a disseminação de doenças em uma população. Prever o quanto determinada doença pode ser disseminada e o impacto que isso causaria na sociedade é de fundamental importância para que medidas preventivas sejam tomadas. No Cap. 7, descrevemos a implementação e o estudo de um modelo de transmissão da dengue. Para modelar essa dinâmica utilizamos equações diferenciais ordinárias. Em nosso modelo levamos em conta tanto a dinâmica do hospedeiro quanto a do vetor. Incluímos também no modelo a hipótese do efeito de reforço com intuito de verificar sua influência na dinâmica de disseminação da doença. O efeito de reforço é considerada uma das principais hipóteses para explicar a dengue hemorrágica. Nesse estágio a doença é muito mais severa podendo levar à morte. Propomos portanto um modelo epidemiológico do dengue com o objetivo de revelar quais são os fatores que levam à disseminação desse caso mais severo da doença.

Ainda no contexto da dengue, no Cap. 8, propomos uma nova abordagem em modelagem de epidemias transmitidas por vetores. Utilizamos princípios da estatística para obter o número médio de infectados dado o número de hospedeiros e o número total de picadas dos vetores. A resolução desse problema revelou-se muito 
rica, relacionando teoria de probabilidades com geometria multi-dimensional.

Em todos os modelos apresentados até aqui, a aproximação de campo médio foi utilizada. Deste modo a informação espacial foi desprezada. No entanto, em epidemiologia, muitas vezes a informação espacial, é importante para entender a dinâmica de disseminação da doença. No Capítulo 9 propomos um modelo alternativo que descreve a propagação da tuberculose na população assim como o aparecimento de resistência às drogas devido ao tratamento com antibióticos. Implementamos as simulações usando um modelo baseado em agentes em que a estrutura espacial é levada em conta.

Por fim, os capítulos 10 e 11 apresentam respectivamente a conclusão e perspectivas deste trabalho. O apêndice A, apresenta mais detalhadamente as propriedades das funções logaritmo e exponencial generalizadas, provenientes da termo estatística não-extensiva, e que são ostensivamente utilizadas nesta tese.

Neste trabalho exploramos as propriedades de modelos aplicados ao crescimento e tratamento de tumores e à disseminação da dengue e tuberculose. O formalismo desses modelos permite uma versatilidade em termos de aplicações. As discussões feitas e soluções obtidas podem ser aplicadas em diferentes contextos e fornecem uma base para a compreensão de aspectos mais fundamentais das leis que regem a dinâmica de sistemas naturais. 


\section{Capítulo}

\section{Dinâmica populacional de uma espécie}

Modelos de dinâmica populacional de uma espécie descrevem as variações no número de indivíduos de uma dada população ao longo do tempo. Nestes modelos, assumimos que essa variação depende da interação entre indivíduos da mesma espécie (interação intraespecífica). As interações com outras espécies (interação interespecífica) e com o meio ambiente são representadas implicitamente utilizando parâmetros que limitam o crescimento da população.

Considere uma população constituída de $N(t)$ indivíduos no instante de tempo t. Podemos definir a lei que rege o crescimento dessa população utilizando uma taxa de crescimento per capita, ou seja, quantos indivíduos cada indivíduo gera. Essa relação é representada matematicamente pela equação:

$$
\frac{d N(t)}{N(t) d t}=\frac{d \ln N(t)}{d t}=G(N)
$$

em que $G(N)$ é conhecida como função induzida de saturação.

A fim de comparar populações em ambientes diferentes é mais interessante trabalhar com a razão entre o tamanho da população e o máximo de indivíduos que o ambiente suporta. Esse valor máximo é representado pela capacidade de suporte $K$. Dessa forma, a variável dependente pode ser escrita na forma $p(t)=N(t) / K$. Na nova variável, a Eq. 2.1 se torna:

$$
\frac{d \ln p(t)}{d t}=G(p)
$$

Nesta notação a contribuição da limitação imposta pelo ambiente se torna parte intrínseca da própria variável. 
É importante observar que quando os recursos são ilimitados $(K \rightarrow \infty)$, é conveniente utilizar $p(t)=N(t)$. Por outro lado, quando há recursos limitados, é conveniente expressar o tamanho da população em relação ao seu valor de equilíbrio, i.e. $p(t)=N(t) / K$. Em um ambiente com recursos limitados, as soluções de estado estacionário podem ser obtidas pela raiz $p^{*} G\left(p^{*}\right)=0$ que são: extinção da espécie quando $p^{*}=0$ ou sua sobrevivência para $0<p^{*} \leq 1$. O número máximo de indivíduos que um ambiente suporta é obtido quando $p(t)=1$.

Inicialmente consideramos modelos com capacidade de suporte infinita. O modelo de Malthus, que é o modelo mais simples de crescimento, é apresentado na Sec. 2.1. Sua generalização, o modelo de von Foerster é mostrado na Sec. 2.2. A seguir passamos a considerar modelos com capacidade de suporte finita, como o de Gompertz (Sec. 2.3) e Verhulst (Sec. 2.4). A generalização destes (modelo de Richards) assim como uma interpretação empírica do fator de generalização é apresentada na Sec. 2.5. Uma outra generalização é obtida pelo modelo de hiperGompertz, introduzido na Sec. 2.6. Por fim, o modelo de Tsoularis-Wallace, que generaliza todos os outros aqui citados e a conclusão, são apresentados nas Sec. 2.7 e Sec. 2.8 respectivamente.

\subsection{Modelo de Malthus}

Com a consolidação do capitalismo e a revolução industrial, houve um acentuado crescimento demográfico durante os séculos XVIII e XIX. Este rápido crescimento provocou discussões que gerariam diversas teorias sobre o crescimento populacional, dentre elas o Malthusianismo. Criada pelo economista e demógrafo inglês Thomas Robert Malthus (1766-1834), a lei de crescimento de Mathus, também é conhecida como lei de crescimento exponencial. De acordo com sua teoria, a população cresceria em progressão geométrica enquanto que o os alimentos e recursos cresceriam em progressão aritmética. Como a produção de alimentos não acompanha o crescimento populacional, esse crescimento desordenado levaria à falta de recursos alimentícios para a população gerando como consequência a fome. Esse cenário ficou conhecido como a catástrofe malthusiana.

No modelo de Malthus, a taxa de variação per capita é constante, ou seja, $G(N)=$ 
$\kappa$. A Eq. 2.1 se torna:

$$
\frac{d \ln N(t)}{d t}=\kappa
$$

cuja solução é facilmente encontrada:

$$
N(t)=N_{0} e^{\kappa t}
$$

com $N_{0}=N(0)$. Neste caso a capacidade de suporte é infinita, ou seja, o ambiente não limita o crescimento da população. Desta forma, a população tende a uma explosão demográfica. O modelo descrito pela Eq. 2.3 é contínuo, embora a descrição original de Malthus seja discreta (em termos de uma progressão geométrica).

\subsection{Modelo de von Foerster}

No modelo de Malthus, o período que leva para uma população dobrar de tamanho não muda com o passar do tempo. Como consequência, a população diverge em um tempo infinito. No modelo de von Foerster, esse período de duplicação diminui ao longo do tempo. Essa diminuição persiste até que em determinado momento esse período de duplicação tende a zero, ou seja, a população cresce infinitamente em um tempo finito.

O trabalho de von Foerster publicado na revista Science em 1960 [5], propõe uma equação que melhor se ajusta aos dados sobre a população mundial disponíveis até aquele momento. A partir de uma população mundial de 2,7 bilhões em 1960, ele previu que a população seria infinita, no dia 13 novembro de 2026 uma sexta-feira, aniversário de 115 anos de von Foerster ${ }^{1}$. Dai então a equação ficar conhecida como "Equação Doomsday"

O modelo de von Foerster considera a taxa de crescimento per capta como uma lei de potência:

$$
\frac{d \ln N}{d t}=\kappa N^{\alpha}
$$

cuja solução é dada por:

$$
N(\tau)=\frac{1}{[\alpha(T-\kappa t)]^{1 / \alpha}}=N_{0} e_{-\alpha}\left(N_{0}^{\alpha} \kappa t\right),
$$

\footnotetext{
${ }^{1}$ Aqueles que conheciam von Foerster puderam reconhecer seu senso de humor neste trabalho.

${ }^{2} \mathrm{O}$ julgamento final e eterno feito por Deus sobre todas as nações.
} 
em que $\alpha$ é um parâmetro de generalização, que produz uma divergência no tempo finito adimensional $T=1 /\left(\alpha N_{0}^{\alpha}\right)$, diferentemente do modelo de Malthus $(\alpha=0)$ em que a divergência é para tempo infinito. A solução da equação de von Foerster pode ser escrita em termos de uma generalização da função exponencial. Analiticamente, a função $\tilde{q}$-exponencial é dada por:

$$
e_{\tilde{q}}(x)= \begin{cases}\lim _{\tilde{q}^{\prime} \rightarrow \tilde{q}}\left[1+\tilde{q}^{\prime} x\right]^{1 / \tilde{q}^{\prime}} & , \text { se } \tilde{q} x \geq-1 \\ 0 & , \text { caso contrário }\end{cases}
$$

A função $\tilde{q}$-exponencial é estritamente não-negativa, $e_{\tilde{q}}(x) \geq 0$, e $e_{\tilde{q}}(0)=1$, para qualquer valor de $\tilde{q}$. Esta função possui a propriedade $1 / e_{\tilde{q}}(x)=-\tilde{q}(-x)$. Esta propriedade é utilizada na simplificação das funções de escala que serão apresentadas no Cap.4. Maiores detalhes das propriedades das funções $\tilde{q}$-exponencial e sua inversa a q̃-logaritmo, são apresentadas no Apêndice A.

\subsection{Modelo de Gompertz}

No séc. XIX, ficou claro que o modelo Malthusiano não estava correto, uma vez que não levara em consideração a mortalidade por falta de recursos, além de fatores como guerras, epidemias e catástrofes naturais. Em 1825, Benjamin Gompertz publicou o estudo On the Nature of the Function Expressive of the Law of Human Mortality, and on a New Mode of Determining the Value of Life Contingencies. Segundo Gompertz, a mortalidade possui duas causas coexistentes: uma probabilística que independe da idade, e outra que cresce a medida que o indivíduo envelhece. Em termos populacionais, a taxa de crescimento per capita é proporcional ao logaritmo do número de indivíduos, ou seja:

$$
\frac{d \ln p(t)}{d t}=-\kappa \ln p(t)
$$

com $p(t)=N(t) / K$. A solução desta equação é dada por:

$$
p(t)=p_{0}^{\exp (-\kappa t)}
$$

O príncipio por trás deste modelo ainda é utilizado nos dias de hoje para o cálculo de seguros de vida $[2,6]$. 


\subsection{Modelo de Verhulst}

Em 1838, Pierre François Verhulst publicou outro modelo de crescimento populacional, baseado na avaliação de estatísticas disponíveis na época, e introduzindo termos que representam os fatores inibidores do crescimento. Seguindo a hipótese de Malthus, Verhulst postulou que populações pequenas cresceriam exponencialmente, uma vez que a oferta de suprimentos era superior à demanda. Quando a demanda e a oferta de suprimentos se equilibrassem, a taxa de crescimento populacional seria nulo, atingindo o valor limite dada pela capacidade de suporte $K$. A equação de Verhulst é:

$$
\frac{d \ln p(t)}{d t}=\kappa[1-p(t)],
$$

lembrando que $p(t)=N(t) / K$. Quando $N(t)=K$, ou seja, $p(t)=1$, o termo $[1-p(t)]$ se anula fazendo com que a taxa de crescimento se anule também. A solução do modelo de Verhulst é dada por:

$$
p(t)=\frac{p_{0} e^{\kappa t}}{1+p_{0}\left(e^{\kappa t}-1\right)} .
$$

Esta é a conhecida função logística que é utilizada em diversas áreas do conhecimento. Por exemplo, na medicina ela é utilizada para modelar crescimento de tumores; em reações químicas, descreve a concentração dos elementos em reações autocalíticas; em economia, ilustra como ocorre a difusão de uma inovação.

\subsection{Modelo de Richards e sua interpretação em- pírica}

O modelo de Richards [4] foi proposto como um modelo empírico para o crescimento de plantas ${ }^{3}$. Na Ref. [7, p. 83], é mostrado que os modelos de Gompertz e Verhulst podem ser generalizados a partir desse modelo simples:

$$
\frac{d \ln p(t)}{d t}=r \frac{\left(1-p^{\tilde{q}}\right)}{\tilde{q}}=-\kappa \ln _{\tilde{q}}(p),
$$

em que $\kappa=r \tilde{q}$ é mantido fixo. Fazendo $\tilde{q}=1$, obtemos o modelo de Verhulst e fazendo $\tilde{q} \rightarrow 0$, o modelo de Gompertz. O modelo de Richards pode ser escrito

\footnotetext{
${ }^{3}$ refere-se ao crescimento de um único indivíduo (planta)
} 
em termos da função logaritmo generalizada. Utilizando apenas argumentos geométricos, essa generalização é similar à obtida no contexto da termodinâmica nãoextensiva $[8,9]$. Para maiores detalhes e propriedades dessa função veja Apêndice A e Ref. [10].

A função logaritmo natural generalizada (ou simplesmente $\tilde{q}$-logaritmo), $\ln _{\tilde{q}}(x)$, $x>0$, pode ser interpretada geometricamente como a área abaixo da curva $f_{\tilde{q}}(t)=$ $1 / t^{1-\tilde{q}}$, com $t \geq 1$, ou seja,

$$
\ln _{\tilde{q}}(x)=\int_{1}^{x} \frac{\mathrm{d} t}{t^{1-\tilde{q}}}=\lim _{\tilde{q}^{\prime} \rightarrow \tilde{q}} \frac{x^{\tilde{q}^{\prime}}-1}{\tilde{q}^{\prime}}= \begin{cases}\frac{x^{\tilde{q}}-1}{\tilde{q}}, & \text { se } \tilde{q} \neq 0, \\ \ln x, & \text { se } \tilde{q}=0 .\end{cases}
$$

É importante não confundir esta função com o logaritmo de base $\tilde{q}, \log _{\tilde{q}}(x)$. Esta é uma generalização da definição da função logaritmo natural, que é obtida como caso particular para $\tilde{q} \rightarrow 0$. Para $x=1$, a área é nula, mantendo a propriedade do logaritmo tradicional: $\ln _{\tilde{q}} 1=0$.

A função q̃-logaritmo é bijetora e, portanto, admite inversão. Geometricamente, isso corresponde a determinar o limite superior do intervalo $[0, y]$ para o qual a área sob a curva $f_{\tilde{q}}(t)$ é igual a $x$, isto é, $\ln _{\tilde{q}}(y)=x$. À função inversa do $\tilde{q}$-logaritmo é a q-exponencial, definida pela Eq. 2.7. Devido às propriedades das funções inversas, e pela definição acima, $e_{\tilde{q}}(x)=y$, então, $e_{\tilde{q}}\left[\ln _{\tilde{q}}(y)\right]=y=\ln _{\tilde{q}}\left[e_{\tilde{q}}(y)\right]$.

A solução do modelo de Richards em termos do parâmetro q̃ é:

$$
p(\tau)=\frac{1}{e_{\tilde{q}}\left\{\ln _{\tilde{q}}\left[1 / p_{0}\right] e^{-\tau}\right\}},
$$

em que $\tau=\kappa t, p_{0} \equiv p(0)$ é a condição inicial.

Uma possível interpretação para o parâmetro $\tilde{q}$ do modelo de Richards pode ser dada tomando como base os trabalhos desenvolvidos por Geoffrey West et al. [11, $12,13]$. Esses pesquisadores mostraram que a lei de potência entre taxa metabólica e a massa de indivíduos - dado pelo expoente $\beta=3 / 4$ (obtido experimentalmente) - é uma consequência da estrutura fractal dos vasos sanguíneos presentes nos indivíduos [11]. Essa lei de escala vale tanto para organismos unicelulares de massa $10^{-12} \mathrm{~g}$, quanto para os mamíferos maiores de massa $\sim 10^{7} \mathrm{~g}[13]$.

Esses mesmos pesquisadores estudaram o crescimento de indivíduos[12]. Eles partiram da ideia de que a energia total produzida pelo indivíduo em um dado 
intervalo de tempo (taxa metabólica) deve obedecer ao princípio da conservação e, portanto, essa energia deve ser transformada em: i) energia para a manutenção das células já existentes; ou ii) na criação de novas células. Assim,

$[$ Energia total $]=[$ Energia para manutenção de células $]+[$ Energia para crivar novas células $]$.

Considerando então que a energia total (taxa metabólica) escala com a massa $M$ do indivíduo, a relação acima dá origem a uma equação diferencial (um modelo) para a dinâmica do número efetivo $N$ de células que constitui o indivíduo em função do tempo. A equação acima pode ser escrita como

$$
B=N B_{c}+E_{c} \frac{d N}{d t}
$$

onde $B$ é a energia total usada pelo individuo num intervalo de tempo $d t ; B_{c}$ é a energia utilizada por uma única célula nesse mesmo intervalo de tempo; $E_{c}$ a energia necessária para se criar uma nova célula; e $N$ o número total de células no instante t. Uma vez que a taxa metabólica escala com a massa $M$ do indivíduo pela forma $B=B_{0} M^{\beta}$, onde $\beta=3 / 4$, e considerando que $N=M / m_{c}$, onde $m_{c}$ é a massa de uma única célula, podemos escrever a equação diferencial (2.14) como

$$
\frac{d N}{d t}=a N^{\beta}-b N
$$

em que

$$
a \equiv \frac{B_{0} m_{c}^{\beta}}{E_{c}}
$$

$\mathrm{e}$

$$
b \equiv \frac{B_{c}}{E_{c}} .
$$

A equação (2.15) é um modelo para a dinâmica da população de células que constitui um organismo. A solução dessa equação é

$$
N(t)=\left[\frac{a}{b}+\left(N_{0}^{1-\beta}-\frac{a}{b}\right) e^{b(\beta-1) t}\right]^{\frac{1}{1-\beta}},
$$

em que $N_{o}$ é a quantidade de células que compõem o indivíduo no seu nascimento, i.e. $N_{0} \equiv N(t=0)$. Para $\beta=3 / 4<1$, temos que a população de células converge para

$$
K \equiv N(t \rightarrow \infty)=\left(\frac{a}{b}\right)^{\frac{1}{1-\beta}}
$$


De acordo com esse modelo, o indivíduo cresce até que a sua massa atinja um valor máximo $M_{\text {saturao }}=K m_{c}$. Evidências experimentais comprovam a previsão desse modelo [12].

Podemos reescrever a equação (2.15) em termos dessa capacidade de suporte, o que nos dá

$$
\frac{d N}{d t}=b N\left[\left(\frac{N}{K}\right)^{\beta-1}-1\right] .
$$

Multiplicando e dividindo essa equação por $(\beta-1)$, temos

$$
\frac{d N}{d t}=b(\beta-1) N \frac{\left[\left(\frac{N}{K}\right)^{\beta-1}-1\right]}{\beta-1} .
$$

Introduzindo $\tilde{q} \equiv \beta-1, r_{\tilde{q}} \equiv-b \tilde{q}$, e usando definição do logaritmo generalizado $\ln _{\tilde{q}}(x)=\left(x^{\tilde{q}}-1\right) / \tilde{q}$, chegamos ao modelo de Richards

$$
\frac{d N}{d t}=-r_{\tilde{q}} N \ln _{\tilde{q}}\left(\frac{N}{K}\right)
$$

Dessa forma, o parâmetro $\tilde{q}$ do modelo de Richards ganha uma interpretação empírica. Ele está relacionado com o expoente $\beta$ da lei de escala entre taxa metabólica e massa corporal dos indivíduos e possui um valor bem determinado: $\tilde{q}=-1 / 4$. Portanto, de acordo com a teoria de West descrita em [11], o parâmetro q do modelo de Richards está relacionado com a estrutura fractal das ramificações sanguíneas dos seres vivos.

\subsection{Modelo de Hiper-Gompertz}

Ao considerarmos um crescimento de acordo com uma lei de potência, como no modelo de von Foerster et al., porém utilizando o termo logaritmo, como no modelo de Gompertz, obtemos o modelo conhecido como hiper-Gompertz [14]:

$$
\frac{d \ln (p)}{d t}=\kappa[-\ln (p)]^{\gamma} .
$$

Baseado na solução do modelo de von Foerster e Gompertz, obtemos a solução analítica do modelo hiper-Gompertz:

$$
p(\tau)=e^{-\left[(\gamma-1) \tau-(-1)^{\gamma}\left(\ln p_{0}\right)^{1-\gamma}\right]^{1 /(1-\gamma)}} .
$$


O parâmetro $\gamma$ regula o tamanho da população na qual a taxa de crescimento é máxima, i.e., o ponto de inflexão $\left(p_{i n f}\right)$. Este valor é dado por: $p_{i n f}=e^{-\gamma}$. Para valores grandes de $\gamma$ o ponto de inflexão tende a 0 , e para valores pequenos de $\gamma$, este tende à capacidade de suporte $K$.

\subsection{Modelo de Tsoularis-Wallace}

O modelo de Tsoularis-Wallace [15] é uma generalização de todos os modelos até aqui apresentados. Sua expressão é dada por ${ }^{4}$ :

$$
\frac{d \ln _{\tilde{q}^{\prime}} p(t)}{d t}=\kappa\left[-\ln _{\tilde{q}} p(t)\right]^{\gamma},
$$

cuja solução é dada por:

$$
\operatorname{raiz}\left[B_{p^{\tilde{q}}(t)}\left(\frac{\tilde{q}^{\prime}}{\tilde{q}}, 1-\gamma\right)-B_{p_{0}^{\tilde{q}}}\left(\frac{\tilde{q}^{\prime}}{\tilde{q}}, 1-\gamma\right)=\kappa t\right]
$$

em que $B_{x}(a, b)=\int_{0}^{x} d t t^{a-1}(1-t)^{b-1}$ é a função beta incompleta. Para esta função, dois conjuntos de valores são aceitáveis:

1. $\tilde{q}^{\prime}>0, \tilde{q}>0$ e $\gamma<1$,

2. $\tilde{q}^{\prime}<0, \tilde{q}<0$ e $\gamma<1$.

A partir deste modelo e com a escolha apropriada dos parâmetros, podemos obtemos qualquer outro modelo apresentado neste capítulo, tornando essa função extremamente versátil para ajustar dados experimentais. Nas palavras dos autores que propuseram o modelo: “...additional growth characteristics are accommodated by this new model, enabling previously unsupported, untypical population dynamics to be modelled by judicious choice of model parameter values alone". Um esquema resumindo as relações entre os modelos até aqui apresentado pode ser visualizado na Fig. 2.1.

\footnotetext{
${ }^{4}$ Note que utilizamos o $\tilde{q}$-logaritmo no lado esquerdo da equação diferencial. O parâmetro $\tilde{q}^{\prime}$ está relacionado com o parâmetro usual $\alpha$ pela relação $\tilde{q}^{\prime}=-\alpha$
} 


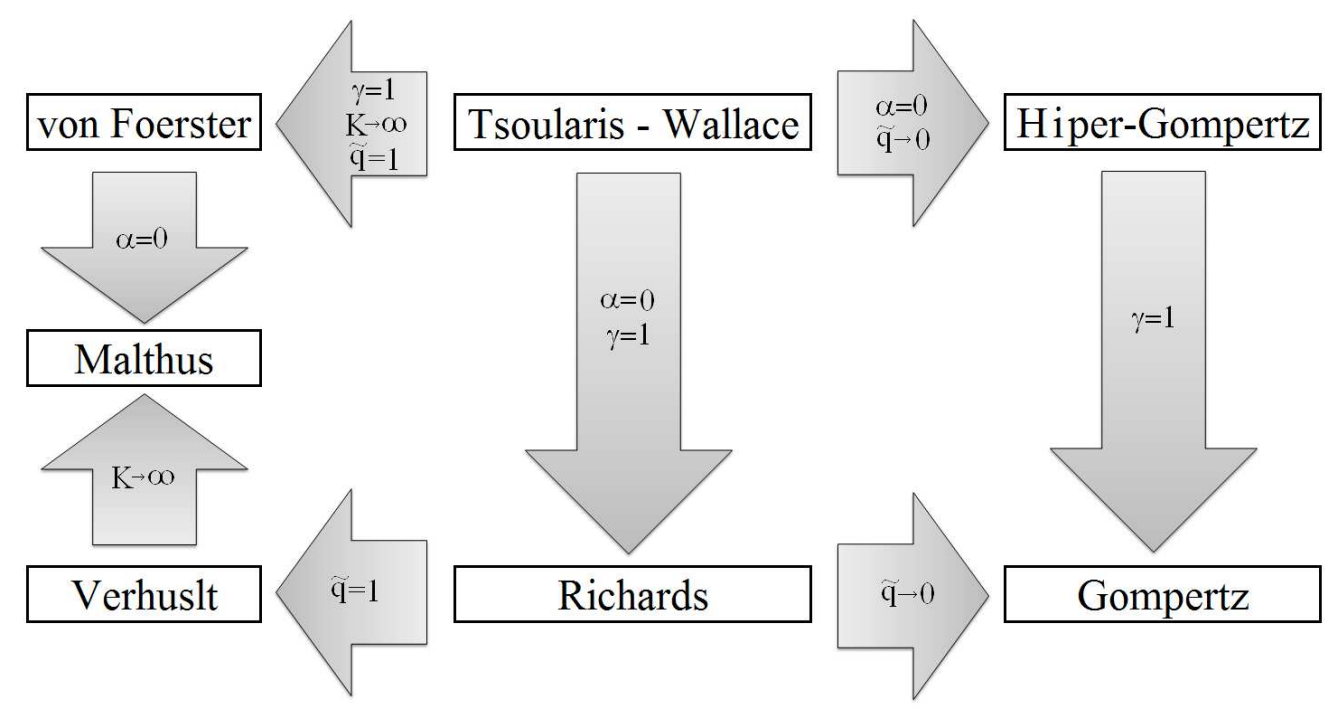

Figura 2.1: Representação das relações entre os modelos de dinâmica populacional de uma espécie. A partir do modelo de Tsoularis-Wallace todos os demais modelos podem ser obtidos com a escolha apropriada dos parâmetros.

\subsection{Conclusão}

Neste capítulo, apresentamos os principais modelos de dinâmica populacional de uma espécie que serão utilizados neste trabalho. Explicitamos suas soluções analíticas e relacionamos os casos mais gerais com seus respectivos casos particulares.

Mostramos que o parâmetro de generalização $\tilde{q}$ do modelo de Richards pode ser relacionado com a estrutura fractal das ramificações sanguíneas. Ao atribuir este significado empírico à $\tilde{q}$, relacionamos o comportamento da curva de crescimento com princípios anatômicos que regem o crescimento dos seres vivos.

No próximo capítulo adicionaremos a esses modelos uma taxa extrínseca de crescimento. Essa taxa considera a remoção ou inserção de indivíduos na população. Mostraremos que ao incluir esse termo, aparecem transições do tipo sobrevivência/extinção da população.

Os modelos de crescimento de uma espécie aqui apresentados podem ser utilizados em modelos multi-espécies. No Caps.5 faremos uma análise detalhada de um modelo de duas espécies em que o termo de Verhulst é usado para modelar o crescimento de cada espécie. No Cap.6, faremos o mesmo estudo mas agora considerando o crescimento de acordo modelo de Richards. 


\section{Capítulo}

\section{Taxa extrínseca de crescimento}

Consideramos neste capítulo uma taxa extrínseca de crescimento, definida como a remoção ou adição de indivíduos proporcionalmente ao tamanho da população. Em modelos matemáticos de crescimento de tumores, a taxa extrínseca de crescimento pode ser associada com o tratamento de câncer e o conhecimento de como a transição entre sobrevivência e extinção ocorre é de fundamental importância para o sucesso do tratamento [16, 17, 18, 19]. Conceitos da física em modelos matemáticos de crescimento de tumores já foram propostos na Ref. [20] em que os autores obtêm uma transição de fase entre crescimento e latência do tumor. Uma transição de fase é também associada com tratamento de câncer na Ref. [21]. Este fator também pode ser visto como o fator de interação quando consideramos modelos de múltiplas espécies.

Na Sec. 3.1, apresentamos o modelo de Schaefer que foi o primeiro a considerar a remoção de indivíduos da população. Na Sec. 3.2, apresentamos o modelo de Richards-Schaefer e sua solução. Uma interpretação microscópica para o parâmetro de Richards é abordado na Sec. 3.3. A seguir, na Sec. 3.4, a taxa extrínseca de crescimento é utilizada como tratamento de tumores ${ }^{1}$. Na Sec. 3.5, mostramos como a essa taxa pode ser relacionada com a capacidade de suporte ${ }^{2}$. Por fim, na Sec. 3.6 consideramos modelos com taxa intrínseca e extrínseca dependentes do tempo e mostramos a relação destes com modelos de duas espécies e também com modelos estocásticos ${ }^{3}$. A conclusão é apresentada na Sec. 3.7.

\footnotetext{
${ }^{1}$ Deste resultado foi publicado o artigo da Ref. [22].

${ }^{2}$ Deste resultado foi publicado o artigo da Ref. [23].

${ }^{3}$ Deste resultado foi publicado o artigo da Ref. [22].
} 


\subsection{Modelo de Schaefer}

O modelo de Schaefer foi proposto em 1954 no trabalho: Some aspects of the dynamics of populations important to the management of the commercial marine fisheries, para auxiliar na gestão do mercado de pesca. O objetivo era avaliar os impactos ambientais e otimizar o lucro sem causar extinção das espécies pescadas [2, 6]. A remoção de peixes de seu habitat, tem o efeito de diminuir o que seria o crescimento natural da espécie, isto é:

$$
\frac{d p}{d t}=f(p)-p \epsilon(t)
$$

em que $f(p)$ é a taxa intrínseca e $p \epsilon(t)$ é a taxa extrínseca de crescimento (taxa de coleta). Na seção seguinte, consideramos o caso em que essa taxa é constante.

\subsection{Taxa extrínseca constante}

Com taxas extrínsecas de crescimento constantes, é possível lidar com transições entre as fases de extinção e sobrevivência. A solução para o estado estacionário $p^{*}$ representa o parâmetro de ordem do modelo, uma vez que é nulo na fase de extinção, e em pontos críticos, se torna não nulo (sobrevivência).

Vamos considerar inicialmente uma taxa extrínseca de crescimento no modelo Tsoularis-Wallace Eq. 2.25, e chamá-lo de modelo Tsoularis-Wallace-Schaefer:

$$
\frac{d \ln p(\tau)}{d \tau}=p^{\alpha}(\tau)\left\{-\ln _{\tilde{q}}[p(\tau)]\right\}^{\gamma}+\epsilon,
$$

em que $\epsilon=\tilde{\epsilon} / \kappa$.

Para $\alpha \neq 0$, Eq. 3.2 pode ser resolvida para casos particulares, os quais estão fora dos objetivos deste estudo. Mantendo $\alpha=0$ e tomando $\gamma=1$, obtém-se da Eq. 3.2 o modelo de Richards com taxa extrínseca de crescimento constante, que denominamos modelo de Richards-Schaefer:

$$
\frac{d \ln p(\tau)}{d \tau}=-\ln _{\tilde{q}}[p(\tau)]+\epsilon
$$

cuja solução é dada por:

$$
p(\tau)=\frac{e_{\tilde{q}}(\epsilon)}{e_{\tilde{q}}\left\{\ln _{\tilde{q}}\left[e_{\tilde{q}}(\epsilon) / p_{0}\right] e^{-(1+\tilde{q} \epsilon) \tau}\right\}},
$$


em que $p_{0}=p(0)$ é a condição inicial.

A seguir uma interpretação microscópica para o parâmetro q é fornecida relacionando o com a dimensão fractal em que as células proliferam e o alcance de interação entre elas.

\subsection{Interpretação microscópica do parâmetro $\tilde{q}$}

A compreensão da auto-organização celular durante o processo de crescimento é de extrema importância na medicina e na biologia. As curvas de crescimento são descritas por variáveis como volume, massa, comprimento ou número de células do tecido em função do tempo. O crescimento de organismos individuais [24], tumores [25] e outros sistemas biológicos [26] são bem ajustado por curvas sigmoidais (em forma de S). Uma descrição empírica amplamente utilizada é a função Gompertz $[24,25,26,27,16,28]$. No entanto, muitos são os trabalhos que apresentam diferentes tipos de tumores que desafiam o modelo Gompertz [29]. Outros modelos, como o logístico (por vezes referido como Verhulstiano) [30] e, sob certas condições, o exponencial [31, 32, 33, 34, 35] também são frequentemente utilizados.

Recentemente, o papel da dinâmica de crescimento de tumores na determinação do curso clínico da doença foi enfatizado, demonstrando como tal conhecimento pode levar a protocolos de tratamento mais eficientes [36]. Muitos modelos de crescimento de tumores têm sido propostos para descrever dados experimentais. Apesar do progresso considerável na compreensão do desenvolvimento do tumor, a lei do crescimento de tumores humanos ainda é uma questão de debate [29, 37, 38, 39].

Porém, o mais popular de todos os modelos de crescimento do tumor é a lei Gompertz [16, 40, 41, 42, 43, 44]. No artigo da Ref. [16], Norton et al. mostra que o crescimento de neoplasias mais comuns de tumores humanos são bem descritas pela equação Gompertz.

Apesar do imenso uso da lei Gompertz na investigação científica, houve sempre o problema de não haver uma derivação a partir de considerações teóricas baseadas na biofísica do crescimento [45]. Na Ref. [45], uma justificativa teórica para aproximação da lei de Gompertz é apresentada. Tal justificativa é baseada no conceito de entropia associada ao crescimento maligno. A fórmula da entropia utilizado na Ref. [45] é a 
bem conhecida entropia de Boltzmann-Gibbs.

A proliferação celular em um organismo é resultado das interações de curto e de longo alcance entre as células. O principal mecanismo de interações de curto alcance é a inibição da proliferação devido ao contato das membranas celulares [46]. Este mecanismo é frequentemente observado durante a cicatrização de uma ferida ou de culturas de células in vitro $[46,47]$. Alguns modelos têm investigado o papel das interações de curta distância sobre o crescimento de populações de células [48]. Interações de longo alcance ocorrerem durante o desenvolvimento de organismos como, por exemplo, a Drosophila $[49,50]$. Elas são mediadas através de substâncias difusivas chamados fatores de crescimento que são moléculas com um papel central no crescimento normal e anormal. Elas interagem com receptores específicos na superfície das células e afetam sua proliferação [51]. No caso de sistemas biológicos, a estrutura fractal do espaço no qual as células interagem é essencial para a sua autoorganização. Assim, os fenômenos biológicos ocorrem no espaço, cujas dimensões não são representados por números inteiros (1, 2, 3, etc.) de espaço euclidiano. Em particular, tumores malignos $[52,53,54,55]$ e células neuronais $[56,57]$ crescem em um espaço de dimensão fractal [58].

Uma justificativa teórica capaz de reproduzir exatamente a lei de Richards e que ainda apresenta uma interpretação microscópica para os parâmetros foi proposta por Monbach et al. [59, 60]. Neste trabalho os autores assumem que a taxa de replicação de uma célula é regulada por uma competição entre o impulso das células de proliferar e um termo de inibição proveniente de outras células através de fatores de crescimento difusivos. Por conseguinte, para $N(t)$ células, no tempo $t$, a taxa de replicação de uma célula $i$ pode ser matematicamente representada por: $R_{i}=$ $G_{i}-J I_{i}$, em que $R_{i}>0, G_{i}$ é a taxa de replicação intrínseca da célula $i$ e $J>0$ é uma constante de forma que a ação inibitória, devido às células restante $N(t)-1$ na célula $i$ é $I_{i}=\sum_{j(\neq i)=1}^{N(t)} 1 /\left|\overrightarrow{r_{i}}-\vec{r}_{j}\right|^{\gamma}$, em que a distância entre as células, $\left|\overrightarrow{r_{j}}-\overrightarrow{r_{i}}\right|$, modula a inibição e o alcance de interação é caracterizado pelo parâmetro ${ }^{4} \gamma$. Observe que $I_{i}>0$. Para eliminar a restrição $j \neq i$ no somatório, considere o delta de Kronecker

\footnotetext{
${ }^{4}$ Este parâmetro não tem relação com o $\gamma$ do modelo de hiper-Gompertz (Sec. 2.6).
} 
$\delta_{i j}$, de modo que:

$$
\begin{aligned}
I_{i} & =\sum_{j=1}^{N(t)} \frac{\left(1-\delta_{i j}\right)}{\left|\overrightarrow{r_{i}}-\vec{r}_{j}\right|^{\gamma}}=\int_{V} d v \sum_{j=1}^{N(t)} \frac{\left(1-\delta_{i j}\right)}{\left|\overrightarrow{r_{j}}-\overrightarrow{r_{i}}\right|^{\gamma}} \delta\left[\vec{r}-\left(\vec{r}_{i}-\vec{r}_{j}\right)\right] \\
& =\int_{V} \frac{d v}{r^{\gamma}} \sum_{j=1}^{N(t)}\left[\delta\left(\vec{r}+\vec{r}_{j}-\vec{r}_{i}\right)-\delta(\vec{r}) \delta_{i j}\right] \\
& =\int_{V} \frac{d v}{r^{\gamma}}\left[\sum_{j=1}^{N(t)} \delta\left(\vec{r}+\vec{r}_{j}-\vec{r}_{i}\right)-\delta(\vec{r})\right],
\end{aligned}
$$

em que $r=|\vec{r}|$ e $\delta(x)$ é a função delta, que tem unidade de inverso do volume e possui a seguinte propriedade: $f\left(\vec{r}_{0}\right)=\int_{V} d v f(\vec{r}) \delta\left(\vec{r}-\vec{r}_{0}\right)$.

Note que $\delta(\vec{r})$ indica a célula $j$, em torno da qual é realizada a integral. O somatório: $\sum_{j=1}^{N(t)} \delta\left(\vec{r}+\vec{r}_{j}-\vec{r}_{i}\right)=\rho\left(\vec{r}-\vec{r}_{j}\right)$ conta o número de células por unidade de volume ao redor de $\vec{r}-\vec{r}_{j}$ e $I_{i}=\int_{V} d v\left[\rho\left(\delta\left(\vec{r}-\vec{r}_{i}\right)-\delta(\vec{r})\right] / r^{\gamma}\right.$. Para um meio isotrópico ao redor da célula $i$, o integrando depende somente da distância e não dos ângulos, assim para um meio com dimensionalidade $D$, temos: $I_{i}=\int_{V} d \Omega_{D-1} \int_{r_{0}}^{r_{\max }} d r r^{D-1}\left[\rho\left(\delta\left(\left|\vec{r}-\vec{r}_{i}\right|\right)-\delta(r)\right] / r^{\gamma}\right.$, em que $r_{\max }>r_{0}>0 . \mathrm{A}$ integral angular resulta $\int_{V} d \Omega_{D-1}=2 \pi^{D / 2} / \Gamma(D / 2)$, em que $\Gamma(z)$ é a função gama. Trocando a origem da célula $j$ para $i$, temos: $I_{i}=\left[2 \pi^{D / 2} / \Gamma(D / 2)\right] \int_{r_{0}}^{r_{\max }} d r[\rho[\delta(\vec{r}-$ $\left.\left.\vec{r}_{i}\right)-\delta(0)\right] / r^{\gamma-D+1}$. Uma vez que $I_{i}$ não depende da posição da célula $i$ todas as células são equivalentes e $\int_{r_{0}}^{r_{\max }} d r \delta(0) / r^{\gamma-D+1}=0$ temos:

$$
I_{i}=I=\frac{2 \pi^{D / 2}}{\Gamma(D / 2)} \int_{r_{0}}^{r_{\max }} \frac{d r}{r^{\gamma-D+1}} \rho(r)
$$

Estamos interessados no número de células, a uma distância $r$, em um volume que é uma hiperesfera de volume $2 \pi^{D / 2} r^{D} / \Gamma(D / 2+1)$, assim, $\rho(r)=$ $\Gamma(D / 2+1) N(r) /\left(2 \pi^{D / 2} r^{D}\right)$. Para um crescimento num ambiente fractal, com dimensionalidade $D_{f}<D$, temos: $N(r)=a^{\prime} r^{D_{f}}$, em que $a^{\prime}$ é uma constante e $\rho(r)=\Gamma(D / 2+1) a^{\prime} r^{D_{f}-D} /\left(2 \pi^{D / 2}\right)$. Dessa forma temos:

$$
I_{i}=I=\omega \int_{r_{0}}^{r_{\max }} \frac{d r}{r^{\gamma-D+1}}=\omega\left[\ln _{D_{f}-\gamma}\left(r_{\max }\right)-\ln _{D_{f}-\gamma}\left(r_{0}\right)\right]
$$


com $\omega=D a^{\prime} / 2$ e $\ln _{\tilde{q}}(x)$ sendo o logaritmo generalizado.

Agora, para obter $r_{\max }$, temos: $N(t)=\int_{v} d v \rho(\vec{r})=\omega \int_{r_{0}}^{r_{\max }} d r r^{D_{f}-1}$. A distância $r_{0}$ é da ordem de grandeza do tamanho de uma célula, isso significa que $r_{0} \ll r_{\max }$, dessa forma $N(t)=\omega \int_{0_{+}}^{r_{\max }} d r r^{D_{f}-1}=\omega r_{\max }^{D_{f}} / D_{f}$, assim

$$
r_{\text {max }}=\left(\frac{D_{f} n}{\omega}\right)^{1 / D_{f}}
$$

Obtemos: $I_{i}=I=\omega\left[\ln _{1-\gamma / D_{f}}\left(D_{f} n / \omega\right)-\ln _{1-\gamma / D_{f}}\left(r_{0}^{D_{f}}\right)\right]$. Considerando a distância medida em unidades do tamanho da célula, temos $r_{0}=1$, and $\ln _{1-\gamma / D_{f}}\left(r_{0}^{D_{f}}\right)=0$

$$
I=\omega \ln _{1-\gamma / D_{f}}\left(\frac{D_{f} n}{\omega}\right) .
$$

Para $N(r) \gg 1$ e $\Delta t \rightarrow 0(\Delta N / N \ll 1)$, o número de células no tempo $t+\Delta t$ é: $N(t+\Delta t)=N(t)+\Delta t \sum_{i=1}^{n} R_{i}$, ou

$$
\frac{d N}{d t}=\sum_{i=1}^{n} R_{i}=\sum_{i=1}^{N}\left(G_{i}-J I_{i}\right)=N\langle G\rangle-N J I
$$

em que $\langle G\rangle=(1 / N) \sum_{i=1}^{N} G_{i}$. Essas suposições resultam em uma equação diferencial para o crescimento do sistema celular:

$$
\frac{d \ln N(t)}{d t}=\langle G\rangle-\frac{J \omega}{D_{f}} \ln _{1-\gamma / D_{f}}\left[\frac{D_{f} N(t)}{\omega}\right]
$$

$N(t)$ é o número de células, $\omega=a \Gamma$, em que $a$ é uma constante e $\Gamma$ é o resultado da integral angular e $D_{f}$ é a dimensão fractal.

Se chamarmos $x(t)=N(t) D_{f} / \omega$, temos:

$$
\tilde{q}=1-\frac{\gamma}{D_{f}}
$$

em que $k=J \omega / D_{f}$, podemos reescrever a Eq.3.11 na forma da Eq. 3.3.

O valor de $p(t)$ na equação de Richards-Schaefer é sempre menor ou igual a unidade, i.e., $p(t) \leq 1$. Neste caso, $\ln _{\tilde{q}} p(t) \leq 0$ e consequentemente o termo $-\ln _{\tilde{q}} p(t)$ representa uma taxa de crescimento positiva.

Obtemos portanto uma interpretação do parâmetro q̃ no contexto de proliferação de células. Esta interpretação pode ser relacionada ao crescimento de tumores. O tratamento desses tumores a partir de uma taxa extrínseca de crescimento é discutido na seção seguinte. 


\subsection{Tratamento de tumores e soluções de estado estacionário}

Em modalidades de tratamento de câncer, a quimioterapia funciona parando ou retardando o crescimento de células cancerosas, que crescem rapidamente e se dividem, mas também podem danificar as células saudáveis que se dividem rapidamente, tais como a dos intestinos e as que fazem o cabelo crescer. Danos às células saudáveis podem causar efeitos colaterais. Muitas vezes, os efeitos colaterais passam após o fim do tratamento. A radioterapia é um método capaz de destruir células tumorais, empregando feixe de radiações ionizantes. A radiação danifica ou destrói as células na área a ser tratada por danificar seu material genético, tornando impossível para essas células continuar a crescer e se dividir. Uma dose pré-calculada de radiação é aplicada, em um determinado tempo, a um volume de tecido que engloba o tumor, buscando erradicar todas as células tumorais, com o menor dano possível às células normais circunvizinhas.

Para que o efeito biológico atinja maior número de células neoplásicas e a tolerância dos tecidos normais seja respeitada, a dose total de radiação a ser administrada é habitualmente fracionada em doses diárias iguais, quando se usa a terapia externa. Em casos de tumores mais avançados é empregada uma terapia mais intensa inicialmente quando o tumor ainda é muito grande e então a dose é diminuída a medida que tumor é reduzido. Na configuração pós-cirúrgico, onde se pensa que apenas resquícios microscópicos de tumor são deixados, o esquema de dose de quimioterapia adjuvante escolhido é muitas vezes menos intensa do que seria utilizada para uma maior extensão do tumor do tipo equivalente. Muitas observações sugerem fortemente que os resquícios microscópicas deixadas após a cirurgia são suficientemente resistentes à quimioterapia e para que eles não são facilmente curáveis pela exposição baixa. Assim, alguns autores [61, 62, 63, 44, 39] têm sugerido a utilização de tratamentos mais intensos, doses mais elevadas, e uma terapia mais prolongada do que o normalmente usado. O nível de terapia adequada para iniciar a regressão pode não ser suficiente para sustentar essa regressão e propiciar a cura. O resultado é que muitos tumores são impossíveis de serem eliminados utilizando os tratamentos convencionais [61, 62, 63, 44, 39]. Norton e colaboradores [61, 62, 63] sugerem uma 
forma de combate ao retardamento da taxa de regressão de um tumor quando este diminui. A estratégia é aumentar a intensidade do tratamento a medida que o tumor se torna menor. Este tipo de esquema de tratamento é chamado de "intensificação tardia". Pode-se pensar que o menor tamanho de tumor resultante para uma dada dose total de terapia é realizado se toda a terapia for dada em um período curto de tempo. Devido à toxicidade, no entanto, esta é geralmente impraticável [61].

Propomos analisar os efeitos da intensidade do tratamento utilizando um taxa extrínseca em modelos de crescimento. Com essa taxa, é possível lidar com transições entre as fases de sobrevivência e extinção. Dessa forma, obtemos as condições necessárias, do ponto de vista teórico, para que o tratamento seja eficiente, ou seja, leve a população de células cancerosas à extinção. A solução para o estado estacionário $p^{*}$ representa o parâmetro de ordem do modelo uma vez que ele se anula na fase de extinção, e em pontos críticos, se torna não nulo, representando fases de sobrevivência.

A solução do estado estacionário é obtida considerando $d p / d \tau=0$ na Eq. 3.2, então $p^{*}\left\{p^{* \alpha}\left[-\ln _{\tilde{q}}\left(p^{*}\right)\right]^{\gamma}+\epsilon\right\}=0$. A solução $p^{*}=0$ representa a fase de extinção, e a solução $p^{* \alpha}\left[-\ln _{\tilde{q}}\left(p^{*}\right)\right]^{\gamma}=-\epsilon$ representa a fase de sobrevivência. Os valores que separam as fases de extinção e sobrevivência são as raízes da equação:

$$
\left(p^{*}\right)^{\alpha / \gamma}-\left(p^{*}\right)^{\alpha / \gamma+\tilde{q}}=\tilde{q}(-\epsilon)^{1 / \gamma}
$$

Para $\alpha=0$, a solução é

$$
p^{*}=p(\infty)=e_{\tilde{q}}\left[-(-\epsilon)^{1 / \gamma}\right]
$$

Pela definição da função exponencial generalizada (Eq. 2.7), a fase de sobrevivência é estável para $\tilde{q}(-\epsilon)^{1 / \gamma}<1$, então a extinção ocorre em um valor crítico

$$
\epsilon_{c}=-\frac{1}{\tilde{q}^{\gamma}}
$$

Note aqui a dependência desse valor crítico com os parâmetros $\tilde{q}$ e $\gamma$. Como visto na Sec. 3.3, o parâmetro $\tilde{q}$ está relacionado com a estrutura fractal do tecido (tumor) e alcance de interação entre as células. Enquanto que $\gamma$ regula o tamanho da população na qual a taxa de crescimento é máxima, conforme descrito na Sec. 2.6. 


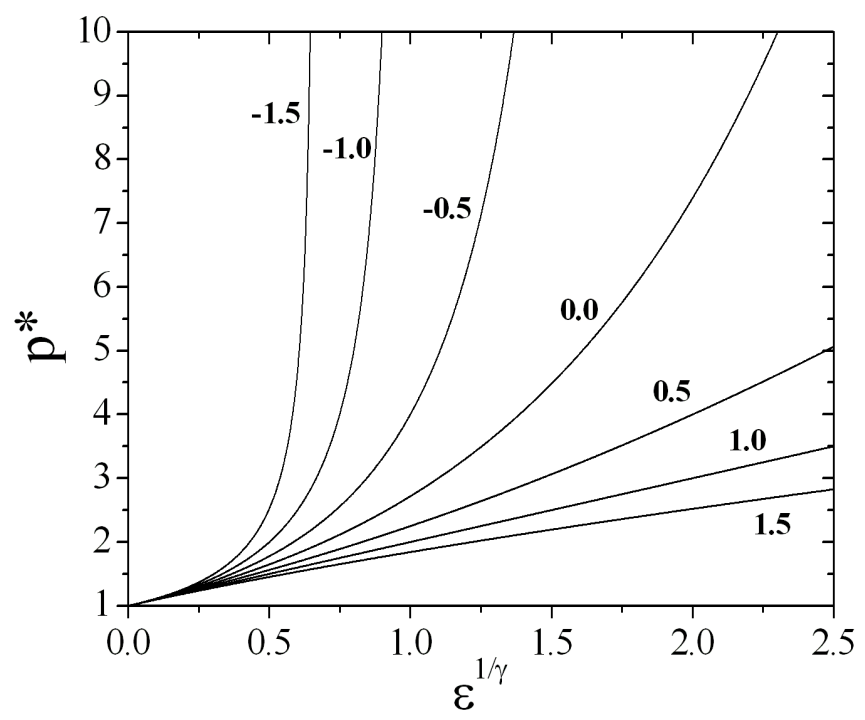

(a)

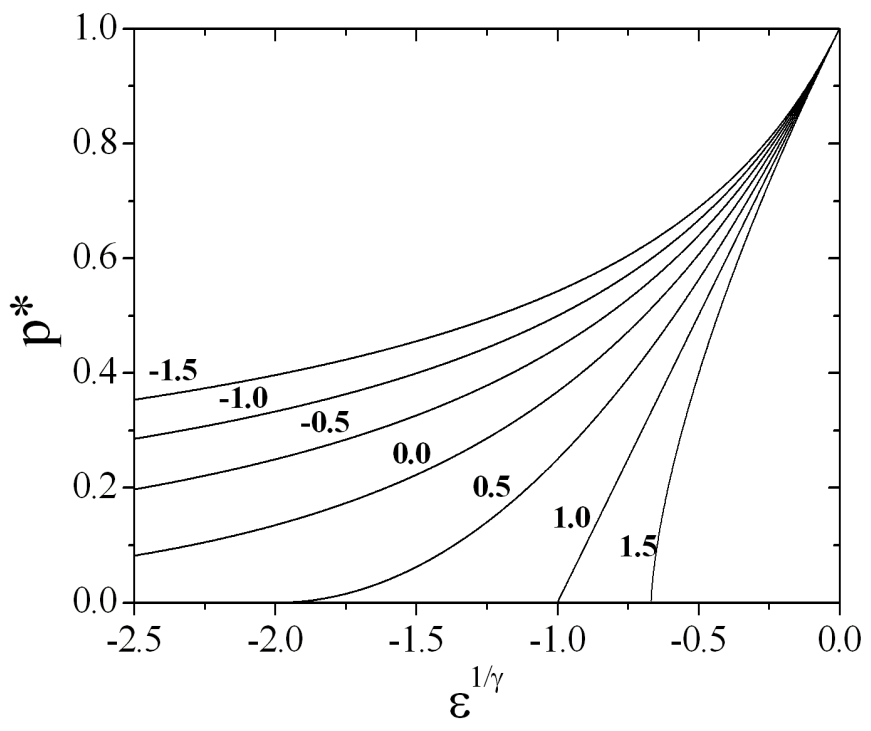

(b)

Figura 3.1: Gráfico da solução estacionária $p^{*}$ em função de $\xi=\epsilon^{1 / \gamma}$ para diferentes valores de $\tilde{q}$. No valor crítico, a população (a) diverge para $\tilde{q}<0$ e (b) se extingue para $\tilde{q}>0$. Não há transição entre as fases quando $\tilde{q} \leq 0$; há uma transição contínua quando $0<\tilde{q}<1$; e há uma transição abrupta (transição de fase de segunda ordem) quando $\tilde{q}>1$. Os parâmetros utilizados são: $\gamma=1$ e os valores de $\tilde{q}$ estão indicados nas respectivas curvas. Extraída da Ref. [22] 
Também é possível calcular os expoentes críticos da transição. Para $\epsilon \gtrsim \epsilon_{c}$, a Eq. (3.14) leva a:

$$
p^{*}=(-1)^{1 /(\gamma \tilde{q})}(-\tilde{q})^{1 / \tilde{q}}\left(\epsilon^{1 / \gamma}-\epsilon_{c}^{1 / \gamma}\right)^{1 / \tilde{q}} \sim\left(\xi-\xi_{c}\right)^{\nu_{1}}
$$

Para $\epsilon<\epsilon_{c}$, de acordo com Eq. (3.14), obtém-se $p^{*}=0$. Note que a grandeza relevante nesse contexto, o parâmetro de controle, é $\xi=\epsilon^{1 / \gamma}$ e o expoente crítico é $\nu_{1}=1 / \tilde{q}$. Esse resultado dá indícios de que ao estabelecer um protocolo de tratamento de um tumor, não devemos considerar apenas a intensidade do tratamento $\epsilon$, mas também dev-se levar em conta a população na qual o crescimento daquele tumor é máximo, dado por $\gamma$. Para $\nu_{1}=1 / \tilde{q} \leq 1$, à medida que o parâmetro de controle diminui, a transição da fase de sobrevivência para a de extinção é abrupta: transição de fase de segunda ordem. Para $\nu_{1}=1 / \tilde{q}>1$, o sistema apresenta uma transição contínua. Quando $\tilde{q}=0$ (modelo de Gompertz), não há transição entre as fases, pois $\epsilon \rightarrow-\infty$, de acordo com Eq. (3.15). A Fig. 3.1 ilustra estas transições. Exemplos destes comportamentos próximos de $\left(\xi-\xi_{c}\right)=0$ com seus expoentes críticos correspondentes são apresentados na Ref. [64].

Também é possível introduzir a susceptibilidade do sistema, $\chi=\partial p^{*} / \partial \xi$, dessa forma $\chi \sim\left(\xi-\xi_{c}\right)^{\nu_{2}}$, com expoente crítico $\nu_{2}=\nu_{1}-1$. Para $\tilde{q}>1$ (que implica $\nu_{1}<1$ ), a susceptibilidade diverge na região crítica. Chamamos a atenção para a dependência dos expoentes críticos somente com $\tilde{q}$. O expoente $\gamma$ interfere somente no parâmetro de controle, i.e. onde a transição ocorre mas não afeta sua forma.

A seguir, apresentamos a relação da taxa extrínseca de crescimento com a capacidade de suporte. Ao considerar a solução do estado estacionário, toda influência externa, gerada pela taxa extrínseca, pode ser vista como uma modificação no ambiente.

\subsection{Capacidade de suporte efetiva}

Conforme visto na Sec. 3.2, acrescentando uma taxa extrínseca de crescimento $\epsilon$ ao modelo de Richards, tem-se o então denominado modelo Richards-Schaefer, Eq. 3.3. Os estados estacionários $p(\infty)$ para esta equação é dado por $d p(t) / d t=0$, 
obtendo:

$$
\begin{aligned}
& p_{1}^{*}=0 ; \\
& p_{2}^{*}=e_{\tilde{q}}(\epsilon) .
\end{aligned}
$$

A primeira solução é trivial, significa a extinção da população. Enquanto que segunda solução mostra que a inserção $(\epsilon>0)$ ou remoção $(\epsilon<0)$ de indivíduos da população altera a solução de estado estacionário. Ao invés de considerar o tamanho da população em relação à capacidade de suporte convencional $K$, consideramos a capacidade de suporte reescalada com a solução do estado estacionário $e_{\tilde{q}}(\epsilon)$. Isto é,

$$
K^{\prime}=e_{\tilde{q}}(\epsilon) K
$$

Isto significa que $N$ indivíduos da população vivem em um ambiente com uma capacidade efetiva de suporte $K^{\prime}$, mas agora sem considerar a inserção ou remoção de indivíduos $\epsilon$. O tamanho da população com relação ao novo valor de equilíbrio é $p^{\prime}=N / K^{\prime}=p / e_{\tilde{q}}(\epsilon)$, obtemos assim o modelo de Richards e sua respectiva solução:

$$
\begin{aligned}
\frac{d \ln p^{\prime}}{d \tau} & =-\ln _{\tilde{q}}\left[p^{\prime}\right] \\
p^{\prime}(\tau) & =\frac{p(\tau)}{e_{\tilde{q}}(\epsilon)}=\frac{1}{e_{\tilde{q}}\left[\ln _{\tilde{q}}\left(1 / p_{0}^{\prime}\right) e^{-\tau}\right]},
\end{aligned}
$$

ou seja,

$$
p(\tau)=\frac{e_{\tilde{q}}(\epsilon)}{e_{\tilde{q}}\left[\ln _{\tilde{q}}\left(e_{\tilde{q}}(\epsilon) / p_{0}\right) e^{-\tau}\right]} .
$$

O caso estacionário $p^{\prime}(\infty)=\left(p^{\prime}\right)^{*}=1$, naturalmente leva a $p^{*}=e_{\tilde{q}}(\epsilon)$. Observe que a Eq. 3.18 é válida apenas para a fase de sobrevivência, i.e., $\tilde{q} \epsilon>-1$; caso contrário, $K^{\prime}$ desaparece.

Comparando as soluções para $p^{*}$ das Eqs. 3.4 e 3.22, percebe-se que os modelos considerados apresentam as mesmas soluções de estado estacionário $e_{\tilde{q}}(\epsilon)$. No entanto, eles possuem diferentes comportamentos de tempos transientes, exceto para o modelo de Gompertz $(\tilde{q} \rightarrow 0)$, em que a equivalência entre o modelo original e o reescalado é completa. Os gráficos da Fig. 3.2 mostram este comportamento. De fato, esta propriedade é proveniente do argumento da função exponencial. Enquanto que na Eq. 3.22 este argumento é $-\tau$, na Eq. 3.4 o argumento é $-(1+\tilde{q} \epsilon) \tau$. A evolução dos dois modelos é a mesma somente quando $\tilde{q} \rightarrow 0$ i.e. modelo Gompertz. 


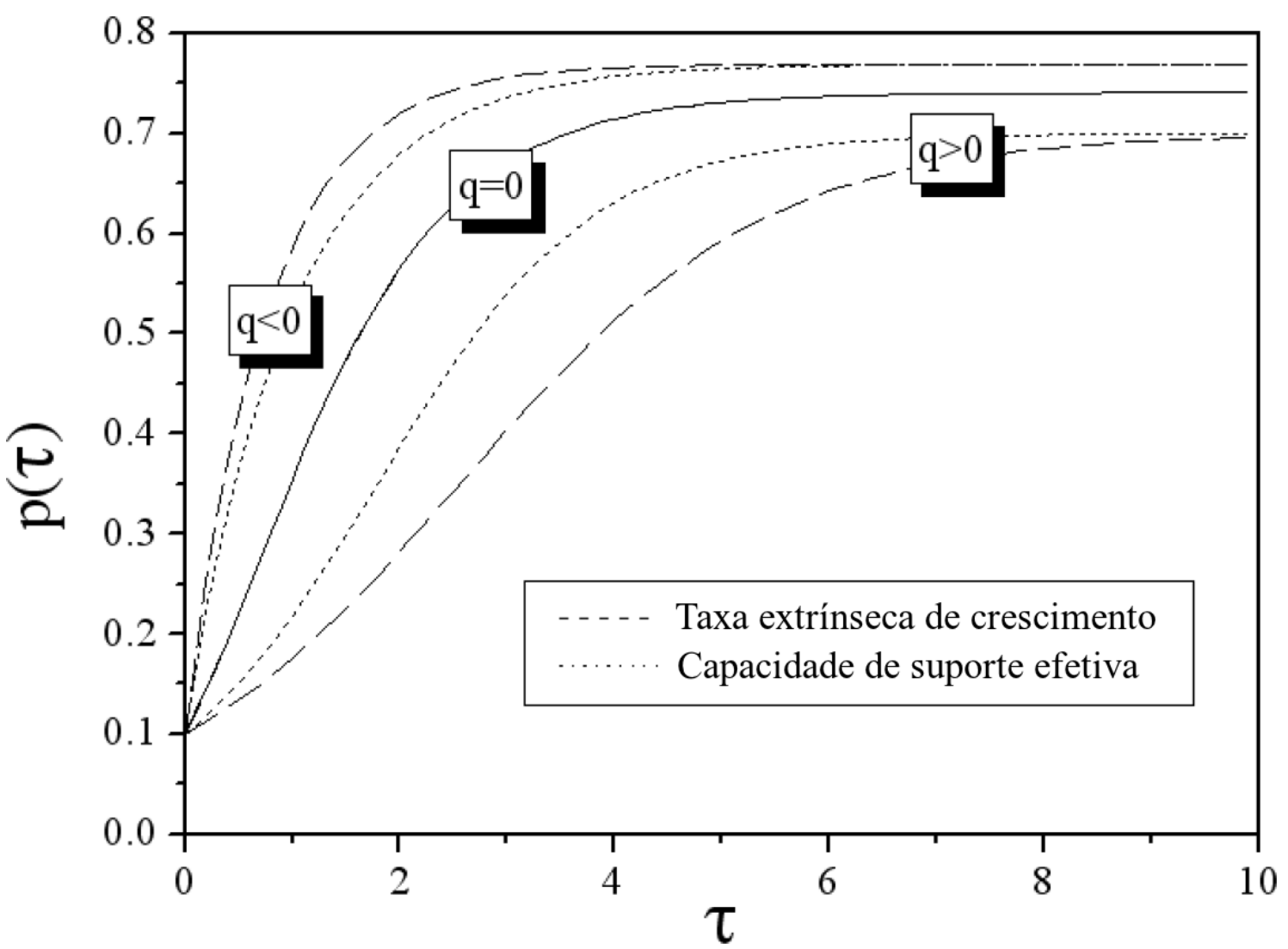

Figura 3.2: Gráfico da população $p(\tau)$ [Eqs. 3.4 e 3.22] como função de $\tau$, com: $p_{0}=$ $1 / 10, \epsilon=-3 / 10, \tilde{q}=-1, \tilde{q} \rightarrow 0$ (modelo Gompertz) e $\tilde{q}=1$ (modelo Verhulst). A equivalência completa entre taxa extrínseca de crescimento e capacidade de suporte efetiva é obtida somente para soluções de estado estacionário. No entanto, para $\tilde{q} \rightarrow 0$, a solução transiente também é equivalente.Adaptada da Ref. [23].

A seguir, consideramos as taxas intrínseca e extrínseca de crescimento dependentes do tempos. Mostramos a relação destes com a dinâmica de duas espécies interagentes.

\subsection{Taxas intrínseca e extrínseca dependentes do tempo}

Considere a dependência das taxas intrínseca e extrínseca de crescimento em função do tempo. Assim, podemos escrever:

$$
\frac{d \ln [p(t)]}{d t}=-\kappa(t) \ln _{\tilde{q}}[p(t)]+\tilde{\epsilon}(t)
$$


Como agora a taxa intrínseca $\kappa$ é função do tempo, a variável independente utilizada é $t$, ao invés do usual $\tau$. A solução dessa equação é dada por:

$$
p(t)=\left\{\frac{1}{\tilde{I}(t)}\left[1+\int_{0}^{t} d t^{\prime} \tilde{I}\left(t^{\prime}\right) \kappa\left(t^{\prime}\right)\right]\right\}^{-1 / \tilde{q}},
$$

em que:

$$
\tilde{I}(t)=p_{0}^{\tilde{q}} e^{\left[\int_{0}^{t} d t^{\prime} \kappa\left(t^{\prime}\right)+\tilde{q} \int_{0}^{t} d t^{\prime} \tilde{\epsilon}\left(t^{\prime}\right)\right]}
$$

e $\tilde{I}(0)=p_{0}^{\tilde{q}}$.

A Eq. 3.23, pode ser considerada a de um modelo com ruído estocástico multiplicativo $\kappa(t)$ e outro aditivo $\epsilon(t)$. Se $\tilde{\epsilon}(t)=0$, pode-se considerar $\kappa(t)=a_{0}(t)+a_{1} \gamma_{1}(t)$, em que $a_{0}(t)$ é um termo determinístico e $\gamma_{1}(t)$ um ruído estocástico multiplicativo $[65,66]$.

Considere agora uma taxa intrínseca constante, $\kappa(t)=\kappa$, mas com uma taxa extrínseca dependente do tempo:

$$
\frac{d \ln p(\tau)}{d \tau}=-\ln _{\tilde{q}} p(\tau)+\epsilon(\tau) .
$$

Esta equação pode ser resolvida explicitamente e a nova solução é convenientemente escrita em termos das funções logaritmo e exponencial generalizadas:

$$
p(\tau)=\frac{e_{\tilde{q}}[\epsilon(\tau)]}{e_{\tilde{q}}\left\{\ln _{\tilde{q}}\left\{\frac{e_{\tilde{q}}[\epsilon(0)]}{p_{0}}\right\} \frac{e_{\tilde{q}}[\epsilon(\tau)]}{e_{\tilde{q}}[\epsilon(0)]} e^{-[1+\tilde{q} \bar{\epsilon}(\tau)] \tau}\right\}},
$$

em que

$$
\bar{\epsilon}(\tau)=\frac{1}{\tau} \int_{0}^{\tau} d \tau^{\prime} \epsilon\left(\tau^{\prime}\right)
$$

é o valor médio de $\epsilon(\tau)$ até o tempo $\tau$. Este resultado [67] permite obter a solução de modelos de duas espécies que serão abordados nas Secs. 5.3 e 6.3.

Para uma taxa extrínseca de crescimento constante $\epsilon(\tau)=\epsilon$ na Eq. 3.27, recupera-se o a solução do modelo de Richards-Schaefer. A solução do estado estacionário $(\tau \rightarrow \infty)$ da Eq. 3.27 é: $p^{*}=p(\infty)=e_{\tilde{q}}(\bar{\epsilon})$, em que $\bar{\epsilon}=\overline{\epsilon(\infty)}$ é o valor médio de $\overline{\epsilon(\tau)}$. A extinção da espécie ocorre para $\tilde{q} \bar{\epsilon}<-1$.

Utilizando a mesma abordagem apresentada anteriormente, podemos escrever o estado estacionário da população como

$$
p^{*} \sim\left(\bar{\epsilon}-\bar{\epsilon}_{c}\right)^{1 / \tilde{q}},
$$


em que

$$
\bar{\epsilon}_{c}=-\frac{1}{\tilde{q}} .
$$

Podemos calcular também a susceptibilidade $\chi=\partial p^{*} / \partial \bar{\epsilon} \sim\left(\bar{\epsilon}-\bar{\epsilon}_{c}\right)^{1 / \tilde{q}-1}$. Deste modo, independentemente do aumento da complexidade, da taxa extrínseca dependente do tempo ou constante, o sistema apresenta o mesmo comportamento crítico.

Se $\epsilon(t)$ for uma variável aleatória, tem-se então uma equação de crescimento estocástico. Neste caso, se seu valor médio se anula $(\overline{\epsilon(\tau)}=0)$ e $\overline{\epsilon\left(\tau_{1}\right) \epsilon\left(\tau_{2}\right)}=\sigma^{2} \delta\left(\tau_{2}-\right.$ $\tau_{1}$ ) (processo gaussiano), então a função densidade de probabilidade de $v=\ln p$ satisfaz a equação de Fokker-Planck: $\partial_{\tau} P(v)=\partial_{v}\left[P(v) \ln _{\tilde{q}}(v)\right]+\left(\sigma^{2} / 2\right) \partial_{v}^{2}[P(v)][68$, 69, 70]. Outros tipos de ruídos e do tipo Levy são abordados nas Refs. [71, 19, 72].

No próximo capítulo mostramos que todos os modelos até aqui considerados, inclusive aqueles com taxas intrínsecas e extrínsecas em função do tempo, podem ser colapsados em uma única curva. Isso é possível a partir do cálculo das funções de escala que permitem que os modelos se tornem independentes dos parâmetros e das condições iniciais.

\subsection{Conclusão}

A remoção ou inserção de indivíduos na população pode ser modelada a partir de uma taxa extrínseca de crescimento. Esta taxa é responsável por provocar transições entre sobrevivência e extinção da população. O caso da extinção é particularmente interessante quando buscamos eliminar células de tumores. A partir de um modelo microscópico proposto na Ref. [59] é possível obter uma interpretação do parâmetro de generalização do modelo de Richards. Isso possibilita uma descrição do modelo em termos biológicos e assim caracterizar curvas de crescimento de acordo com as características físicas do tumor. Nesse contexto, podemos utilizar conceitos de transição de fase e expoentes críticos de forma a obter grandezas relevantes em protocolos de tratamento de tumores.

A relação da taxa extrínseca de crescimento de crescimento com a capacidade de suporte permite considerar toda influência externa como uma modificação no ambiente, provocando um aumento ou diminuição na população máxima. Ao considerar as taxas intrínseca e extrínseca dependentes do tempos é possível abordar modelos 
de dinâmica de duas espécies assim como modelos estocásticos, em que o ruído é um fator relevante. 


\section{Capítulo}

\section{Funções de escala e colapso de dados em modelos de crescimento}

Possivelmente, van der Waals foi o primeiro pesquisador a reescalar e colapsar dados em uma curva não trivial. Para um dado volume, diferentes gases se liquefazem em diferentes temperaturas e pressões, levando a uma transição de primeira ordem. Entretanto, para valores críticos de volume, temperatura e pressão, a transição se torna de segunda ordem (sem calor latente). Para cada gás, dividindo a temperatura, pressão e volume pelo seus respectivos valores críticos, obtêm-se uma curva colapsada (comum). Essa curva comum revela aspectos semelhantes em todos os gases reais (volume finito da partícula e interação de curto alcance entre elas). Este colapso de dados teve consequências importantes na estimativa da temperatura de liquefação do gás Hélio, que levou a descobertas relevantes como a supercondutividade e super fluidez [73]. Nos dias de hoje, a ideia de colapso de dados foi estendida às funções de escala [74], que é um aspecto particular da hipótese de escala [75]. A hipótese de escala também lida com leis de escala nos valores críticos de transição (como na teoria de campo médio de van der Waals) e teoria de grupos de renormalização, porém estes aspectos estão fora do escopo desse trabalho. Focamos apenas no poder das funções de escala de conectar grandezas aparentemente independentes em grandezas relevantes simples [76] em modelos de dinâmica populacional e em expoentes críticos de transição.

Conforme visto no Cap.2, o modelo de Richards une os modelos de Gompertz e Verhulst através de uma constante $\tilde{q}$. Formas generalizadas das equações clássicas de crescimento logístico de Verhulst e Gompertz são mais convenientes como 
modelos preditivos. Mais características de crescimento permitem que dinâmicas populacionais antes atípicas possam ser modeladas pela escolha adequada dos valores dos parâmetros. Como exemplo, o modelo de Tsoularis-Wallace unifica todos os modelos citados e apresenta solução analítica não explícita.

Neste capítulo, mostramos como obter a função de escala. Esta função depende da combinação de grandezas de forma que os modelos se tornem independentes das condições iniciais e parâmetros. O colapso de dados, obtido a partir da função de escala, ocorre mesmo para o modelo de Tsoularis-Wallace, em que a solução analítica explicita não é conhecida ${ }^{1}$.

\subsection{Funções de Escala}

Modelos de crescimento de uma espécie são geralmente representados por:

$$
\frac{d \ln p(\tau)}{d \tau}=G(p)
$$

em que $\tau=\kappa t$ é a medida do tempo em termos da taxa intrínseca de crescimento $\kappa$ e $G(p)$ é a taxa de crescimento per capita. Modelos de dinâmicas de população de uma espécie (crescimento) caem em duas categorias: uma com capacidade infinita e outra com capacidade de suporte finita. Para lidar com esses dois tipos de modelos, introduzimos a variável $p$. Por um lado, quando os recursos são ilimitados $(K \rightarrow \infty)$, como no caso do modelo de Malthus e von Foerster et al., é conveniente utilizar $p=N$, onde $N$ é o número de indivíduos. Por outro lado, quando há recursos limitados, como no caso do modelo de Verhulst e Gompertz, é conveniente expressar o tamanho da população à respeito do seu valor de equilíbrio, i.e. $p=N / K$. Em um ambiente com recursos limitados, as soluções de estado estacionário são extinção da espécie $\left(p^{*}=0\right)$ ou sobrevivência $\left(0<p^{*} \leq 1\right)$ dada pela raiz $G\left(p^{*}\right)=0$. A exploração ótima de um ambiente é atingida quando $p(\tau)=1$.

A equação:

$$
s(\tau)=\int_{p_{0}}^{p(\tau)} \frac{d p}{p G(p)}=\int_{\ln p_{0}}^{\ln p(\tau)} \frac{d \ln p}{G(\ln p)}=\int_{v_{0}}^{v(\tau)} \frac{d v}{G(v)}=\tau-\tau_{0}=\Delta \tau,
$$

é um procedimento geral para obter a função de escala dos modelos de função de crescimento. Aqui, $v(\tau)=\ln p(\tau)$ e $p_{0} \equiv p\left(\tau_{0}\right)$ é a condição inicial. Esta função de

\footnotetext{
${ }^{1}$ Deste resultado foi publicado o artigo da Ref. [22].
} 
escala é linear em $\tau$ (ver Fig. 4.1) e o colapso de dados torna o modelo independente dos parâmetros e da condição inicial.

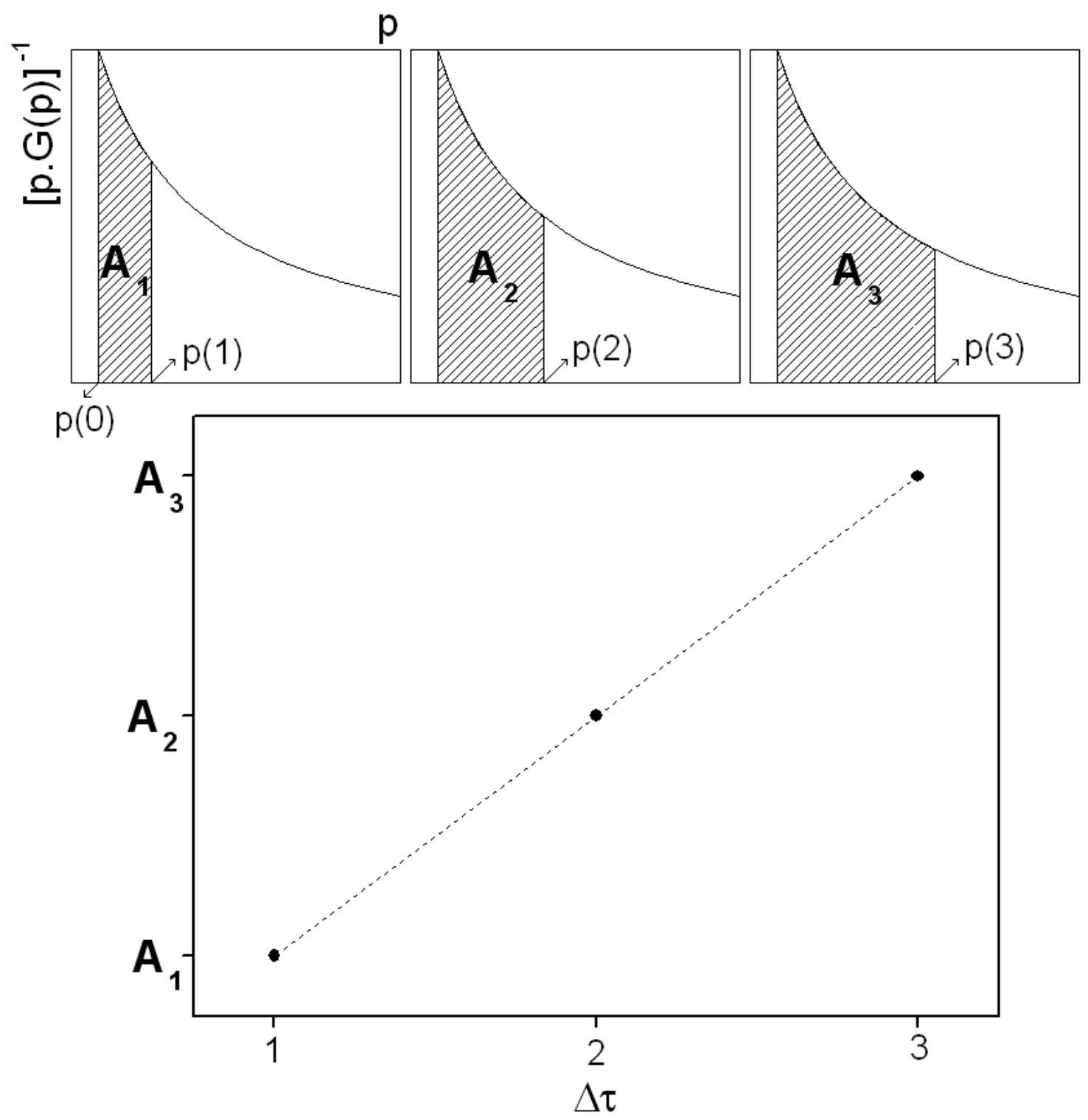

Figura 4.1: A área sob a curva 1/[p.G(p)] cresce linearmente como função de $\tau-\tau_{0}$. Este comportamento não depende do modelo considerado.Extraída da Ref. [22].

No caso de capacidade suporte infinita, $p(\tau)=N(\tau)$, escrevemos variáveis til $\left({ }^{\prime}\right)$. Por exemplo, a função de escala da Eq. (4.2) é $\tilde{s}(\tau)$. Para $\tilde{G}_{\alpha}(N)=N^{\alpha}$ (modelo de von Foerster et al.) [5], onde $\alpha$ é um parâmetro de generalização que produz uma divergência no tempo finito (adimensional) $T$, a solução da Eq. (4.1) é: $N(\tau)=$ $1 /[\alpha(T-\tau)]^{1 / \alpha}$. A função de escala da Eq. (4.2) para o modelo de von Foerster et 
al. é:

$$
\tilde{s}_{\alpha}(\tau)=\frac{N_{0}^{-\alpha}-N^{-\alpha}(\tau)}{\alpha}=N_{0}^{-\alpha} \ln _{-\alpha}\left[\frac{N(\tau)}{N_{0}}\right],
$$

onde utilizamos a função $\tilde{q}$-logarítmica generalizada (ver apêndiceA). Obtém-se uma reta no gráfico de $\tilde{s}_{0} \times \tau$, independente dos parâmetros do modelo (taxa intrínseca de crescimento $\kappa$ ) e condição inicial $\left(N_{0}\right)$. Com $\alpha \rightarrow 0$, recupera-se o modelo de Malthus, $\tilde{G}(N)=1: d N(\tau) / d \tau=N(\tau)$, resultando no crescimento exponencial: $N(\tau) / N_{0}=e^{\tau}\left(N_{0}=e^{T}\right)$. Assim a função de escala para o modelo de Malthus é:

$$
\tilde{s}_{0}(\tau)=\ln \left[\frac{N(\tau)}{N_{0}}\right] .
$$

O modelo de Richards $[4,68,77,78]$ pode ser convenientemente escrito em termos da função $\tilde{q}$-logarítmica: $d \ln p(\tau) / d \tau=-\ln _{\tilde{q}}[p(\tau)]$. Quando discretizada, esta função leva a um mapa logístico generalizado [79]. A solução do modelo pode ser escrita em termos das funções logarítmica e exponencial generalizadas como $p(\tau)=1 / e_{\tilde{q}}\left[\ln _{\tilde{q}}\left(p_{0}^{-1}\right) e^{-\tau}\right]$. O limite assintótico $(\tau \rightarrow \infty)$ é $p^{*}=p(\infty)=1$, independentemente da escolha de $\tilde{q}$. O modelo de Gompertz é recuperado com $\tilde{q} \rightarrow 0$ : $d \ln p / d \tau=-\ln p$, e tem $p(\tau)=e^{\left(\ln p_{0}\right) e^{-\tau}}$ como solução. O modelo de Verhulst é recuperado com $\tilde{q}=1: d \ln p / d \tau=1-p$, e tem $p(\tau)=1 /\left[1-\left(1-p_{0}^{-1}\right) e^{-\tau}\right]$ como solução. A função de escala para o modelo de Richards é

$$
s_{\tilde{q}}(\tau)=\ln \left\{\frac{\ln _{-\tilde{q}}\left(p_{0}\right)}{\ln _{-\tilde{q}}[p(\tau)]}\right\},
$$

com os seguintes casos limites:

- $s_{0}(\tau)=\ln \left\{\frac{\ln \left(p_{0}\right)}{\ln [p(\tau)]}\right\}$ (Gompertz);

- $s_{1}(\tau)=\ln \left\{\frac{p_{0}^{-1}-1}{\left[p^{-1}(\tau)-1\right]}\right\}$ (Verhulst).

Com este procedimento, elimina-se a dependência com a condição inicial e parâmetros. Apesar de E. W. Montroll ter utilizado esta informação para o modelo de Verhulst na Ref [68, p. 4634], ele não chamou atenção para o colapso de dados.

Um modo de incluir a capacidade de suporte finito $K$ no modelo de von Foerster et al. é substituir $N$ por $p=N / K$, reescalar as constantes e substituir $N^{\alpha}$ por $[-\ln (N / K)]^{\gamma}$ na função de saturação. O modelo de von Foerster et al. na variável $\ln p$, é conhecido como modelo hiper-Gompertz [14]: $d \ln p(\tau) / d \tau=\{-\ln [p(\tau)]\}^{\gamma}$, 
cuja solução é: $p(\tau)=e^{-\left[(\gamma-1) \tau-(-1)^{\gamma}\left(\ln p_{0}\right)^{1-\gamma}\right]^{1 /(1-\gamma)}}$. A função de escala para o modelo hiper-Gompertz é dada por:

$$
\begin{aligned}
s_{\gamma}(\tau) & =\frac{\left[-\ln p_{0}\right]^{1-\gamma}-[-\ln p(\tau)]^{1-\gamma}}{1-\gamma} \\
& =\left(-\ln p_{0}\right)^{1-\gamma} \ln _{1-\gamma}\left[\frac{\ln p(\tau)}{\ln p_{0}}\right]=\left(-\ln p_{0}\right)^{1-\gamma} \ln _{1-\gamma}\left\{\ln \left[p(\tau)-p_{0}\right]\right\}
\end{aligned}
$$

Até agora, todos os modelos apresentados têm soluções analíticas explícitas e podem ser unificados no modelo Tsoularis-Wallace (TW), que não possui uma solução explícita. Todavia, sua função de escala ainda pode ser obtida no caso geral. Em termos da função q̃-logarítmica, o modelo TW é escrito como [15]:

$$
\frac{d \ln p}{d \tau}=p^{\alpha}(\tau)\left\{-\ln _{\tilde{q}}[p(\tau)]\right\}^{\gamma}
$$

A solução $p(\tau)$ da Eq. (4.7) é dada pelas raízes de: $B_{p^{\tilde{q}}(\tau)}(-\alpha / \tilde{q}, 1-\gamma)-B_{p_{0}^{\tilde{q}}}(-\alpha / \tilde{q}, 1-$ $\gamma)=\tilde{q}^{1-\gamma} \tau$, em que $B_{x}(a, b)=\int_{0}^{x} t^{a-1}(1-t)^{b-1} d t$ é a função beta incompleta; e a função de escala da Eq. (4.2) é:

$$
\begin{aligned}
s_{\alpha, \tilde{q}, \gamma}(\tau) & =\frac{B_{p^{\tilde{q}}(\tau)}\left(-\frac{\alpha}{\tilde{q}}, 1-\gamma\right)-B_{p_{0}^{\tilde{q}}}\left(-\frac{\alpha}{\tilde{q}}, 1-\gamma\right)}{\tilde{q}^{1-\gamma}} \\
& =\frac{1}{\tilde{q}^{1-\gamma}} \int_{p_{0}^{\tilde{q}}}^{p^{\tilde{q}}(\tau)} \frac{d p^{\prime}}{p^{1+\alpha / \tilde{q}}\left(1-p^{\prime}\right)^{\gamma}} .
\end{aligned}
$$

Todos os modelos estudados podem ser recuperados pela escolha conveniente de $\alpha$, $\gamma$ e $\tilde{q}$.

Mesmo em um modelo mais geral, com um termo aditivo como o modelo Tsoularis-Wallace-Schaefer (Eq. 3.2), é possível obter a função de escala a partir da Eq. 4.2:

$$
s_{\alpha, \tilde{q}, \gamma, \epsilon}(\tau)=\int_{p_{0}}^{p(\tau)} \frac{d p^{\prime}}{p^{\prime}\left\{p^{\alpha}\left[-\ln _{\tilde{q}}\left(p^{\prime}\right)\right]^{\gamma}+\epsilon\right\}}
$$

Embora esta não seja uma solução geral explícita, tomando $\gamma=1$ e $\alpha=0$, é possível resolver a integral e obter uma expressão analítica explícita a partir do modelo Richards-Schaefer:

$$
s_{\tilde{q}, \epsilon}(\tau)=-\left[e_{\tilde{q}}(\epsilon)\right]^{-\tilde{q}} \ln \left\{\frac{\ln _{-\tilde{q}}\left[p(\tau) / e_{\tilde{q}}(\epsilon)\right]}{\ln _{-\tilde{q}}\left[p_{0} / e_{\tilde{q}}(\epsilon)\right]}\right\} .
$$




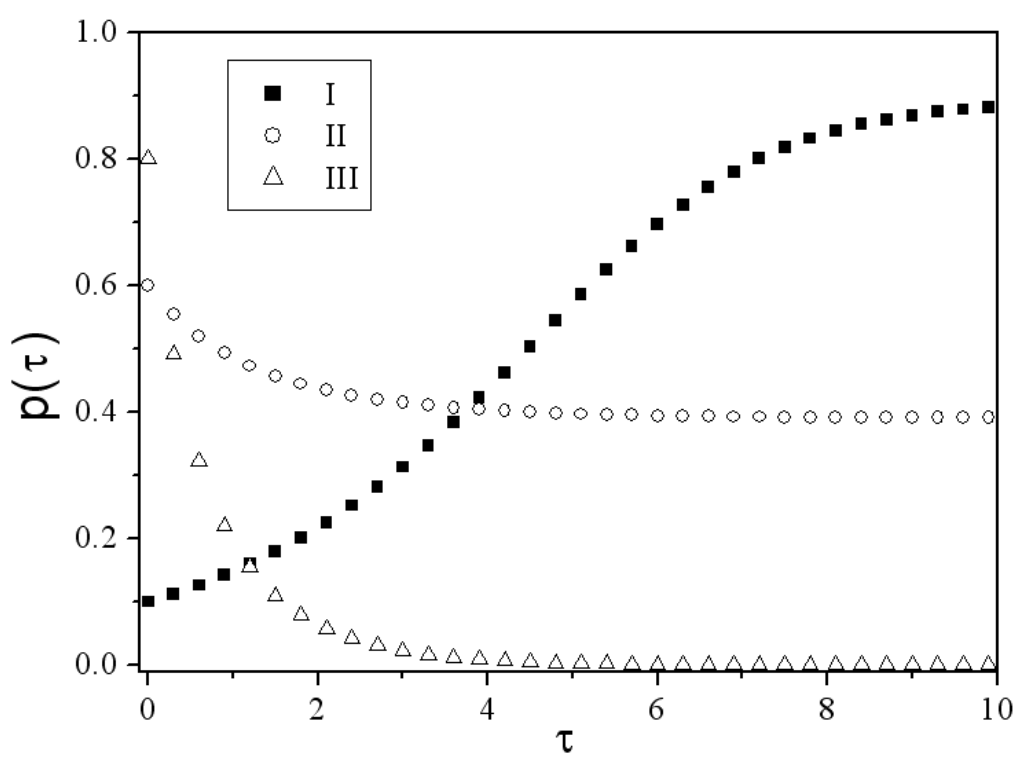

(a)

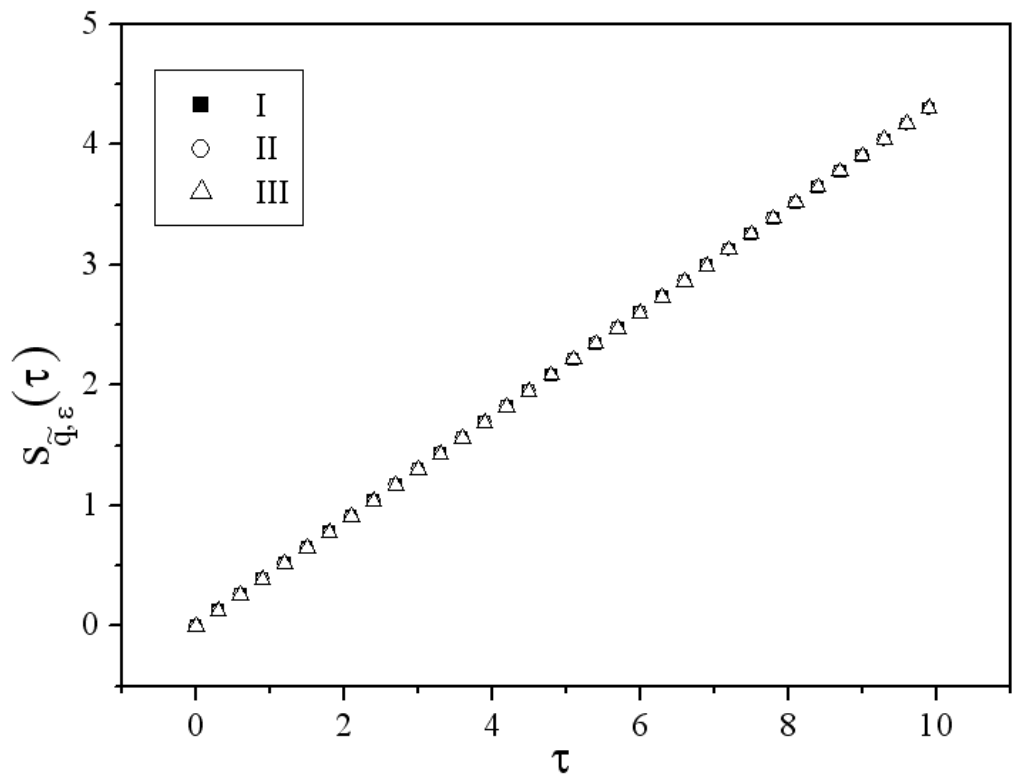

(b)

Figura 4.2: Curva da população $p(\tau)$ utilizando o modelo Richards-Schaefer, para diferentes valores de parâmetros e condições iniciais. (I) $p_{0}=0.1, \tilde{q}=2.0$ e $\epsilon=-0.1$; (II) $p_{0}=0.6, \tilde{q}=0.5$ e $\epsilon=-0.75$ e (III) $p_{0}=0.8, \tilde{q}=1.0$ e $\epsilon=-2.0 . \quad 4.2$ (b). O mesmo conjunto de parâmetros utilizando a forma escalada da solução de Richards-Schaefer $S_{\tilde{q}, \epsilon}$. Com a função apropriada de escala, todos os comportamentos diferentes em (a) colapsam em uma única curva em (b).Extraída da Ref. [22] 
Quando $\epsilon=0 \Rightarrow e_{\tilde{q}}(0)=1$ e recupera-se a Eq. 4.5. A Fig. 4.2 ilustra o colapso de dados neste caso mais geral. Utilizando três conjuntos diferentes de parâmetros, uma única curva é obtida quando a função de escala adequada é utilizada.

Também é possível calcular a função de escala ao considerarmos as taxas intrínsecas e extrínsecas dependentes do tempo:

$$
s_{\kappa(t), \tilde{q}, \tilde{\epsilon}(t)}(t)=\tilde{I}(t) p^{-\tilde{q}}(t)-1=\int_{0}^{t} d t^{\prime} \tilde{I}\left(t^{\prime}\right) \kappa\left(t^{\prime}\right) .
$$

Ao fazer $\kappa(t)=\kappa$, a função de escala do modelo Richards-Schaefer com a taxa extrínseca dependente do tempo é dada por:

$$
s_{\tilde{q}, \epsilon(\tau)}(\tau)=-\left\{e_{\tilde{q}}[\epsilon(\tau)]\right\}^{-\tilde{q}} \ln \left\{\frac{\ln _{-\tilde{q}}\left\{p(\tau) / e_{\tilde{q}}[\epsilon(\tau)]\right\}}{\ln _{-\tilde{q}}\left\{p_{0} / e_{\tilde{q}}[\epsilon(\tau)]\right\}}\right\} .
$$

A seguir, a Tab4.1 resume as equações que representam os modelos de uma espécie aqui tratados, assim como suas respectivas soluções analíticas e funções de escala. 
Tabela 4.1: Tabela resumo com as taxas de crescimento per capta dos modelos de uma espécie, reescaladas com a variável independente $\tau=\kappa t$, e suas respectivas soluções e funções de escala.

\begin{tabular}{|c|c|c|c|}
\hline Modelo & Taxa de crescimento per capita & Solução analítica & Função de escala \\
\hline Malthus & 1 & $N_{0} e^{\tau}$ & $\ln \left[\frac{N(\tau)}{N_{0}}\right]$ \\
\hline von Foerster & $N^{\alpha}$ & $N_{0} e_{-\alpha}\left(N_{0}^{\alpha} \tau\right)$ & $N_{0}^{-\alpha} \ln _{-\alpha}\left[\frac{N(\tau)}{N_{0}}\right]$ \\
\hline Gompertz & $-\ln p$ & $e^{\left(\ln p_{0}\right) e^{-\tau}}$ & $\ln \left\{\frac{\ln \left(p_{0}\right)}{\ln [p(\tau)]}\right\}$ \\
\hline Verhulst & $1-p$ & $\frac{1}{/}\left[1-\left(1-p_{0}^{-1}\right) e^{-\tau}\right]$ & $\ln \left\{\frac{\left(p_{0}^{-1}-1\right)}{\left[p^{-1}(\tau)-1\right]}\right\}$ \\
\hline Richards & $-\ln _{\tilde{q}}(p)$ & $\frac{1}{/} e_{\tilde{q}}\left[\ln _{\tilde{q}}\left(p_{0}^{-1}\right) e^{-\tau}\right]$ & $\ln \left\{\frac{\ln _{-\tilde{q}}\left(p_{0}\right)}{\ln _{-\tilde{q}}[p(\tau)]}\right\}$ \\
\hline Hiper-Gompertz & $\{-\ln [p(\tau)]\}^{\gamma}$ & $\exp \left\{-\left[(\gamma-1) \tau-(-1)^{\gamma}\left(\ln p_{0}\right)^{1-\gamma}\right]^{1 /(1-\gamma)}\right\}$ & $\left(-\ln p_{0}\right)^{1-\gamma} \ln _{1-\gamma}\left\{\ln \left[p(\tau)-p_{0}\right]\right\}$ \\
\hline Tsoularis-Wallace & $p^{\alpha}(\tau)\left\{-\ln _{\tilde{q}}[p(\tau)]\right\}^{\gamma}$ & $\operatorname{raiz}\left[B_{p^{\tilde{q}}(\tau)}(-\alpha / \tilde{q}, 1-\gamma)-B_{p_{0}^{\tilde{q}}}(-\alpha / \tilde{q}, 1-\gamma)=\tilde{q}^{1-\gamma} \tau\right]$ & $\frac{1}{\tilde{q}^{1-\gamma}} \int_{p_{0}^{\tilde{q}}}^{p^{\tilde{q}}(\tau)} \frac{d p^{\prime}}{p^{\prime 1+\alpha / \tilde{q}}\left(1-p^{\prime}\right)^{\gamma}}$ \\
\hline Richards-Schaefer I & $-\ln _{\tilde{q}}[p(\tau)]+\epsilon$ & $\frac{e_{\tilde{q}}(\epsilon)}{e_{\tilde{q}}\left\{\ln _{\tilde{q}}\left[e_{\tilde{q}}(\epsilon) / p_{0}\right] e^{-(1+\tilde{q} \epsilon) \tau}\right\}}$ & $-\left[e_{\tilde{q}}(\epsilon)\right]^{-\tilde{q}} \ln \left\{\frac{\ln _{-\tilde{q}}\left[p(\tau) / e_{\tilde{q}}(\epsilon)\right]}{\ln _{-\tilde{q}}\left[p_{0} / e_{\tilde{q}}(\epsilon)\right]}\right\}$ \\
\hline Richards-Schaefer II & $-\ln _{\tilde{q}} p(\tau)+\epsilon(\tau)$ & $\frac{e_{\tilde{q}}[\epsilon(\tau)]}{e_{\tilde{q}}\left\{\ln _{\tilde{q}}\left\{\frac{e_{\tilde{q}}[\epsilon(0)]}{p_{0}}\right\} \frac{e_{\tilde{q}}[\epsilon(\tau)]}{e_{\tilde{q}}[\epsilon(0)]} e^{-[1+\tilde{q} \bar{\epsilon}(\tau)] \tau}\right\}}$ & $-\left\{e_{\tilde{q}}[\epsilon(\tau)]\right\}^{-\tilde{q}} \ln \left\{\frac{\ln _{-\tilde{q}}\left\{p(\tau) / e_{\tilde{q}}[\epsilon(\tau)]\right\}}{\ln _{-\tilde{q}}\left\{p_{0} / e_{\tilde{q}}[\epsilon(\tau)]\right\}}\right.$ \\
\hline Richards-Schaefer III & $-\kappa(t) \ln _{\tilde{q}}[p(t)]+\tilde{\epsilon}(t)$ & $\left\{\frac{1}{\tilde{I}(t)}\left[1+\int_{0}^{t} d t^{\prime} \tilde{I}\left(t^{\prime}\right) \kappa\left(t^{\prime}\right)\right]\right\}^{-1 / \tilde{q}}$ & $\tilde{I}(t) p^{-\tilde{q}}(t)-1=\int_{0}^{t} d t^{\prime} \tilde{I}\left(t^{\prime}\right) \kappa\left(t^{\prime}\right)$ \\
\hline
\end{tabular}




\subsection{Conclusão}

Usando a função de escala apropriada, todos os modelos considerados podem ser escritos como um modelo linear simples. Se uma taxa extrínseca de crescimento é incluída nos modelos, o colapso de dados permanece. Esta taxa extrínseca pode representar a aproximação de campo médio da interação entre espécies. Assim, podemos inferir que o colapso de dados é válido para modelos com múltiplas espécies. Ao considerar também esta taxa como um termo de estocasticidade nos modelos, como um ruído aditivo ou multiplicativo, conjecturamos que os modelos estocásticos também apresentam colapso de dados. 


\section{Capítulo}

\section{Modelo de Lotka-Volterra competitivo}

A riqueza da comunidade ecológica não pode ser propriamente descrita somente por modelos de uma espécie. A comunidade ecológica é composta por uma rede complexa de interações na qual a remoção de uma única espécie pode causar mudanças radicais em todo o sistema. As interações entre as espécies se tornaram melhor formalizadas com as equações de Lotka-Volterra [2], as quais explicam o comportamento da dinâmica presa-predador e outros tipos de fenômenos tais como, o comportamento oscilatório de uma reação química, a pesca em ecologia, células e carga viral em imunologia [80], econofísica etc. As equações de Lotka-Volterra são um par de equações diferenciais:

$$
\left\{\begin{array}{l}
\frac{d N_{1}}{d t}=N_{1}\left(\alpha-\beta N_{2}\right) \\
\frac{d N_{2}}{d t}=N_{2}\left(\gamma-\delta N_{1}\right)
\end{array}\right.
$$

em que as variáveis $N_{1}$ e $N_{2}$ são o número de presas e predadores respectivamente em função do tempo. Os parâmetros são: taxa de natalidade das presas $\alpha$, taxa de mortalidade dos predadores $\gamma$, enquanto que $\beta$ e $\delta$ estão relacionados à intensiade da interação entre a presa e o predador.

Em imunologia, a introdução de modelos do tipo Lotka-Volterra foi uma das principais contribuições da dinâmica populacional no século XX. A maior compreensão da dinâmica do HIV, vírus causador da AIDS, verificada na última década e que tem levado a tratamentos mais eficientes, deve-se ao artigo Antigenic Diversity Thresholds and The Development of Aids [80]. Neste, os autores desenvolvem um 
modelo tipo Lotka-Volterra para as células do sistema imunológico e para a carga viral.

Este capítulo está organizado da seguinte forma: na Sec.5.1 apresentamos o modelo de Lotka-Volterra competitivo e os tipos de regimes ecológicos na Sec. 5.2, as soluções dos estados estacionários do modelo são apresentadas assim como a estabilidade dessas soluções. Estas soluções correspondem ao regime ecológico estável no diagrama do espaço de parâmetros. Neste diagrama nota-se a existência de uma transição sobrevivência/extinção e de uma região não física no regime de mutualismo. Na seção 5.3, as soluções analíticas para o casos neutralismo, amensalismo e comensalismo são apresentadas. Em seguida, são apresentadas as soluções analíticas para os regimes de mutualismo, predação e competição. Ainda nesta seção, é feita uma discussão sobre a aplicação do modelo em tratamento de câncer a partir de vírus replicantes. A conclusão deste capítulo é apresentada na Sec. 5.4.

\subsection{Tipos de relações ecológicas}

O modelo de interação entre duas espécies que assume o termo de Verhulst para o crescimento da população é conhecido como modelo de Lotka-Volterra competitivo. O termo competitivo refere-se a competição entre indivíduos de mesma espécie que disputam os mesmos recursos. Esse modelo é descrito pelo seguinte par equações diferenciais $[2,81]$ :

$$
\left\{\begin{array}{l}
\frac{d N_{1}}{d t}=\kappa_{1} N_{1}\left(1-\frac{N_{1}}{K_{1}}+\alpha_{1} \frac{N_{2}}{K_{1}}\right), \\
\frac{d N_{2}}{d t}=\kappa_{2} N_{2}\left(1-\frac{N_{2}}{K_{2}}+\alpha_{2} \frac{N_{1}}{K_{2}}\right),
\end{array}\right.
$$

em que $N_{i} \geq 0, \kappa_{i}$ e $K_{i}>0$ são os números de indivíduos, taxa de reprodução líquida e capacidade de suporte da espécie $i(=1,2)$ respectivamente.

Considerando a espécie 1 , o termo $-\kappa_{1} N_{1}^{2} / K_{1}$ representa a competição entre os indivíduos da mesma espécie (competição intraespecífica). A competição entre os membros de uma mesma espécie é uma das forças motrizes por trás da evolução e da seleção natural. É a competição por recursos como comida, água, território que determinam o domínio da variante da espécie que melhor se adapta ao ambiente. O 
termo $\kappa_{1} \alpha_{1} N_{1} N_{2} / K_{1}$ representa a interação entre indivíduos de espécies diferentes (interação interespecífica).

De forma a utilizar grandezas adimensionais no modelo de Lotka-Volterra competitivo, escrevemos $p_{i}=N_{i} / K_{i} \geq 0, \operatorname{com} i=1,2$. O tempo é medido em relação a taxa de reprodução líquida da espécie $1, \tau=\kappa_{1} t \geq 0$. Nos restringimos aqui ao caso em que $\kappa_{i}>0$. O tempo reescalado é sempre positivo já que tomamos a condição inicial $t_{0}=0$. Além disso, as duas taxas de reprodução líquidas formam um único parâmetro $\rho=\kappa_{2} / \kappa_{1}>0$, fixando uma segunda escala temporal para o sistema: $\tau^{\prime} \equiv \rho \tau=\kappa_{2} t$. Os parâmetros $\alpha_{1}$ e $\alpha_{2}$ representam além do tipo de interação, a intensidade dessa interação. Os parâmetros adimensionais dessas interações são dados por $\epsilon_{1}$ e $\epsilon_{2}$. De forma a representar diferentes interações ecológicas, os valores de $\epsilon_{i}, \operatorname{com}(i=1,2)$ podem variar no intervalo $[-\infty, \infty]$. Com essas grandezas, o modelo de Verhulst-Lotka-Volterra competitivo se torna:

$$
\left\{\begin{array}{l}
\frac{d p_{1}}{d \tau}=p_{1}\left[1-p_{1}+\epsilon_{1} p_{2}\right]=f\left(p_{1}, p_{2}\right) \\
\frac{d p_{2}}{d \tau}=\rho p_{2}\left[1-p_{2}+\epsilon_{2} p_{1}\right]=g\left(p_{1}, p_{2}\right)
\end{array}\right.
$$

\subsubsection{Predação}

A predação descreve uma interação biológica onde um predador (um organismo que é o caçador) alimenta-se de sua presa (o organismo que é caçado). Podemos citar como exemplo de predação uma aranha comendo uma mosca ou o clássico exemplo da lebre e lince das florestas boreais canadenses. Com relação aos predadores podemos separá-los em dois grupos: os especialistas que se alimentam de poucos ou mesmo um tipo de presa e os generalistas que podem se alimentar de várias espécies. Ao contrário dos especialistas, os generalistas são pouco afetados quando um ou mais tipos de presas deixam de fazer parte de seu habitat. Para a relação de predação, temos $\epsilon_{1}<0$ e $\epsilon_{2}>0$ ou $\epsilon_{2}<0$ e $\epsilon_{1}>0$.

\subsubsection{Competição}

A competição interespecífica é uma competição onde duas espécies diferentes disputam um mesmo nicho ecológico em um mesmo local. O objetivo da disputa pode estar relacionado com recursos alimentares ou com o território. Um exemplo 
de competição interespecífica é entre leões e tigres que disputam tipos similares de presas. No regime de competição $\epsilon_{1}<0$ e $\epsilon_{2}<0$.

\subsubsection{Mutualismo}

Se as espécies favorecem umas às outras, temos protocooperação ou simbiose. $\mathrm{Na}$ simbiose, as duas espécies não podem viver separadas. O exemplo clássico são os líquens, em que temos os fungos fazendo o papel de absorção e das algas fazendo o papel de fotossíntese. Na protocooperação, as duas espécies são beneficiadas e podem viver independentemente ou trocar de parceiro, como é o caso das aves que comem parasitas na pele do gado.

\subsubsection{Amensalismo e comensalismo}

Se somente uma espécie é afeta pela outra, existem duas possibilidades: amensalismo, se a espécie considerada afeta negativamente a outra; e comensalismo quando ela favorece a outra. Como exemplo de amensalismo, temos o fungo penicillium. Este fungo expele um componente químico (penicilina) como parte de seu metabolismo e este composto é tóxico para as bactérias. Como exemplo de comensalismo podemos citar as remoras que comem as sobras de alimento dos tubarões.

Ao considerar o modelo de Lotka-Volterra competitivo assumimos que, na interação de predação, o predador é generalista. Enquanto que o mutualismo é do tipo protocooperação.

Damos aqui uma nova interpretação ao modelo de Lotka-Volterra competitivo, já que não restringimos a escolha dos valores dos parâmetros de interação $\epsilon_{i}$ como foi feito em estudos anteriores [82, 83, 84]. A ausência de restrição nos parâmetros de interação nos permite obter diferentes regimes ecológicos de acordo com a Fig. 5.1. Para esses tipos de interações ecológicas podemos obter diferentes estados estacionários que vão desde a coexistência até a extinção de uma das espécies.

\subsection{Soluções dos estados estacionários}

Para obter as soluções dos estados estacionários $p_{1}^{*}=p_{1}(\tau \rightarrow \infty)$ e $p_{2}^{*}=p_{2}(\tau \rightarrow$ $\infty)$ do sistema Eq. 5.3, fazemos $d p_{1} / d \tau=d p_{2} / d \tau=0$, que implica em $f\left(p_{1}^{*}, p_{2}^{*}\right)=$ 


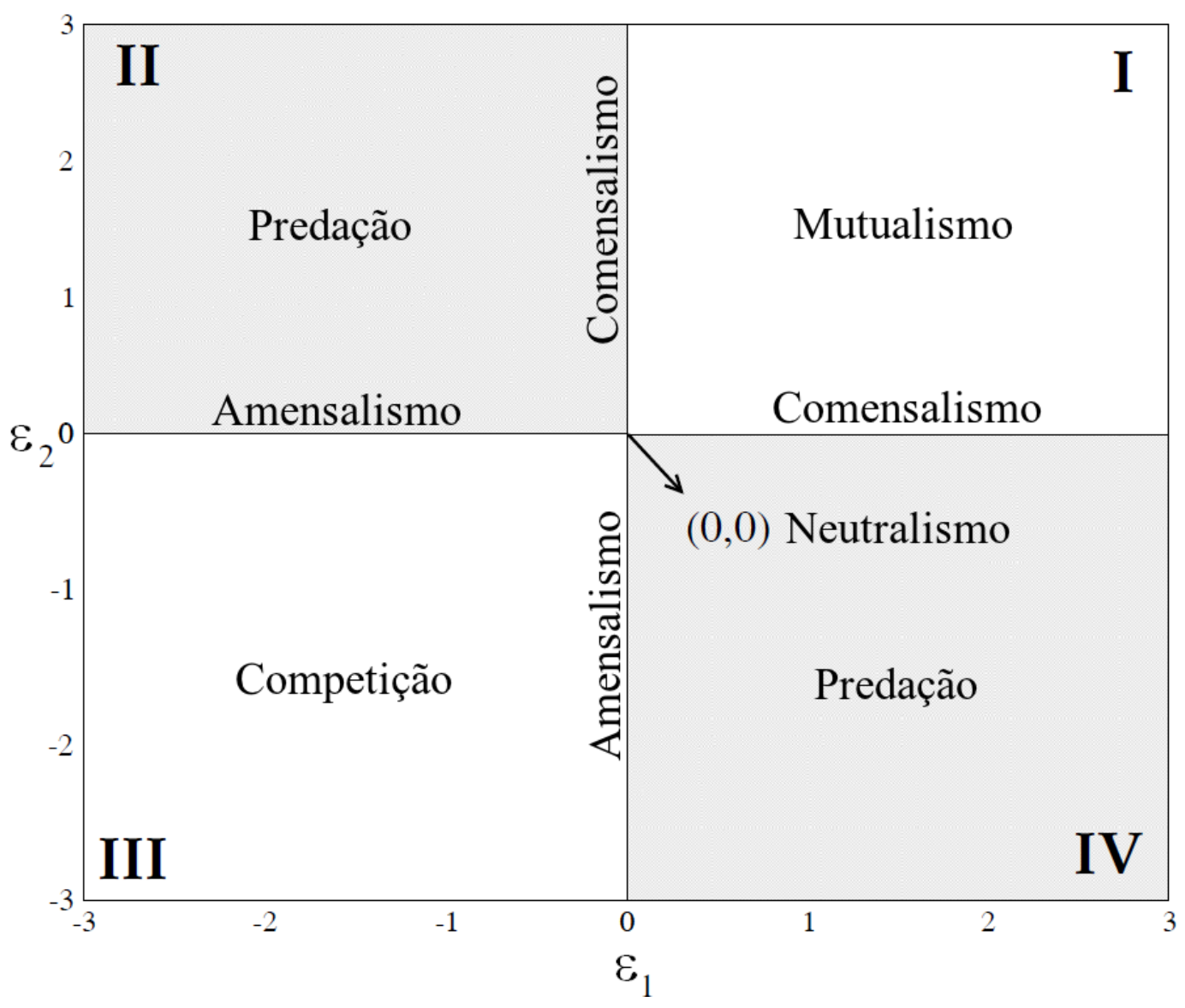

Figura 5.1: Diagrama das interações ecológicas entre duas espécies de acordo com parâmetros de interações $\left(\epsilon_{1}, \epsilon_{2}\right)$. Neste diagrama, cada quadrante representa um tipo de interação: I: mutualismo; II e IV: predação; III: competição. A abcissa e a ordenada representam ou amensalismo ou comensalismo. A origem representa neutralidade. Adaptada da Ref. [6ri]

$g\left(p_{1}^{*}, p_{2}^{*}\right)=0$ e leva a $p_{1}^{*}\left(1-p_{1}^{*}+\epsilon_{1} p_{2}^{*}\right)=0$ e $p_{2}^{*}\left(1-p_{2}^{*}+\epsilon_{2} p_{1}^{*}\right)=0$. Obtemos assim os pares de soluções triviais ("t"), semi-triviais ("st"), e não triviais ("nt"):

$$
\begin{aligned}
& \left\{\begin{array}{l}
p_{1, t}^{*}=0 ; \\
p_{2, t}^{*}=0
\end{array}\right. \\
& \left\{\begin{array}{l}
p_{1, s t}^{*}=1 ; \\
p_{2, s t}^{*}=0
\end{array}\right.
\end{aligned}
$$


$\mathrm{Ou}$

$$
\left\{\begin{array}{l}
p_{1, s t}^{*}=0 \\
p_{2, s t}^{*}=1
\end{array}\right.
$$

$\mathrm{e}$

$$
\left\{\begin{array}{l}
p_{1, n t}^{*}=\left(1+\epsilon_{1}\right) /\left(1-\epsilon_{1} \epsilon_{2}\right) ; \\
p_{2, n t}^{*}=\left(1+\epsilon_{2}\right) /\left(1-\epsilon_{1} \epsilon_{2}\right) .
\end{array}\right.
$$

Essas soluções assintóticas precisam ser caracterizadas de acordo com sua estabilidade. A seguir, mostramos as condições de estabilidade para o modelo estudado.

\subsubsection{Análise de estabilidade}

As soluções do estado estacionário precisam ser analisadas quanto à estabilidade. A matriz de estabilidade, também chamada de matriz comunidade [2], é dada por:

$$
A\left(p_{1}^{*}, p_{2}^{*}\right)=\left(\begin{array}{ll}
\partial_{p_{1}} f & \partial_{p_{2}} f \\
\partial_{p_{1}} g & \partial_{p_{2}} g
\end{array}\right)_{p_{1}^{*}, p_{2}^{*}}
$$

As soluções de estado estacionário $p_{1}^{*}$ e $p_{2}^{*}$ são estáveis se o traço e o determinante da matriz comunidade forem negativo e positivo respectivamente. Temos então:

$$
\begin{aligned}
\operatorname{Tr}\left[A\left(p_{1}^{*}, p_{2}^{*}\right)\right]= & 1+\rho+\left(\rho \epsilon_{2}-2\right) p_{1}^{*}+\left(\epsilon_{1}-2 \rho\right) p_{2}^{*} \\
\operatorname{Det}\left[A\left(p_{1}^{*}, p_{2}^{*}\right)\right]= & \rho\left\{1+p_{1}^{*}\left[\epsilon_{2}-2\left(1+\epsilon_{2} p_{1}^{*}\right)\right]+\right. \\
& \left.+p_{2}^{*}\left[\epsilon_{1}-2\left(1+\epsilon_{1} p_{2}^{*}\right)\right]+4 p_{1}^{*} p_{2}^{*}\right\}
\end{aligned}
$$

A seguir analisamos cada par de soluções $p_{1}^{*}$ e $p_{2}^{*}$ quanto à estabilidade.

\subsubsection{Soluções triviais}

Vamos começar com a análise de estabilidade para o solução dos casos triviais $p_{1, t}^{*}=0$ e $p_{2, t}^{*}=0$, o que significa extinção de ambas as espécies. Temos:

$$
\begin{aligned}
\operatorname{Tr}[A(0,0)] & =1+\rho \\
\operatorname{Det}[A(0,0)] & =\rho .
\end{aligned}
$$


Uma vez que $\rho>0$, $\operatorname{Det}[A(0,0)]>0$ e $\operatorname{Tr}[A(0,0)]>1$, o par de soluções para o caso trivial não é estável para nenhum valor no espaço de parâmetros. Dessa forma a extinção mútua nunca ocorre para o modelo estudado.

\subsubsection{Soluções semi-triviais}

As soluções para os casos semi-triviais são dadas por: $p_{1, s t}^{*}=1$ e $p_{2, s t}^{*}=0 \mathrm{ou}$ $p_{1, s t}^{*}=0$ e $p_{2, s t}^{*}=1$ e significam que uma das espécies é extinta. Considerando a espécie 1 como extinta, temos:

$$
\begin{aligned}
\operatorname{Tr}[A(0,1)] & =1+\epsilon_{1}-\rho \\
\operatorname{Det}[A(0,1)] & =-\rho\left(1+\epsilon_{1}\right) .
\end{aligned}
$$

Para essas soluções serem estáveis, é necessário que $\epsilon_{1}<-1$, independentemente do valor de $\rho$. Uma análise similar leva-nos a concluir que a extinção da espécie 2 só é estável para $\epsilon_{2}<-1$.

\subsubsection{Soluções não-triviais}

As soluções não triviais $p_{1, n t}^{*}=\left(1+\epsilon_{1}\right) /\left(1-\epsilon_{1} \epsilon_{2}\right)$ e $p_{2, n t}^{*}=\left(1+\epsilon_{2}\right) /\left(1-\epsilon_{1} \epsilon_{2}\right)$ levam a:

$$
\begin{aligned}
\operatorname{Tr}\left[A\left(p_{1, n t}^{*}, p_{2, n t}^{*}\right)\right] & =\left[1+\epsilon_{1}+\left(1+\epsilon_{2}\right) \rho\right]\left(\epsilon_{1} \epsilon_{2}-1\right) \\
\operatorname{Det}\left[A\left(p_{1, n t}^{*}, p_{2, n t}^{*}\right)\right] & =-\frac{\left(1+\epsilon_{1}\right)\left(1+\epsilon_{2}\right) \rho}{\left(\epsilon_{1} \epsilon_{2}-1\right)} .
\end{aligned}
$$

Por um lado, se $\epsilon_{1} \epsilon_{2}<1$, o denominador é positivo e o numerador $p_{1, n t}$ e $p_{2, n t}$ se anulam ou são positivos. Pela condição $p_{1, n t}^{*} \geq 0$, esta solução somente é estável se $\epsilon_{1} \geq \epsilon_{1}^{(c)}=-1$; caso contrário $p_{1, t}^{*}=0$ é a solução estável. Isto produz uma transição do regime em que as duas espécies coexistem para um regime em que a espécie 1 é extinta (transição de Gause). A mesma transição ocorre para o parâmetro $\epsilon_{2}$. Por outro lado, se $\epsilon_{1} \epsilon_{2}>1$, o denominador é negativo e o numerador de $p_{1, n t}$ e $p_{2, n t}$ é positivo. Da condição, $p_{1, n t}^{*} \geq 0$, esta solução é estável somente quando $\epsilon_{1}<\epsilon_{1}^{(c)}=-1$; caso contrário $p_{1, t}^{*}=0$ é a solução estável. Do critério de estabilidade, espécies podem coexistir somente se $\epsilon_{1}>-1$ e $\epsilon_{2}>-1$. De acordo com os valores de $\epsilon_{1}$ e $\epsilon_{2}$, cada regime ecológico pode apresentar diferentes soluções estáveis. 


\subsubsection{Diagrama de fases}

Na figura 5.2. as soluções do estado estacionário do sistema da Eq. 5.3 são apresentadas no espaço de parâmetros. Este diagrama apresenta simetria em relação ao eixo $\epsilon_{2}=\epsilon_{1}$ e resume os resultados: a fase de coexistência e a extinção de uma espécie. Essas fases se estendem para diferentes regimes ecológicos, o que significa que interações ecológicas diferentes podem levar à mesma fase do diagrama.

Para $\epsilon_{1}>-1$ e $\epsilon_{2}>-1$, as soluções não triviais são estáveis. Elas passam pelas quatro regiões ecológicas consideradas, ao redor da origem do diagrama de fases ( círculo tracejado na Fig. 5.2). Para o caso de mutualismo, o primeiro quadrante do diagrama das Figs. 5.1 e 5.2, como $\epsilon_{1} \epsilon_{2} \rightarrow 1^{-}$, a cooperação mútua leva a um crescimento desenfreado de ambas as populações, assim $p_{i, n t} \sim\left(1-\epsilon_{1} \epsilon_{2}\right)^{-\beta}$ diverge com expoente $\beta=1$. A região $\epsilon_{2}>1 / \epsilon_{1}$ é proibida uma vez que $p_{i, n t}^{*}<0$, não apresenta realidade biológica.

A figura 5.3 mostra a transição entre os regimes de coexistência e extinção. Mantendo $\epsilon_{2}$ fixo, esta transição ocorre em $\epsilon_{1}=\epsilon_{1}^{c}=-1$. Uma expansão de Taylor da solução estacionária não trivial nos permite escrever $p_{1, n t}^{*}=\left(\epsilon_{1}-\epsilon_{1}^{c}\right) /\left(1+\epsilon_{2}\right)+$

$\mathcal{O}\left(\left(\epsilon_{1}-\epsilon_{1}^{c}\right)^{2}\right)$. Isso significa que próximo do ponto crítico $\epsilon_{1}^{c}$ a espécie 1 é extinta de forma linear, isto é, $p_{1, n t}^{*} \sim\left(\epsilon_{1}-\epsilon_{1}^{c}\right)$. O expoente crítico relacionado ao parâmetro de ordem é $\beta=1$. Um processo análogo ocorre para a espécie 2.

Para $\epsilon_{1} \leq-1$ ou $\epsilon_{2} \leq-1$ e $\epsilon_{1} \epsilon_{2}<1$, as regiões remanescentes do diagrama são caracterizadas pela estabilidade das soluções semi-triviais. Para $\epsilon_{1}<-1$ e $\epsilon_{2}<-1$, diferentemente de todas as outras regiões do diagrama de fases, as soluções do estado estacionário dependem das condições iniciais. Uma separatriz demarca o limite a partir de qual condição inicial será atingido um ou outro equilíbrio $\left(p_{1}^{*}, p_{2}^{*}\right)=(0,1)$ ou $(1,0)$, maiores detalhes na Ref. [2].

\subsection{Soluções analíticas}

Nesta seção apresentamos as soluções analíticas do modelo Lotka-Volterra competitivo. Começamos apresentando as soluções em que pelo menos um dos parâmetros de interação se anula. Em seguida, apresentamos a solução para o modelo completo. 


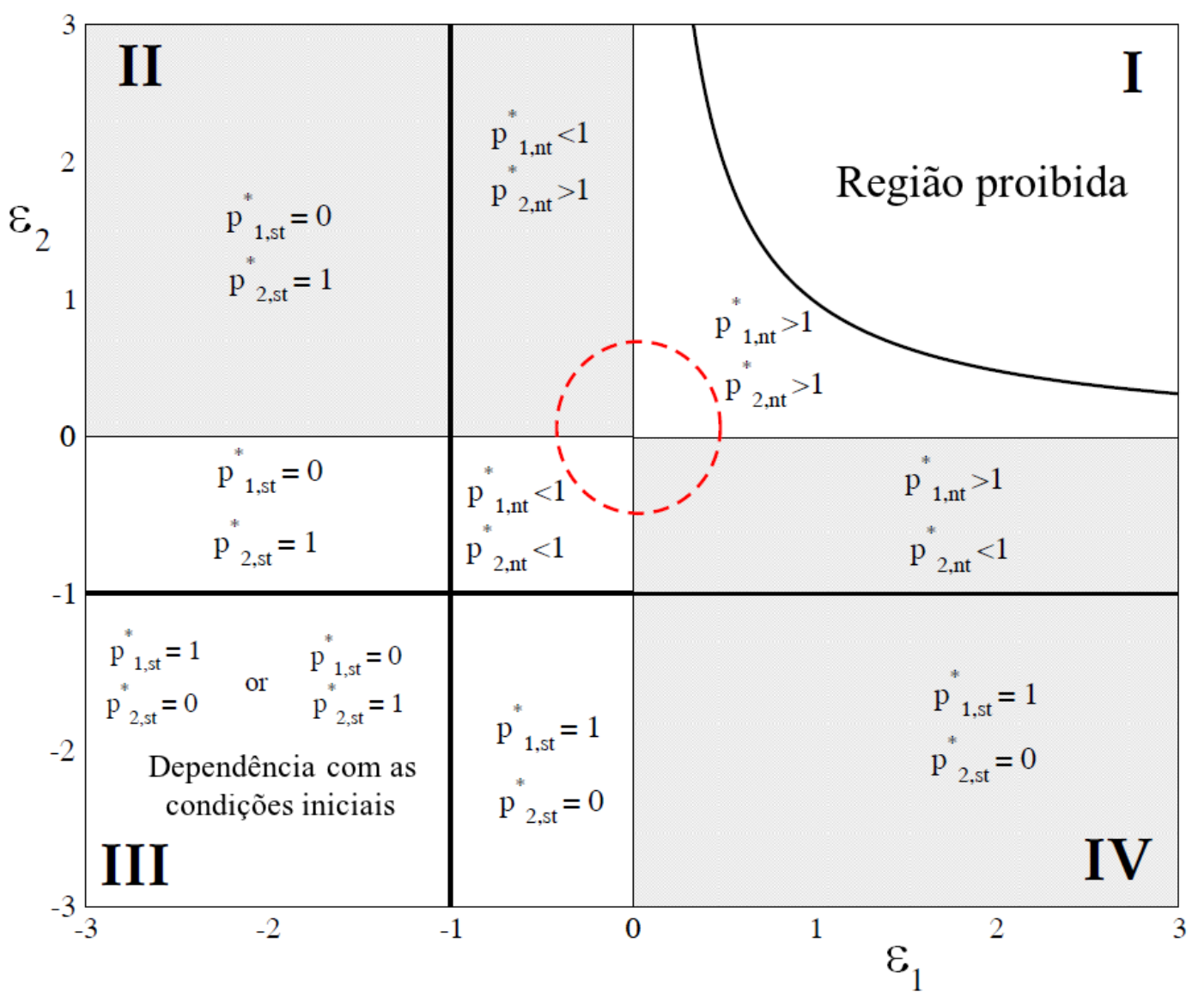

Figura 5.2: Diagrama das interações ecológicas entre duas espécies de acordo com o par $\epsilon_{1}, \epsilon_{2}$. Neste diagrama, cada quadrante representa um tipo de interação. I: Mutualismo; II e IV: Predação; III: Competição. O eixo das abscissas e ordenadas representam amensalismo ou comensalismo. A origem representa neutralismo. As soluções não triviais $\left(\epsilon_{1}>-1, \epsilon_{2}>-1\right.$ e $\left.\epsilon_{1} \epsilon_{2}<1\right)$ correspondem à fase de coexistência. Nesta fase, mutualismo, comensalismo, amensalismo, predação, competição e neutralismo podem ocorrer, por exemplo, dentro do círculo tracejado. A região complementar é caracterizada pela fase de extinção e uma região proibida. A fase de extinção $\left(\epsilon_{1}<-1\right.$ e/ou $\left.\epsilon_{2}<-1\right)$ revela uma região para $\epsilon_{1}<0$ e $\epsilon_{2}<0$ em que, ao contrário dos outros casos, as soluções do estado estacionário dependem das condições iniciais. Para $\epsilon_{1}>1$ e $\epsilon_{2}>0$ e $\epsilon_{2}>1 / \epsilon_{1}$, existe uma região proibida em que não há realidade biológica (número negativo de indivíduos).Adaptado da Ref. [67] 


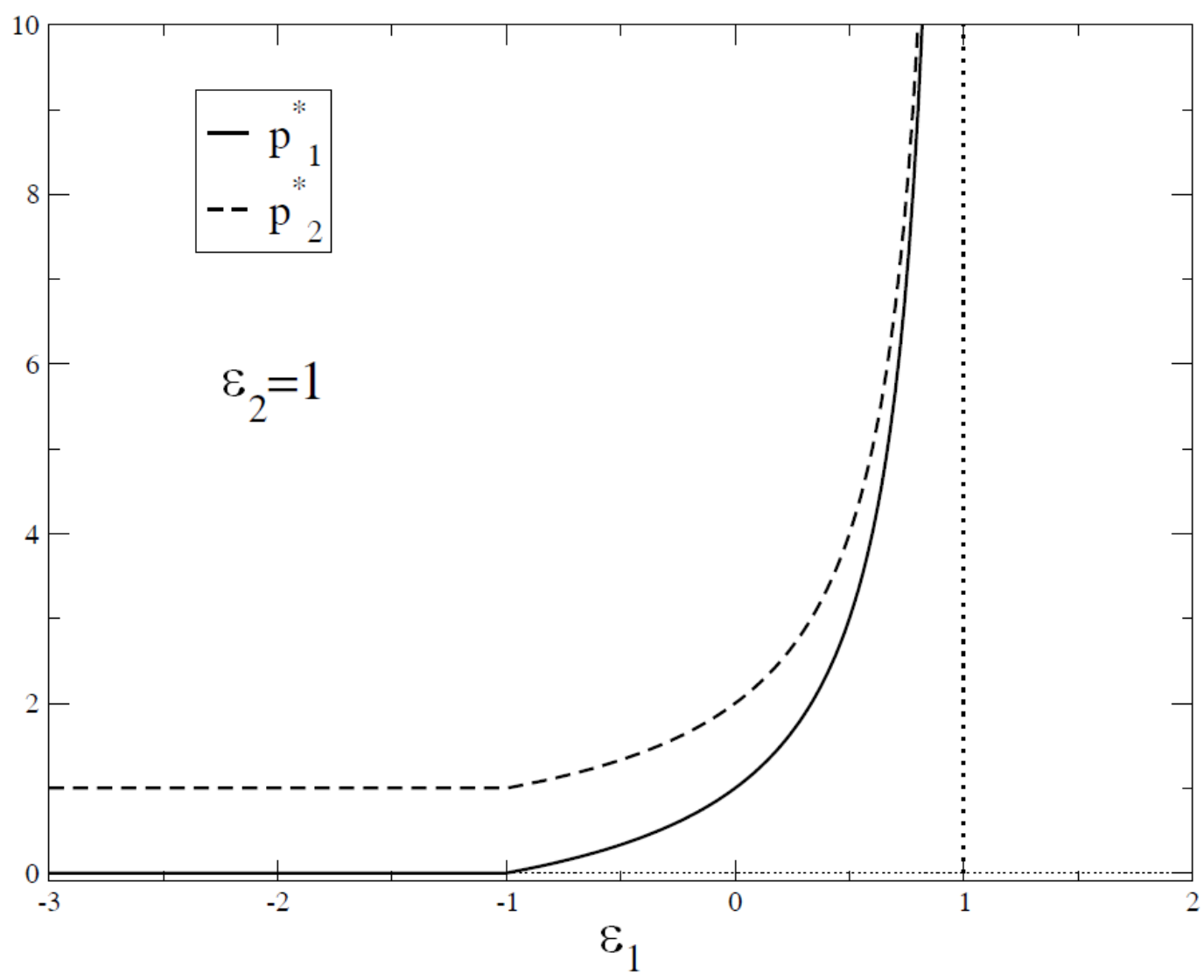

Figura 5.3: Gráfico das soluções dos estados estacionários $p_{1, n t}^{*}=\left(1+\epsilon_{1}\right) /\left(1-\epsilon_{1} \epsilon_{2}\right)$ e $p_{2, n t}^{*}=\left(1+\epsilon_{2}\right) /\left(1-\epsilon_{1} \epsilon_{2}\right)$ do modelo da Eq. 5.3 em função de $\epsilon_{1}$, com $\epsilon_{2}=1$. Nestas curvas vemos duas transições de fase. A primeira é a transição coexistênciaextinção no regime de predação, que ocorre para $\epsilon_{1}=-1$. Próximo ao ponto crítico $\epsilon_{1}^{c}$, a espécie 1 é extinta de uma forma linear, isto é, $p_{1, n t}^{*} \sim\left(\epsilon_{1}-\epsilon_{1}^{c}\right)$. A segunda é a transição de coexistência (mutualismo) para uma região proibida (sem realidade biológica). Ambas as transições possuem expoente crítico $\beta=1$. Adaptada da Ref. [67]

\subsubsection{Casos particulares $\left(\epsilon_{1} \epsilon_{2}=0\right)$}

Esta seção é restrita ao caso particular $\epsilon_{1} \epsilon_{2}=0$, onde um ou ambos os parâmetros de interação se anulam. Isto corresponde aos eixos do espaço de parâmetros $\epsilon_{2} \times \epsilon_{1}$ da Fig. 5.1.

Assim, três regimes ecológicos são permitidos nesta situação:

- amensalismo $\epsilon_{1}=0$ e $\epsilon_{2}<0$ (extinção da espécies 2 se $\epsilon_{2} \leq-1$ e coexistência caso contrário) ou $\epsilon_{2}=0$ e $\epsilon_{1}<0$ (extinção da espécie 1 se $\epsilon_{1} \leq-1$ coexistência das espécies caso contrário); 
- neutralismo $\epsilon_{1}=\epsilon_{2}=0$;

- comensalismo $\epsilon_{1}>0$ e $\epsilon_{2}=0$ ou $\epsilon_{1}=0$ e $\epsilon_{2}>0$.

Nestes casos, pode-se obter as soluções analíticas da Eq. 5.3. Abaixo abordamos cada um dos casos com mais detalhes.

\subsubsection{Neutralismo}

Considere o caso particular em que cada espécie cresce independentemente uma da outra. Esse regime ecológico é representado pela Eq. 5.3 quando $\epsilon_{1}=\epsilon_{2}=0$, isto é:

$$
\left\{\begin{array}{l}
\frac{d p_{1}}{d \tau}=p_{1}\left[1-p_{1}\right] \\
\frac{d p_{2}}{\rho d \tau}=p_{2}\left[1-p_{2}\right],
\end{array}\right.
$$

Levando a duas soluções do modelo de Verhulst:

$$
\begin{aligned}
& p_{1}(\tau)=\frac{1}{\left[1+\left(p_{1,0}^{-1}-1\right) e^{-\tau}\right]} \\
& p_{2}(\tau)=\frac{1}{\left[1+\left(p_{2,0}^{-1}-1\right) e^{-\rho \tau}\right]},
\end{aligned}
$$

em que $p_{i, 0}=p_{i}(0)$ é a condição inicial para a espécie $i=1,2$.

As soluções de Verhulst são guiadas por diferentes tempos característicos $\tau=\kappa_{1} t$ e $\tau^{\prime}=\rho \tau=\kappa_{2} t$. Para $\tau \gg 1$, de modo que $\rho \tau \gg 1$, os comportamentos assintóticos $p_{1}^{*}=p_{1}(\infty)=1$ e $p_{2}^{*}=p_{2}(\infty)=1$ são obtidos. Assim as populações das espécies acabam atingindo o máximo valor possível considerando os recursos disponíveis no ambiente. Para $\kappa_{2}>\kappa_{1}$ i.e., $\rho>1$, a espécie 2 cresce mais rapidamente do que a espécie 1. Para $\kappa_{2}<\kappa_{1}$ i.e., $\rho<1$, o inverso ocorre.

\subsubsection{Comensalismo e amensalismo}

Considere que duas espécies interagem de forma assimétrica. Por exemplo, considere que os indivíduos da espécie 1 não são afetados pela espécie 2, embora, os indivíduos da espécies 2 são negativamente afetados pela espécie 1. Este é o regime de amensalismo. O regime de comensalismo tem a mesma estrutura que do amensalismo, porém uma das espécies é favoravelmente afetada pela outra. Estas interações 
podem ser matematicamente representadas pelas seguintes equações diferenciais:

$$
\begin{cases}\frac{d p_{1}(\tau)}{d \tau}= & p_{1}(\tau)\left[1-p_{1}(\tau)\right] \\ \frac{d p_{2}(\tau)}{\rho d \tau}= & p_{2}(\tau)\left[1-p_{2}(\tau)+\epsilon_{2} p_{1}(\tau)\right]\end{cases}
$$

em que $\epsilon_{2}$ é negativo para amensalismo e positivo para comensalismo.

Nesse tipo de interação, a população da espécie 1, descrita por 5.18, segue o modelo de Verhulst. A dinâmica da espécie 2 segue o modelo de Verhulst-Schaefer dependente do tempo, descrita na Sec. 3.6, cuja solução é [22]:

$$
\frac{1}{p_{2}(\tau)}=\frac{1}{1+\epsilon_{2} p_{1}(\tau)}+\frac{e^{-\rho \tau\left[1+\epsilon_{2} \bar{p}_{1}(\tau)\right]}\left(1-p_{2,0}+\epsilon_{2} p_{1,0}\right)}{p_{2,0}+\epsilon_{2} p_{1,0} p_{2,0}},
$$

em que o tamanho médio relativo da espécie 1 até o valor de tempo $\tau$ é:

$$
\begin{aligned}
\bar{p}_{1}(\tau) & =\frac{1}{\tau} \int_{0}^{\tau} d \tau^{\prime} p_{1}\left(\tau^{\prime}\right)=\int_{0}^{\tau} \frac{d \tau^{\prime}}{1+\left(p_{1,0}^{-1}-1\right) e^{-\tau^{\prime}}} \\
& =\ln \left[1+p_{1,0}\left(e^{\tau}-1\right)\right] .
\end{aligned}
$$

Usando a solução de Verhulst para $p_{1}(\tau)$ e colocando o resultado da Eq. 5.22 na Eq. 5.21, obtêm-se:

$$
\begin{aligned}
\frac{1}{p_{2}(\tau)}= & \frac{e^{-\tau}\left[1+\left(-1+e^{\tau}\right) p_{1,0}\right]^{2}}{p_{1,0}\left\{1+\left[-1+e^{\tau}\left(1+\epsilon_{2}\right)\right] p_{1,0}\right\}}+ \\
& \frac{e^{-\rho \tau}\left[1+\left(-1+e^{\tau}\right) p_{1,0}\right]^{-\epsilon_{2} \rho \tau}\left(1+\epsilon_{2} p_{1,0}-p_{2,0}\right)}{p_{2,0}+\epsilon_{2} p_{1,0} p_{2,0}}
\end{aligned}
$$

Os gráficos de $p_{2}(\tau)$ para diferentes valores de $\epsilon_{2}$ são apresentados na figura 5.4.

As soluções do estado estacionário da Eq. 5.20 são respectivamente: $p_{1}^{*}=$ $p_{1}(\infty)=1$ e $p_{2}^{*}=p_{2}(\infty)=1+\epsilon_{2}$, se $\epsilon_{2}>-1$ ou são nulas caso contrário. Ve-

mos que $\epsilon_{2}^{(c)}=-1$ é um valor crítico que separa duas fases distintas: $\epsilon_{2} \leq-1$, em que a espécie 2 é extinta e $\epsilon_{2}>-1$, em que a espécie 2 coexiste com a espécie 1. O primeiro caso ocorre no regime de amensalismo, enquanto que o segundo pode ocorrer nos regimes amensalismo $\left(\epsilon_{2}<0\right)$, neutralismo $\left(\epsilon_{2}=0\right)$ ou no comensalismo $\left(\epsilon_{2}>0\right)$. As conclusões são análogas para o caso $\epsilon_{2}=0$ e $\epsilon_{1} \neq 0$.

\subsubsection{Mutualismo, competição e predação $\left(\epsilon_{1} \epsilon_{2} \neq 0\right)$}

A seguir, abordamos o caso em que $\epsilon_{1} \epsilon_{2} \neq 0$, ou seja, mutualismo, competição e predação (ver Fig. 5.1). Se 


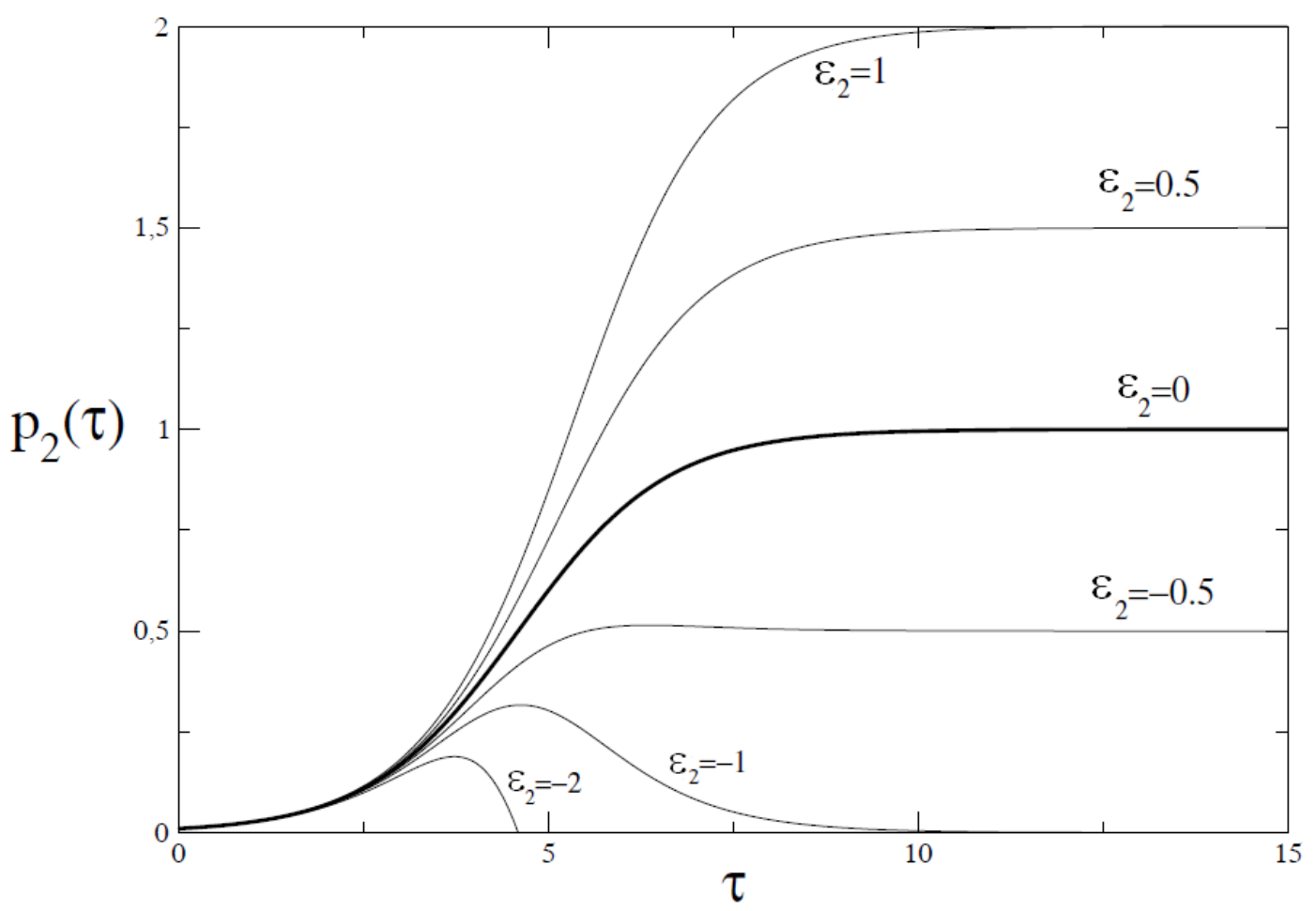

Figura 5.4: Curvas da solução da Eq. 5.20, dada pela Eq. 5.24, para diferentes valores do parâmetro de interação $\epsilon_{2}$ e $\rho=1$. O regime de comensalismo é obtido para $\epsilon_{2}>0$, em que o valor assintótico, devido à outra espécie, é maior que um. $\mathrm{O}$ regime de neutralismo é obtido para $\epsilon_{2}=0$. O regime de amensalismo é obtido para $\epsilon_{2}<0$, em que o valor assintótico não é nulo (coexistência das espécies) para $\epsilon_{2}>-1$ e se torna nulo (extinção da espécie) quando $\epsilon_{2} \leq-1$. Adaptada da Ref. [67]

- $\epsilon_{1} \epsilon_{2}>0$, cada espécie tem o mesmo tipo de influência sobre a outra. Isto corresponde tanto ao regime de competição quanto ao de mutualismo. Os seguintes regimes ocorrem:

- $\epsilon_{1}>0$ e $\epsilon_{2}>0$ : mutualismo, que corresponde ao primeiro quadrante no diagrama do espaço de fases, restrito à região $\epsilon_{2}<1 / \epsilon_{1}$;

- $\epsilon_{1}<0$ e $\epsilon_{2}<0$ : competição, que corresponde ao terceiro quadrante no diagrama do espaço de fases.

- Se $\epsilon_{1} \epsilon_{2}<0$, o regime de predação ocorre, o qual pertence ao segundo e quarto quadrantes no diagrama do espaço de fases. 
Esses regimes ecológicos são casos particulares da Eq. 5.3, cuja solução é dada por:

$$
\frac{1}{p_{1}(\tau)}=\frac{1}{1+\epsilon_{1} p_{2}(\tau)}+\frac{e^{-\tau\left[1+\epsilon_{1} \bar{p}_{2}(\tau)\right]}\left(1-p_{1,0}+\epsilon_{1} p_{2,0}\right)}{p_{1,0}+\epsilon_{1} p_{1,0} p_{2,0}},
$$

em que $p_{2}(\tau)$ é dado por 5.21, e o tamanho médio relativo das populações até o instante $\tau$ é dado pela Eq. 5.22 com resultado análogo para $\bar{p}_{2}(\tau)$.

Usando as Eqs. 5.21 em 5.24, obtemos uma equação quadrática para $p_{1}(\tau)$. A solução fica dependente apenas das condições iniciais $p_{1}(0)$ e $p_{2}(0)$ e dos valores médios $\bar{p}_{1}(\tau)$ e $\bar{p}_{2}(\tau)$. O tamanho da população $p_{2}(\tau)$ se comporta de forma análoga. Assim, o acoplamento entre as duas população é dado pelos seus valores médios. As curvas das soluções das Eqs. 5.24 e 5.21 são apresentados na Fig. 5.5 para os três regimes em que $\epsilon_{1} \epsilon_{2} \neq 0$. Com $\tau \rightarrow \infty$, as soluções de estado estacionário da Eq. 5.3 são atingidos.

Com a solução analítica, pode-se obter de crescimento de uma determinada população. Essa dinâmica possui informações importantes quando tratamos da coexistência predador/presa e também de espécies competidoras [85]. Estudos de surtos de insetos ou de doenças, se concentram em grande parte na dinâmica transiente [86, 87, 88, 89, 90, 91, 92]. No dinâmica de transmissão da tuberculose (ver Cap. 9), por exemplo, o tempo transiente pode revelar aspectos importantes além dos estados assintóticos tais como a emergência de resistência às drogas [93]. A Fig. 5.5 ilustra a importância do transiente na evolução temporal das densidades das espécies. Considere o caso da competição: para $\tau<5$ a população da espécie 2 é menor do que da espécie 1, apesar da espécie 2 ser a competidora mais forte $\left(\epsilon_{2}>\epsilon_{1}\right)$. A solução transiente é exatamente o oposto da solução de estado estacionário (população da espécie 2 maior do que para a espécie 1). Ou seja, se o sistema observado ainda não atingiu o equilíbrio, a análise de estado estacionário pode ser enganosa.

Observe que quando $\epsilon_{1}=0$ na Eq. 5.24 e a substituímos em 5.21, recuperamos a solução de amensalismo e comensalismo. Desta forma, estas equações de evolução podem ser vistas como uma solução geral válida para todos os tipos de regime de interação.

Na próxima seção mostramos uma aplicação do modelo de Lotka-Volterra competitivo em tratamento de câncer a partir de vírus replicantes. Com as soluções 


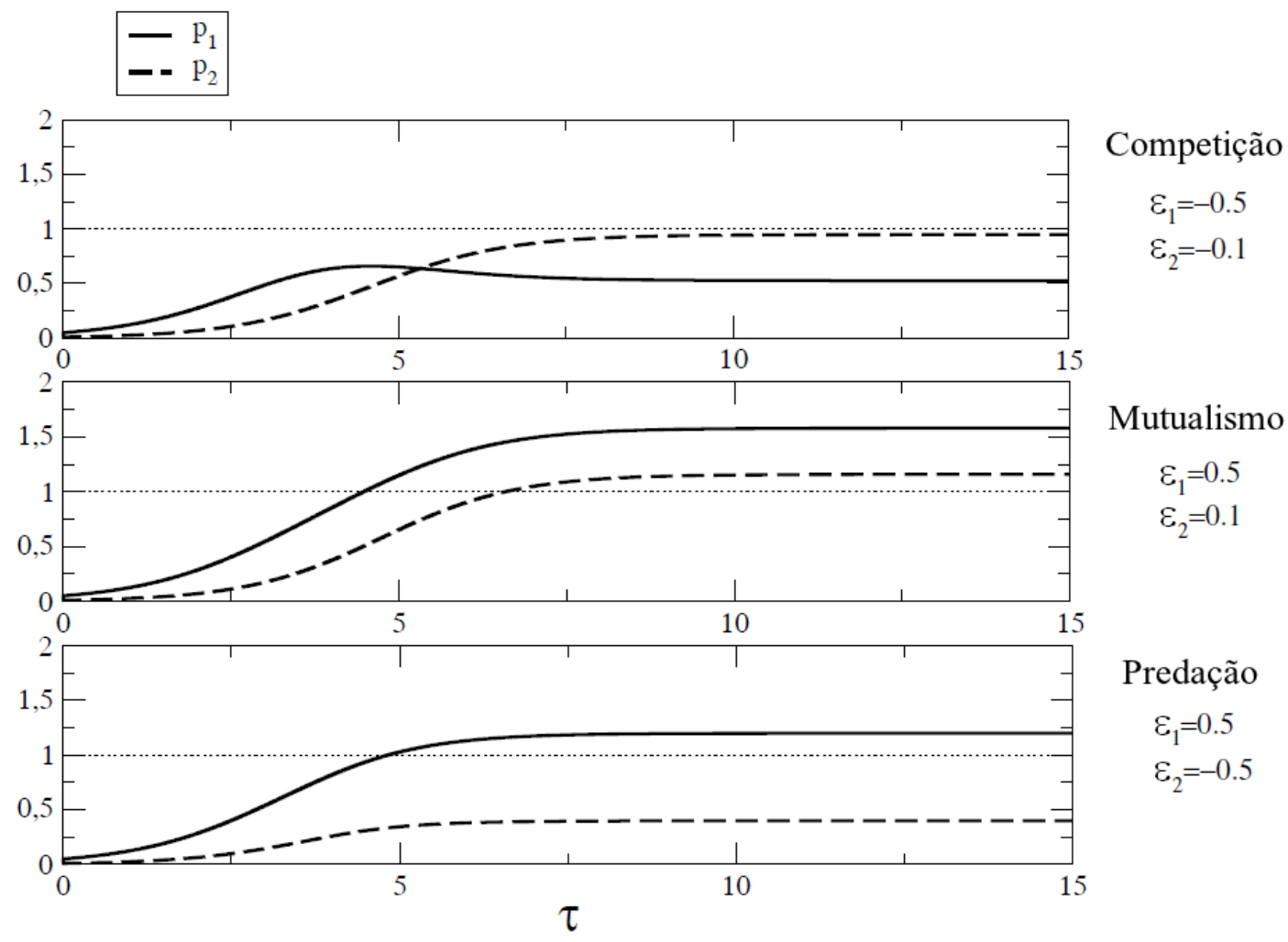

Figura 5.5: Gráficos das Eqs. 5.24 e 5.21, que são soluções da Eq. 5.3. A condição inicial é $p_{1,0}=p_{2,0}=1 / 100$ e $\rho=1$. Os parâmetros de interação $\epsilon_{1} \epsilon_{2} \neq 0$ são: para competição, $\epsilon_{1}=-1 / 2$ e $\epsilon_{2}=-1 / 10$; para mutualismo, $\epsilon_{1}=1 / 2$ e $\epsilon_{2}=1 / 10$; e para predação: $\epsilon_{1}=1 / 2$ e $\epsilon_{2}=-1 / 2$. Adaptada da Ref. [6]

analíticas aqui obtidas, torna-se possível o controle da evolução desse tipo de tratamento.

\subsubsection{Tratamento de câncer a partir de vírus replicantes}

Em terapia de câncer, vírus replicantes seletivos a tumores oferecem vantagens sobre terapias convencionais e permitem uma abordagem promissora no tratamento de câncer humano. Um vírus oncológico é um vírus que preferencialmente infecta células tumorais. Modelos teóricos da interação entre vírus e células tumorais são construídos utilizando adaptações de técnicas empregadas anteriormente para a modelagem de outros tipos de interação vírus-célula [80]. Um modelo tipo LotkaVolterra foi apresentado por Wodarz [94] e descreve a interação entre dois tipos de células tumorais: as que estão infectadas pelo vírus e as que não estão infectadas, 
mas são suscetíveis à infecção. Este modelo pode ser escrito como [95]:

$$
\left\{\begin{array}{l}
\frac{d x}{d \tau}=x[1-(x+y)]-\beta x y \\
\frac{d y}{d \tau}=\gamma y[1-(x+y)]-\beta x y-\delta y,
\end{array}\right.
$$

em que $x$ e $y$ são as populações de células não infectadas e infectadas respectivamente. O parâmetro $\gamma$ fornece a relação entre as taxas de crescimento de células infectadas e não infectadas, $\beta$ está relacionado com o parâmetro de interação entre as células não infectadas e infectadas e $\delta$ está relacionado com a taxa de mortalidade das células infectadas pelo vírus. Usando o sistema dado pela Eq. 5.3 e fazendo: $\epsilon_{1}=-(1+\beta), \epsilon_{2}=(\beta / \gamma-1)$ e $\gamma \gg \delta$, recupera-se o modelo de Wodarz. Além de ser mais simples, o modelo da Eq. 5.3 apresenta todo o comportamento qualitativo demonstrado pelo modelo de Wodarz, ou seja, quatro cenários diferentes para os estados assintóticos: (i) ausência de células infectadas, (ii) ausência de células não infectadas, (iii) a coexistência dos dois tipos de células e (iv) dependência com as condições iniciais (todas as células infectadas ou não infectadas).

\subsection{Conclusão}

Abordamos nesse capítulo o modelo de Lotka-Volterra competitivo e a partir dos parâmetros de interação $\epsilon_{1}$ e $\epsilon_{2}$, podemos obter os diferentes regimes ecológicos, i.e. neutralismo, comensalismo, amensalismo, competição, predação e mutualismo. Tais regimes podem ser classificados de acordo com o produto dos parâmetros de interação $\epsilon_{1} \epsilon_{2}$. Se este termo se anula, pelo menos uma das espécies se torna independente da outra. Se $\epsilon_{1} \epsilon_{2}>0$, tem-se mutualismo (ambos positivos) ou competição (ambos negativos). Para $\epsilon_{1} \epsilon_{2}<0$, tem-se a predação. O nível coletivo é obtido a partir da estabilidade da solução de estado estacionário, de onde se obtém três fases: a extinção de uma espécie $\left(\epsilon_{i}<-1\right)$, a coexistência de espécies e uma fase proibida $\left(\epsilon_{2}>1 / \epsilon_{1}\right)$. Embora o modelo estudado tenha sido considerado em outros casos isolados, o nosso estudo revela o aspecto mais geral de um conjunto de equações matemáticas simples, que representam cenários ecológicos muito ricos que podem ser descritos analiticamente. Em modelos de tratamento de câncer a partir de vírus replicantes, as soluções analíticas aqui obtidas podem fornecer informações a respeito 
da população de células cancerosas no tempo transiente, possibilitando uma melhoria no planejamento do tratamento. Todos os resultados aqui apresentados podem ser estendidos usando um modelo de crescimento mais geral, por exemplo o modelo de Richards [4, 78, 79], e as implicações de tais generalizações serão detalhadas no próximo capítulo. 


\section{Capítulo}

\section{Modelo generalizado de Lotka-Volterra competitivo}

As riquezas ecológicas são parcialmente apreciadas no modelo de duas espécies com o termo de Verhulst (Lotka-Volterra competitivo), apresentado no Cap. 5. Ele revela naturalmente outros regimes ecológicos e soluciona o problema de estabilidade do modelo de duas espécies com o termo de Malthus (Lotka-Volterra tradicional). Neste capítulo, propomos uma generalização do modelo Lotka-Volterra competitivo. Esta generalização é feita utilizando o termo de Richards para o crescimento das espécies. Para este modelo, apresentamos a análise da estabilidade das soluções assintóticas e seu diagrama de fases. Soluções analíticas são obtidas para as fases de amensalismo e comensalismo.

Este capítulo está estruturado da seguinte forma: na Sec. 6.1, apresentamos as equações diferenciais que representam o modelo de Lotka-Volterra competitivo generalizado. A partir da análise de estabilidade, apresentada na Sec.6.2, mostramos que o termo de Richards pode levar à extinção mútua, a qual não é observada quando o termo de Verhulst é utilizado. Mostramos também que o termo de Gompertz suprime a transição de extinção, de modo que a sobrevivência das espécies é a única fase estável. Na Sec. 6.3, apresentamos os tipos de regimes ecológicos. Calculamos a solução analítica para os regimes de amensalismo e comensalismo. Apresentamos também a relação desse modelo de duas espécies com a taxa extrínseca de crescimento. A Sec. 6.4 mostra a relação entre modelos de duas espécies com modelos epidemiológicos que serão abordados no capítulos seguintes. Finalmente na Sec. 6.5, apresentamos a conclusão desse capítulo. 


\subsection{Modelo do tipo Richards para duas espécies}

Nas equações originais de Lotka-Volterra, consideramos o termo de Richards no lugar do de Malthus e permitimos que os parâmetros de interações variem de valores negativos até valores positivos, de forma a cobrir todos os regimes ecológicos. Assim, obtemos o seguinte sistema de equações diferenciais[23]:

$$
\left\{\begin{array}{l}
\frac{d p_{1}}{d \tau}=p_{1}\left[-\ln _{\tilde{q}_{1}} p_{1}+\epsilon_{1} p_{2}\right]=f\left(p_{1}, p_{2}\right) \\
\frac{d p_{2}}{d \tau}=\rho p_{2}\left[-\ln _{\tilde{q}_{2}} p_{2}+\epsilon_{2} p_{1}\right]=g\left(p_{1}, p_{2}\right)
\end{array}\right.
$$

Para utilizar grandezas adimensionais no modelo do tipo Richards para duas espécies, escrevemos $p_{i}=N_{i} / K_{i} \geq 0$, para $i=1,2$, onde $N_{i} \geq 0, \kappa_{i}$ e $K_{i}>0$ são o número de indivíduos (tamanho), taxa de reprodução da rede, e capacidade de suporte das espécies $i(=1,2)$, respectivamente. O tempo é medido em relação à taxa de reprodução da espécie $1, \tau=\kappa_{1} t \geq 0$. Aqui, nós nos restringimos ao caso $\kappa_{i}>0$. O tempo reescalado é positivo, uma vez que tomamos a condição inicial como $t_{0}=0$. O termo $p_{1} \ln _{\tilde{q}_{1}} p_{1}$ representa a competição entre os indivíduos de mesma espécie (competição intraespecífica), e $\epsilon_{1} p_{1} p_{2}$ representa a interação entre indivíduos de diferentes espécies (interação interespecífica) [2, 81]. Os parâmetros adimensionais das interações populacionais são dados por $\epsilon_{1}$ e $\epsilon_{2}$, que não são restritos e representam diferentes interações ecológicas. Ao contrário de $\rho$, que não possui grande relevância para este modelo (já que consideramos somente $\rho>0$ ), o produto $\epsilon_{1} \epsilon_{2}$ possui um papel importante, assim $\epsilon_{1} \epsilon_{2}<0$ significa predação; $\epsilon_{1} \epsilon_{2}=0$ significa comensalismo, amensalismo, ou neutralismo; e $\epsilon_{1} \epsilon_{2}>0$ significa mutualismo ou competição como descrito no diagrama da Fig. 5.1. Para $\tilde{q}_{1}=\tilde{q}_{2}=1$, recupera-se o modelo do tipo Verhulst para duas espécies estudado no Cap.5.

\subsection{Estabilidade das soluções dos estados estaci- onários}

Inicialmente, apresentamos as soluções dos estados estacionários e em seguida, analisamos essas soluções quanto à estabilidade. A partir do sistema da Eq. 6.1 e 
considerando: $d p_{1} / d \tau=0$ temos as seguintes isóclinas ${ }^{1}$ :

$$
\begin{aligned}
& p_{1}=0 \\
& p_{2}=\frac{1}{\epsilon_{1}} \ln _{\tilde{q}_{1}}\left(p_{1}\right)
\end{aligned}
$$

as quais vamos nos referir a isóclina $1 a$ e isóclina $1 b$, respectivamente.

Para $d p_{2} / d \tau=0$, temos:

$$
\begin{aligned}
& p_{2}=0 ; \\
& p_{1}=\frac{1}{\epsilon_{2}} \ln _{\tilde{q}_{2}}\left(p_{2}\right),
\end{aligned}
$$

as quais vamos nos referir a isóclina $2 a$ e isóclina $2 b$, respectivamente. O valor do estado estacionário da população $i$ com $i=1,2$ e $p_{i} \geq 0$, é obtido quando as isóclinas $1 a$ ou $1 b$ se cruzam com as isóclinas $2 a$ ou $2 b$. Dessa forma, há quatro possibilidades para as soluções do estado estacionário: No cruzamento da isóclina $1 a$ com a $2 a$, obtemos a solução trivial:

$$
\begin{aligned}
& p_{1, t}^{*}=0 \\
& p_{2, t}^{*}=0
\end{aligned}
$$

O cruzamento das isóclinas $1 a$ com $2 b$ gera a solução semi-trivial:

$$
\begin{aligned}
& p_{1, s t}^{*}=0 \\
& p_{2, s t}^{*}=1
\end{aligned}
$$

Enquanto que para o cruzamento de $1 b$ com $2 a$ obtemos outra solução semi-trivial:

$$
\begin{aligned}
& p_{1, s t}^{*}=1 ; \\
& p_{2, s t}^{*}=0 .
\end{aligned}
$$

A solução não-trivial é obtidas pelo cruzamento das isóclinas $1 b$ com $2 b$ :

$$
\begin{aligned}
& p_{1, n t}^{*}=e_{\tilde{q}_{1}}\left[\epsilon_{1} e_{\tilde{q}_{2}}\left(\epsilon_{2} p_{1, n t}^{*}\right)\right] ; \\
& p_{2, n t}^{*}=e_{\tilde{q}_{2}}\left[\epsilon_{2} e_{\tilde{q}_{1}}\left(\epsilon_{1} p_{2, n t}^{*}\right)\right] .
\end{aligned}
$$

\footnotetext{
${ }^{1} \mathrm{O}$ termo correto seria isóclina de crescimento zero, uma vez que são curvas de mesma inclinação cujo valor é nulo. Por motivos de simplificação chamaremos apenas de isóclinas.
} 
A matriz comunidade, dada pela Eq.5.8, caracteriza o sistema de acordo com sua estabilidade. Os elementos dessa matriz são:

$$
\begin{aligned}
\left.\partial_{p_{1}} f\right|_{p_{1}^{*}, p_{2}^{*}} & =\epsilon_{1} p_{2}^{*}-1-\left(1+\tilde{q}_{1}\right) \ln _{\tilde{q}_{1}} p_{1}^{*} \\
\left.\partial_{p_{2}} f\right|_{p_{1}^{*}, p_{2}^{*}} & =\epsilon_{1} p_{1}^{*} \\
\left.\partial_{p_{1}} g\right|_{p_{1}^{*}, p_{2}^{*}} & =\rho \epsilon_{2} p_{2}^{*} \\
\left.\partial_{p_{2}} g\right|_{p_{1}^{*}, p_{2}^{*}} & =\rho\left[\epsilon_{2} p_{1}^{*}-1-\left(1+\tilde{q}_{2}\right) \ln _{\tilde{q}_{2}} p_{2}^{*}\right]
\end{aligned}
$$

As soluções de estado estacionário $p_{1}^{*}$ e $p_{2}^{*}$ são estáveis se ambos:

$$
-\operatorname{Tr}\left[A\left(p_{1}^{*}, p_{2}^{*}\right)\right]=1-\epsilon_{1} p_{2}^{*}+\left(1+\tilde{q}_{1}\right) \ln _{\tilde{q}_{1}} p_{1}^{*}+\rho\left[1-\epsilon_{2} p_{1}^{*}+\left(1+\tilde{q}_{2}\right) \ln _{\tilde{q}_{2}} p_{2}^{*}\right]
$$

e

$$
\operatorname{Det}\left[A\left(p_{1}^{*}, p_{2}^{*}\right)\right] / \rho=\left[1-\epsilon_{1} p_{2}^{*}+\left(1+\tilde{q}_{1}\right) \ln _{\tilde{q}_{1}} p_{1}^{*}\right]\left[1-\epsilon_{2} p_{1}^{*}+\left(1+\tilde{q}_{2}\right) \ln _{\tilde{q}_{2}} p_{2}^{*}\right]-\epsilon_{1} \epsilon_{2} p_{1}^{*} p_{2}^{*}
$$

forem positivos. A seguir, analisamos as soluções triviais, semi-triviais e não triviais quanto à estabilidade.

\subsubsection{Soluções triviais: extinção mútua}

Vamos iniciar com a análise da estabilidade para as soluções triviais: $p_{1, t}^{*}=0 \mathrm{e}$ $p_{2, t}^{*}=0$. Isto significa extinção para ambas as espécies. Para este caso temos:

$$
\operatorname{Tr}[A(0,0)]=\frac{1}{\tilde{q}_{1}+\rho / \tilde{q}_{2}}
$$

$\mathrm{e}$

$$
\operatorname{Det}[A(0,0)]=\frac{\rho}{\tilde{q}_{1} \tilde{q}_{2}} .
$$

Uma vez que $\rho>0$, $\operatorname{Det}[A(0,0)]>0$ se, e somente se, $\tilde{q}_{1} \tilde{q}_{2}>0$, i.e., $\tilde{q}_{1}$ e $\tilde{q}_{2}$ devem ter o mesmo sinal. Para $\operatorname{Tr}[A(0,0)]<0$, então $\tilde{q}_{1}$ e $\tilde{q}_{2}$ devem ser negativos. O par de soluções triviais é então estável, para $\tilde{q}_{1}<0$ e $\tilde{q}_{2}<0$. Caso contrário, a extinção mútua não é estável. Esta fase não é estável no modelo do tipo Lotka-Volterra competitivo com o termo de Verhulst, uma vez que $\tilde{q}_{1}=\tilde{q}_{2}=1$. 


\subsubsection{Soluções semi-triviais: extinção de uma espécie}

As soluções semi-triviais são $p_{1, s t}^{*}=0$ e $p_{2, s t}^{*}=1$ ou $p_{1, s t}^{*}=1$ e $p_{2, s t}^{*}=0$. Isso significa que uma das espécies é extinta e a outra atinge o valor máximo de população. Considerando a extinção da espécie 1, tem-se:

$$
\operatorname{Tr}[A(0,1)]=\epsilon_{1}+\frac{1}{\tilde{q}_{1}}-\rho
$$

$\mathrm{e}$

$$
\operatorname{Det}[A(0,1)]=-\rho\left(\epsilon_{1}+\frac{1}{\tilde{q}_{1}}\right) .
$$

A condição de estabilidade $\operatorname{Tr}[A(0,1)]<0$, implica que $\epsilon_{1}<\rho-1 / \tilde{q}_{1}$ e a condição $\operatorname{Det}[A(0,1)]>0$, uma vez que $\rho>0$, tem-se que $\epsilon_{1}<-1 / \tilde{q}_{1}$ e a espécie 1 é extinta para $\epsilon_{1}<\epsilon_{1}^{(c)}$ em um valor crítico:

$$
\epsilon_{1}^{(c)}=\frac{-1}{\tilde{q}_{1}} .
$$

Uma análise análoga, mostra que a extinção da espécie 2 é estável somente para $\epsilon_{2}<\epsilon_{2}^{(c)}$, com:

$$
\epsilon_{2}^{(c)}=\frac{-1}{\tilde{q}_{2}}
$$

Este resultado é geral e tem como caso particular $\tilde{q}_{1}=1$ e $\tilde{q}_{2}=1$ os resultados apresentados na Sec. 5.2.1.2. No caso do modelo tipo Gompertz para duas espécies $\tilde{q}_{1}=0$ e $\tilde{q}_{2}=0$, a fase em que uma espécie é extinta só é estável em uma situação limite em que $\epsilon_{1}^{(c)}$ ou $\epsilon_{2}^{(c)}=-\infty$.

Devemos analisar aqui as quatro possíveis combinações de valores:

- (i) $\tilde{q}_{1}<0$ e $\tilde{q}_{2}<0$

- (ii) $\tilde{q}_{1}<0$ e $\tilde{q}_{2}>0$

- (iii) $\tilde{q}_{1}>0$ e $\tilde{q}_{2}<0$

- (iv) $\tilde{q}_{1}>0$ e $\tilde{q}_{2}>0$

cujos diagramas estão representados nas Figs. 6.1a-6.1d.

Para $\tilde{q}_{1}>0$ e $\tilde{q}_{2}>0$, a coexistência de fases pode consistir de vários regimes ecológicos: mutualismo, predação, competição, amensalismo, neutralismo e comensalismo. A fase de extinção também consiste de vários regimes ecológicos: predação, competição e amensalismo, ver Fig. 6.1d. As espécies são proibidas de coexistir na fase de competição se um dos $\tilde{q}$ for menor que zero, ver Fig. 6.1a- 6.1c. 


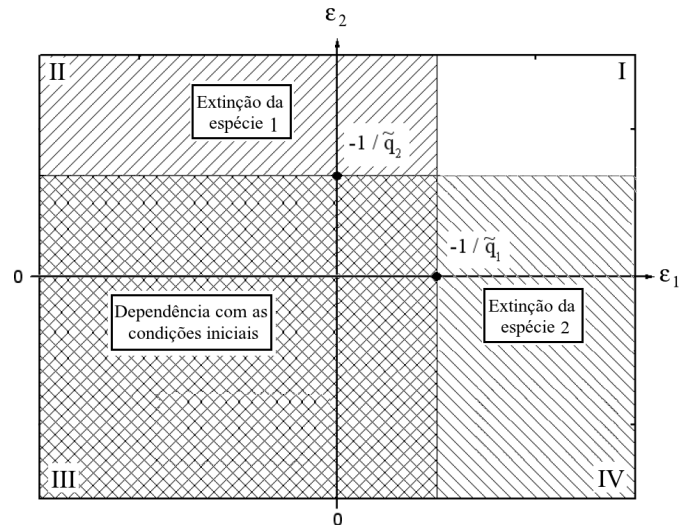

(a) $\tilde{q}_{1}<0$ e $\tilde{q}_{2}<0$

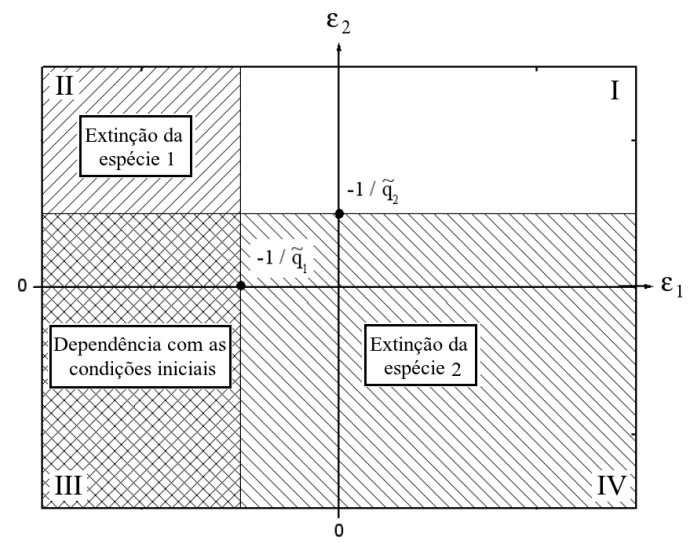

(c) $\tilde{q}_{1}>0$ e $\tilde{q}_{2}<0$

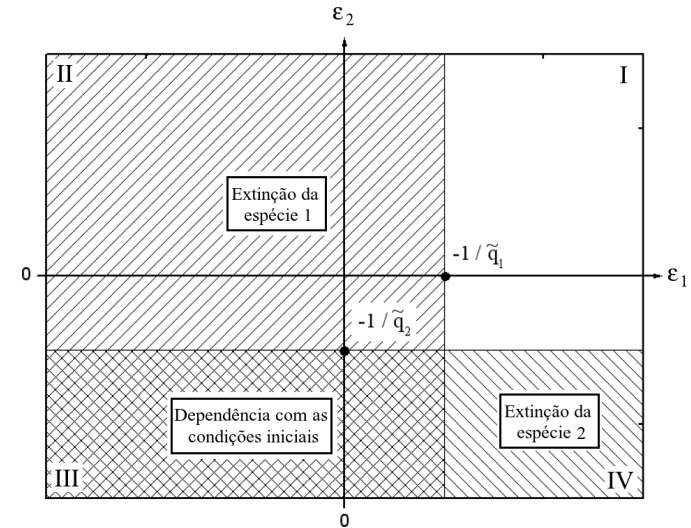

(b) $\tilde{q}_{1}<0$ e $\tilde{q}_{2}>0$

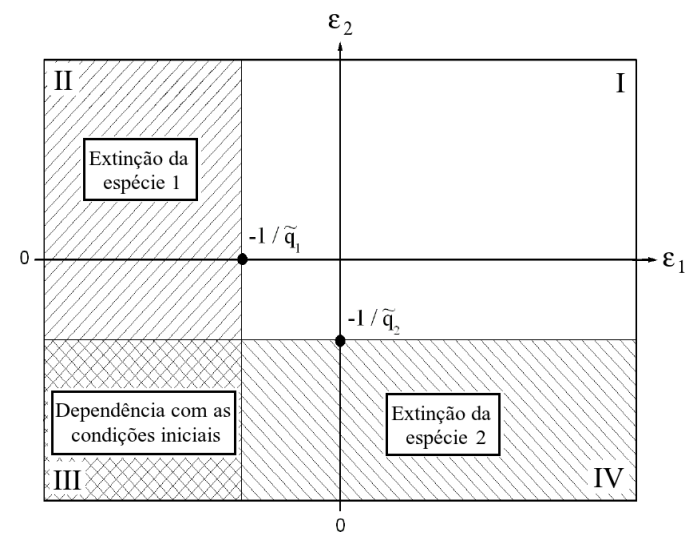

(d) $\tilde{q}_{1}>0$ e $\tilde{q}_{2}>0$

Figura 6.1: Diagrama da interações ecológicas entre duas espécies de acordo com o par $\left(\epsilon_{1}, \epsilon_{2}\right)$. Neste diagrama, cada quadrante representa um tipo de interação (ver Fig. 5.1): I: mutualismo; II e IV: predação e III: competição. A abcissa e a ordenada representam cada uma os regimes de amensalismo $\left(\epsilon_{1}\right.$ ou $\left.\epsilon_{2}<0\right)$ e comensalismo $\epsilon_{1}$ ou $\epsilon_{2}>0$. A origem representa o regime de neutralismo. As soluções não triviais $\left(\epsilon_{1}>-1 / \tilde{q}_{1}, \epsilon_{2}>-1 / \tilde{q}_{2}\right)$ correspondem à coexistência de fases. A fase de extinção $\left(\epsilon_{1}<-1 / \tilde{q}_{1}\right.$ e/ou $\left.\epsilon_{2}<-1 / \tilde{q}_{2}\right)$ revela uma região para $\epsilon_{1}<0$ and $\epsilon_{2}<0$ em que, ao contrário dos outros casos, as soluções de estado estacionário dependem da condição inicial.

\subsubsection{Soluções não-triviais: coexistência das espécies}

As soluções não triviais, Eqs. 6.12 e 6.13, são estáveis se $\epsilon_{1}>-1 / \tilde{q}_{1}$ e $\epsilon_{2}>-1 / \tilde{q}_{2}$. Para estudar essas equações, vamos considerar inicialmente o produto $\epsilon_{1} \epsilon_{2}$ e sua relação com os regimes ecológicos. Caso o produto se anule, temos neutralismo, amensalismo ou comensalismo. Temos predação, competição ou mutualismo caso contrário. 


\subsection{Regimes ecológicos}

Nesta seção é feita uma análise quanto à estabilidade das soluções do estado estacionário considerando cada tipo de regime ecológico. Mostramos a dependência dessa estabilidade em relação aos parâmetros $\tilde{q}$ e $\epsilon$.

\subsubsection{Neutralismo, amensalismo ou comensalismo $\left(\epsilon_{1} \epsilon_{2}=0\right)$.}

Conforme mostrado no Cap.5, esta situação, leva pelo menos uma solução do estado estacionário a se tornar unitária.

Para o regime de neutralismo, as duas espécies não interagem entre si $\left(\epsilon_{1}=\right.$ $\left.\epsilon_{2}=0\right)$. Então, a solução para cada espécie representada no sistema da Eq. 6.1 é dado pela Eq.2.13. Enquanto que para o regime de amensalismo e comensalismo, consideramos $\epsilon_{1}=0$ e $\epsilon_{2} \neq 0$. Importante salientar que toda a análise feita aqui é análoga caso considerássemos $\epsilon_{1} \neq 0$ e $\epsilon_{2}=0$.

No regime de amensalismo, temos $\epsilon_{1}=0$ e $\epsilon_{2}<0$. Considerando $\epsilon_{1}=0$ na Eq. 6.1, as soluções não triviais do estado estacionário (Eqs. 6.12 e 6.13) se tornam:

$$
\begin{aligned}
& p_{1, n t}^{*}=1, \\
& p_{2, n t}^{*}=e_{\tilde{q}_{2}}\left(\epsilon_{2}\right),
\end{aligned}
$$

com a condição imposta pela função $\tilde{q}$-exponencial: $\tilde{q}_{2} \epsilon_{2}>-1$. Observe que a espécie 1 maximiza a utilização dos recursos do meio enquanto a espécie 2 deve coexistir com a espécie 1, para $\tilde{q}_{2} \epsilon_{2}>-1$ ou ser extinta, caso contrário. A única forma de eliminar essa transição é considerar $\tilde{q}_{2}=0$ (modelo de Gompertz).

Os valores de $p_{2}^{*}$ em função de $\tilde{q}_{2}$, para $\epsilon_{1}=0$ e $\epsilon_{2}<0$, são mostrados na Fig. 6.2. Note a semelhança dessas curvas com as da Fig. 3.1(b) em que é considerado o modelo de uma espécie com uma taxa extrínseca de crescimento. O comportamento de $p_{2}^{*}$ em função de $\epsilon_{2}$ é mostrado na Fig. 6.3.

Conforme esperado, $p_{2}^{*}<1$ para todo $\epsilon_{2}<0$. Além disso, notamos que a extinção da espécie 2 ocorre quando $\epsilon_{2} \tilde{q}_{2} \leq-1$. Há uma transição de fase em que o sistema passa da coexistência para extinção de uma das espécies.

Para o comensalismo, temos $\epsilon_{1}=0$ e $\epsilon_{2}>0$. Obtemos as soluções dadas pelas Eqs. 6.12 e 6.13. A Fig. 6.4 mostra a dependência de $p_{2}^{*}$ com $\epsilon_{2}$ para diferentes 


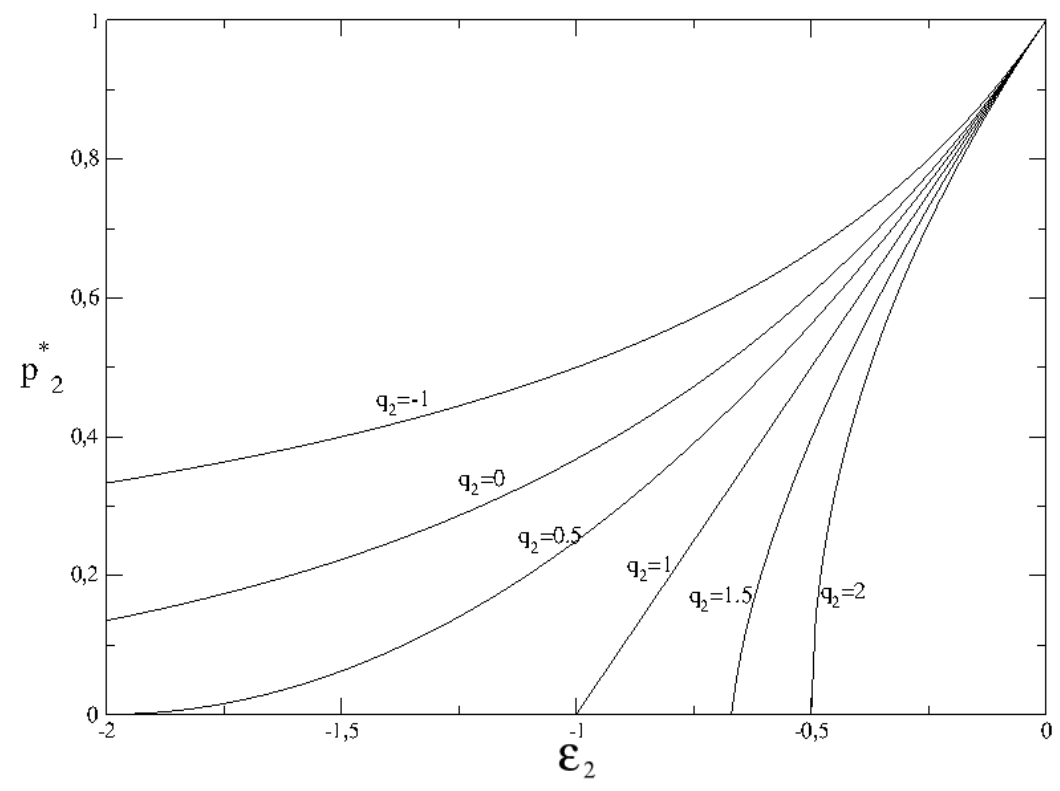

Figura 6.2: Soluções do estado estacionário para a espécie 2 no regime de amensalismo. Valor de $p_{2}^{*}$ em função de $\epsilon_{2}$, para $\tilde{q_{2}}=-1 ; 0 ; 1 / 2 ; 1 ; 3 / 2$ e 2 . Quando $\tilde{q}_{2} \epsilon_{2}<-1$, então $p_{2}^{*}=0$.

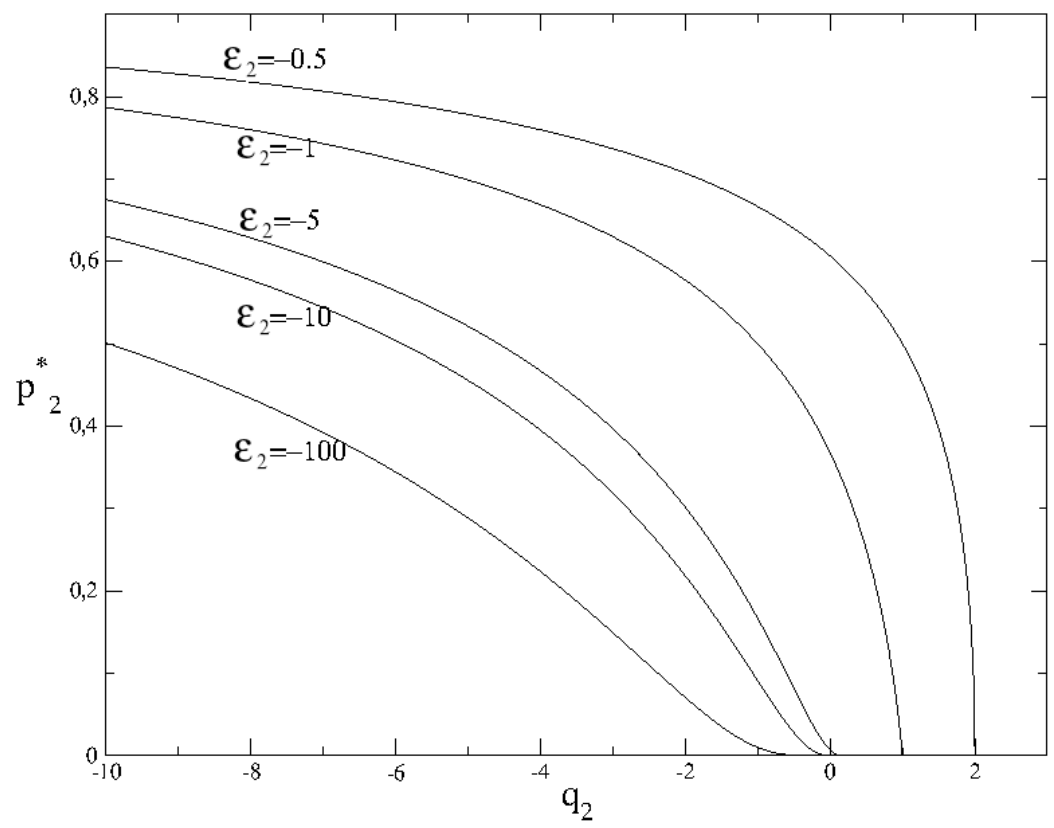

Figura 6.3: Soluções do estado estacionário para a espécie 2 no regime de amensalismo. Valor de $p_{2}^{*}$ em função de $\tilde{q}_{2}$ para $\epsilon_{2}=-100 ;-10 ;-15 ;-1$ e $-1 / 2$. Quando $\tilde{q}_{2} \epsilon_{2}<-1$, então $p_{2}^{*}=0$. 
valores de $\tilde{q}_{2}$ enquanto que a Fig. 6.5 mostra $p_{2}^{*}$ em função de $\tilde{q}_{2}$ para diferentes valores de $\epsilon_{2}$.

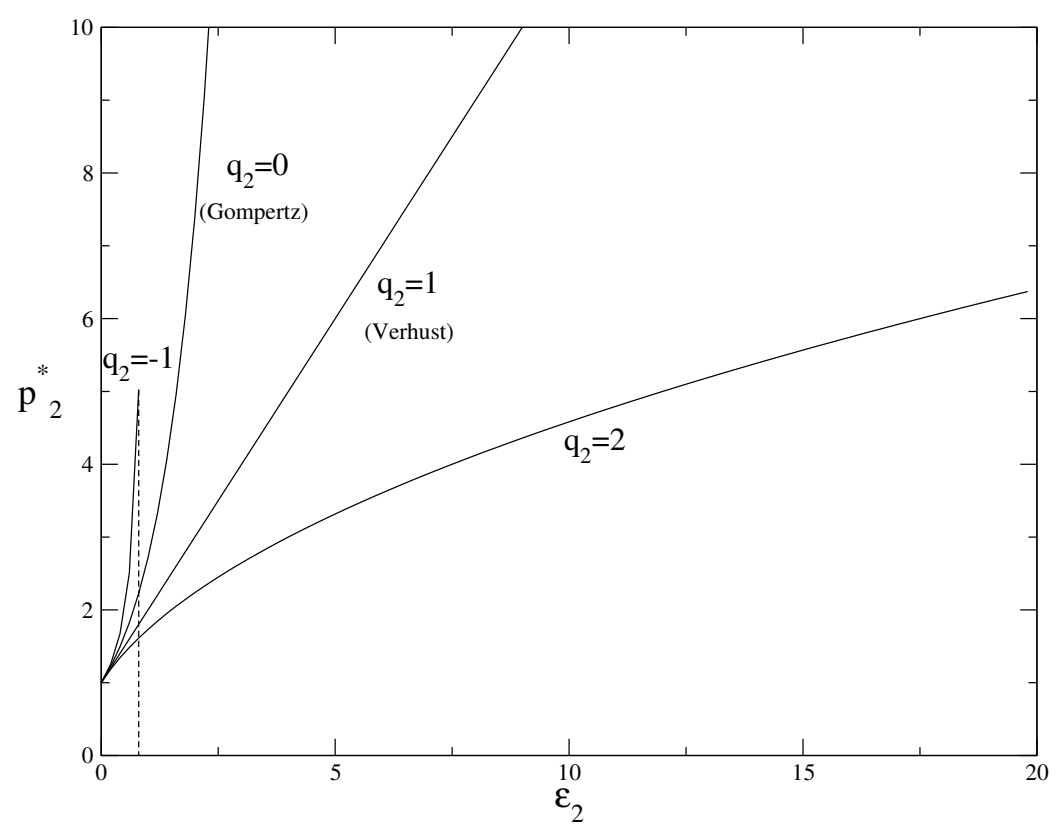

Figura 6.4: Soluções do estado estacionário para a espécie 2 no regime de comensalismo. Valor de $p_{2}^{*}$ em função de $\epsilon_{2}$, para $\tilde{q_{2}}=-1 ; 0 ; 1 ;$ e 2 .

A partir destes gráficos, pode-se perceber que, como consequência da função q̃exponencial, $p_{2}^{*}$ se anula, para $\epsilon_{2} \tilde{q}_{2}<-1$. Para as curvas de $p_{2}^{*}$ em função de $\epsilon_{2}$, a solução do estado estacionário cresce exponencialmente, para $\tilde{q}_{2}<1$, linearmente para $\tilde{q}_{2}=1$ (modelo de Verhulst) e de forma logarítmica para $\tilde{q}_{2}>1$.

Considere que os indivíduos da espécie 1 não são afetados pela espécie 2. A taxa de variação per capta da espécie 1 é dada pela Eq. 2.11, com solução dada pela Eq. 2.13. Os indivíduos da espécie 2 são afetados pela espécie 1 por meio do fator extrínseco de crescimento $\epsilon_{2}^{\prime}(\tau)$, e escreve-se a equação para a espécie 2 como:

$$
\frac{d \ln p_{2}}{d \tau}=-\rho\left[\ln _{\tilde{q}_{2}} p_{2}-\epsilon_{2}^{\prime}(\tau)\right]
$$

em que,

$$
\epsilon_{2}^{\prime}(\tau)=\epsilon_{2} p_{1}(\tau)=\frac{\epsilon_{2}}{e_{\tilde{q}_{1}}\left[\ln _{\tilde{q}_{1}}\left(p_{10}^{-1}\right) e^{-\tau}\right]} .
$$

A solução da Eq. (6.28) foi obtida na Sec. 3.6 e vale:

$$
p_{2}(\tau)=\frac{e_{\tilde{q}_{2}}\left[\epsilon_{2}^{\prime}(\tau)\right]}{e_{\tilde{q}_{2}}\left\{\ln _{\tilde{q}_{2}}\left\{\frac{e_{\tilde{q}_{2}}\left[\epsilon_{2}^{\prime}(0)\right]}{p_{2,0}}\right\} \frac{e_{\tilde{q}_{2}}\left[\epsilon_{2}^{\prime}(0)\right]}{e_{\tilde{q}_{2}}\left[\epsilon_{2}^{\prime}(\tau)\right]} e^{-\left[1+\tilde{q}_{2} \bar{\epsilon}_{2}^{\prime}(\tau)\right] \rho \tau}\right\}},
$$




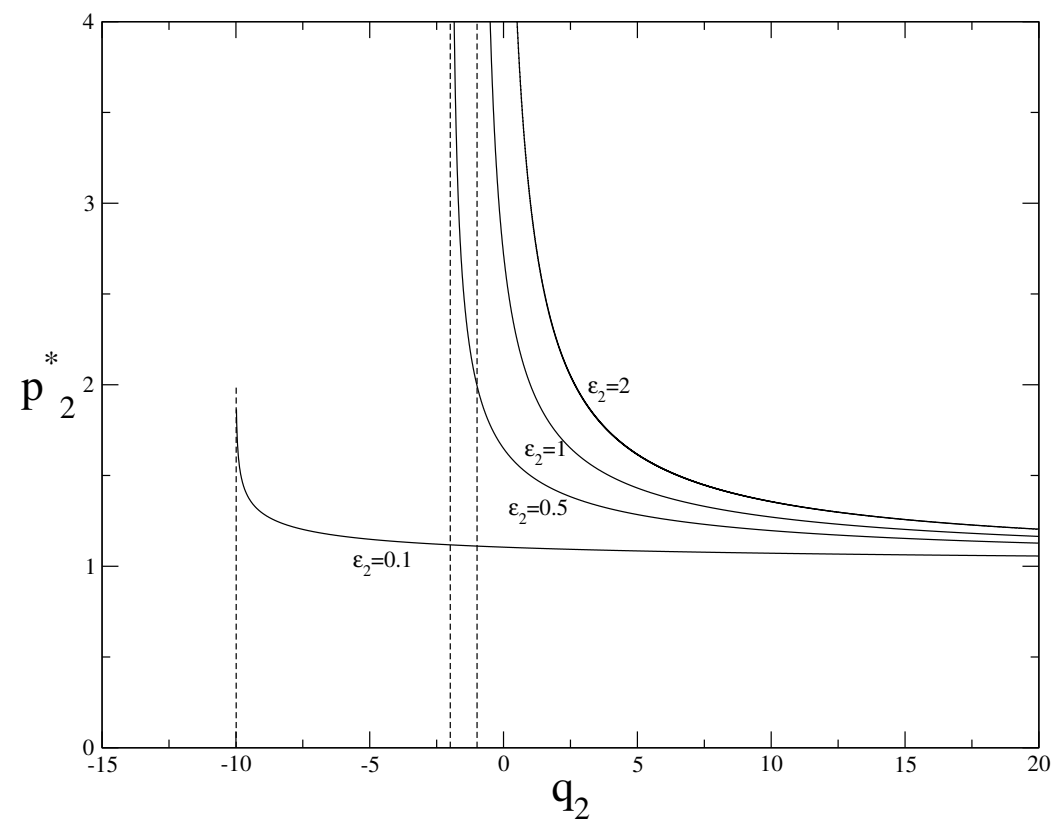

Figura 6.5: Soluções do estado estacionário para a espécie 2 no regime de comensalismo. Valor de $p_{2}^{*}$ em função de $\tilde{q}_{2}$ para $\epsilon_{2}=1 / 10 ; 1 / 2 ; 1$; e 2 . A linha tracejada vertical representa o ponto em que a solução do estado estacionário diverge.

em que a condição inicial é $p_{2,0}=p_{2}(0)$, o estado estacionário é $p_{2}(\infty)=p_{2}^{*}=e_{\tilde{q}_{2}}\left(\epsilon_{2}\right)$ $\mathrm{e}$

$$
\bar{\epsilon}_{2}^{\prime}(\tau)=\frac{1}{\tau} \int_{0}^{\tau} d \tau^{\prime} \epsilon_{2}^{\prime}\left(\tau^{\prime}\right)
$$

é o valor médio de $\epsilon_{2}^{\prime}(\tau)$ até $\tau$.

Para $\epsilon_{2}<0\left(\epsilon_{2}>0\right)$, tem-se amensalismo (comensalismo), então a espécie 1 afeta a espécie 2 negativamente (positivamente). O mofo de pão (Penicillium) é um exemplo comum de amensalismo. Esse fungo secreta penicilina, uma substância química que mata bactérias. O termo de interação $\epsilon_{2}^{\prime}$ pode ser interpretado como taxa extrínseca de crescimento do modelo de uma espécie. Como vimos na Sec. 3.5, essa taxa extrínseca pode ser incorporada na capacidade de suporte. Desta forma, um modelo de duas espécies pode ser interpretado como modelo de uma espécie com capacidade de suporte efetiva ${ }^{2}$, conforme ilustrado na Fig. 6.6.

A evolução de ambas as espécies é apresentada nas Figs. 6.7 e 6.8, para dois valores diferentes de $\tilde{q}_{1}$. O tempo de transiente depende da espécie 1 , por meio do fator extrínseco efetivo $\epsilon_{2}^{\prime}(\tau)$. Para $\tilde{q} \neq 0$, há uma dependência com o valor médio

\footnotetext{
${ }^{2}$ Deste resultado foi publicado o artigo da Ref. [23]
} 


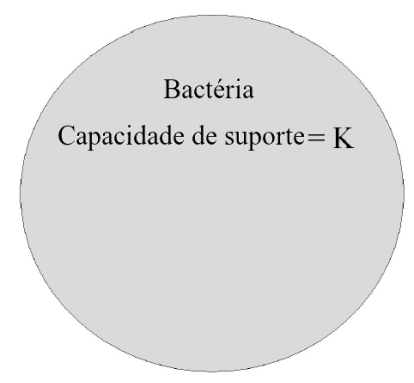

(a)

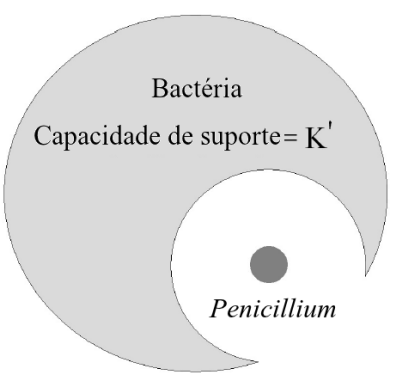

(b)

Figura 6.6: Representação da interação ecológica de amensalismo entre o mofo de pão e a bactéria. Um modelo de duas espécies pode ser simplificado a um modelo de uma espécie com capacidade de suporte efetiva. (a) Bactéria ocupando todo espaço disponível com capacidade de suporte $K$. (b) Crescimento restrito de bactérias devido à interação com o fungo, capacidade de suporte $K^{\prime}<K$.Adaptada da Ref. [23]

$\bar{\epsilon}_{2}^{\prime}(\tau)$, ver Eq. (6.30). Considerando o modelo Gompertz $\left(\tilde{q}_{2} \rightarrow 0\right)$, a solução pode ser simplificada para:

$$
p_{2}(\tau)=e^{\epsilon_{2}^{\prime}(\tau)}\left[\frac{p_{2,0}}{e^{\epsilon_{2}^{\prime}(0)}}\right]^{e^{\left[\epsilon_{2}^{\prime}(0)-\epsilon_{2}^{\prime}(\tau)-\rho \tau\right]}} .
$$

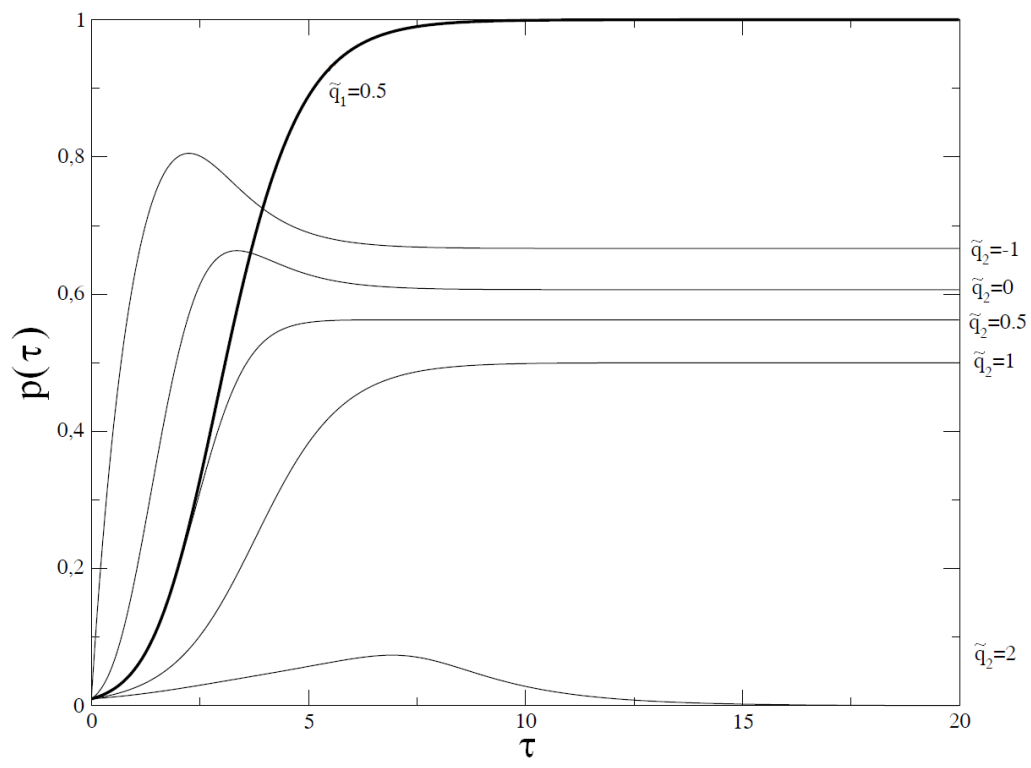

Figura 6.7: Valor da população $p(\tau)$ para o regime de amensalismo. Para $\tilde{q}_{1}=1 / 2$ e para diversos valores de $\tilde{q}_{2}$, gráficos de $p_{1}(\tau)$ (linha grossa), dada pela Eq. 2.13 e de $p_{2}(\tau)$ (linhas finas), dadas pela Eq. 6.30, em que a integral desta equação foi calculada numericamente. Parâmetros: $\rho=1, \epsilon_{1}=0$ e $\epsilon_{2}=1 / 2$. 


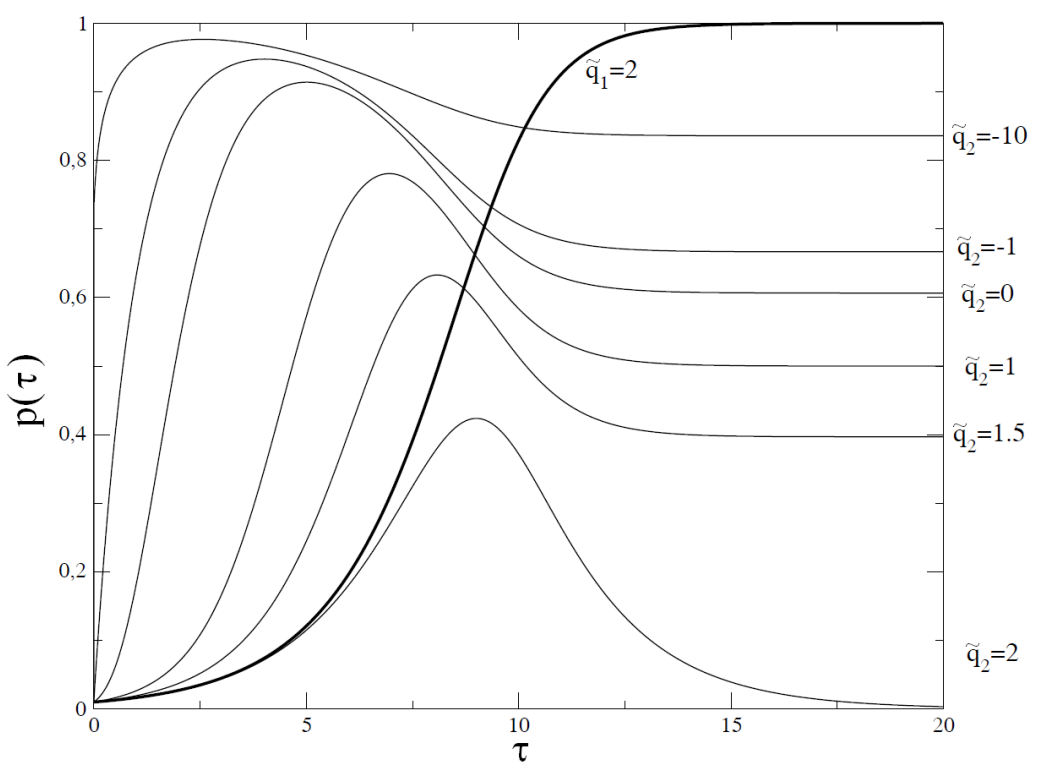

Figura 6.8: Valor da população $p(\tau)$ para o regime de amensalismo. Para $\tilde{q}_{1}=2 \mathrm{e}$ para diversos valores de $\tilde{q}_{2}$, gráficos de $p_{1}(\tau)$ (linha grossa), dada pela Eq. 2.13 e de $p_{2}(\tau)$ (linhas finas), dadas pela Eq. 6.30, em que a integral da Eq. 6.30 foi calculada numericamente. Parâmetros: $\rho=1, \epsilon_{1}=0, \epsilon_{2}=1 / 2$.

\subsubsection{Casos particulares $\left(\epsilon_{1} \epsilon_{2} \neq 0\right)$.}

As soluções não triviais do estado estacionário são dadas pelas Eqs. 6.12 e 6.13. Neste caso, não há soluções algébricas pois se trata de equações transcendentais ${ }^{3}$. Elas são funções reais se: $\tilde{q}_{1} \epsilon_{1} e_{\tilde{q}_{2}}\left(\epsilon_{2} p_{1, n t}^{*}\right)>-1$ e $\tilde{q}_{2} \epsilon_{2} e_{\tilde{q}_{1}}\left(\epsilon_{1} p_{2, n t}^{*}\right)>-1$. Isto é:

$$
\left\{\begin{array}{c}
\epsilon_{1}>\frac{-1}{\tilde{q}_{1} e_{\tilde{q}_{2}}\left(\epsilon_{2} p_{1, n t}^{*}\right)}=\frac{\epsilon_{1}^{c}}{e_{\tilde{q}_{2}}\left(\epsilon_{2} p_{1, n t}^{*}\right)} \\
\epsilon_{2}>\frac{-1}{\tilde{q}_{2} e_{\tilde{q}_{1}}\left(\epsilon_{1} p_{2, n t}^{*}\right)}=\frac{\epsilon_{2}^{c}}{e_{\tilde{q}_{1}}\left(\epsilon_{1} p_{2, n t}^{*}\right)} .
\end{array}\right.
$$

em que $\epsilon_{i}^{c}, i=1,2$, é dado pelas Eqs. 6.24 e 6.25. Fora desta região as soluções são não-físicas, ou seja, o modelo prevê um número negativo de indivíduos.

\subsubsection{Mutualismo}

Para o regime de mutualismo $\left(\epsilon_{1}>0\right.$ e $\left.\epsilon_{2}>0\right)$, vamos analisar as soluções estacionárias não triviais por meio das isóclinas $1 b$ e $2 b$, Eqs. 6.3 e 6.5 respectivamente.

\footnotetext{
${ }^{3}$ Uma função transcendental é uma função que "transcende"a álgebra no sentido de que ela não pode ser expressa em termos de uma sequência finita de operações algébricas de multiplicação, adição, e extração de raiz.
} 
Quando $\tilde{q}_{1}>1$ e $\tilde{q}_{2}>1$ a isóclina $1 \mathrm{~b}$ é uma função convexa, enquanto que a isóclina $2 \mathrm{~b}$ é uma função côncava. Conforme ilustrado na Fig. 6.9, as duas isóclinas se interceptam no ponto que satisfaz a relação:

$$
\epsilon_{1} \ln _{\tilde{q}_{1}}\left(p_{1}\right)=\epsilon_{2} \ln _{\tilde{q}_{2}}\left(p_{2}\right)
$$

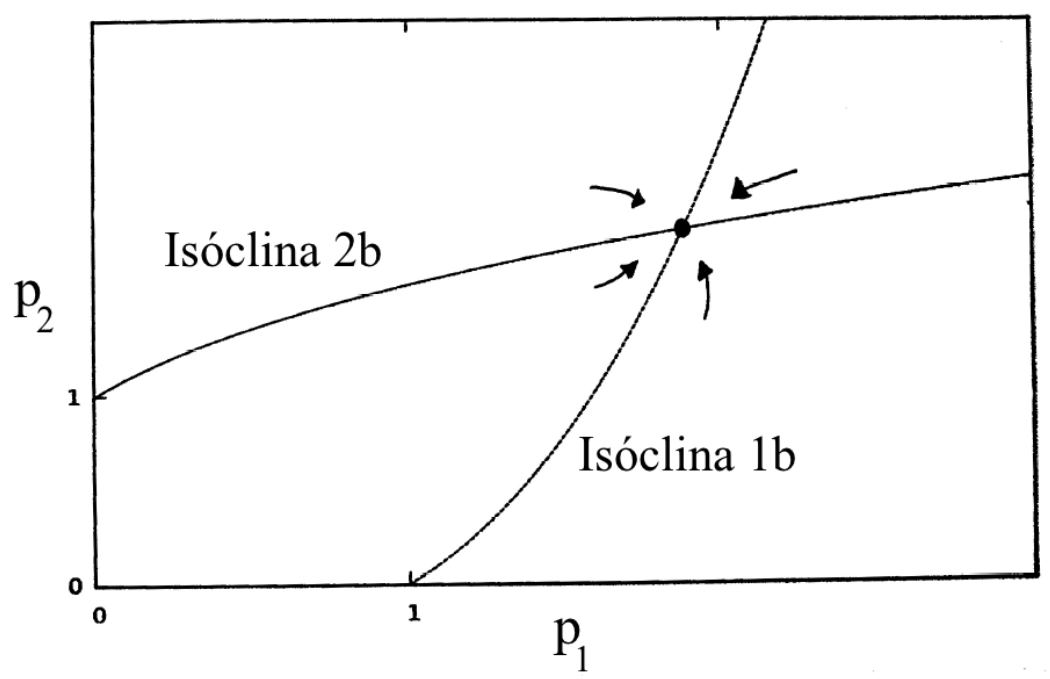

Figura 6.9: Isóclinas $1 b$ e $2 b$ com $\epsilon_{1}>0$ e $\epsilon_{2}>0$ (mutualismo); $\tilde{q}_{1}>1$ e $\tilde{q}_{2}>1$. O cruzamento das isóclinas fornece o valor do estado estacionário.

Podemos obter numericamente o estado estacionário pelas seguintes relações:

$$
\begin{aligned}
& p_{1}^{*}=\frac{1}{\epsilon_{2}} \ln _{\tilde{q}_{2}}\left[\frac{1}{\epsilon_{1}} \ln _{\tilde{q}_{1}}\left(p_{1}^{*}\right)\right], \\
& p_{2}^{*}=\frac{1}{\epsilon_{1}} \ln _{\tilde{q}_{1}}\left[\frac{1}{\epsilon_{2}} \ln _{\tilde{q}_{2}}\left(p_{2}^{*}\right)\right] .
\end{aligned}
$$

Por outro lado, quando $\tilde{q}_{1}<1$ e $\tilde{q}_{2}<1$, as isóclinas não se cruzam em nenhum ponto conforme Fig. 6.10. Dessa forma o sistema não apresenta um estado estacionário e as duas populações crescem indefinidamente.

\subsubsection{Competição}

Para o regime de competição $\epsilon_{1}<0$ e $\epsilon_{2}<0$ a análise de estabilidade mostra que quando a solução do estado estacionário está acima da reta $p_{2}=1-p_{1}$, ela é estável, conforme mostrado nas Figs. 6.11 e 6.12. O valor deste ponto é dado pelas 


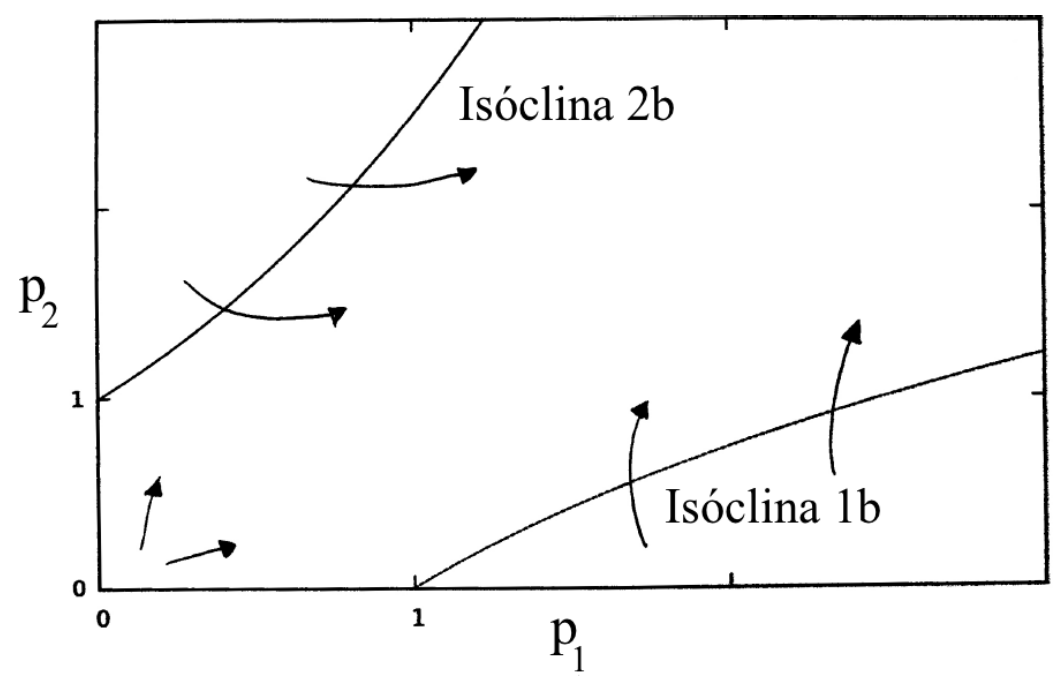

Figura 6.10: Isóclinas $1 b$ e $2 b$ com $\epsilon_{1}>0$ e $\epsilon_{2}>0$ (mutualismo); $\tilde{q}_{1}<1$ e $\tilde{q}_{2}<1$. As isóclinas nunca interceptam e as populações crescem indefinidamente.

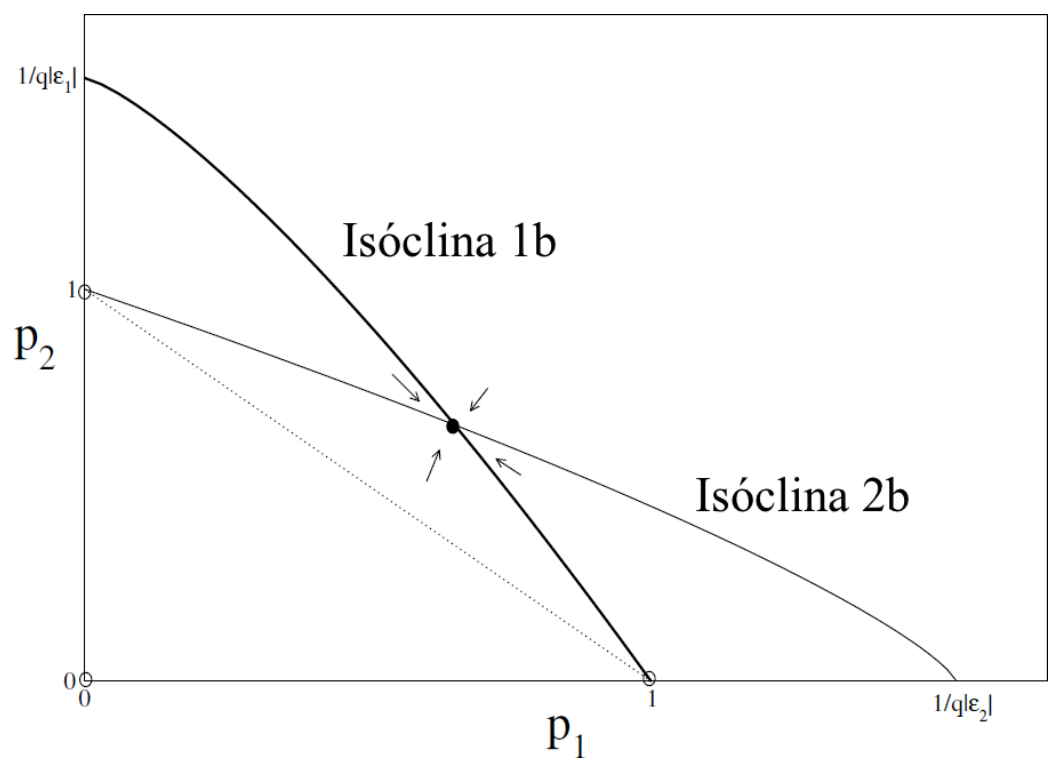

Figura 6.11: Isóclinas para o regime de competição considerando $\tilde{q}_{1}>1$ e $\tilde{q}_{2}>1$. Quando a solução do estado estacionário está acima da curva $p_{2}=1-p_{1}$ ela é estável. 


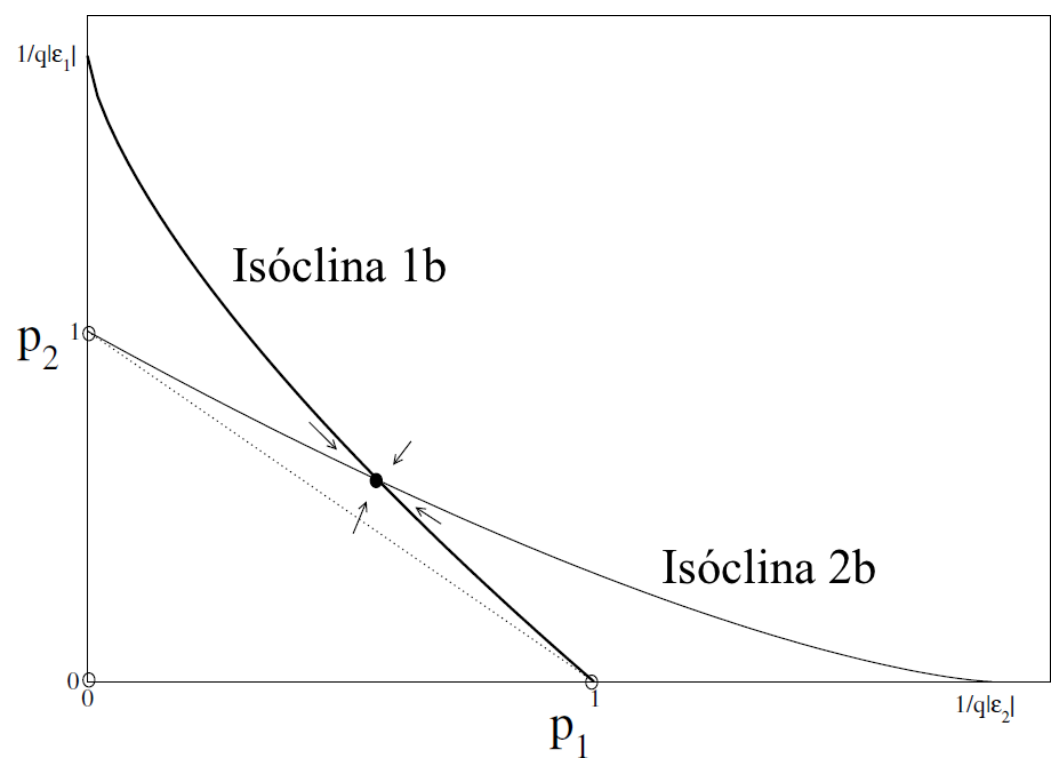

Figura 6.12: Isóclinas para o regime de competição considerando $\tilde{q}_{1}<1$ e $\tilde{q}_{2}<1$. Quando a solução do estado estacionário está acima da curva $p_{2}=1-p_{1}$ ela é estável.

Eqs. 6.35 e 6.36. Podemos dizer que nesse caso temos uma competição fraca pois a coexistência é estável.

Por outro lado, quando o ponto de intersecção das isóclinas está abaixo da reta $p_{2}=1-p_{1}$, a solução não trivial se torna estável e a semi trivial passa a ser estável. A separatriz é uma reta que passa pela origem das coordenadas e demarca o limite que define a partir de qual condição inicial será atingido um ou outro equilíbrio $\left(p_{1}^{*}, p_{2}^{*}\right)=(0,1)$ ou $(1,0)$. Neste caso temos uma competição forte pois uma das espécies é extinta. A Fig. 6.13 ilustra esse comportamento.

\subsubsection{Predação}

No regime de predação, consideramos a espécie 1 como predadora e a espécie 2 como presa, dessa forma $\epsilon_{1}>0$ e $\epsilon_{2}<0$. As curvas das Figs. 6.14 e 6.15 mostram uma predação fraca, uma vez que a coexistência (ponto fixo não trivial) é um regime estável. Conforme esperado, a espécie 1 é beneficiada pela espécie 2, enquanto que que espécie 2 é prejudicada pela 1 , isto é, $p_{1, n t}>1$ e $p_{2, n t}<1$. O valor desse equilíbrio é dado pelas Eqs. 6.35 e 6.36 .

Para $\tilde{q}_{2}\left|\epsilon_{2}\right|>1$, a solução estável é a semi trivial. Nesse caso, as isóclinas não se cruzam, conforme ilustra as Figs. 6.16 e 6.17. Assim, como as duas espécies são 


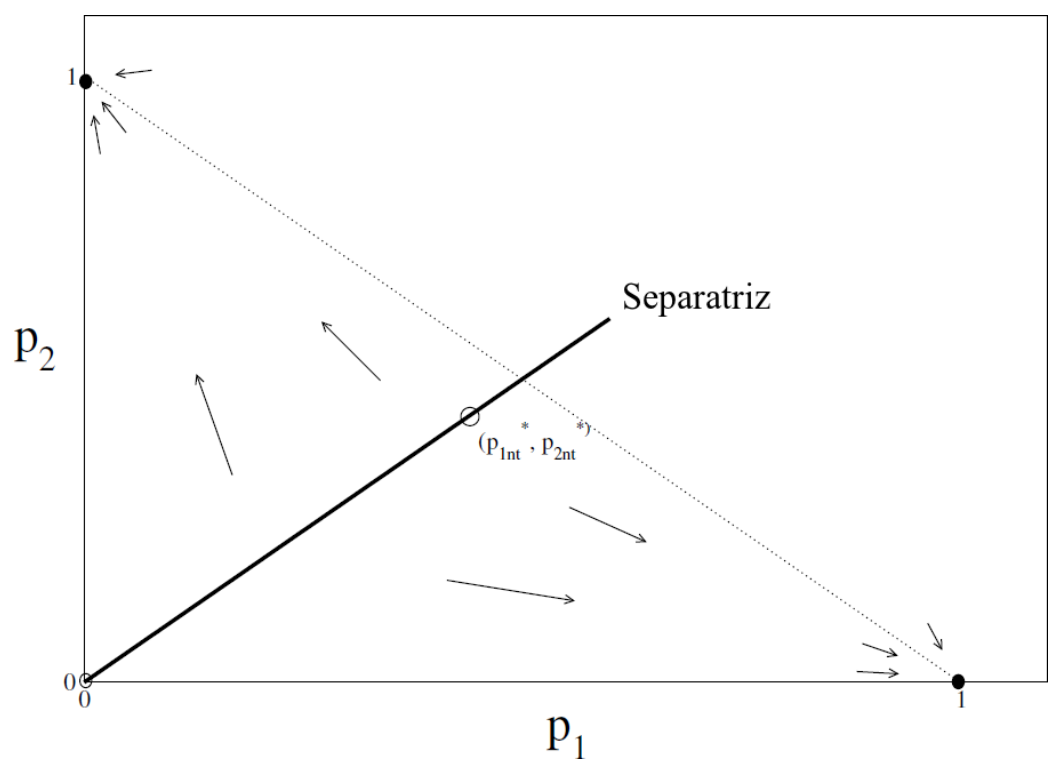

Figura 6.13: Representação dos pontos de equilíbrio para o regime de competição. O ponto cheio representa equilíbrio estável e o vazio instável. Quando o ponto fixo da solução não trivial fica abaixo da reta $p_{2}=1-p_{1}$, o ponto se torna instável e as soluções semi triviais passam a ser estáveis. A separatriz demarca o limite que define a partir de qual condição inicial será atingido um ou outro equilíbrio $\left(p_{1}^{*}, p_{2}^{*}\right)=(0,1)$ ou $(1,0)$.

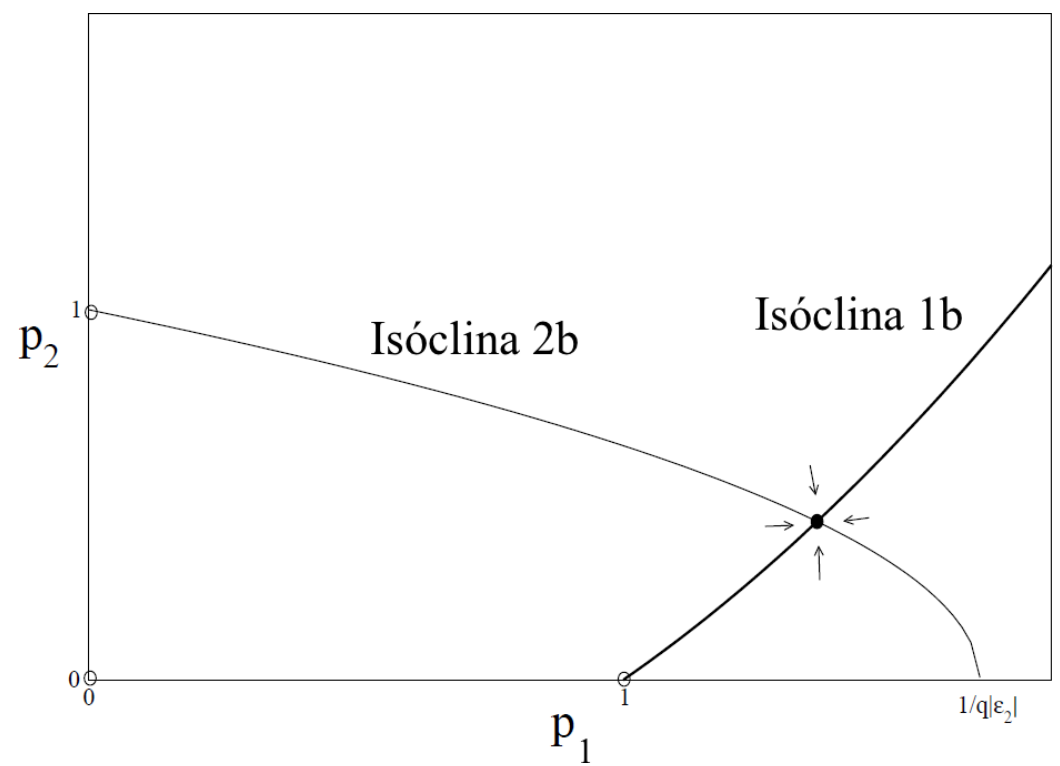

Figura 6.14: Regime de predação sendo a espécie 1 a predadora. Para a predação fraca $\tilde{q}_{2}\left|\epsilon_{2}\right|<1$, a solução não trivial é estável e temos coexistência das espécies com $\tilde{q}_{1}>1$ e $\tilde{q}_{2}>1$. 


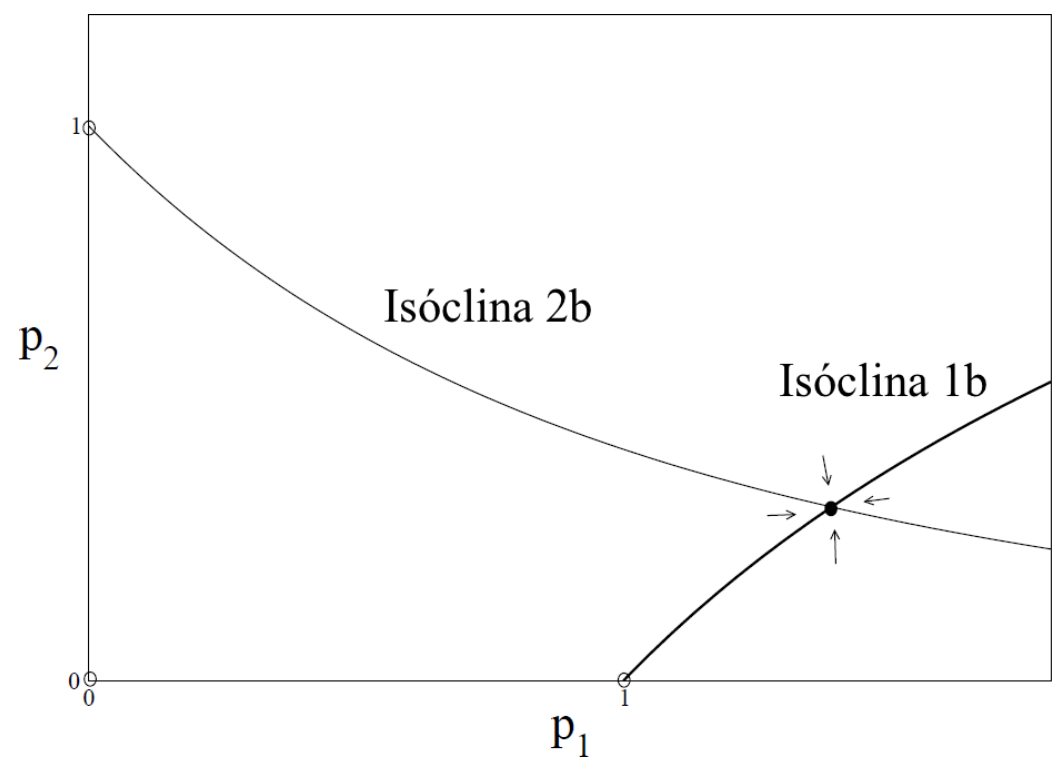

Figura 6.15: Regime de predação em que a espécie 1 é a predadora. Para a predação fraca $\tilde{q}_{2}\left|\epsilon_{2}\right|<1$, a solução não trivial é estável e temos coexistência das espécies com $\tilde{q}_{1}<1$ e $\tilde{q}_{2}<1$.

extintas temos predação forte.

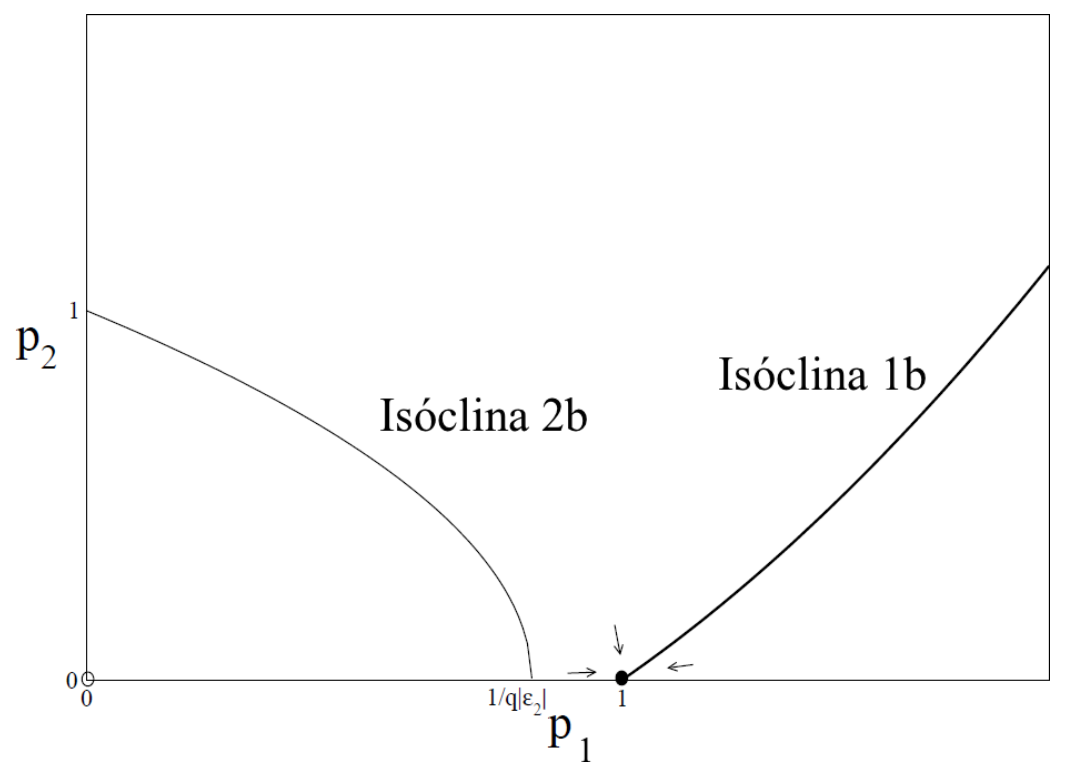

Figura 6.16: Regime de predação em que a espécie 1 é a predadora. Neste caso $\tilde{q}_{2}\left|\epsilon_{2}\right|>1$ e a solução semi trivial é estável. Nesse caso não há intersecção entre as isóclinas com $\tilde{q}_{1}>1$ e $\tilde{q}_{2}>1$.

Os modelos de uma e de duas espécies apresentados até aqui podem ser relacionados com modelos epidemiológicos. Na seção seguinte, apresentamos essas relações 


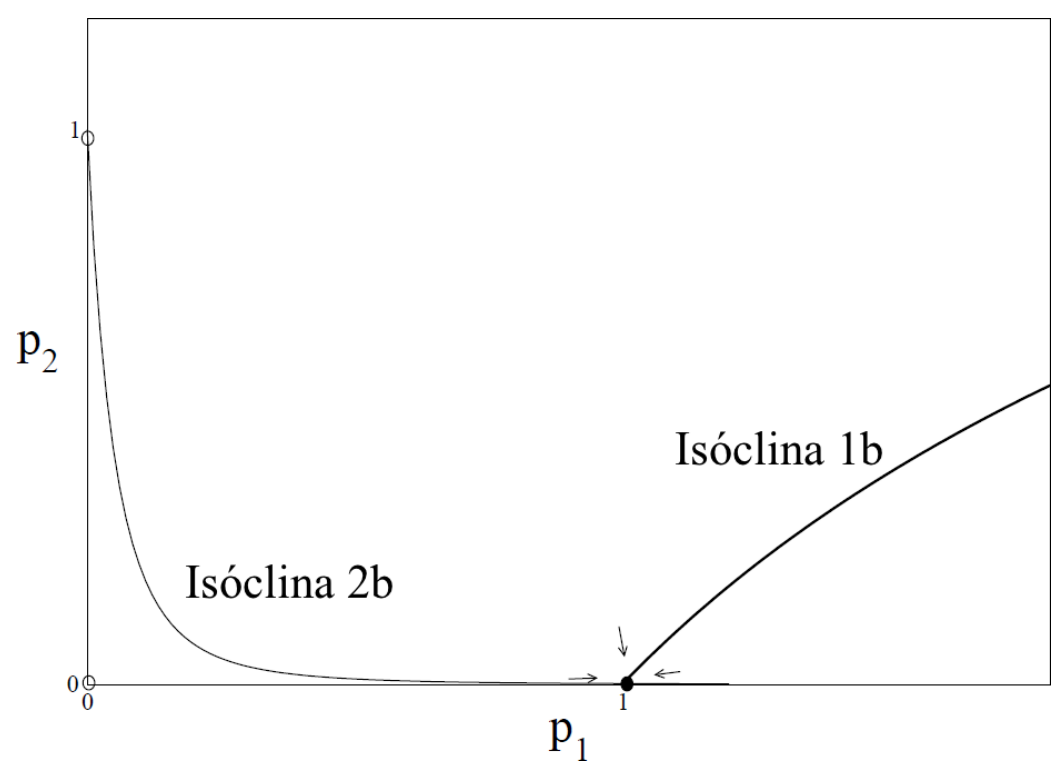

Figura 6.17: Regime de predação em que a espécie 1 é a predadora. Neste caso $\tilde{q}_{2}\left|\epsilon_{2}\right|>1$ e a solução semi trivial é estável. Nesse caso não há intersecção entre as isóclinas com $\tilde{q}_{1}<1$ e $\tilde{q}_{2}<1$.

e mostramos como as soluções obtidas podem ser usadas para esses modelos.

\subsection{Relações entre modelos de crescimento e epi- demiologia}

Até aqui, os modelos de dinâmica populacional apresentados foram utilizados para descrever o crescimento de uma população ao longo do tempo. No entanto tais modelos também podem ser usados para descrever a dinâmica de transmissão de doenças. Nesta seção, mostramos as relações entre modelos de crescimento populacional com modelos epidemiológicos.

Suponha que determinada população possa ser dividida em duas partes, as quais chamaremos de compartimentos. Em um compartimento têm-se $N_{I}$ indivíduos portadores de uma determinada doença, podendo infectar outros indivíduos. No outro compartimento, têm-se $N_{S}$ indivíduos que não têm esta doença, mas que são susceptíveis tê-la. O número total de indivíduos da população é $N=N_{I}+N_{S}$. Devemos distinguir que os indivíduos infectados podem estar em dois estágios da doença: expostos ou infeccioso. No estado exposto, o indivíduo tem a doença, mas não a transmite. Já no estado infeccioso, o indivíduo tem a doença e a transmite. Aqui 
não consideramos o estado exposto, ou seja, todos os indivíduos infectados são infecciosos. Considera-se também que os indivíduos infectados não podem ser curados, como por exemplo a infecção causada pelo vírus da AIDS (HIV).

Considere que a doença espalha-se através do contato entre indivíduos infecciosos $I$ e susceptíveis $S$. Considere também que indivíduos de ambos os grupos movem-se livremente entre si, de modo que o número de contatos é proporcional ao produto $N_{I} N_{S}$, ou seja, cada indivíduo infeccioso pode encontrar, com a mesma probabilidade, com os $N_{S}$ indivíduos susceptíveis. A taxa de disseminação da doença é proporcional ao número de tais contatos, $d N_{I} / d t=\beta N_{I} N_{S}$, em que a constante $\beta$ é chamada de taxa de contatos. Esta situação é representada pela Figura 6.18 e implica em:

$$
\begin{gathered}
\frac{d N_{S}(t)}{d t}=-\beta N_{I}(t) N_{S}(t) . \\
N_{S} \stackrel{\beta}{\longrightarrow} N_{I}
\end{gathered}
$$

Figura 6.18: Este esquema nos permite escrever: $d N_{S} / d t=-\beta N_{S} N_{I} / N$.

Seja $S(t)=N_{S}(t) / N$ a proporção dos indivíduos susceptíveis, e $I(t)=N_{I}(t) / N$ a proporção dos indivíduos infecciosos; então $S+I=1$. Os modelos mais realistas consideram que a taxa de disseminação é proporcional a proporção de indivíduos infectados e não a seu valor absoluto ${ }^{4}$, assim a Eq. 6.37 passa a ser escrita como:

$$
\frac{d N_{S}(t)}{d t}=-\beta \frac{N_{I}(t)}{N} N_{S}(t)=-\beta I(t) N_{S}(t) .
$$

A grandeza $\beta N_{I}(t) / N=\beta I(t)$ é chamada de força da infecção. Dividindo a Eq. 6.38 por $N$, obtemos a equação diferencial para as proporções:

$$
\frac{d S(t)}{d t}=-\beta I(t) S(t)
$$

Como $S=1-I$, a taxa de disseminação vale:

$$
\frac{d I(t)}{d t}=\beta I(t)[1-I(t)]
$$

onde $\beta$ é um fator de proporcionalidade positiva e $I(0)=I_{0}$ é a proporção inicial de indivíduos infecciosos. A solução estacionária é obtida impondo-se a condição

\footnotetext{
${ }^{4}$ Uma discussão rigorosa sobre este assunto é apresentado em um trabalho que estamos redigindo no momento.
} 
$d I(t) / d t=0$, o que resulta em $I_{s}=1$, ou seja, toda a população se torna infectada. A solução completa em função do tempo é dada por:

$$
I(t)=\frac{1}{1+\left(I_{0}^{-1}-1\right) e^{-\beta t}} .
$$

Esta solução é a mesma que para o modelo de Verhulst: $d \ln p(t) / d t=k[1-p(t)]$ cuja solução é: $p(t)=1 /\left[1+\left(p_{0}^{-1}-1\right) e^{-k t}\right]$.

Ao incluirmos a dinâmica vital no modelo $S I$, ou seja, admitirmos que há mortes por causas naturais tanto no compartimento $S$ como no $I$, podemos escrever o sistema de equações:

$$
\left\{\begin{array}{l}
\frac{d S(t)}{d t}=\mu[N-S(t)]-\beta S(t) I(t) \\
\frac{d I(t)}{d t}=\beta S(t) I(t)-\gamma I(t),
\end{array} .\right.
$$

em que $\mu$ é a taxa de natalidade e de mortalidade dos indivíduos susceptíveis e $\gamma$ a taxa de mortalidade dos indivíduos infecciosos.

A não ser pelo termo $\mu(N-S(t))$, este modelo possui a mesma estrutura do modelo de Lotka-Volterra, com o susceptíveis fazendo papel das presas e os infecciosos dos predadores. A única diferença em relação ao modelo Lotka-Volterra é a taxa de mortalidade da presa: no modelo epidêmico a taxa de natalidade é proporcional à $N-S(t)$, ao invés de $S(t)$, como no caso do modelo presa-predador. Note que, se somente os susceptíveis se reproduzirem, obtemos o modelo de LotkaVolterra, Eq.5.1. Esta comparação mostra que modelos epidemiológicos pertencem à uma classe mais geral que também contém modelos tipo presa-predador, parasitahospedeiro e herbívoro-planta [96]. No capítulo seguinte, exploramos um modelo de epidemia da dengue que utiliza a mesma estrutura de equações diferenciais ordinárias apresentada aqui.

\subsection{Conclusão}

A generalização do modelo de Lotka-Volterra competitivo modifica as soluções do estado estacionário nos diferentes regimes ecológicos. Para $\tilde{q}_{1}<0$ e $\tilde{q}_{2}<0$, 
não existe coexistência no regime de competição e pode haver extinção de uma das espécies até mesmo no regime de mutualismo.

No regime de predação, quando $\tilde{q}_{1}<0$ e $\tilde{q}_{2}>0$ ou $\tilde{q}_{1}>0$ e $\tilde{q}_{2}<0$, pode haver extinção do predador, desde que que a condição inicial do sistema seja favorável à presa. Ainda para o regime de predação, o produto $\tilde{q}_{1} \epsilon_{1}$, com $i=(1,2)$ define se ela é do tipo forte ou fraca. Quando $\tilde{q}_{1} \epsilon_{1}<1$ temos predação fraca e é forte caso contrário.

O mesmo comportamento qualitativo do diagrama de fases da Fig. 5.2 é obtido ao assumirmos $\tilde{q}_{1}>0$ e $\tilde{q}_{2}>0$. A magnitude de $\tilde{q}$ regula a sensibilidade das espécies aos parâmetros de interação $\epsilon_{1}$ e $\epsilon_{2}$. Tornando-as mais sensíveis quanto maior o valor do módulo de $\tilde{q}$. 


\section{Capítulo}

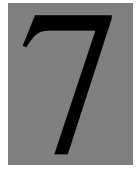

\section{Modelo de transmissão da dengue hemorrágica}

O dengue é uma infecção causada por vírus e transmitida por mosquitos ("arbovirose") que, nas últimas décadas, tornou-se um sério problema de saúde pública internacional. Sua incidência cresceu vertiginosamente em todo o mundo, sendo que cerca de 2,5 bilhões de pessoas (dois quintos da população mundial) estão agora em risco de dengue. A Organização Mundial da Saúde (OMS) estima que, atualmente, pode haver 50 milhões de infecções por dengue no mundo a cada ano. Só em 2007, existiam mais de 890.000 casos notificados de dengue nas Américas, dos quais 26.000 casos foram de dengue hemorrágica [97].

No Estado de São Paulo, desde o final de 1990, ocorrem epidemias todos os anos. O período de maiores incidências, desde 1990 até 2005, foi constatado entre 2001 e 2002, com 192 e 185 municípios com transmissão, respectivamente, correspondendo a $38 \%$ dos municípios com infestação domiciliar por Aedes aegypti. Em 2003, a incidência continuou elevada, porém, menor do que no ano anterior (51,6 casos/100.000 habitantes), tendo sido identificada a transmissão em 166 municípios. Em 2004, a queda de incidência foi extraordinária, chegando a 7,8/100.000 habitantes, incluindo 47 municípios [98]. Em 2005, houve um pequeno aumento na incidência para 13,4/100.000 habitantes, em um total de 5.433 casos no estado. Em 2006 e 2007, novamente foi registrado um período de incidência altíssima, ultrapassando o período de 2000-2001, com 50.022 casos em 2006 e 90.218 em 2007, e incidência de 125,6/100.000 habitantes e de 226,5/100.000 habitantes, respectivamente.

Em Ribeirão Preto, a primeira epidemia ocorreu em 1990, quando foram regis- 
trados 7.325 casos [99]. De 1992 a 1994, a incidência de dengue se manteve baixa, em torno de um caso por 100.000 habitantes, mas em 1995 aumentou para cerca de 50 casos por 100.000 habitantes [100], mantendo-se semelhante no período de 1996 a 2000. Em 2001, registrou-se um elevado número de casos (2.761). Mais recentemente, em 2006 e 2007, foram registrados 4.454 e 2.679 casos, respectivamente.

A propagação da doença é atribuída à expansão da distribuição geográfica dos vírus da dengue e de seus mosquitos vetores, dentre os quais a espécie mais importante é o Aedes (Stegomyia) aegypti. Um rápido aumento da população urbana do mosquito está fazendo com que mais pessoas tenham contato com este vetor, especialmente em áreas que são favoráveis para a reprodução do mosquito, por exemplo, onde é comum o armazenamento doméstico de água e onde os serviços de eliminação dos resíduos sólidos são insuficientes [97].

Considerando a ausência de uma vacina eficaz contra a doença, o controle da transmissão da dengue consiste, principalmente, no combate ao vetor. No entanto, apesar das intensas e contínuas campanhas de controle do vetor, o resultado desejado ainda não foi alcançado, já que o Aedes aegypti se encontra disperso por todos os estados brasileiros, evidenciando que as medidas adotadas não tem sido suficientes e/ou adequadas.

Esta parte do trabalho teve como objetivo entender a influência, em termos populacionais, de dois sorotipos da doença circulando na mesma população. Tal estudo pode revelar mecanismos que levam à incidência de dengue hemorrágica, a forma mais letal da doença, assim como a periodicidade das epidemias ${ }^{1}$.

O teoria do efeito de reforço, responsável pelo surgimento da dengue hemorrágica, é apresentado na Sec. 7.1. O modelo de disseminação da dengue com dois sorotipos utilizando a teoria do reforço é descrito na Sec. 7.2. A implementação do modelo e resultados preliminares são mostrados na Sec. 7.3 enquanto que os comentários finais são apresentados na Sec. 7.4.

\footnotetext{
${ }^{1}$ Esse trabalho foi realizado em colaboração com a Profa. Dra. Gail S. K. Wolkowicz do Department of Mathematics and Statistics da McMaster University.
} 


\subsection{Efeito de reforço}

O vírus da dengue apresenta 4 sorotipos diferentes: DEN1, DEN2, DEN3 e DEN4. Atualmente, os 4 sorotipos circulam simultaneamente em várias regiões da África, Ásia e Américas e, em geral, apenas um sorotipo é o mais abundante. A infecção com o vírus da dengue pode produzir vários sintomas. Após um período de 2 a 7 dias de incubação, um quadro agudo da doença se inicia caracterizado por febre, dores de cabeça, dores severas nos músculos e articulações e manchas vermelhas pelo corpo. Infecções assintomáticas são comuns, porém em alguns casos a infecção pelo vírus pode produzir condições clínicas mais sérias, sendo a febre hemorrágica $(\mathrm{FH})$ e a síndrome do choque (SC) as mais notáveis. Os sinais da FH começam por volta do sexto dia do estágio agudo da doença e podem levar à hemorragia espontânea que pode ser fatal. A SC ocorre se o paciente desenvolver hipotensão e choque profundo devido ao extravasamento do plasma e falha do sistema circulatório. Isto ocorre em aproximadamente um terço dos casos (especialmente em crianças) e a ela está associada a uma alta taxa de mortalidade.

Apesar da prevalência e severidade da FH e da SC, sua etiologia permanece incerta. Existem pelo menos três possíveis explicações, sendo a mais citada o aumento da replicação viral devido à infecção reforçada dos monocitos na presença de anticorpos da dengue em níveis subneutralizantes ${ }^{2}$. Este mecanismo é conhecido como reforço dependente de anticorpos (RDA), do inglês Antibody-Dependent Enhancement (ADE) [101]. Uma representação esquemática da abundância de vírus e anticorpos em função do tempo é ilustrada na Fig. 7.1.

A infecção inicial com o vírus da dengue leva a uma viremia moderada e a uma produção de anticorpos específicos ao sorotipo que fornece imunidade a este sorotipo para o resto da vida. Por um breve período de tempo (geralmente menor que 12 semanas) esses anticorpos podem inibir infecções subsequentes com outros sorotipos (imunidade cruzada) e rapidamente caem para um nível baixo de forma a não ter mais impacto contra infecções a outros sorotipos (heterólogos). Se o hospedeiro for infectado com um segundo sorotipo, antes do nível de anticorpos atingir um segundo limiar, pode ocorrer então um aumento da replicação viral (reforço) [101].

\footnotetext{
${ }^{2}$ As duas outras hipóteses estão relacionadas com a virulência de diferentes estirpes do vírus e com a maior susceptibilidade genética de alguns hospedeiros à dengue hemorrágica. [101]
} 


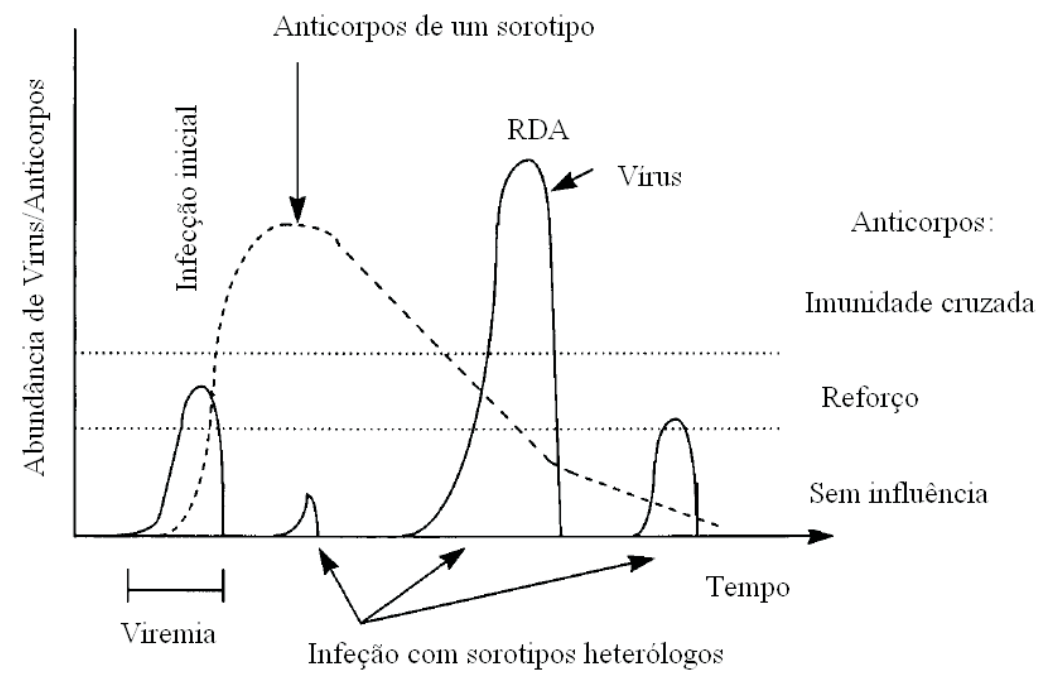

Figura 7.1: Ilustração esquemática da relação entre o curso da infecção da dengue e a viremia em um hospedeiro. Adaptado da Ref. [101].A infecção inicial leva a uma viremia moderada e a uma produção de anticorpos específicos ao sorotipo. Por um breve período de tempo esses anticorpos podem inibir infecções subsequentes com sorotipos heterólogos (imunidade cruzada) e rapidamente caem de forma a não ter mais impacto contra infecções a outros sorotipos (heterólogos). Se o hospedeiro for infectado com um segundo sorotipo, antes do nível de anticorpos baixar até um segundo limiar, essa quantidade moderada de anticorpos pode favorecer a replicação viral (reforço) [101].

\subsection{Transmissão com dois sorotipos}

Para poder abordar o problema da dengue hemorrágica, consideramos dois sorotipo da dengue na população. O modelo proposto leva em conta não só a dinâmica dos hospedeiros mas também a dos vetores.

Hospedeiros susceptíveis $S$ podem ser infectados ao serem picados por vetores infecciosos $V_{I_{i}}$ com um dado sorotipo $i=1,2$. Os indivíduos no estado $S$ que foram infectados se tornam expostos $E_{i}$ ao sorotipo $i$. O indivíduo $E_{i}$ apesar de infectado não infecta outros mosquitos. Após um período de tempo $1 / \sigma_{I}$ esse hospedeiro se torna infeccioso $I_{i}$. Os mosquitos se tornam infectados ao picarem hospedeiros infecciosos. Em seguida, passado um tempo $1 / \sigma_{C}$ o hospedeiro fica com imunidade cruzada $C_{i}$, ou seja, não pode ser infectado por nenhum outro sorotipo e após um período $1 / \sigma_{A}$ pode sofrer o efeito de reforço $A_{i}$ caso seja picado por um vetor infeccioso com sorotipo $j$ se tornando exposto à forma hemorrágica $E_{A_{i}}$ e em infeccioso na 
forma hemorrágica $H_{i j}$ em um tempo $1 / \sigma_{H}$. Nesse compartimento ele está sofrendo de dengue hemorrágica e os mosquitos que o picarem poderão ser infectados com o sorotipo $j$. O hospedeiro finalmente se recupera após um tempo $1 / \sigma_{R H}$. Porém, se o hospedeiro permanecer um tempo suficiente $1 / \sigma_{S}$ no compartimento $A_{i}$ sem contrair outro sorotipo do vírus, ele simplesmente se recupera de uma dengue comum, se tornando susceptível ao sorotipo $j$ mas imune ao $i S_{i}$. Nesse compartimento se infectado com outro sorotipo, desenvolve a doença em sua severidade normal.

O modelo proposto leva em conta não só a dinâmica dos hospedeiros mas também a dos vetores. A dinâmica dos vetores é mais simples possuindo apenas três compartimentos: vetores susceptíveis $V_{S}$, expostos $V_{E_{i}}$ com sorotipo $i=1,2$ e infecciosos $V_{I_{i}}$. Assumimos que quando infectados ficam neste estado até morrerem.

O modelo é formado por 27 compartimentos incluindo a dinâmica dos vetores (mosquitos) e é formulado pelas seguintes equações diferenciais:

$$
\left.\begin{array}{rl}
S^{\prime} & =\mu(N-S)-\frac{\lambda_{v}}{N}\left(\sum_{i=1}^{2} V_{I_{i}}\right) S, \\
E_{i}^{\prime} & =\frac{\lambda_{v}}{N} V_{I_{i}} S-\left(\mu+\sigma_{I}\right) E_{i}, \\
I_{i}^{\prime} & =\sigma_{I} E_{i}-\left(\mu+\sigma_{C}\right) I_{i}, \\
C_{i}^{\prime} & =\sigma_{C} I_{i}-\left(\mu+\sigma_{A}\right) C_{i}, \\
A_{i}^{\prime} & =\sigma_{A} V_{I_{j}} C_{i}-\left(\mu+\frac{\lambda_{v}}{N} V_{I_{j}}+\sigma_{S}\right) A_{i}, \\
E_{A_{i}}^{\prime} & =\frac{\lambda_{v}}{N} V_{I_{j}} A_{i}-\left(\mu+\sigma_{H}\right) E_{A_{i}}, \\
H_{i j}^{\prime} & =\sigma_{H} E_{A_{i}}-\left(\mu+\sigma_{R_{H}}\right) H_{i j}, \\
S_{i}^{\prime} & =\sigma_{S} A_{i}-\left(\mu+\frac{\lambda_{v}}{N} V_{I_{j}}\right) S_{i}, \\
E_{i j}^{\prime} & =\frac{\lambda_{v}}{N} V_{I_{j}} S_{i}-\left(\mu+\sigma_{I}\right) E_{i j}, \\
I_{i j}^{\prime} & =\sigma_{I} E_{i j}-\left(\mu+\sigma_{R}\right) I_{i j}, \\
S_{i j}^{\prime} & =\sigma_{R} I_{i j}+\sigma_{R_{H}} H_{i j}-\mu S_{i j}, \\
V_{S}^{\prime} & =r(t) V-d(t) V_{S}-\frac{\lambda_{h}}{N}\left[\sum_{i=1}^{2} I_{i}+\sum_{\substack{i, j=1 \\
i \neq j}}^{2}\left(I_{i j}+\alpha H_{i j}\right)\right] V_{S},
\end{array}\right]
$$




$$
\begin{aligned}
V_{E_{i}}^{\prime} & =\frac{\lambda_{h}}{N}\left(I_{i}+I_{j i}+\alpha H_{j i}\right) V_{s}-[d(t)+\gamma(t)] V_{E_{i}}, \\
V_{I_{i}}^{\prime} & =\gamma(t) V_{E_{i}}-d(t) V_{I_{i}} .
\end{aligned}
$$

A Fig. 7.2 ilustra a interação entre esses compartimentos ${ }^{3}$. A Tab. 7.1 resume o significado dos compartimentos enquanto que a Tab. 7.2 fornece os significados e os valores dos parâmetros do modelo.

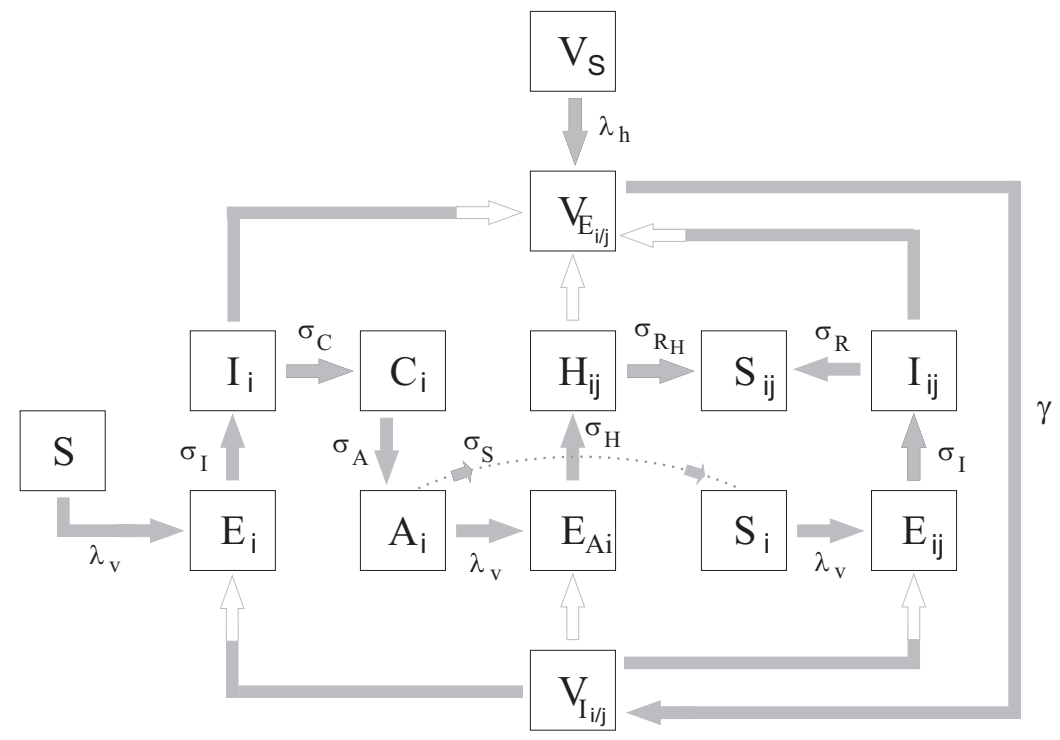

Figura 7.2: Representação esquemática da dinâmica de transmissão da dengue para dois sorotipos. As transições entre os compartimentos definidos na Tab. 7.1 são regidos por taxas mostradas na Tab. 7.2.

\subsection{Implementação numérica e resultados}

Implementamos o sistema de equações diferenciais em linguagem MatLab, e utilizamos a função $O D E$ solver que resolve as equações através do método de RungeKutta de quarta ordem. Os valores de entrada são: parâmetros mostrados na Tabela 7.2; número de indivíduos iniciais em cada compartimento e número total de hospedeiros e vetores.

No programa podemos incluir um novo sorotipo a qualquer momento. Tal inclusão é feita através da adição de hospedeiros ou vetores infecciosos.

\footnotetext{
${ }^{3}$ Note que as setas preenchidas de cor cinza indicam as transições entre compartimentos enquanto que as setas com as pontas não preenchidas (brancas) indicam a interação entre compartimentos.
} 
Tabela 7.1: Compartimentos do modelo de transmissão da dengue e seus respectivos significados.

\begin{tabular}{ll} 
Compartimento & Definição \\
\hline$S$ & hospedeiros susceptíveis \\
$E_{i}$ & hospedeiros expostos ao sorotipo $i$ \\
$I_{i}$ & hospedeiros infecciosos com sorotipo $i$ \\
$C_{i}$ & hospedeiros infectados com sorotipo $i$ e com imunidade ao sorotipo $j$ \\
$A_{i}$ & hospedeiros infectados com sorotipo $i$ que podem contrair dengue hemorrágica \\
$S_{i}$ & hospedeiros recuperados do sorotipo $i$ e susceptíveis ao $j$ \\
$E_{i j}$ & hospedeiros recuperados do sorotipo $i$ e expostos ao $j$ \\
$I_{i j}$ & hospedeiros recuperados do sorotipo $i$ e infecciosos com $j$ \\
$E_{A_{i}}$ & hospedeiros expostos ao sorotipo $j$ que irão evoluir para dengue hemorrágica \\
$H_{i j}$ & hospedeiros infecciosos com sorotipo $j$ e com dengue hemorrágica \\
$S_{i j}$ & hospedeiros recuperados de ambos sorotipos \\
$V_{S}$ & vetores susceptíveis \\
$V_{E_{i}}$ & vetores expostos ao sorotipo $i$ \\
$V_{I_{i}}$ & vetores infecciosos com sorotipo $i$ \\
\hline &
\end{tabular}

Para ilustrar a emergência da dengue hemorrágica, resolvemos numericamente o sistema de equações diferenciais considerando inicialmente 10 indivíduos infectantes com sorotipo 1. Assumimos populações fixas de $10^{6}$ indivíduos e $10^{5}$ mosquitos. Para a Fig. 7.3 a introdução de 10 indivíduos infectantes com sorotipo 2 ocorre 300 anos após a introdução do primeiro sorotipo. O longo intervalo entre os dois sorotipos, teve como intuito verificar a influência de um novo sorotipo após o estado estacionário ter sido atingido para o sorotipo anterior.

Pelos gráficos da Fig. 7.3 notamos que após cada epidemia há um decréscimo abrupto de indivíduos susceptíveis, tanto hospedeiros quanto vetores. Isso promove um intervalo entre as epidemias. Apesar de não considerarmos no modelo nenhum método preventivo contra a dengue e assumirmos a população total de vetores e hospedeiros constante, a periodicidade das epidemias emerge naturalmente no sistema. A dengue hemorrágica aparece quando o segundo sorotipo é introduzido. Note que 
Tabela 7.2: Parâmetros do modelo de transmissão da dengue e seus respectivos significados e unidades. A constante $\alpha$ refere-se ao fato de que indivíduos com dengue hemorrágica possuem uma carga viral maior, portanto possuem maior probabilidade de infectar um mosquito. Note também que a princípio utilizamos valores constantes para $r(t), d(t)$ e $\gamma(t)$.

\begin{tabular}{lll}
\hline Parâmetro & Definição & Valor \\
\hline $1 / \mu$ & expectativa de vida dos hospedeiros & $65 \mathrm{anos}$ \\
$r(t)$ & taxa de natalidade dos vetores no tempo $t$ & $1 / 30 \mathrm{dia}^{-1}$ \\
$d(t)$ & taxa de mortalidade dos vetores no tempo $t$ & $1 / 30 \mathrm{dia}^{-1}$ \\
$1 / \gamma(t)$ & tempo que o vetor fica no compartimento $V_{E_{i}}$ no tempo $t$ & 7 dias \\
$\lambda_{v}$ & taxa de infecção de hospedeiros por vetor por tempo & 1 hosp. $\times$ vetor $^{-1} \times t^{-1}$ \\
$\lambda_{h}$ & taxa de infecção de vetores por hospedeiro por tempo & 1 hosp. $\times$ vetor $^{-1} \times t^{-1}$ \\
$1 / \sigma_{I}$ & tempo que o hospedeiro fica no compartimento $E_{i}$ & 6 dias \\
$1 / \sigma_{C}$ & tempo que o hospedeiro fica no compartimento $I_{i}$ & 6 dias \\
$1 / \sigma_{A}$ & tempo que o hospedeiro fica no compartimento $C_{i}$ & 3 dias \\
$1 / \sigma_{S}$ & tempo que o hospedeiro fica no compartimento $A_{i}$ & 6 dias \\
$1 / \sigma_{H}$ & tempo que o hospedeiro fica no compartimento $E_{A_{i}}$ & 6 dias \\
$1 / \sigma_{R_{H}}$ & tempo que o hospedeiro fica no compartimento $H_{i j}$ & $\frac{1}{\sigma_{C}}+\frac{1}{\sigma_{A}}+\frac{1}{\sigma_{S}}$ dias \\
$1 / \sigma_{R}$ & tempo que o hospedeiro fica no compartimento $I_{i j}$ & $1 / \sigma_{R_{H}}$ dias \\
$\alpha$ & efeito de amplificação da infecção & 1,1 \\
\hline
\end{tabular}

para estes casos $\left(H_{12}\right.$ e $\left.H_{21}\right)$ a periodicidade também ocorre.

O estado estacionário, após a introdução do primeiro sorotipo, caracteriza uma endemia de dengue. Ou seja, apesar de não haver surtos da doença, uma pequena parcela da população mantém o vírus circulando. Uma nova epidemia surge apenas quando o novo sorotipo é introduzido. Interessante notar que, junto com a introdução do novo sorotipo, voltam a aparecer novas epidemias do antigo sorotipo, Isso sugere que a introdução do novo sorotipo abala o equilíbrio endêmico do sorotipo anterior. A introdução do novo sorotipo também diminui o número total de indivíduos susceptíveis da população.

A Fig. 7.4 mostra o comportamento do sistema quando a introdução do segundo 

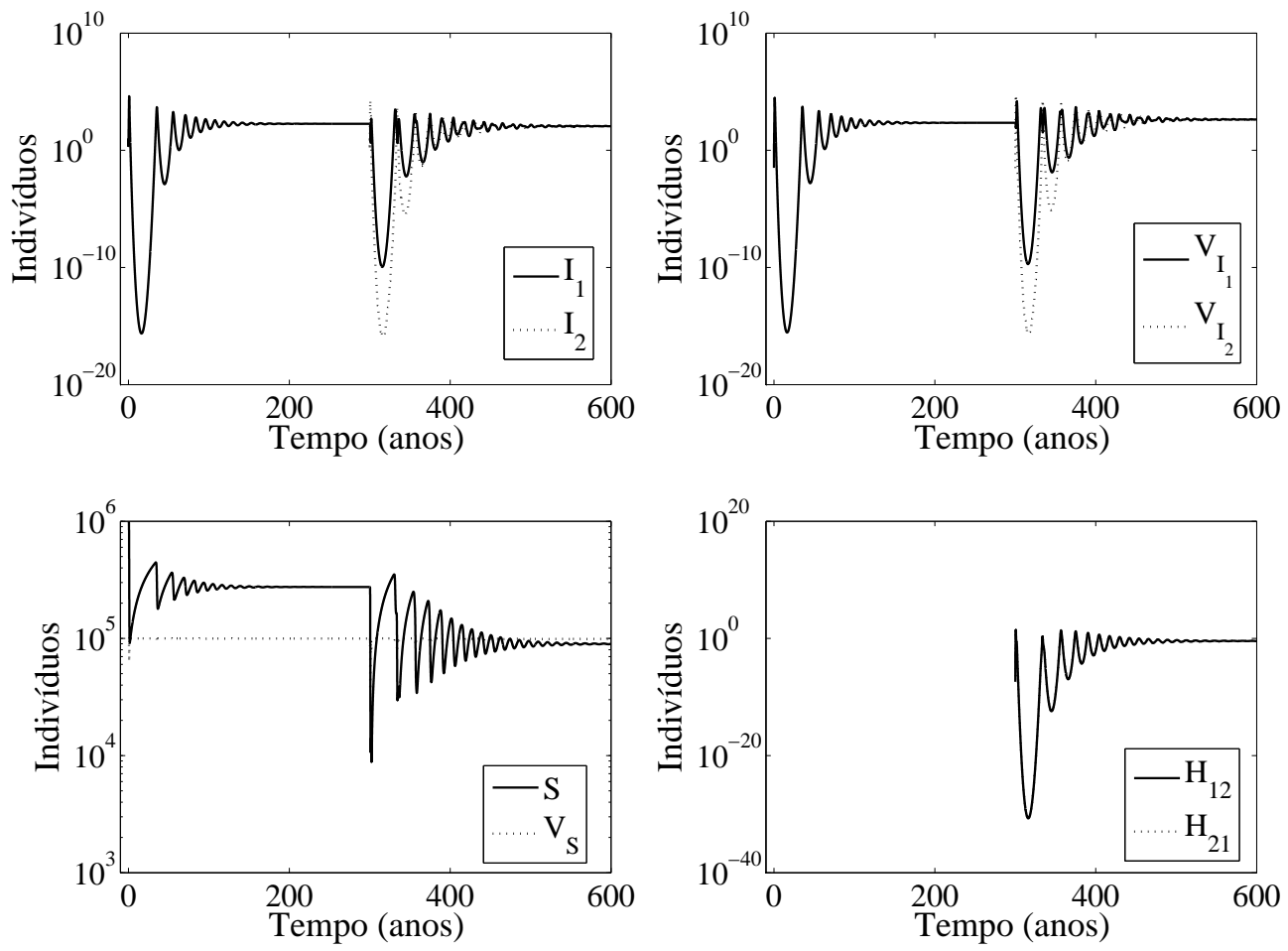

Figura 7.3: Número de indivíduos ao longo do tempo para os compartimentos: $I_{1}$, $I_{2}, V_{I_{1}}, V_{I_{2}}, S, V_{S}, H_{12}$ e $H_{21}$. Um segundo sorotipo é introduzido 300 anos após o primeiro.

sorotipo é feita um ano após o primeiro.

Verifica-se pelos gráficos, oscilações das epidemias porém em um regime não muito bem definido, com períodos variáveis. Isso é típico das epidemias de dengue encontradas nas grandes cidades, conforme descrito na introdução deste capítulo. Importante notar que apesar das epidemias de um único sorotipo $\left(I_{1}\right.$ ou $\left.I_{2}\right)$ não possuírem um período definido, as epidemias simultâneas $\left(I_{1}\right.$ e $\left.I_{2}\right)$ possuem um comportamento mais regular. O reflexo desse comportamento pode ser visto na maior regularidade nos picos de casos de dengue hemorrágica $\left(H_{12}\right.$ e $\left.H_{21}\right)$.

\subsection{Conclusão}

O efeito do reforço é a teoria mais aceita atualmente que explica a emergência da dengue hemorrágica. O modelo de disseminação da dengue para dois sorotipos aqui proposto permite obter as curvas de epidemia, tanto para um sorotipo quanto 

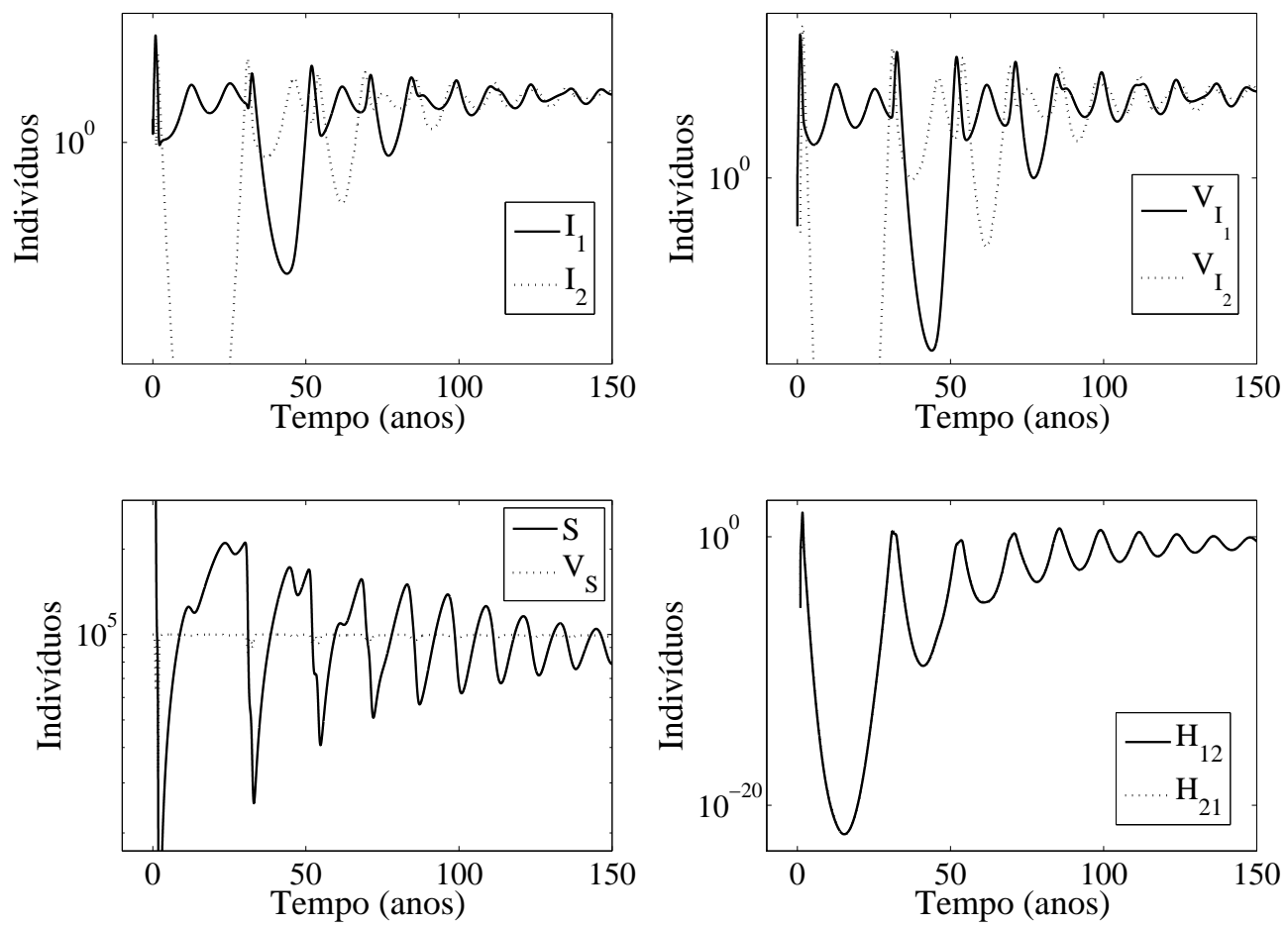

Figura 7.4: Número de indivíduos ao longo do tempo para os compartimentos: $I_{1}$, $I_{2}, V_{I_{1}}, V_{I_{2}}, S, V_{S}, H_{12}$ e $H_{21}$. Um segundo sorotipo é introduzido 1 ano após o primeiro.

para a dengue hemorrágica. Os casos de dengue hemorrágica estão mais associados às internações devido a sua severidade. O conhecimento prévio do comportamento dessas epidemias mais severas pode possibilitar políticas públicas de saúde de combate ao vetor mais intensa e possibilitar um planejamento do número de leitos em hospitais para suprir a demanda de internações.

Focamos nossa análise em grandezas qualitativas como surgimento de epidemias, endemias, periodicidade e emergência da dengue hemorrágica. Há uma forte dependência, em termos quantitativos, do número total de vetores e hospedeiros do sistema . Uma análise mais detalhada do modelo ainda precisa ser feita. As implementações e estudos a serem realizados são detalhados no Cap. 11. 


\section{Capítulo}

\section{Abordagem probabilística em modelos de disseminação de doenças transmitidas por vetores}

Do ponto de vista de doenças infecciosas, os vetores são os transmissores de organismos causadores de doenças que levam os agentes patogênicos de um hospedeiro para outro. Pelo uso comum, os vetores são considerados animais invertebrados, geralmente artrópodes. Artrópodes representam mais de $85 \%$ por cento de todas as espécies animais conhecidas, e eles são os vetores das doenças mais importantes. Vários gêneros de artrópodes desempenham um papel na doença em humanos, mas os mosquitos e carrapatos são os vetores de doenças mais notáveis. O modo mais significativo de transmissão de doenças é o de transmissão por artrópodes hematófagos. O patógeno se multiplica dentro do artrópode, e é transmitido quando o artrópode se alimenta do sangue. Os principais componentes que determinam a ocorrência de doenças transmitidas por vetores incluem: a abundância de vetores e hospedeiros intermediários assim como a quantidade de reservatórios, a prevalência da doença de patógenos causadores devidamente adaptados aos vetores e do hospedeiro humano ou animal, as condições ambientais locais, especialmente temperatura e umidade e do estado imunológico da população humana.

Suponha que uma dada doença seja transmitida ao hospedeiro através da picada de um determinado vetor. Considere uma população com $N$ hospedeiros, e que estes estejam distribuídos entre os vetores. O número total de picadas de todos os vetores juntos é dado por $b$. Assumindo que os vetores estão distribuídos homogeneamente 
entre os hospedeiros, surge a questão: quantos hospedeiros, em média, serão infectados? Para responder a essa pergunta, podemos fazer uma analogia com o problema clássico de retirar bolas de uma urna. Dada uma urna com $N$ bolas de cores diferentes e $b$ amostragens com reposição, quantas cores diferentes são obtidas? A solução para esta questão será descrita na Sec. 8.1. Alguns resultados preliminares são apresentados na Sec. 8.2 e os comentários finais na Sec. 8.3.

\subsection{Cálculo do número médio de indivíduos infec- tados}

Considere uma urna com $N$ bolas distintas (cores diferentes). Dessa urna, retiram-se $b$ bolas, uma de cada vez, em uma amostragem com reposição. Perguntase: Em média, quantas bolas diferentes são retiradas? Esse valor pode ser calculado pela equação:

$$
\bar{x}(N, b)=\frac{\sum_{x=1}^{x_{\max }} x \Omega_{x}}{\sum_{x=1}^{x_{\max }} \Omega_{x}}=\frac{\sum_{x=1}^{x_{\max }} x \Omega_{x}}{N^{b}}
$$

em que $\Omega_{x}$ é o número de maneiras distintas que podemos observar a ocorrência de exatamente $x$ bolas distintas quaisquer nas $b$ bolas retiradas e $x_{\max }=\min (N, b)$. Para calcularmos os valores de $\Omega_{x}$ analisemos inicialmente alguns casos particulares.

\subsubsection{Urna com duas bolas distintas e seis amostragens}

Suponha que a urna possua apenas duas bolas, uma branca e outra cinza. Na Fig. 8.1(a) estão representados os possíveis resultados, onde $b_{1}$ representa o número de bolas brancas e $b_{2}$ o número de bolas cinzas. Cada um desses resultados pode ocorrer de $b ! /\left(b_{1} ! b_{2} !\right)$ maneiras diferentes (permutação de $b$ elementos, dos quais $b_{1}$ são do tipo 1 e $b_{2}$ do tipo 2). Esta expressão corresponde justamente à $b$-ésima linha do triângulo de Pascal, representado na Fig. 8.1(b). Na Fig. 8.1(c), vemos os possíveis valores assumidos por $b_{1}$ e $b_{2}$ representados num sistema de 2 eixos cartesianos.

Com seis retiradas de uma urna com duas bolas distintas, o valor médio de cores distintas retiradas é obtido pela Eq. 8.1 e seu valor é $\bar{x}(2,6)=\approx 1,97$. 


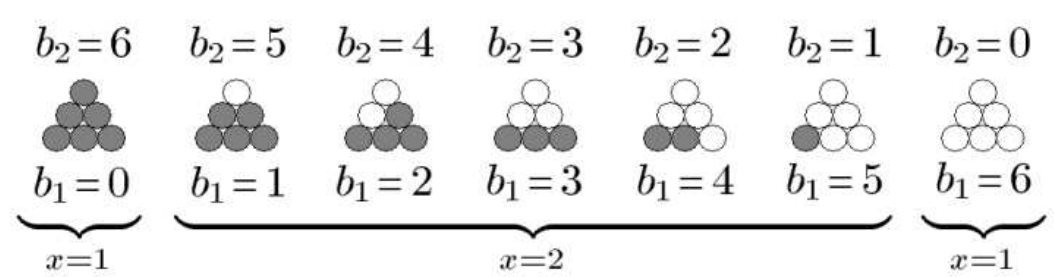

(a)

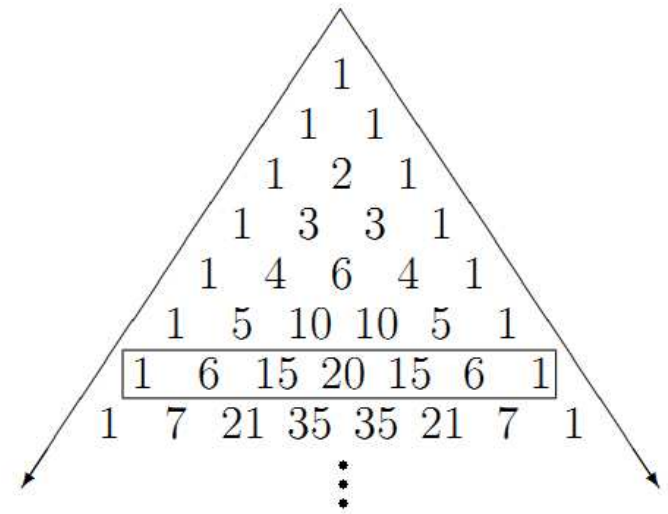

(b)

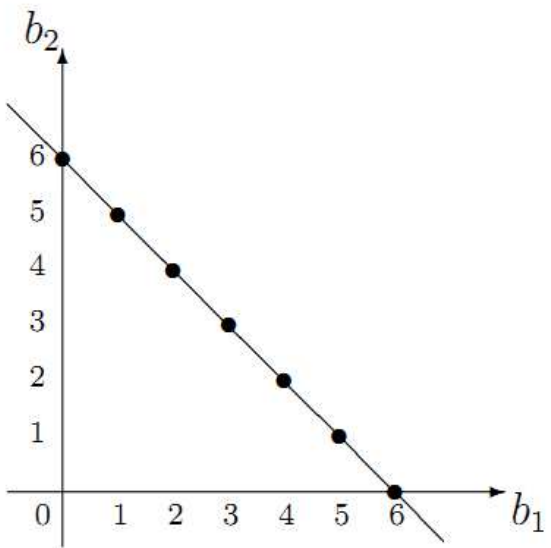

(c)

Figura 8.1: (a) Possíveis resultados para $b=6$ bolas retiradas de uma urna com $N=2$ bolas. (b) Primeiras 7 linhas do triângulo de Pascal, com a $7^{\text {a }}$ linha em destaque, cuja soma dos elementos é $2^{6}=64$. (c) Possíveis valores assumidos por $b_{1}$ e $b_{2}$ de modo a obedecerem as restrições $b_{1}+b_{2}=b, b_{1} \geq 0$ e $b_{2} \geq 0$.

\subsubsection{Urna com três bolas distintas e seis amostragens}

Suponha agora que a urna possua três bolas diferentes: branca, cinza e preta. A Fig. 8.2 representa os possíveis resultados para $b=6$ bolas retiradas de uma urna com $N=3$ bolas. Aqui $b_{1}$ representa o número de bolas brancas, $b_{2}$ o número de bolas pretas e $b_{3}$ o número de bolas cinzas. Observe que a última linha do triângulo da Fig. 8.2(a) corresponde exatamente à Fig. 8.1(a).

Cada resultado da Fig. 8.2 pode ocorrer de $b ! /\left(b_{1} ! b_{2} ! b_{3} !\right)$ maneiras diferentes. Esta expressão corresponde justamente à b-ésima camada da pirâmide de Pascal Fig. 8.3(a), uma generalização do triângulo de Pascal. Os possíveis valores assumidos por $b_{1}, b_{2}$ e $b_{3}$ através de um sistema de 3 eixos cartesianos estão representados na Fig. 8.3(b).

Com seis retiradas de uma urna com três bolas distintas, o valor médio de cores 


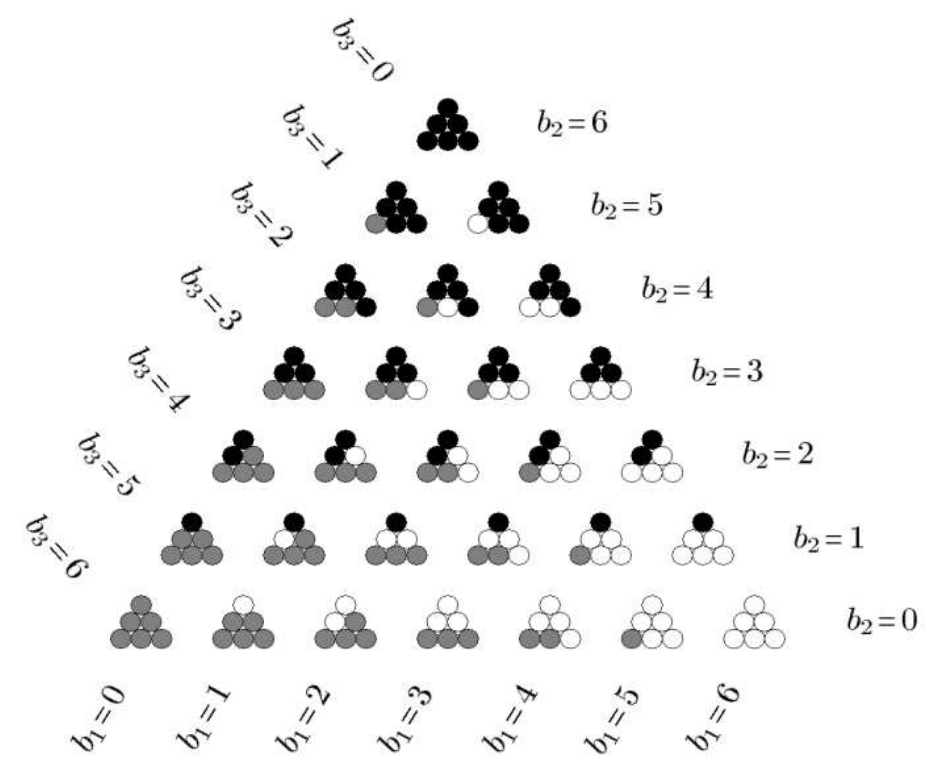

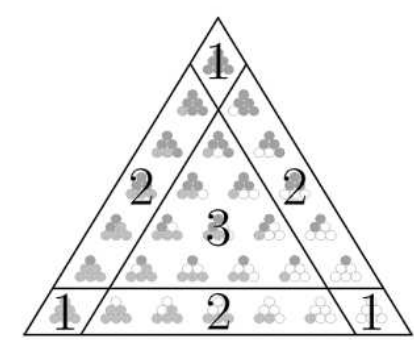

(b)

(a)

Figura 8.2: (a) Possíveis resultados para $b=6$ bolas retiradas de uma urna com $N=3$ bolas. (b) Resultados estão agrupados segundo o número $x$ de cores.

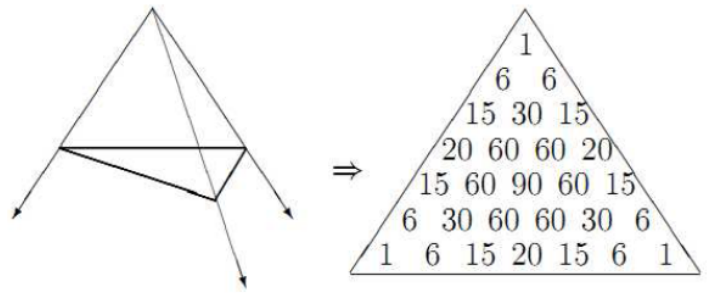

(a)

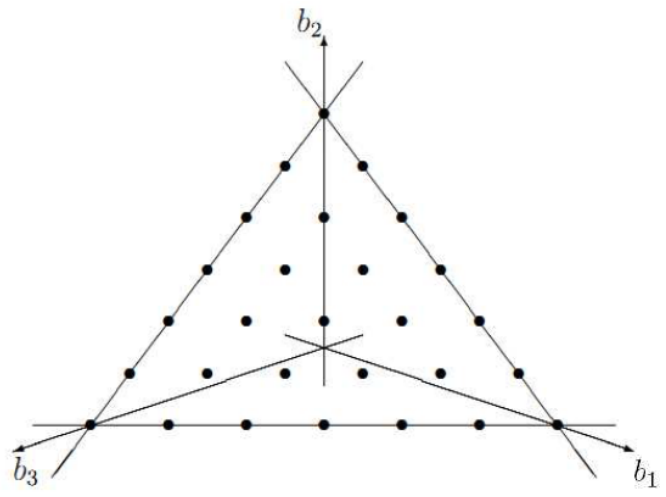

(b)

Figura 8.3: (a) Pirâmide de Pascal com a $7^{\mathrm{a}}$ camada em destaque, cuja soma dos elementos é $3^{6}=729$. (b) Possíveis valores de $b_{1}, b_{2}$ e $b_{3}$ representados através de um sistema de 3 eixos cartesianos, de modo a obedecer às restrições $b_{1}+b_{2}+b_{3}=b$, $b_{1} \geq 0, b_{2} \geq 0$ e $b_{3} \geq 0$.

distintas retiradas é $\bar{x}(3,6)=\approx 2,74$. 


\subsubsection{Urna com quatro bolas distintas e seis amostragens}

Considere agora que a urna com quatro bolas: branca, cinza claro, cinza escuro e preta. A Fig. 8.4 mostra a hiper-pirâmide de Pascal para o caso $N=4$ e $b=6$. Observe que a face visível esquerda do tetraedro da Fig. 8.4(a) corresponde exatamente ao triângulo da Fig. 8.2(a). Representando por $b_{1}, b_{2}, b_{3}$ e $b_{4}$ o número de bolas de cada tipo (cada cor), cada resultado pode ocorrer de $b ! /\left(b_{1} ! b_{2} ! b_{3} ! b_{4} !\right)$ maneiras diferentes. Esta expressão corresponde à $b$-ésima hiper-camada da hiper-pirâmide de Pascal Fig. 8.4(b) e (c).

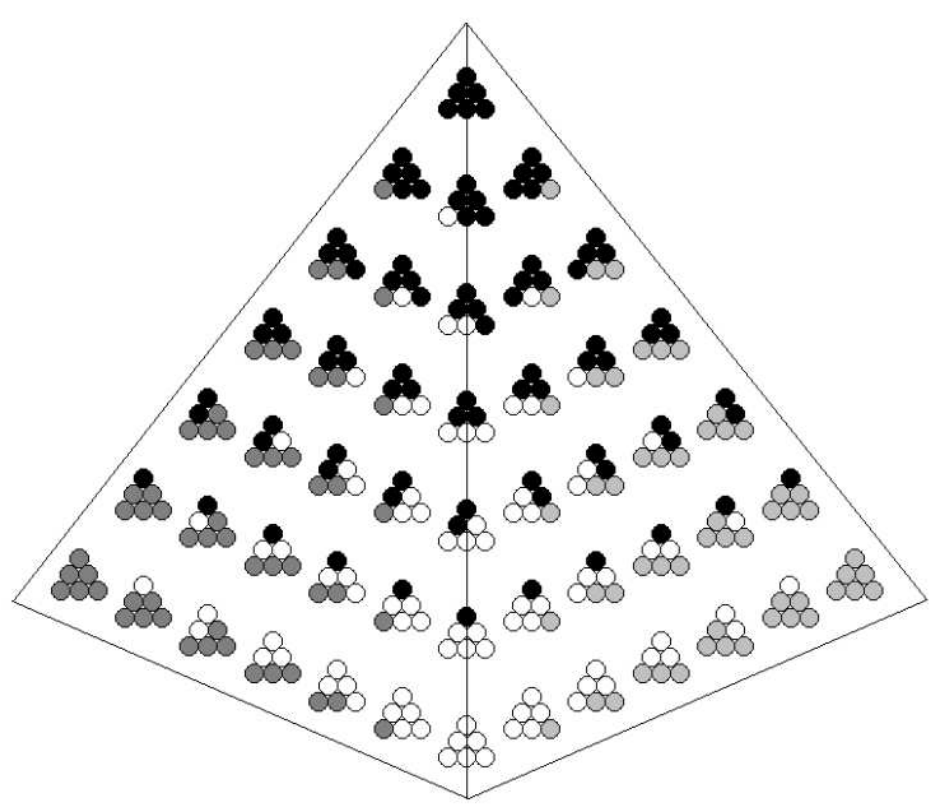

(a)

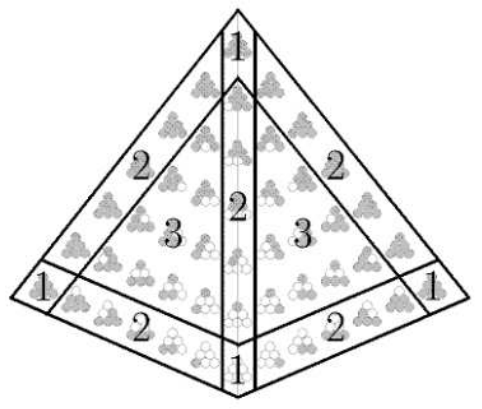

(b)

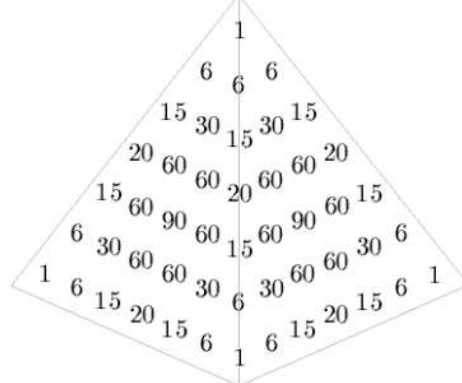

(c)

Figura 8.4: (a) Possíveis resultados para $b=6$ retiradas de uma urna com $N=$ 4 bolas. (b) Resultados estão agrupados segundo o número $x$ de cores. (c) $7^{\mathrm{a}}$ camada da hiper-pirâmide de Pascal, cuja soma de seus elementos é $4^{6}=4096$.

Com 6 retiradas de uma urna com 4 bolas distintas, o valor médio de cores distintas retiradas é $\bar{x}(4,6)=\approx 3,29$

O fator crucial para o cálculo de $\bar{x}(N, b)$ é a obtenção do número de microestados para $x$, ou seja, $\Omega_{x}$. A seguir mostramos como calcular esse valor para $N$ e $b$ arbitrários. 


\subsubsection{Urna com $N$ bolas distintas e $b$ amostragens}

Como as $N$ bolas da urna são todas distintas (de cores diferentes), a quantidade total de cores disponíveis na urna também é $N$. Dessas $N$ cores disponíveis, apenas $x$ cores comporão a amostra final (as demais $N-x$ cores, ou bolas, não serão selecionadas em nenhuma das $b$ retiradas). Portanto, a quantidade $\Omega_{x, 1}$ de possíveis paletas com exatamente $x$ cores, obtidas a partir das $N$ cores disponíveis na urna, é dada pelo binômio:

$$
\Omega_{x, 1}=\left(\begin{array}{c}
N \\
x
\end{array}\right)
$$

Devemos também calcular a quantidade $\Omega_{x, 2}$ de maneiras que uma determinada paleta pode ocorrer. Denotando por $b_{i}$ a quantidade de bolas da cor $i$ (com $1 \leq i \leq$ $x$ ) observadas após as $b$ retiradas temos as seguintes restrições:

$$
\sum_{i=1}^{x} b_{i}=b
$$

em que $b_{i} \geq 1$. Para a ocorrência de uma paleta particular é necessário que cada uma das $x$ cores que a compõem ocorra ao menos uma vez. Concluímos, então, que $\Omega_{x, 2}$ é dado pelo somatório de todas as possíveis permutações de $b$ elementos, classificados em $x$ categorias, com $b_{i}$ repetições em cada categoria $i$.

$$
\Omega_{x, 2}=\sum_{\Sigma_{i} b_{i}=b} \frac{b !}{\prod_{i} b_{i} !} \quad \text { com } b_{i} \geq 1,1 \leq i \leq x .
$$

A Eq. 8.2 define no espaço $x$-dimensional um hiperplano e, em conjunto com as restrições $b_{i} \geq 1$, define um $(x-1)$-simplex ${ }^{1}$.

Variando os valores dos $b_{i}$ 's na Eq. 8.3 obtemos a $b$-ésima hiper-camada da hiperpirâmide de Pascal, que é um $(x-1)$-simplex e apresenta as seguintes propriedades:

- os elementos de seus vértices (0-face) são iguais a 1;

- cada aresta (1-face) corresponde à b-ésima linha do triângulo de pascal;

- cada face (2-face) corresponde à b-ésima camada da pirâmide de pascal;

\footnotetext{
${ }^{1}$ Em topologia, um simplex é uma generalização do conceito de triângulo a outras dimensões.Ele é chamado assim por ser sempre o polígono mais simples de sua dimensão, isto é, um triângulo (2D) é o polígono que possui menos vértices e arestas, o tetraedro (3D) é o que possui menos vértices e arestas e faces e assim por diante.
} 
- cada célula (3-face) corresponde à b-ésima hiper-camada da hiper-pirâmide de pascal;

- cada $n$-face corresponde a um $n$-simplex;

- a soma de todos os seus elementos é igual a $x^{b}$.

Assim, $\Omega_{x}$ é dado por:

$$
\Omega_{x}=\Omega_{x, 1} \Omega_{x, 2}=\left(\begin{array}{c}
N \\
x
\end{array}\right) \sum_{\Sigma_{i} b_{i}=b} \frac{b !}{\prod_{i} b_{i} !}, \quad b_{i} \geq 1, \quad 1 \leq i \leq x
$$

Que também pode ser escrito da seguinte forma:

$$
\Omega_{x}=\left(\begin{array}{c}
N \\
x
\end{array}\right) f_{b}(x)
$$

em que

$$
f_{b}(x)=x^{b}-\sum_{i=1}^{x-1}\left(\begin{array}{l}
x \\
i
\end{array}\right) f_{b}(i)
$$

O número de microestados $\Omega_{x}$, que conta as possibilidades em que que $x$ indivíduos são infectados, é dado pela soma dos elementos das $(x-1)$-faces (ver Tab.8.1) da $(b+1)$ fatia da hiper-pirâmide $N$-dimensional de Pascal.

O interior (miolo) de um $\Delta_{n}$ pode ser obtido calculando-se a retro-diferença finita de $n$-ésima ordem $\nabla^{n}$.

A retro-diferença finita de $n$-ésima ordem de uma função $f(x)$ é dada por

$$
\nabla_{h}^{n}[f](x)=\sum_{i=0}^{n}(-1)^{i}\left(\begin{array}{c}
n \\
i
\end{array}\right) f(x-i h)
$$

onde $h$ é o espaçamento. Fazendo $h=1$ e escolhendo $f(x)=x^{b}$, o miolo $\left(\Omega_{2}\right)$ é calculado fazendo $x=n$ :

$$
\nabla^{n}=\left[\nabla_{1}^{n}[f](x)\right]_{x=n}=\sum_{i=0}^{n}(-1)^{i}\left(\begin{array}{c}
n \\
i
\end{array}\right)(n-i)^{b}
$$


Tabela 8.1: Número de faces de um $n$-simplex.

\begin{tabular}{|c|c|c|c|c|c|c|c|}
\hline Simplex & $\begin{array}{c}\text { 0-faces } \\
\text { (vértices) }\end{array}$ & $\begin{array}{l}\text { 1-faces } \\
\text { (arestas) }\end{array}$ & $\begin{array}{l}2 \text {-faces } \\
\text { (faces) }\end{array}$ & $\begin{array}{c}\text { 3-faces } \\
\text { (células) }\end{array}$ & 4 -faces & 5 -faces & representação vetorial \\
\hline$\Delta_{0}($ ponto $)$ & 1 & & & & & & $(1,0,0,0,0,0)$ \\
\hline$\Delta_{1}$ (segmento de reta) & 2 & 1 & & & & & $(2,1,0,0,0,0)$ \\
\hline$\Delta_{2}$ (triângulo) & 3 & 3 & 1 & & & & $(3,3,1,0,0,0)$ \\
\hline$\Delta_{3}($ tetraedro $)$ & 4 & 6 & 4 & 1 & & & $(4,6,4,1,0,0)$ \\
\hline$\Delta_{4}$ & 5 & 10 & 10 & 5 & 1 & & $(5,10,10,5,1,0)$ \\
\hline$\Delta_{5}$ & 6 & 15 & 20 & 15 & 6 & 1 & $(6,15,20,15,6,1)$ \\
\hline
\end{tabular}

Assim, a função $f_{b}(x)$ também pode ser escrita como a seguinte soma alternada:

$$
f_{b}(x)=\sum_{i=0}^{x-1}(-1)^{i}\left(\begin{array}{l}
x \\
i
\end{array}\right)(x-i)^{b} .
$$

A seguir mostramos os gráficos dos valores de $\bar{x}(N, b)$ utilizando as Eqs. 8.1, 8.6 e 8.10 .

\subsection{Resultados e discussão}

O gráfico para o valor de $\bar{x}(N, b)$ em função de $b$ para diferentes valores de $N$ é apresentado na Fig. 8.5.

Verificamos que essas curvas podem ser aproximadas pela seguinte expressão:

$$
\bar{x}(N, b)=N\left(1-e^{-b / N}\right)
$$

No contexto do estudo do Cap. 4, também é possível obter o colapso de dados para esta curva ao fazermos:

$$
\ln \left[\frac{N}{N-\bar{x}(N, b)}\right]=\frac{b}{N} .
$$

Esse colapso remete à teoria apresentada no Cap. 4 . 


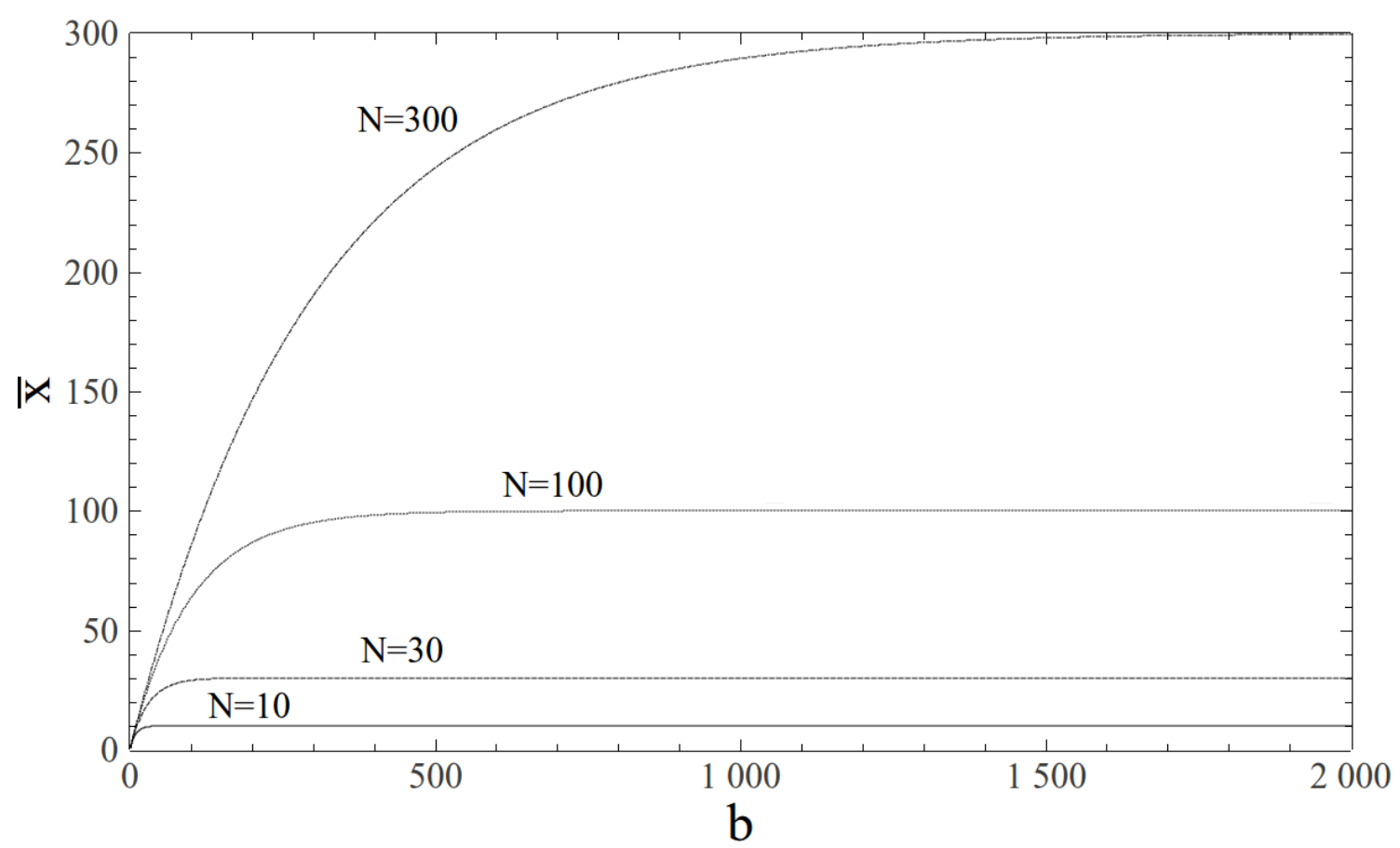

Figura 8.5: O gráfico para o valor de $\bar{x}(N, b)$ em função de $b$ para diferentes valores de $N$.

\subsection{Conclusão}

Em doenças transmitidas por vetores, o número de vezes que o vetor se alimenta (picadas) é um parâmetro importante quando queremos saber o número médio de indivíduos que serão infectados. A analogia feita entre a dinâmica de transmissão e o sorteio de bolas de uma urna, possibilitou a resolução do problema utilizando conceitos de probabilidade. Apesar dessa abordagem ainda estar em estudo no momento, a resolução desse problema aparentemente simples, revelou ser muito rica ao relacionar geometria multi-dimensional com conceitos de probabilidade e estatística. O número de indivíduos $N$ está relacionado à dimensionalidade da hiper-pirâmide de Pascal enquanto que o número amostragens $b$ tem relação com a camada dessa hiper-pirâmide. Os elementos dessa hiper-pirâmide: vértices, arestas, faces, etc. relaciona-se com o número de microestados para um dado número de infectados. A partir da curva de ajuste dos dados verificou-se que é possível obter o colapso dessas curvas, revelando um comportamento padrão que independe de $N$ e $b$. Algumas modificações ainda podem ser feitas ao considerar "pesos" ao microestados e dessa forma mimetizar uma mistura não homogênea entre vetores e hospedeiros. 
1028 - Abordagem probabilística em modelos de disseminação de doenças transmitidas por vetores 


\section{Capítulo}

\section{Modelo baseado em agentes para a disseminação da tuberculose.}

De acordo com a Organização Mundial de Saúde, mais de dois bilhões de pessoas estão infectadas com M. tuberculosis [102], a bactéria que causa a Tuberculose (TB). Esta doença é responsável por mais mortes entre adultos que todas as outras infecções juntas $[103,104]$. Portanto, programas eficazes para o controle global da tuberculose se fazem necessários.

Modelos matemáticos têm sido utilizados para estudar a dinâmica de epidemias como uma tentativa de predizer seus comportamentos e controlá-las através de vacinação e programas de saúde pública. A maioria destes modelos descreve o comportamento de uma dada doença através de equações diferenciais ordinárias (EDOs) e as transições entre os estados da doença considerada são regidas por taxas [2]. Estas aproximações matemáticas e computacionais têm sido aplicadas para compreender um grande problema de saúde pública: a tuberculose. A fim de auxiliar no desenvolvimento de políticas de saúde pública, alguns modelos matemáticos para estudo da TB foram implementados. Utilizando EDOs, foram realizadas simulações computacionais para compreender a dinâmica de disseminação da tuberculose assim como para verificar a prevalência e emergência da resistência à droga devido ao tratamento com antibióticos [104, 105, 106, 107]. Nas referências [104, 105, 106, 107], Blower e seus colaboradores estudaram a prevalência da TB sob diferentes regimes de tratamento. Além do tratamento, também é estudada uma terapia preventiva, denominada quimioprofilaxia, à qual pessoas são submetidas enquanto no estado de latência. Esta terapia tem por objetivo evitar o progresso da doença, impedindo 
que o paciente atinja o estado ativo da doença. Além disso, levam-se em conta a emergência da resistência à droga devido a tratamentos com antibióticos.

Tomando este modelo baseado em EDOs como referência, nós propomos um modelo computacional alternativo baseado em agentes para estudar as dinâmicas da TB e emergência de resistência à droga. Nossa aproximação oferece a possibilidade de representar explicitamente as heterogeneidades em um nível individual, permitindo visualizar os padrões espaciais da disseminação da TB.

Este capítulo está organizado da seguinte forma. Na Sec. 9.1, nós apresentamos o modelo de Blower et al. [104]. A Seção 9.2 é voltada à explicação do modelo baseado em agentes para TB. A implementação do modelo computacional ${ }^{1}$, assim como alguns resultados obtidos ${ }^{2}$, são discutidos na seção 9.3. A exploração do espaço de parâmetros é feita na Sec. 9.4 Considerações finais e possíveis extensões deste modelo são apresentadas na Sec. 9.5.

\subsection{Modelagem da tuberculose}

Blower et al. desenvolveram um modelo compartimental da disseminação da tuberculose em uma população [104, 105, 106, 107], no qual cada um dos estados da doença é definido como um compartimento. Indivíduos que estão em um mesmo estado pertencem a um mesmo compartimento, ou seja, suscetível $(X)$, latente $\left(L_{i}\right)$, infectado de forma latente que recebeu efetivamente quimioprofilaxia $\left(C_{S}\right)$, infecciosos $\left(T_{i}\right)$ e indivíduos efetivamente tratados $\left(E_{i}\right)$. Os subscritos $i$ definem se o patógeno é sensível $(i=S)$ ou resistente $(i=R)$ aos antibióticos.

O modelo compartimental consiste de oito equações diferenciais ordinárias (EDOs) que representam a dinâmica entre os compartimentos (Ver Refs. [104, 105, 106, 107] para mais detalhes).

Conforme descrito na Ref. [108], a modelagem baseada em EDOs utilizada por Blower e seus colaboradores apresenta algumas limitações, tais como assumir que a população está bem misturada, i.e., que há um movimento homogêneo entre as subpopulações e que cada indivíduo pode interagir com qualquer outro com a mesma probabilidade.

\footnotetext{
${ }^{1}$ Algoritmo computacional disponibilizado no sítio:sourceforge.net/projects/tuberculosis/files/

${ }^{2}$ Deste resultado foi publicado o artigo da Ref. [93]
} 
O modelo para o estudo do espalhamento da tuberculose, proposto neste capítulo, foi construído utilizando-se a modelagem baseada em agentes, que oferece a possibilidade de representar explicitamente heterogeneidades em nível individual. Este tipo de abordagem permite lidar com cada indivíduo em particular [109, 110, 111, 112], diferentemente dos modelos de equaões diferenciais, em que todos os indivíduos que estão em um mesmo compartimento interagem de forma semelhante, como em uma interação de campo médio. Por isso, daqui em diante, substituiremos o termo compartimento pelo termo estado, pois estaremos nos referindo ao estágio da doença de um único indivíduo.

\subsection{Evolução da doença}

Considera-se $I_{i j}$, com $(i, j)=\{1,2, \ldots, L\}$, um indivíduo disposto em um sítio de uma rede quadrada de lado $L$. O indivíduo $I_{i j}$ pertence a uma população de tamanho $N=L \times L$ e pode ter cinco estados possíveis: $I_{i j} \in\left\{X, L_{S}, L_{R}, T_{S}, T_{R}\right\}$. Se $I_{i j}=X$, o indivíduo é susceptível à tuberculose, i.e., não exposto ao patógeno que a causa. O indivíduo $I_{i j}=L_{k}$, com $k=S, R$, está em um estado de latência, ou exposto à bactéria que causa TB, mas ele(a) não está doente. O subscrito $k$ define se o patógeno é sensível $(S)$ ou resistente $(R)$ ao antibiótico. Por fim, o indivíduo $I_{i j}=T_{k}$, com $k=S, R$, é denominado infeccioso, i.e., este indivíduo tem tuberculose ativa podendo infectar outros indivíduos. Indivíduos podem sofrer transições probabilísticas entre estados do sistema. Os parâmetros principais que determinam essas transições são apresentados na Tab. 9.1. As transições entre os estados e suas respectivas probabilidades podem ser vistas no esquema mostrado na Figura 9.1.

Neste modelo, assumimos que os indivíduos curados ou mortos são substituídos na rede por indivíduos susceptíveis. Esta substituição é feita a fim de imitar a taxa de recrutamento ${ }^{3}$ utilizada em modelos por EDOs [104, 105, 106, 107]. Porém, os estados curado e morto não aparecem no esquema da Figura 9.1.

A seguir descrevemos cada estado do modelo e as dinâmicas de interações entre eles.

\footnotetext{
${ }^{3}$ Refere-se a taxa na qual novos indivíduos susceptíveis entram no sistema.
} 
Tabela 9.1: Descrição dos parâmetros do modelo de disseminação da tuberculose.

\begin{tabular}{ll}
\hline Parâmetros & Definições \\
\hline$\mu$ & probabilidade de morte natural \\
$\mu_{T}$ & probabilidade de morte devido à tuberculose \\
$p$ & probabilidade de desenvolver tuberculose ativa a partir do estado $X$ \\
$v$ & probabilidade de progresso da doença em indivíduos latentes \\
$\sigma$ & probabilidade de uma eficácia na terapia quimioprofilaxia \\
$\phi$ & probabilidade de tratamento eficaz para indivíduos infecciosos \\
$r$ & eficácia relativa do tratamento \\
$\delta$ & proporção de indivíduos latentes que são submetidos a quimioprofilaxia \\
$n_{L}$ & proporção de indivíduos infecciosos que são submetidos ao tratamento \\
$n_{T}$ &
\end{tabular}

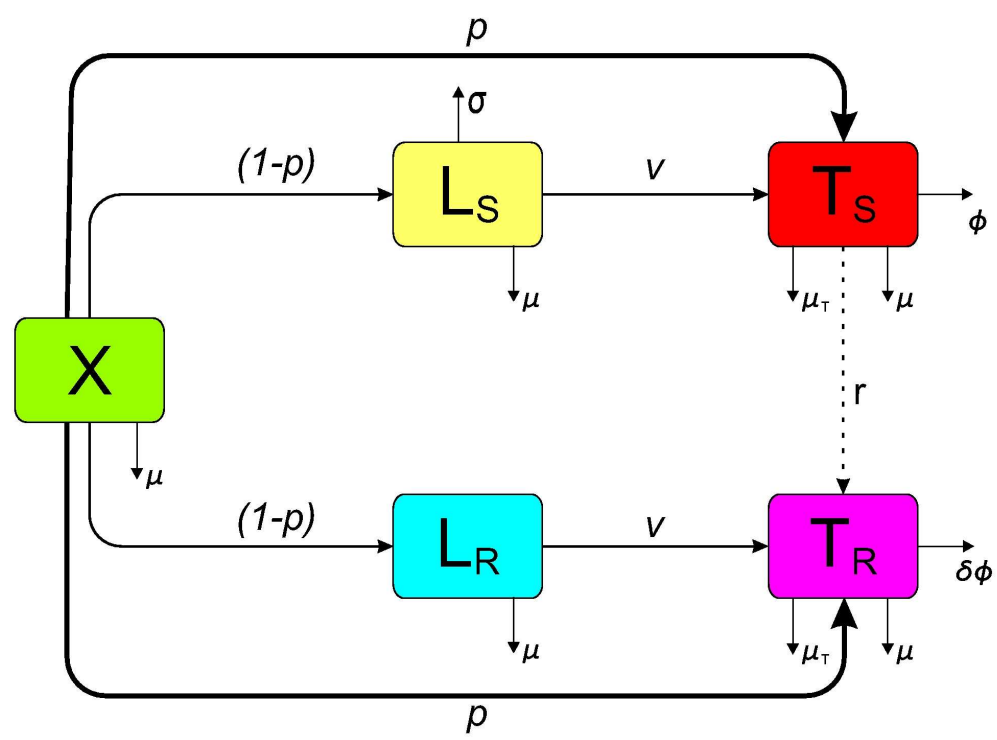

Figura 9.1: Representação esquemática da interação entre os cinco estados da tuberculose. Adaptada da Ref. [93] 


\subsubsection{Contágio de indivíduos susceptíveis}

Indivíduos no estado $X$ podem ser infectados com TB devido à presença de:

(i) vizinhos infecciosos $T_{S}$ e/ou $T_{R}$ (infecção de origem local); e

(ii) indivíduos infecciosos $T_{S}$ e/ou $T_{R}$ no restante da rede (infecção de origem global).

Note que em ambos os casos, somente indivíduos infecciosos $T_{S}$ ou $T_{R}$ sem tratamento podem transmitir a doença.

A existência de duas fontes de infecção significa que uma pessoa pode ser infectada por um indivíduo vizinho ou um não-vizinho infeccioso e esses eventos devem ocorrer a priori com diferentes probabilidades.

A probabilidade local de um indivíduo no estado $X$ estar infectado com a bactéria do tipo $S$ é dada por [113]:

$$
P_{\mathcal{L}_{S}}=1-\left(1-\beta_{S}\right)^{N_{T_{S}}}
$$

onde $\beta_{S}$ é a infecciosidade da bactéria do tipo $S$ e $N_{T_{S}}$ é o número de vizinhos infecciosos $^{4}$ sem tratamento no estado $T_{S}$. Da mesma forma que para Eq. 9.1, a infecção local pode também ser causada pela bactéria do tipo $R$ :

$$
P_{\mathcal{L}_{R}}=1-\left(1-\beta_{R}\right)^{N_{T_{R}}}
$$

onde $\beta_{R}=\alpha \beta_{S}$ é a infecciosidade do tipo $R$ de bacteria $^{5}$ e $N_{T_{R}}$ é o número de indivíduos infecciosos sem tratamento no estado $T_{R}$. Por fim, a probabilidade de infecção local devido aos dois tipos de bactéria é:

$$
P_{\mathcal{L}}=P_{\mathcal{L}_{S}}+P_{\mathcal{L}_{R}}-P_{\mathcal{L}_{S}} P_{\mathcal{L}_{R}}
$$

Na Eq. 9.3, a avaliação da probabilidade local leva em conta a concomitância dos eventos (coinfecção), já que eles não são mutualmente exclusivos. De qualquer forma, se ocorre coinfecção, nós assumimos que este indivíduo está infectado somente pela bactéria do tipo $R$.

\footnotetext{
${ }^{4}$ Em todas as simulações, para calcular probabilidades locais, nós consideramos a vizinhança de Moore (oito vizinhos) em torno do indivíduo no estado $X$.

${ }^{5}$ A Bactéria do tipo $R$ possui uma transmissividade mais baixa que o tipo $S$. Então, $0<\alpha<1$. Ver Refs. [114].
} 
Além da probabilidade de ser infectado pelos vizinhos, também há a probabilidade de contágio devido a indivíduos com TB no restante da rede. Assim, a probabilidade global de ser infectado pela bactéria do tipo $S$ é:

$$
P_{\mathcal{G}_{S}}=\beta_{S} \frac{T_{T_{S}}}{N}
$$

onde $T_{T_{S}}$ é o número total de indivíduos infecciosos $T_{S}$ sem tratamento na rede. Da mesma forma, a contribuição para a probabilidade global devido a indivíduos infecciosos com a bactéria do tipo $R$ é:

$$
P_{\mathcal{G}_{R}}=\beta_{R} \frac{T_{T_{R}}}{N}
$$

onde $T_{T_{R}}$ é o número total de indivíduos infecciosos $T_{R}$ sem tratamento na rede. Assim, a probabilidade global de se tornar infectado pelos dois tipos de bactéria é dada por:

$$
P_{\mathcal{G}}=P_{\mathcal{G}_{S}}+P_{\mathcal{G}_{R}}-P_{\mathcal{G}_{S}} P_{\mathcal{G}_{R}}
$$

Novamente, na Eq. 9.6, a avaliação da probabilidade local leva em conta a concomitância dos eventos (coinfecção).

As Eqs. 9.3 e 9.6 nos dão a probabilidade de que uma infecção seja causada por fontes locais ou globais, respectivamente. A intensidade destes efeitos, locais ou globais, pode ser ajustada pelo parâmetro $\Lambda$, onde $\Lambda \in[0,1]$. A grandeza $\Lambda$ é a intensidade dos efeitos locais de infecção e, consequentemente, $1-\Lambda$ está relacionada com seus efeitos globais. Dado este parâmetro, podemos expressar a probabilidade total de infecção como combinação linear de probabilidades locais e globais:

$$
P=\Lambda P_{\mathcal{L}}+(1-\Lambda) P_{\mathcal{G}}
$$

Para um indivíduo susceptível $X$ na rede, todas as probabilidades de infecção são calculados utilizando as Eqs. 9.1-9.7. Em seguida, um número aleatório $r n \in$ $[0,1] \subset \Re$ é gerado e comparado com a probabilidade total de infecção (Eq. 9.7). Se $r n<P$, a infecção ocorre; caso contrário, o indivíduo é mantido no estado $X$. Se a infecção ocorre, um novo número aleatório é gerado para escolher se a infecção será causada por fontes locais ou globais. Se $r n<\Lambda P_{\mathcal{L}} / P$, a fonte de infecção é local; caso contrário, é global. 
Em seguida definimos qual tipo de bactéria, $S$ ou $R$, é a causa da infecção. Conforme mencionado anteriormente, casos de coinfecção são considerados como uma infecção pela bactéria do tipo $R$. Portanto, a probabilidade local normalizada de ser infectado pela bactéria do tipo $S$ é:

$$
\tilde{P}_{\mathcal{L}_{S}}=\frac{P_{\mathcal{L}_{S}}\left(1-P_{\mathcal{L}_{R}}\right)}{P_{\mathcal{L}_{S}}+P_{\mathcal{L}_{R}}-P_{\mathcal{L}_{S}} P_{\mathcal{L}_{R}}}
$$

A probabilidae normalizada para o patógeno do tipo $R$ é simplesmente $\tilde{P}_{\mathcal{L}_{R}}=1$ $\tilde{P}_{\mathcal{L}_{S}}$, desde que os casos de coinfecção sejam considerados infecção do tipo $R$. Um número aleatório é comparado com o valor da Eq. 9.8, se $r n<\tilde{P}_{\mathcal{L}_{S}}$ a infecção é localmente causada pela bactéria do tipo $S$; caso contrário, é causada localmente pela bactéria $R$. De uma forma similar, se a infecção é de origem global, a probabilidade normalizada de ser infectado pela bactéria do tipo $S$ é:

$$
\tilde{P}_{\mathcal{G}_{S}}=\frac{P_{\mathcal{G}_{S}}\left(1-P_{\mathcal{G}_{R}}\right)}{P_{\mathcal{G}_{S}}+P_{\mathcal{G}_{R}}-P_{\mathcal{G}_{S}} P_{\mathcal{G}_{R}}},
$$

e $\tilde{P}_{\mathcal{G}_{R}}=1-\tilde{P}_{\mathcal{G}_{S}}$. O valor obtido na Eq. 9.9 é comparado com um número aleatório. Se $r n<\tilde{P}_{\mathcal{G}_{S}}$ a infecção é devido à bactéria do tipo $S$, e, caso contrário do tipo $R$.

Ainda há duas possibilidades para uma mudança de estado:

(i) ir diretamente para o estado infectado (tuberculose ativa) $T_{k}(k=S, R)$ com probabilidade $p$ ou

(ii) entrar no estado latente $L_{k}(k=S, R)$ com probabilidade $1-p$.

\subsubsection{Indivíduos latentes}

Indivíduos no estado latente são apenas portadores do patógeno e não transmitem a doença. Se o patógeno é detectado nesse estado, os indivíduos podem ser submetidos à quimioprofilaxia que pode eliminar tais patógenos.

Em nosso modelo, uma proporção dos indivíduos latentes, $n_{L}$, é escolhida aleatoriamente para receber quimioprofilaxia. Durante a terapia, os indivíduos podem:

(i) ser curados com probabilidade $\sigma$, deixando o estado $L_{S}$ para o estado $X$;

(ii) progredir para um dos estados infecciosos, $T_{S}$ ou $T_{R}$, com probabilidade $v$; ou 
(iii) permanecer no estado latente.

Indivíduos latentes que chegaram ao fim da terapia mas não foram curados, permanecem latentes. Os outros indivíduos latentes, os quais não recebem quimioprofilaxia, podem:

(i) progredir para um dos estados infecciosos com probabilidade $v$;

(ii) permanecer no estado de $1-v$.

Note que a quimioprofilaxia não surte efeito em indivíduos latentes com o tipo resistente da bactéria $(R)$. Assim, mesmo sob quimioprofilaxia, a taxa de permanência ou progressão de indivíduos para outros estados é a mesma para indivíduos que não estão recebendo quimioprofilaxia.

\subsubsection{Indivíduos infecciosos}

Indivíduos infecciosos estão no estado ativo da TB e podem transmitir o patógeno. Existem dois estados diferentes para estes indivíduos: $T_{S}$, para aqueles que carregam o tipo de bactéria sensível ao antibiótico, e $T_{R}$, para aqueles que possuem a bactéria resistente ao antibiótico.

Uma porção, $n_{T}$, de indivíduos infecciosos são aleatoriamente escolhidos para receber tratamento com antibióticos. Em cada passo da simulação ${ }^{6}$, os indivíduos que estão nos estados $T_{S}$ e $T_{R}$ podem morrer de tuberculose com probabilidade $\mu_{T}$, independentemente de estar sob tratamento ou não.

Indivíduos $T_{S}$ que estão sob tratamento podem:

(i) ser tratados com sucesso, eliminando a infecção com probabilidade ${ }^{7}(1-r) \phi$;

(ii) desenvolver resistência à droga devido à probabilidade de fracasso do tratamento $r \phi[115,116]$;

(iii) alcançar o fim do tratamento sem eliminar a infecção, mas também sem desenvolver resistência à droga, permanecendo no estado $T_{S}$.

\footnotetext{
${ }^{6}$ Intervalo de tempo de Monte Carlo.

${ }^{7}$ Note que a probabilidade de tratamento eficaz $\phi$ é alterada dependendo do valor da probabilidade de fracasso do tratamento $r$.
} 
Para indivíduos no estado $T_{R}$, o procedimento é o mesmo descrito acima, mas o tratamento com antibióticos para linhagens resistentes da bactéria tem uma menor eficácia em relação aos casos envolvendo bactérias sensíveis às drogas [104]. Em nosso modelo, a eficácia relativa é ajustada pelo parâmetro $\delta$, i.e., a probabilidade de cura dos pacientes $T_{R}$ será dada pelo produto $\delta \phi$ com $0<\delta<1$.

\subsection{Implementação numérica e resultados}

No tempo $t=0$, somente indivíduos suscetíveis, $X$, e infectados com o tipo sensível da bactéria, $T_{S}$, estão presentes na rede $L \times L$. O número inicial de indivíduos $T_{S}$ representa $20 \%$ da população total e sua distribuição na rede é aleatória e uniforme. A rede é atualizada de forma síncrona, i.e., esta atualização ocorre ao mesmo tempo para todos os indivíduos e é feita após todos os indivíduos serem testados durante cada passo da simulação.

Os valores dos parâmetros utilizados nas simulações numéricas são: $L=317$, $\alpha=4 / 5, n_{L}=1 / 10, n_{T}=3 / 5, \mu_{T}=2,74 \times 10^{-4} / \mathrm{dia}, \mu=3,65 \times 10^{-5} / \mathrm{dia}$, $p=1,37 \times 10^{-4} /$ dia, $v=3,13 \times 10^{-5} /$ dia, $\beta_{S}=2,47 \times 10^{-3} /$ dia, e $\delta=7 / 10$. Os parâmetros restantes: $\phi, \sigma, r$ and $\Lambda$ possuem um valor específico para cada cenário e seus valores são atribuídos em cada caso. Ressaltamos que estes valores foram ajustados para que cada passo da simulação representasse um dia.

A fim de ilustrar a distribuição espacial dos indivíduos na rede, assim como a evolução no tempo do sistema. as Figs. 9.2a-9.2d mostram as configurações da rede em quatro instantes diferentes, $t=0, t=199, t=220$ e $t=300$ anos. Na Fig. 9.2a, o sistema é mostrado em $t=0$ onde pode-se ver somente indivíduos $X$ (verde) e $T_{S}$ (vermelho). Como mencionado acima, a quantidade de indivíduos $T_{S}$ é $20 \%$ da população local. O sistema não envolve intervenção de saúde pública (sem tratamento da TB) até o $199^{\circ}$ ano, o qual é plotado na Fig. 9.2b. Neste estágio, três estados podem ser vistos na rede: $X$ (verde), $L_{S}$ (amarelo) e $T_{S}$ (vermelho). A redução da quantidade de $T_{S}$ é causada devido à morte de indivíduos doentes, uma vez que não há tratamento com antibióticos. Na mesma figura, também pode ser vista uma grande quantidade de indivíduos latentes, o que pode ser explicado pela ausência de tratamento com antibióticos e quimioprofilaxia. 


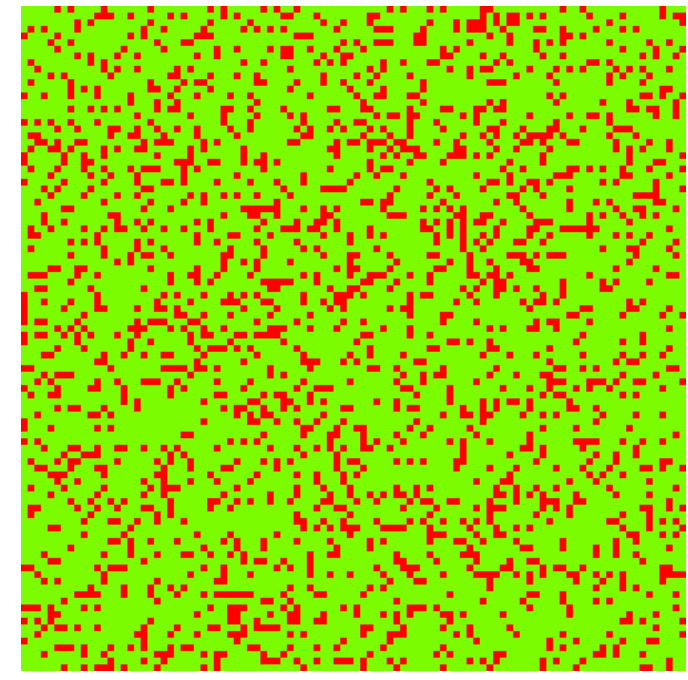

(a) $t=0$

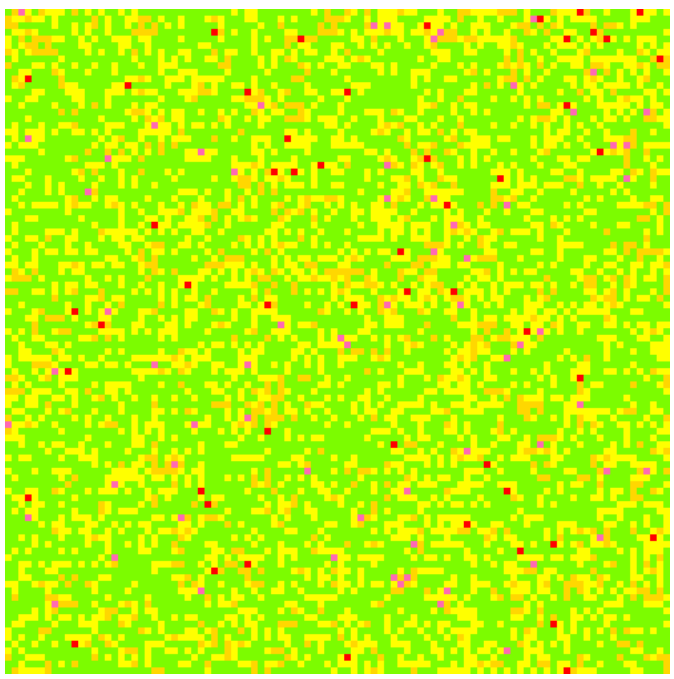

(c) $t=220$

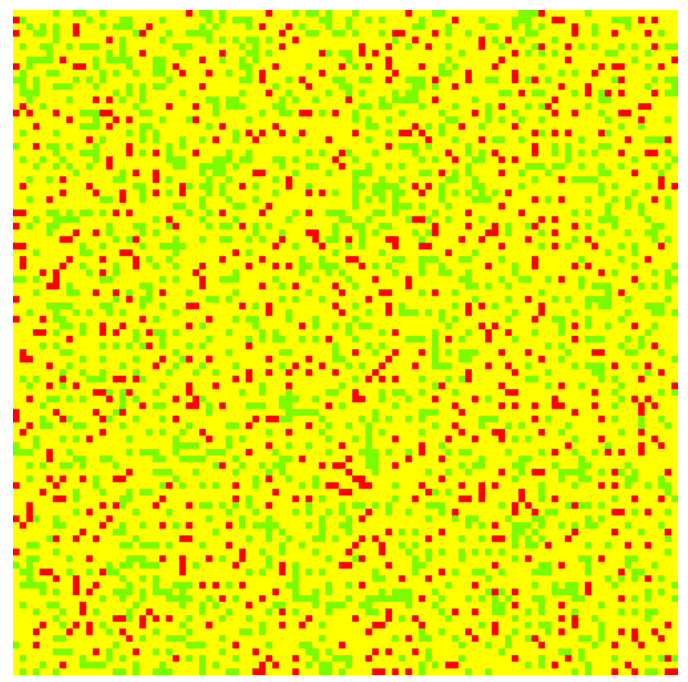

(b) $t=199$

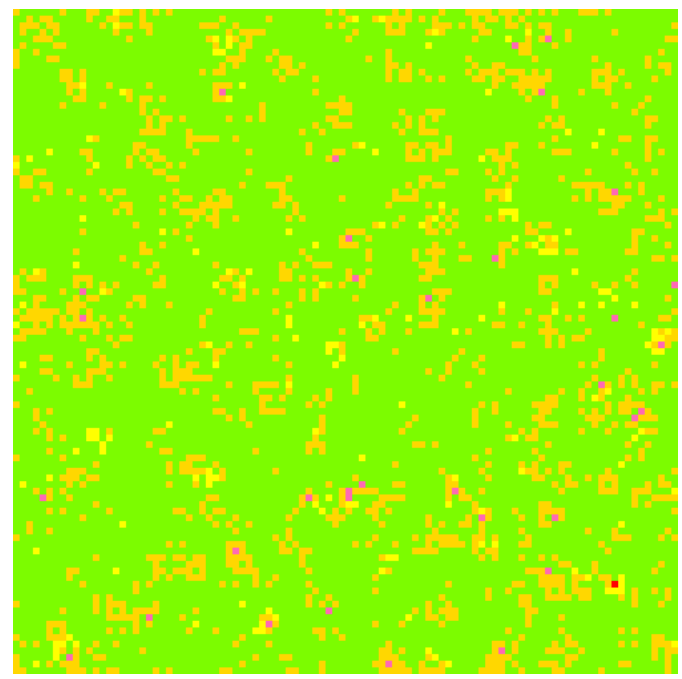

(d) $t=300$

Figura 9.2: Configurações da rede em quatro instantes diferentes. Cada cor representa um estado: verde, $X$; amarelo, $L_{S}$; laranja, $L_{R}$, vermelho, $T_{S}$; e rosa, $T_{R}$. Os parâmetros da simulação são: $L=100, n_{T}=3 / 5, n_{L}=1 / 10, \phi=1 / 2, \sigma=1 / 5 \mathrm{e}$ $r=9 / 10$. Adaptada da Ref. [93]

O tratamento com antibióticos e quimioprofilaxia se iniciou no primeiro dia do $200^{\circ}$ ano. Então, a fim de visualizar o efeito dessa intervenção na saúde pública, na Fig. 9.2c pode-se observar a configuração do sistema no 220o ano, i.e., 20 anos após o início da intervenção. Como esperado, a quantidade de indivíduos $T_{S}$ diminuiu drasticamente devido ao tratamento com probabilidade de $50 \%$ de eficácia de cura $(\phi=1 / 2)$. Também há diminuição da quantidade de indivíduos $L_{S}$ devido à menor 


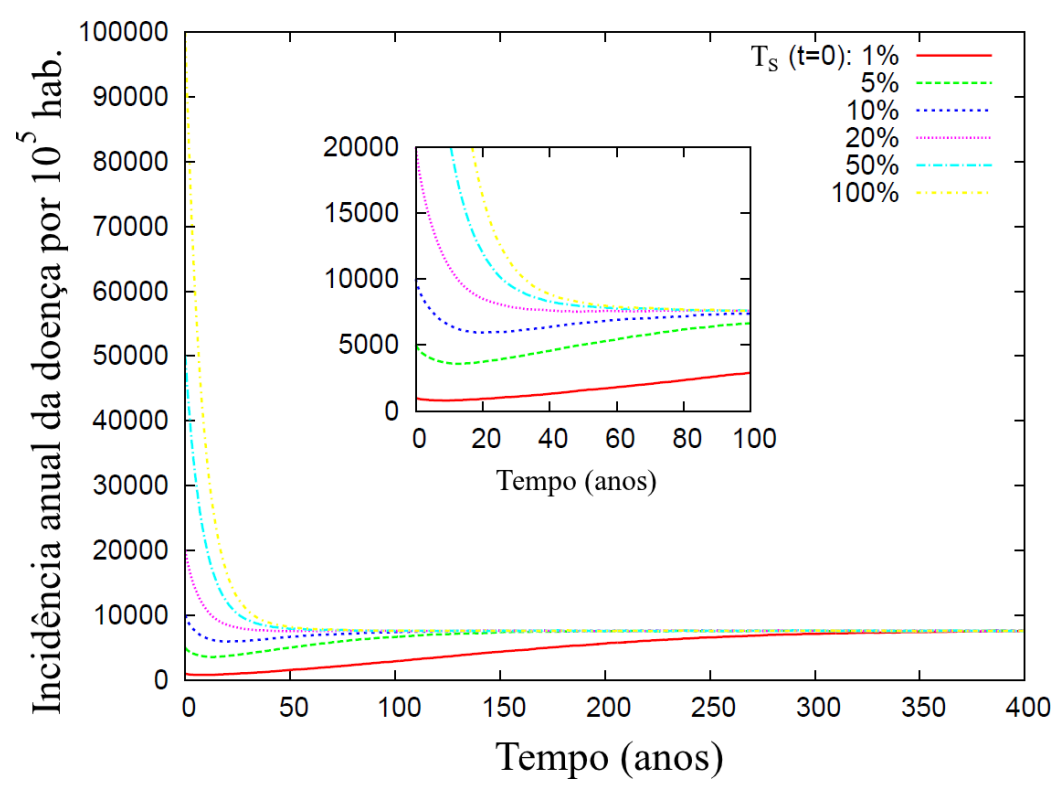

Figura 9.3: Evolução de tuberculose em um modelo de rede representando 400 anos, para proporções iniciais diferentes de indivíduos infecciosos com o tipo $s$ de bactéria, $T_{S}(t=0)$. O sistema evolui apenas com interações locais $(\Lambda=1)$. Inset:um zoom para o período do ano 0 até o 100. Tratamento e quimioprofilaxia não são aplicados durante toda a evolução do sistema.Adaptada da Ref. [93]

quantidade de pessoas $T_{S}$ (fonte da infeção) e a resposta à quimioprofilaxia. Outra consequência do tratamento com antibióticos é a emergência de resistência à droga, i.e., a emergência de indivíduos $L_{R}$ (laranja) e $T_{R}$ (roxo).

Por fim, na Fig. 9.2d, no $300^{\circ}$ ano, o sistema alcança o estado estacionário. Casos de tuberculose causada pela bactéria do tipo $S$ não ocorrem mais devido ao tratamento com antibióticos. Por outro lado, o uso dessas drogas causaram a emergência de resistência à droga. Ambos efeitos podem ser vistos nesta figura: a quantidade de indivíduos $X$ é maior que nos períodos passados e os casos $L_{R}$ e $T_{R}$ de tuberculose estão presentes na rede.

Nas Figs. 9.3 e 9.4, pode-se ver a evolução do sistema durante 400 anos para diferentes proporções iniciais de indivíduos infectados com o tipo $s$ de bactéria. Os valores são $T_{S}(t=0)=\{1 \%, 5 \%, 10 \%, 20 \%, 50 \%, 100 \%\}$ de uma população total de $10^{5}$ indivíduos. Nessas simulações não há tratamento $\left(n_{T}=0\right)$ nem quimioprofilaxia $\left(n_{L}=0\right)$. Por isso, as curvas dos estados estacionários são os estados endêmicos da tuberculose sem a intervenção dos sistemas de saúde. Também nas Figuras 9.3 e 9.4, é evidente que o estado endêmico não depende das condições iniciais do sistema. 


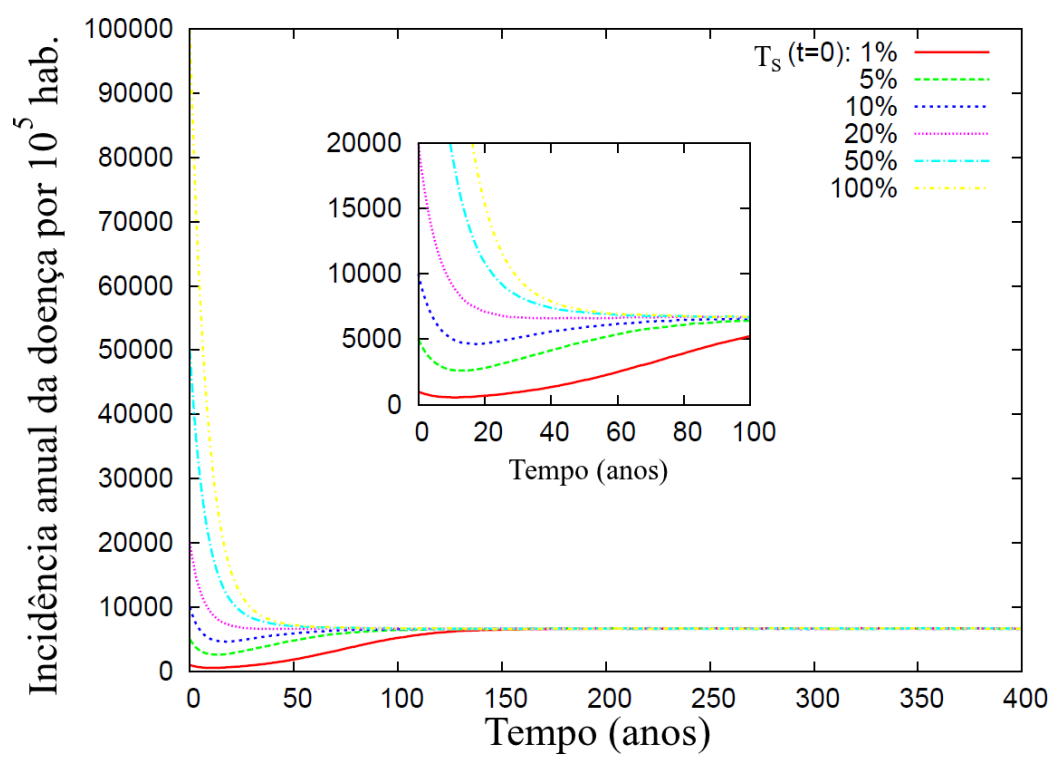

Figura 9.4: Evolução da tuberculose em um modelo de rede representando 400 anos, para diferentes proporções iniciais de indivíduos infecciosos que possuem o tipo $S$ de bactéria, $T_{S}(t=0)$. O sistema evolui somente com interações globais $(\Lambda=0)$. Inset: ampliação para o período do ano 0 até o 100. Tratamento e quimioprofilaxia não são aplicados durante toda a evolução do sistema.Adaptada da Ref. [93]

No entanto, o tempo transiente para atingir os estados estacionários depende da condição inicial de $T_{S}(t=0)$. A comparação entre essas figuras mostra que o tempo para atingir o estado estacionário é maior quando assumimos apenas interações locais $(\Lambda=1)$ na Fig. 9.3. Quando somente interações locais são levadas em conta a disseminação da doença é limitada à vizinhança de indivíduos suscetíveis. Por outro lado, quando somente interações globais estão presentes (Fig. 9.4), o conjunto de indivíduos suscetíveis sujeitos a ser infectados é maior, acelerando a disseminação da TB.

A evolução da tuberculose durante 500 anos é mostrado na Fig. 9.5. A partir do primeiro dia do ano 0 até o último dia do ano 199 ano, não há tratamento $\left(n_{T}=0\right)$ ou quimioprofilaxia $\left(n_{L}=0\right)$. Então, o sistema pode ir para um estado endêmico de tuberculose sem intervenção. Do primeiro dia do $200^{\circ}$ ano, o tratamento com antibióticos é introduzido com uma proporção de indivíduos sob tratamento igual a $n_{T}=6 / 10$ e $95 \%$ de eficácia $(\phi=95 / 100)$. Também é introduzida a terapia com quimioprofilaxia com $n_{L}=1 / 10$ e $58 \%$ de eficácia $(\sigma=58 / 100)$. Na Fig. 9.5, dois efeitos se tornam aparentes assim que o tratamento e a quimioprofilaxia começam: 


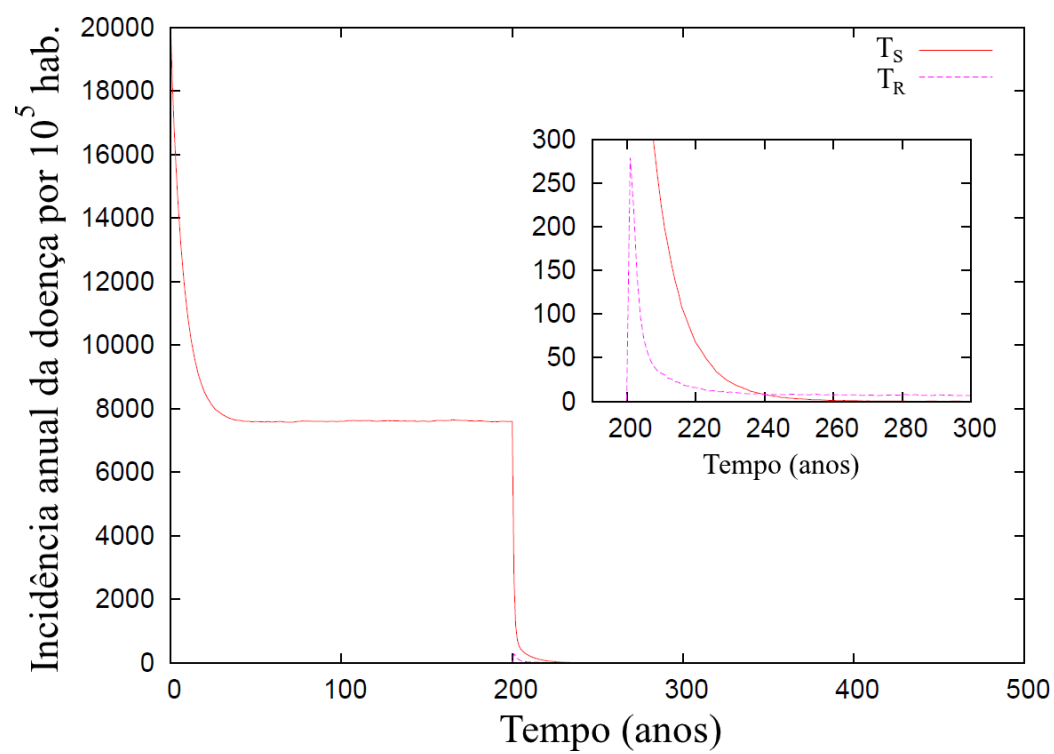

Figura 9.5: Evolução da tuberculose no modelo de rede, representando 500 anos. Tratamento e quimioprofilaxia começam no ano 200. Inset: Ampliação do período dos anos de 190 a 300. Os parâmetros da simulação são: $n_{T}=3 / 5, n_{L}=1 / 10$, $\phi=95 / 100, \sigma=58 / 100, r=1 / 10$ e $\Lambda=1$.Adaptada da Ref. [93]

(i) um caimento abrupto no número de indivíduos $T_{S}$ devido à alta eficiência do tratamento;

(ii) emergência da resistência às drogas, devido $10 \%$ de probabilidade de falha do tratamento $(r=1 / 10)$.

O inset da Fig. 9.5 mostra uma ampliação do período entre o $190^{\circ}$ e o $300^{\circ}$ ano. Neste, pode ser visto que os casos de tuberculose sensível aos antibióticos $\left(T_{S}\right)$ desaparecem por volta de 60 anos após o início de tratamento. Assim que o tratamento se inicia, devido à probabilidade de fracasso do tratamento, $r$, emerge uma resistência à droga e há um pico no número de indivíduos $T_{R}$ entre o $201^{\circ}$ e o $205^{\circ}$ ano. A emergência de casos $T_{R}$ depende do fracasso no tratamento dos casos $T_{S}$. Assim, inicialmente, a quantidade de indivíduos $T_{S}$ é maior, o que cria um grupo de indivíduos $T_{S}$ a serem convertidos em casos $T_{R}$. Depois de alguns anos, assim que os indivíduos $T_{S}$ diminuem, a quantidade de casos $T_{R}$ também diminui, e o pico mostrado na figura converge para um estado endêmico estável. Lembre-se que os casos $T_{R}$ são curados com uma eficiência relativa aos casos $T_{S}$ definidos pelo parâmetros $\delta$. É então esperado que indivíduos infecciosos $T_{R}$ permaneçam na população, mesmo 


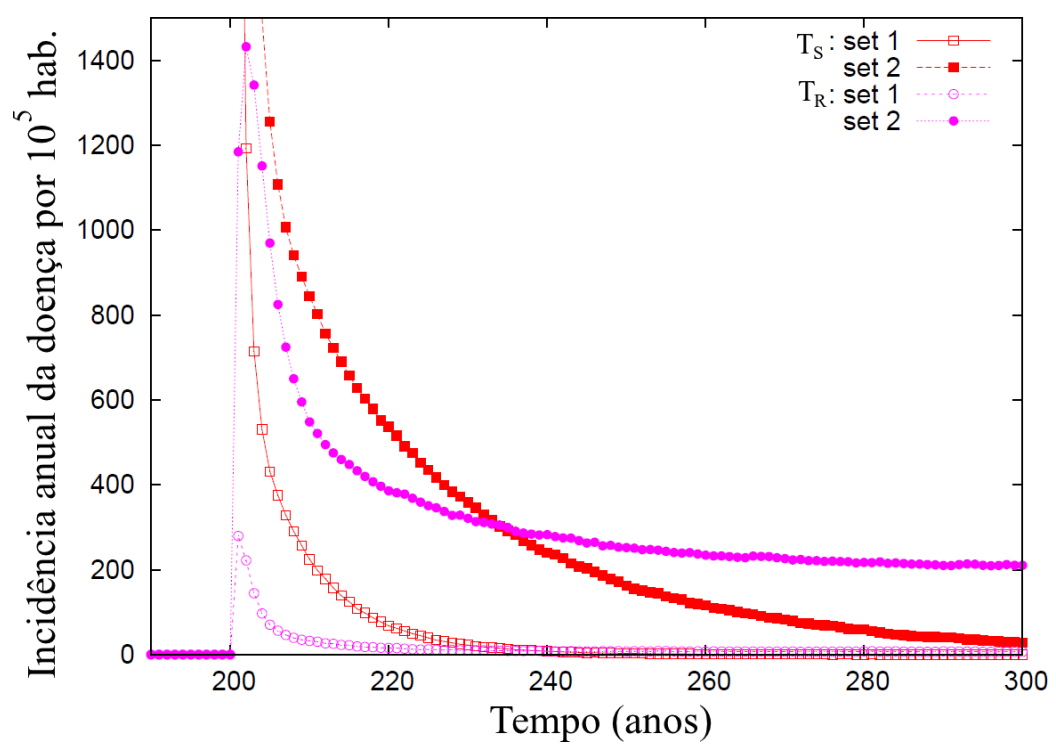

Figura 9.6: Evolução da tuberculose durante 300 anos com tratamento e quimioprofilaxia iniciando no ano 200 para dois conjuntos de parâmetros. Conjunto 1: $n_{T}=3 / 5, n_{L}=1 / 10, \phi=95 \%, \sigma=58 \%, r=1 / 10$ e $\Lambda=1$. Conjunto $2: n_{T}=3 / 5$, $n_{L}=1 / 10, \phi=1 / 2, \sigma=1 / 5, r=1 / 2$ e $\Lambda=1$.Adaptada da Ref. [93]

no caso de tratamentos de alta eficácia.

A fim de checar o impacto do uso de antibióticos na evolução das dinâmicas de tuberculose, nós testamos duas situações com dois conjuntos de parâmetros: conjunto $1=\{\phi=\% 95, \sigma=\% 58, r=1 / 10, \Lambda=1\}$ e conjunto $2=$ $\{\phi=1 / 2, \sigma=1 / 5, r=1 / 2 e \Lambda=1\}$. A evolução da TB para esses casos são representados na Figura 9.6.

O primeiro conjunto de parâmetros com $\phi=95 \%, \sigma=\% 58$ e $r=1 / 10$ representa um sistema de saúde em um país desenvolvido. A eficácia do tratamento e da quimioprofilaxia é alta e combinados com uma baixa probabilidade de emergência de resistência à droga. Nesta primeira situação tem-se a cura para $100 \% \operatorname{dos} \operatorname{casos} T_{S}$ em 60 anos depois do início do tratamento, com um nível endêmico baixo e estável para os casos $T_{R}$.

Por outro lado, o segundo conjunto de parâmetros representa um sistema de saúde em um país em desenvolvimento, com baixa eficácia de tratamento e quimioprofilaxia em comparação àqueles de um país desenvolvido, combinado com $50 \%$ de probabilidade de fracasso do tratamento. Nessa segunda situação, até 100 anos depois do início do tratamento, vários casos de indivíduos infecciosos $T_{S}$ ainda per- 


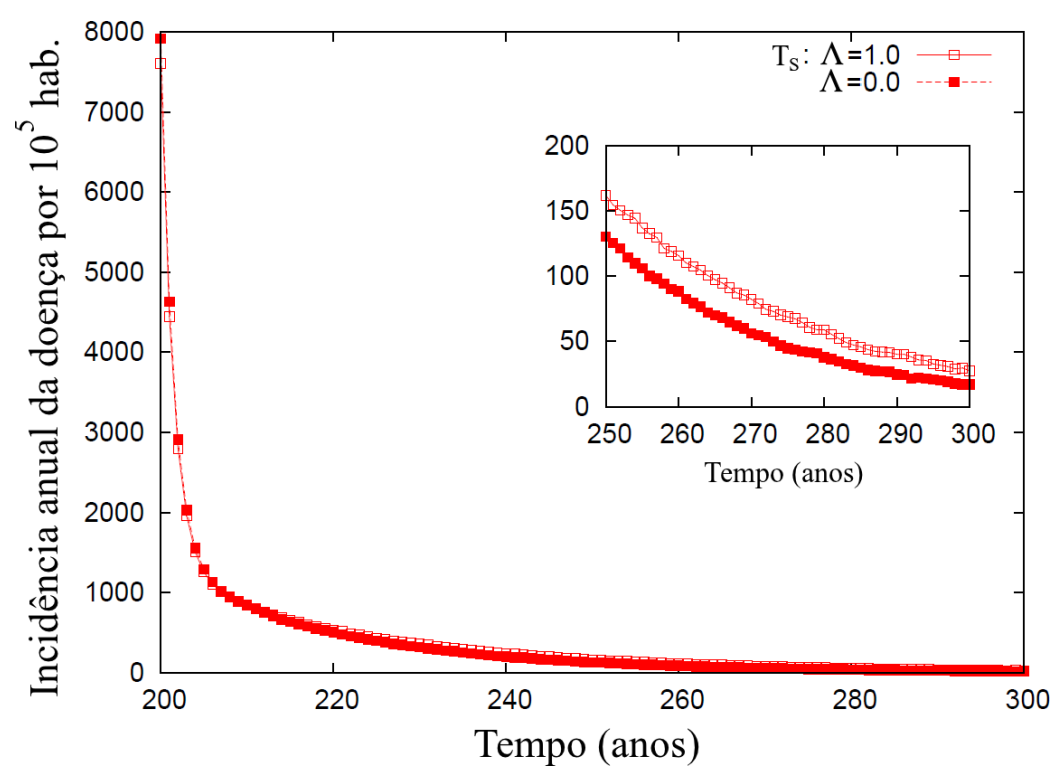

Figura 9.7: Evolução da tuberculose durante 300 anos com tratamento e quimioprofilaxia começando no ano 200 somente com interações locais, $\Lambda=1$, e somente com interações globais, $\Lambda=0$. A série de tempo a partir do ano 0 até o 299 foi omitida. Somente casos $T_{S}$ são mostrados nessa figura. Inset: estado estacionário para indivíduos $T_{S}$ do $250^{\circ}$ ao $300^{\circ}$ ano. Os parâmetros são: $\phi=1 / 2, \sigma=1 / 5 \mathrm{e}$ $r=1 / 2$.Adaptada da Ref. [93]

manecem na população. Além do grande predomínio de casos $T_{S}$ devido à baixa eficácia da intervenção $(\phi=1 / 2, \sigma=1 / 5$ e $r=1 / 2)$, a emergência de resistência à droga é muito alta. Portanto, a baixa eficácia das estratégias do sistema de saúde não resolvem o problema de casos de TB com o tipo $S$ de bactéria. Além disso, ela cria um novo e mais grave problema que é um grande predomínio de casos de TB com bactérias do tipo $R$.

O parâmetro $\Lambda$ controla a intensidade entre efeitos locais e globais. Portanto, a fim de verificar a influência deste parâmetro na dinâmica do sistema, nós mostramos nas figuras 9.7 e 9.8 o estado estacionário para $T_{S}$ e $T_{R}$, respectivamente, para dois casos: $\Lambda=1$ (somente efeitos locais) e $\Lambda=0$ (somente efeitos globais).

A figura 9.7 descreve a evolução do sistema durante 300 anos com tratamento e quimioprofilaxia começando no ano 200. Nesta figura, são exibidas duas curvas para casos $T_{S}$, uma somente para as interações locais (quadrados vazios) e outra somente para interações globais (quadrados cheios). A parte superior da Fig. 9.7 é uma ampliação da região dos anos 250 até o 300. Ele mostra o estado estacionário 


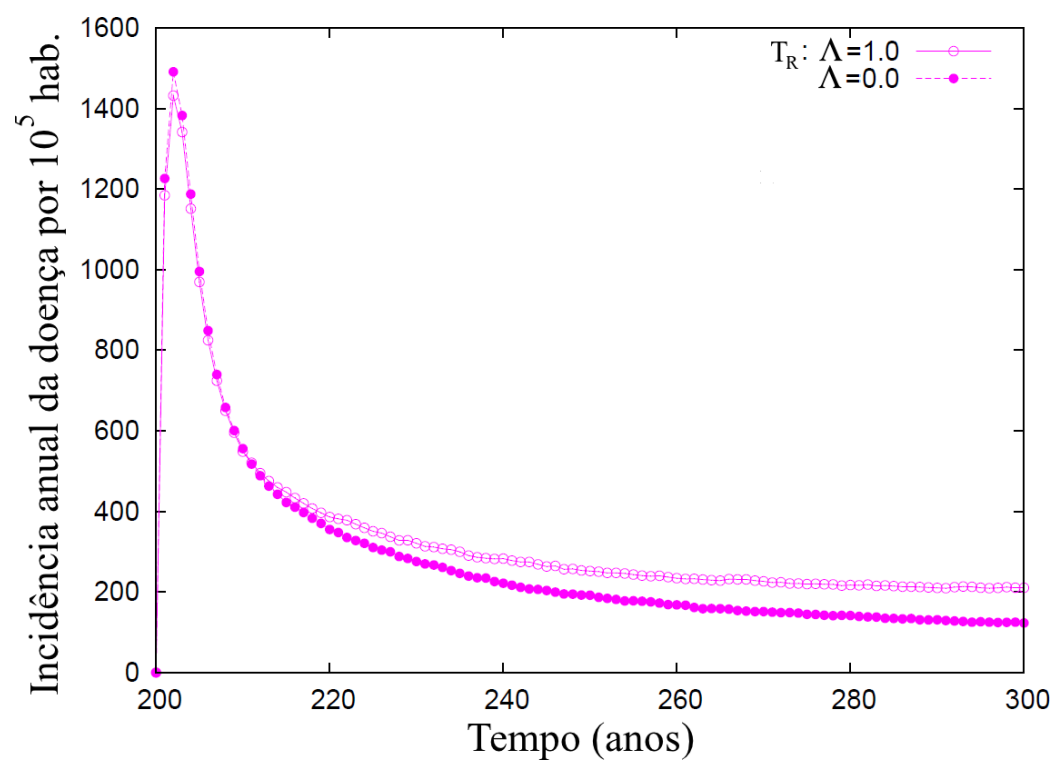

Figura 9.8: Evolução da tuberculose durante 300 anos com tratamento e quimioprofilaxia iniciando no ano 200 somente com interações locais, $\Lambda=1$, e somente interações globais, $\Lambda=0$. A série de tempo dos anos 0 ao 299 está omitida. Somente casos $T_{R}$ são exibidos nessa figura. Os parâmetros são: $\phi=1 / 2, \sigma=1 / 5$, $r=1 / 2$.Adaptada da Ref. [93]

dos casos $T_{S}$ para $\Lambda=1$ e $\Lambda=0$. Quando somente as interações locais são levadas em conta $(\Lambda=1)$, é evidente que o estado endêmico é mais elevado nos casos nos quais estão presentes somente as interações globais $(\Lambda=0)$.

A Figura 9.8 apresenta casos $T_{R}$ para somente interações locais e somente interações globais, do $200^{\circ}$ ao $300^{\circ}$ ano, em ambas as curvas. A quantidade de casos $T_{R}$ depende do conjunto de indivíduos $T_{S}$ disponíveis cujo tratamento fracassou. então, como os casos $T_{S}$ são maiores para interações locais somente $(\Lambda=1)$, a quantidade de casos $T_{R}$ será também mais elevada.

O motivo pelo qual somente interações locais $(\Lambda=1)$ favorecem um predomínio maior de casos $T_{S}$ e $T_{R}$ pode ser compreendido observando a Fig. 9.9. Esta figura retrata a evolução no tempo da probabilidade média local, $\left\langle P_{\mathcal{L}}\right\rangle$, e da probabilidade média global, $\left\langle P_{\mathcal{G}}\right\rangle$ avaliada pelas Eqs. 9.3-9.6, respectivamente. No tempo $t$, a probabilidade local, $P_{\mathcal{L}}(i, j)$ é calculada para todos os indivíduos $X$ dispostos nas coordenadas $(i, j)$ da rede. Então, todas as probabilidades são somadas, $\sum_{(i, j)} P_{\mathcal{L}}(i, j)$ e divididas pelo número total de indivíduos $X$. O mesmo procedimento é realizado para o cálculo da probabilidade local $P_{\mathcal{G}}(i, j)$. 


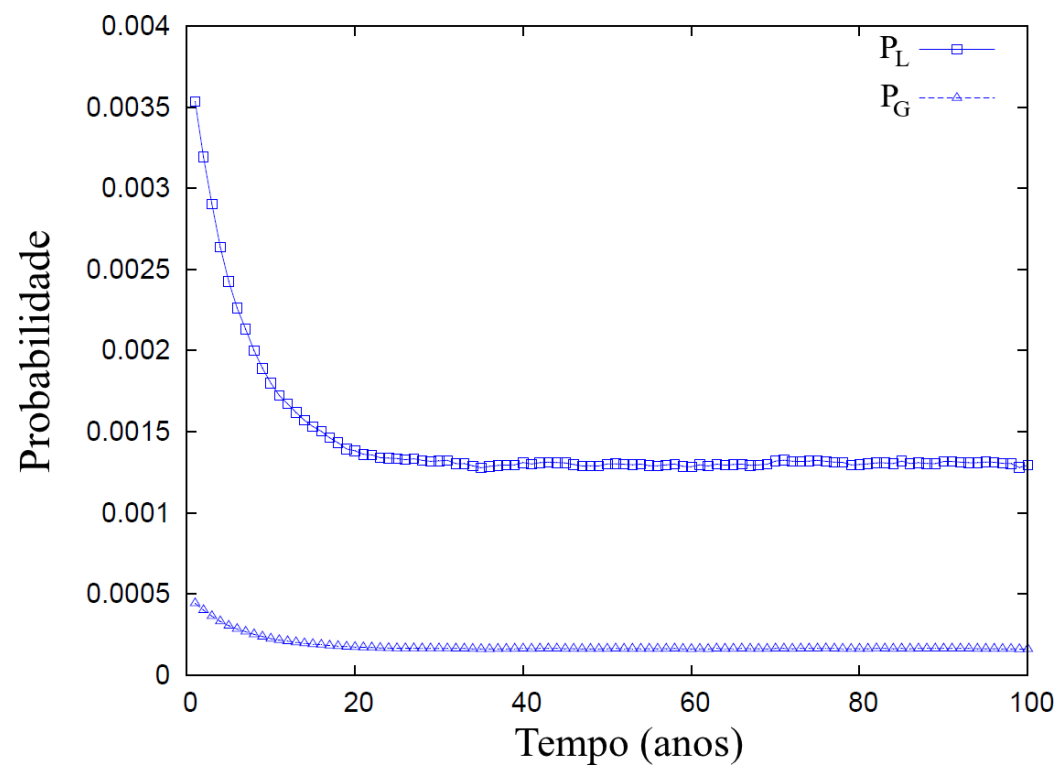

Figura 9.9: Evolução no tempo da probabilidade média para interações locais, $P_{\mathcal{L}}$, e globais, $P_{\mathcal{G}}$. Quadrados: média $\left\langle P_{\mathcal{L}}\right\rangle$; triângulos: média $\left\langle P_{\mathcal{G}}\right\rangle$. Os parâmetros usados são: $\phi=1 / 2, \sigma=1 / 5, r=1 / 2$ e $\Lambda=1$.Adaptada da Ref. [93]

A figura 9.9 mostra claramente que a probabilidade média local é maior que a probabilidade média global durante a evolução do sistema. Os valores $\left\langle P_{\mathcal{L}}\right\rangle \gg\left\langle P_{\mathcal{G}}\right\rangle$ explicam porque nas Figs. 9.7 e 9.8 os estados endêmicos para ambos os casos $T_{S}$ e $T_{R}$ são maiores para a situação com interações locais apenas $(\Lambda=1)$.

Como já foi definido na Seção 9.2, os parâmetros $\sigma$ e $\phi$ são a probabilidade de eficácia da terapia com quimioprofilaxia e a probabilidade de eficácia do tratamento para indivíduos infecciosos, respectivamente. Em nosso modelo, esses parâmetros são ajustados a fim de simular diferentes situações acerca da eficácia da terapia com quimioprofilaxia e tratamento com antibióticos. Em outras palavras, isto significa que $\sigma$ e $\phi$ são predeterminados ao invés de ser consequência da dinâmica do sistema. Assim, $n_{T}$, a proporção de indivíduos infecciosos que recebem o tratamento e $n_{L}$, a proporção de indivíduos latentes que recebem quimioprofilaxia, servem como controle do ponto de vista da intervenção do sistema de saúde.

Na Fig. 9.10 pode-se ver o estado endêmico da TB como função da proporção de indivíduos infecciosos que recebem tratamento, $n_{T}$. Os valores apresentados na figura são referentes ao $220^{\circ}$ ano, i.e., 20 anos após o início do tratamento e da quimioprofilaxia. Para todos os valores de $n_{T}$, a proporção de indivíduos latentes 


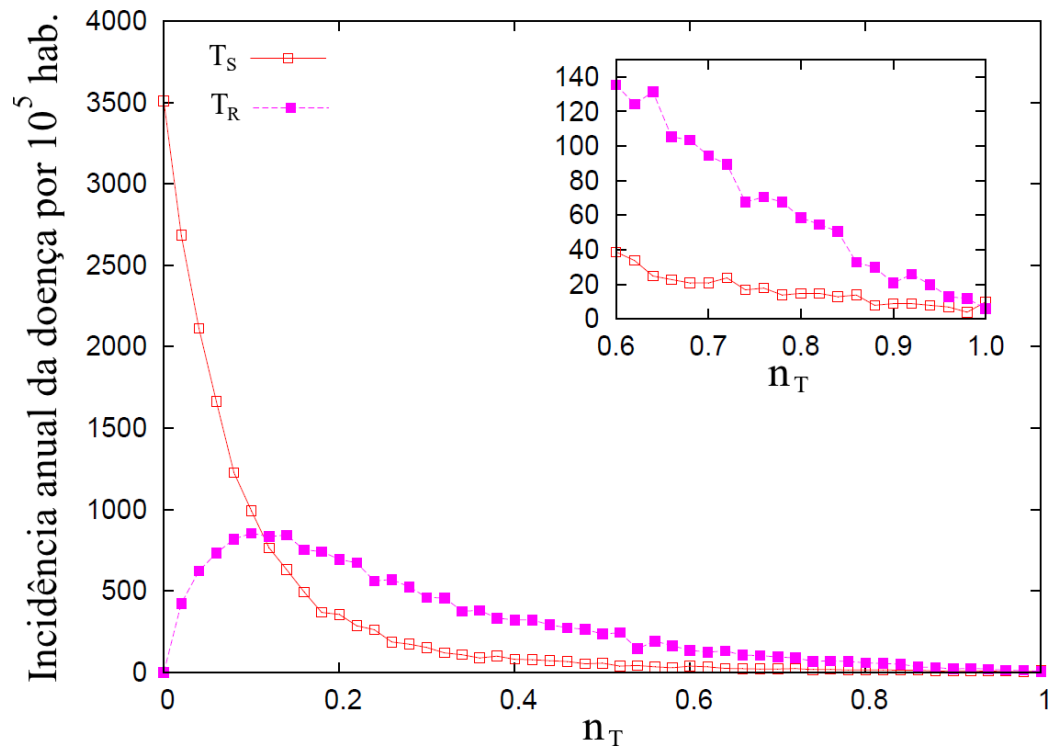

Figura 9.10: Casos $T_{S}$ e $T_{R}$ como função da proporção de indivíduos infecciosos que recebem tratamento, $n_{T}$. Os valores apresentados na figura são referentes ao $220^{\circ}$ ano. O tratamento e a quimioprofilaxia são iniciados no ano 200. Os parâmetros são: $n_{L}=1 / 5, \phi=1 / 2, \sigma=1 / 5, r=1 / 2$ e $\Lambda=1$.Adaptada da Ref. [93]

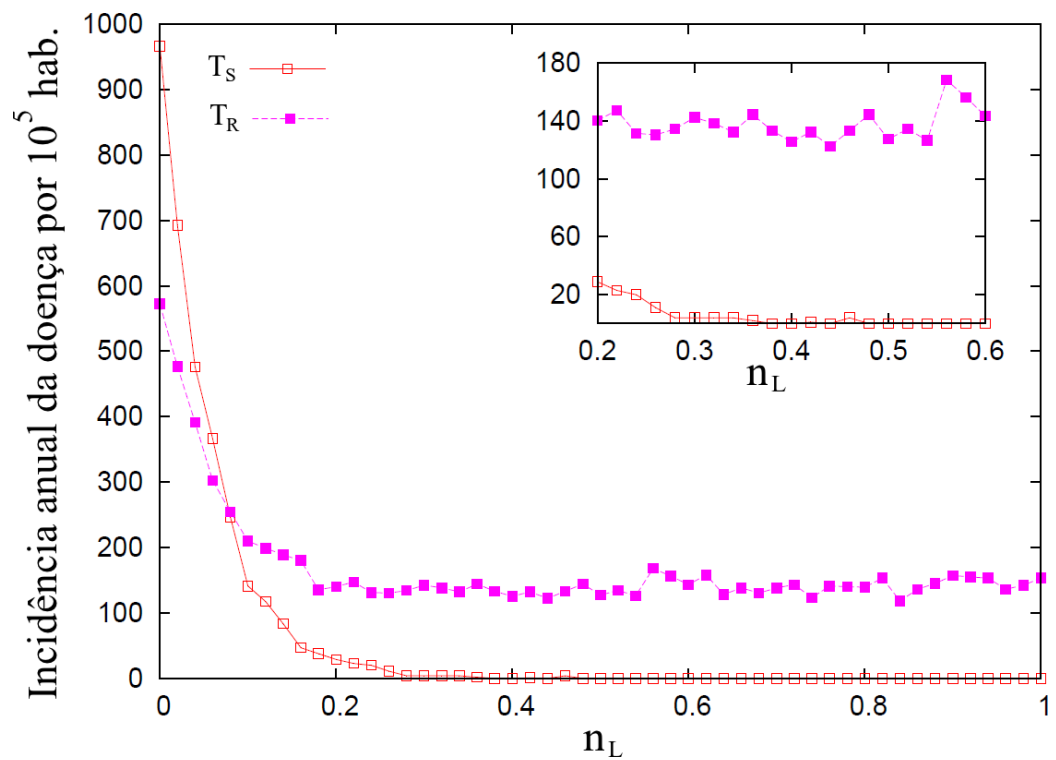

Figura 9.11: Casos $T_{S}$ e $T_{R}$ como função da proporção de indivíduos latentes que recebem quimioprofilaxia, $n_{L}$. Os valores apresentados na figura são referentes ao $220^{\circ}$ ano. O tratamento e quimioprofilaxia são iniciados no ano 200. Parâmetros usados: $n_{T}=3 / 5, \phi=1 / 2, \sigma=1 / 2, r=1 / 2$ e $\Lambda=1$.Adaptada da Ref. [93] 
que recebem quimioprofilaxia é mantida constante, $n_{L}=1 / 5$.

Quando não há indivíduos sob tratamento no sistema, $n_{T}=0$, o predomínio de casos de TB com o tipo $S$ de bactéria é bem elevado. Mas não há casos envolvendo o tipo $R$ da bactéria, porque a emergência de bacilos resistentes é devido ao fracasso do tratamento. À medida que a proporção de indivíduos sob tratamento aumenta, casos $T_{R}$ emergem e há um pico por volta de $n_{T} \approx 3 / 20$. Por outro lado, para $n_{T}>3 / 20$, a quantidade de indivíduos $T_{S}$ que são curados aumenta, consequentemente, os casos de $T_{R}$ têm que diminuir. Todavia, até para $n_{T}=1$, i.e., todos os indivíduos doentes estão sob tratamento, ainda há casos remanescentes de $T_{S}$ e $T_{R}$. Este comportamento é uma consequência da probabilidade de eficácia de tratamento para indivíduos infecciosos $\phi<1$.

O gráfico do estado endêmico da TB como função da proporção de indivíduos latentes que recebem quimioprofilaxia, $n_{L}$, pode ser visto na Fig. 9.11. Os valores apresentados na figura são referentes ao $220^{\circ}$ ano, i.e., 20 anos após o início do tratamento e quimioprofilaxia. Para todos os valores de $n_{L}$, a proporção de indivíduos infecciosos que recebem tratamento, $n_{T}$, é mantida constante e igual a $3 / 5$.

Na Fig. 9.11 pode-se ver que o total de casos $T_{S}$ e $T_{R}$ diminui à medida que $n_{L}$ aumenta. Há dois resultados interessantes que podem ser vistos nesta figura. $\mathrm{O}$ primeiro resultado é que para $n_{L} \approx 38 / 100$, a população é livre de casos $T_{S}$. Em outras palavras, quando somente $38 \%\left(n_{L}=38 / 100\right)$ dos indivíduos latentes da população recebem quimioprofilaxia, o tipo $S$ de bactéria desaparece. Isto sugere que as políticas de saúde pública deveriam atentar mais para a prevenção da TB, assim que a $M$. tuberculose fosse detectada em uma pessoa. O segundo resultado diz respeito ao caso estacionário e mostra que há predomínio de casos $T_{R}$ para $n_{L}>9 / 50$. Este comportamento é explicado porque em nosso modelo a terapia com quimioprofilaxia não tem efeito em indivíduos latentes com a bactéria $R, L_{R}$.

\subsection{Exploração do espaço de parâmetros}

Apresentamos aqui os resultados obtidos a partir da exploração do espaço de parâmetros. Todos os valores apresentados nos gráficos são médias de 30 realizações. Os parâmetros fixos utilizados nas simulações são: $L=317, \mu_{T}=2,74 \times 10^{-4} /$ dia, 
$\mu=3,65 \times 10^{-5} /$ dia, $p=1,37 \times 10^{-4} /$ dia, $v=3,13 \times 10^{-5} /$ dia e $\beta_{S}=2,47 \times$ $10^{-3} /$ dia.

A eficácia do tratamento, $\phi$, depende basicamente da políticas públicas de saúde. Geralmente os países mais desenvolvidos são os que mais investem em saúde. Assim, o parâmetro $\phi$ é associado ao nível de desenvolvimento do país.

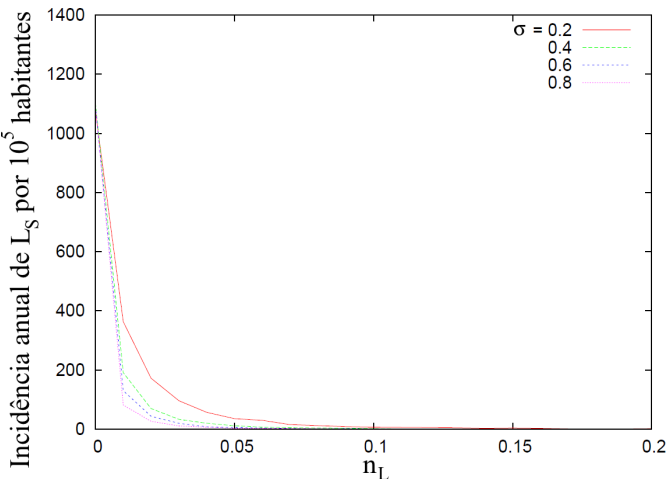

(a) $L_{S}$ : países desenvolvidos.

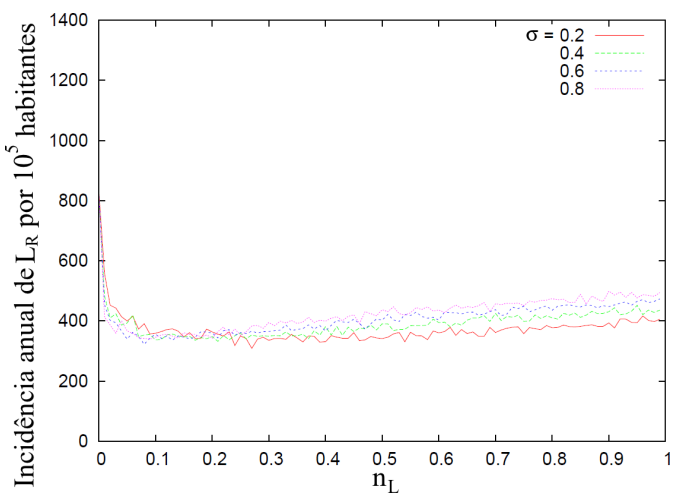

(c) $L_{R}$ : países desenvolvidos.

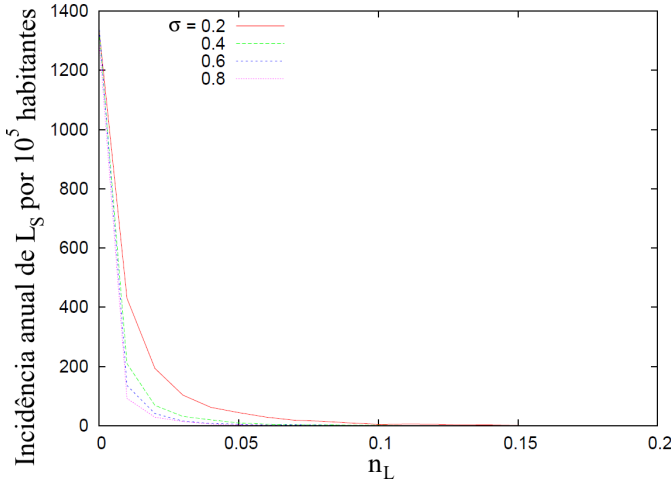

(b) $L_{S}$ : países em desenvolvimento.

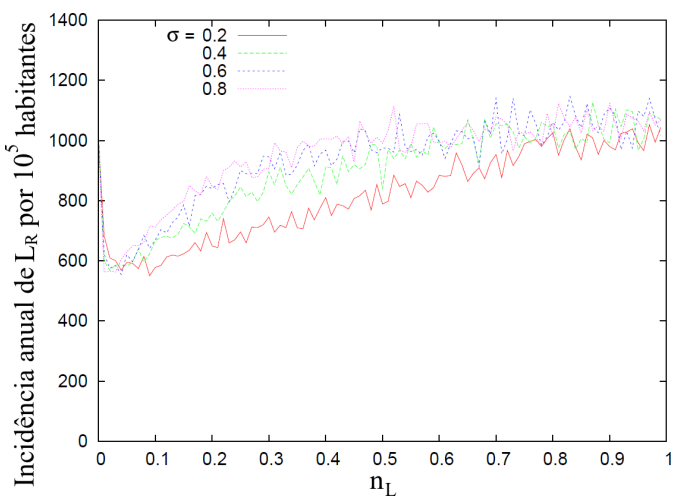

(d) $L_{R}$ : países em desenvolvimento.

Figura 9.12: $L_{S}$ e $L_{R}$ casos como função de $n_{L}$ para países desenvolvidos $(\phi=95 \%)$ e em desenvolvimento $(\phi=1 / 2)$. Parâmetros: $r=1 / 2, \delta=4 / 5$ e $n_{T}=3 / 5$.

Nos gráficos das Figs. 9.12a-9.12d, podemos observar a incidência anual dos casos latentes $L_{S}$ e $L_{R}$, como função da proporção de indivíduos latentes que recebem quimioprofilaxia, $n_{L}$. Os gráficos das Figs. 9.12a e9.12b descrevem a incidência dos casos latentes com bactéria tipo $S$ como função de $n_{L}$ para países desenvolvidos e em desenvolvimento, respectivamente. Ambos os gráficos apresentam um comportamento similar, com exceção do caso $n_{L} \approx 0$. Uma vez que a eficácia da quimioprofilaxia não depende do valor de $\phi$, é esperado que o resultado seja o mesmo tanto para países desenvolvidos quanto para países em desenvolvimento. Para valo- 
res de $n_{L}>1 / 10$, a quantidade de indivíduos latentes se anula independentemente do valor de $\sigma$. Assim, para os casos de latência com patógenos sensíveis, a quimioprofilaxia tem um impacto maior na eliminação das bactérias. O número de casos de latência com bactéria tipo $R$ como função de $n_{L}$ podem ser vistos nos gráficos das Figs. 9.12c e 9.12d. Em nosso modelo, a quimioprofilaxia não remove a bactéria tipo $R$, independentemente da eficácia $\sigma$. Assim, a medida que $n_{L}$ cresce, apenas indivíduos $L_{S}$ são curados, e indivíduos $L_{R}$ permanecem na população. No processo de contágio, a competição entre as linhagens $S$ e $R$ desaparece. Por esta razão, em países desenvolvidos e em desenvolvimento, a eliminação dos patógenos $S$ devido à quimioprofilaxia ajuda a disseminação da linhagem tipo $R$.

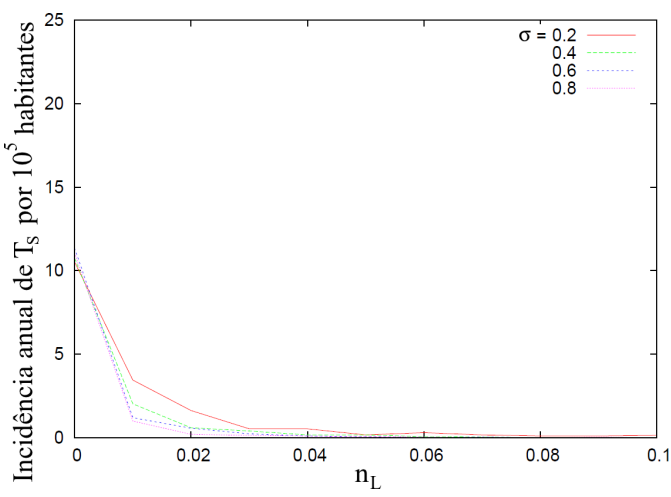

(a) $T_{S}$ : países desenvolvidos.

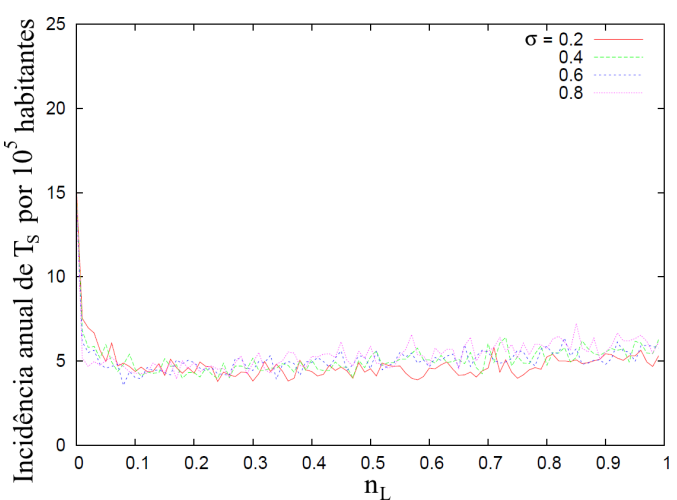

(c) $T_{R}$ : países desenvolvidos.

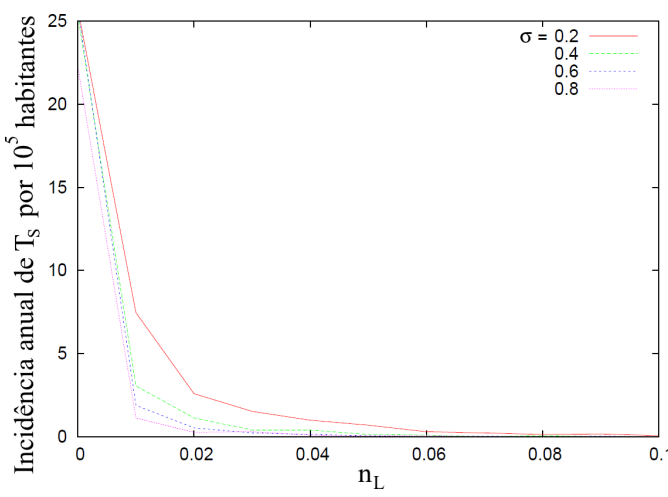

(b) $T_{S}$ : países em desenvolvimento.

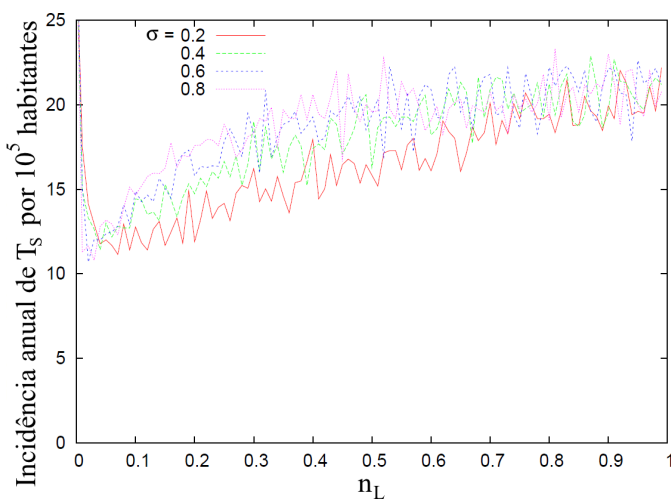

(d) $T_{R}$ : países em desenvolvimento.

Figura 9.13: Número de casos $T_{S}$ e $T_{R}$ como função de $n_{L}$ para países desenvolvidos $(\phi=95 \%)$ e em desenvolvimento $(\phi=1 / 2)$. Parâmetros usados: $r=1 / 2, \delta=4 / 5$, $n_{T}=3 / 5$.

As Figs. 9.13a - 9.13d mostram os casos infecciosos de tuberculose, $T_{S}$ e $T_{R}$, como função de $n_{L}$, para diferentes valores de $\sigma$. Novamente, a caracterização do país como 
desenvolvido ou em desenvolvimento é determinado pela eficácia do tratamento, $\phi$. Para os casos $T_{S}$, nas curvas das Figs. 9.13a e 9.13b, independentemente dos valores de $\sigma$, a eliminação total da doença ocorre para $n_{L} \approx 1 / 10$, para países desenvolvidos e em desenvolvimento Este fenômeno é explicado pelo fato da quimioprofilaxia curar rapidamente indivíduos no estado latente $L_{S}$. Dessa forma, a progressão da doença do estado latente para o infeccioso é interrompido. Considerando um valor fixo de $n_{L}$, o aumento de $\sigma$ reduz a incidência anual da doença. Por sua vez, os número de casos $T_{R}$ mostrados nos gráficos das Figs. $9.13 \mathrm{c}$ e $9.13 \mathrm{~d}$, tendem a crescer quando $n_{L}$ é aumentado. Como mencionado acima, a quimioprofilaxia cura apenas indivíduos latentes com patógeno tipo $S$. Por esta razão, quando $n_{L}$ cresce, a quantidade de indivíduos latentes $L_{R}$ também cresce. Consequentemente, a taxa de progressão para o estado infeccioso $T_{R}$ também cresce. A incidência anual de casos $T_{R}$ apresenta valores maiores para países em desenvolvimento, conforme mostrado na Fig. 9.13d. Uma taxa de eficácia de tratamento menor, $\phi=1 / 2$, favorece a emergência de resistência às drogas e, consequentemente, a dispersão da linhagem resistente.

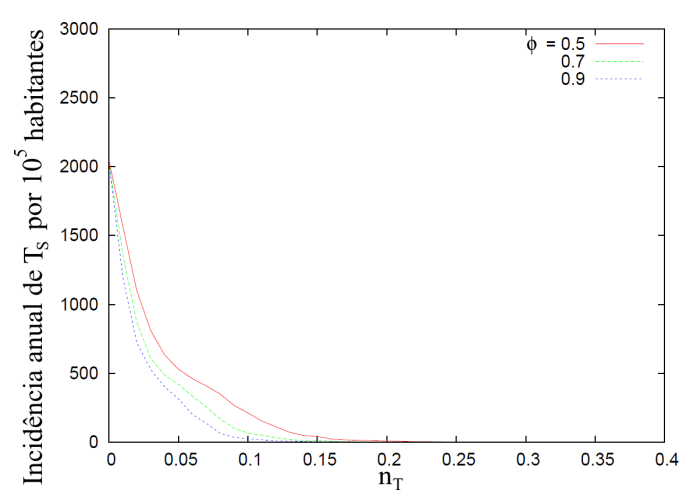

(a) $T_{S}$

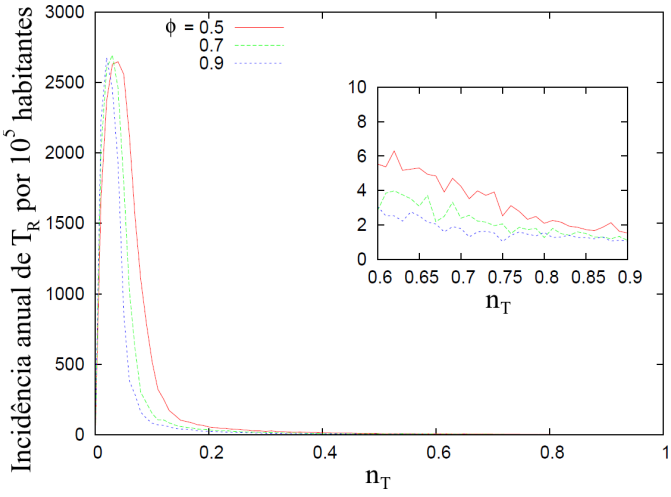

(b) $T_{R}$

Figura 9.14: Casos $T_{S}$ e $T_{R}$ em função de $n_{T}$ para diferentes valores de $\phi$. O inset de (b) mostra uma ampliação da região $3 / 5<n_{T}<9 / 10$. Parâmetros: $\delta=4 / 5$, $\sigma=1 / 5$ e $n_{L}=1 / 10$.

Os gráficos das Figs. 9.14a e 9.14b mostram os casos $T_{S}$ e $T_{R}$ em função da proporção de indivíduos infectantes que recebem tratamento, $n_{T}$. Em ambos os gráficos, curvas diferentes representam três eficácias diferentes de tratamento: $\phi=1 / 2$, $\phi=7 / 10$ e $\phi=9 / 10$. Para esclarecimento, um detalhe da faixa $n_{T}=3 / 5$ até $n_{T}=9 / 10$ na Fig. 9.14b. Nas curvas das Fig. 9.14a vemos que quando $n_{T}$ aumenta, 
a quantidade de indivíduos $T_{S}$ diminui. Para os três valores de eficácia do tratamento, todos os casos $T_{S}$ são eliminados para $n_{T} \approx 1 / 5$ Um resultado esperado mostrado nesta figura é que quanto maior $\phi$, mais rápido é o declínio de indivíduos $T_{S}$ na população. Os casos resistentes à drogas, $T_{R}$, em função de $n_{T}$, podem ser vistos nos gráficos da Fig. 9.14b. Note que para as três curvas, a emergência de resistência às drogas possui um pico em $n_{T} \approx 1 / 20 \mathrm{~A}$ conbinação de dois efeitos concorrentes explicam este pico nas curvas da Fig. 9.14b: a quantidade de indivíduos $T_{S}$ na população e a probabilidade de falha no tratamento, $r \phi$. Aumentando $n_{T}$, aumentamos o número de indivíduos sob tratamento. Assim, o número de falhas no tratamento também aumenta,i.e., emergência de resistência às drogas é maior. Portanto, mesmo que os casos de $T_{S}$ sejam reduzidos, o número de casos de indivíduos $T_{R}$ é aumentado. Este comportamento ocorre na região $0<n_{T} \lesssim 1 / 20$. Para $n_{T} \gtrsim 1 / 20$, os casos $T_{R}$ são eliminados rapidamente. Novamente, quanto maior $n_{T}$, maior a quantidade de indivíduos $T_{S}$ sob tratamento que são curados. Neste caso, o número de indivíduos $T_{S}$ (Fig. 9.14a) é reduzido a valores que não favorecem um aumento na emergência de resistência às drogas.

O parâmetro $\Lambda \in[0,1]$ ajusta a combinação de efeitos locais e globais. O impacto de efeitos locais e globais na disseminação da TB para países desenvolvidos e em desenvolvimento são mostrados na Fig. 9.15. Neste gráfico, $\Lambda$ varia de $\Lambda=0$, somente efeitos globais, até $\Lambda=1$, somente efeitos locais. Ambas as curvas apresentam um comportamento similar, i.e., a incidência de $T_{R}$ decresce quando $\Lambda$ cresce. Este comportamento claramente indica que efeitos locais são mais importantes no processo de contágio.

\subsection{Conclusão}

Neste capítulo propusemos um modelo baseado em agentes para a disseminação da tuberculose e emergência de resistência à droga devido ao uso de antibióticos. O modelo é baseado nas interações entre indivíduos dispostos nos sítios de uma rede quadrada. Diferentemente dos modelos baseados em equações diferenciais, a estrutura espacial é levada em conta neste modelo. Estes indivíduos podem estar em um dos cinco estados da doença: suscetível $(X)$, latente com o tipo $S$ da bactéria 


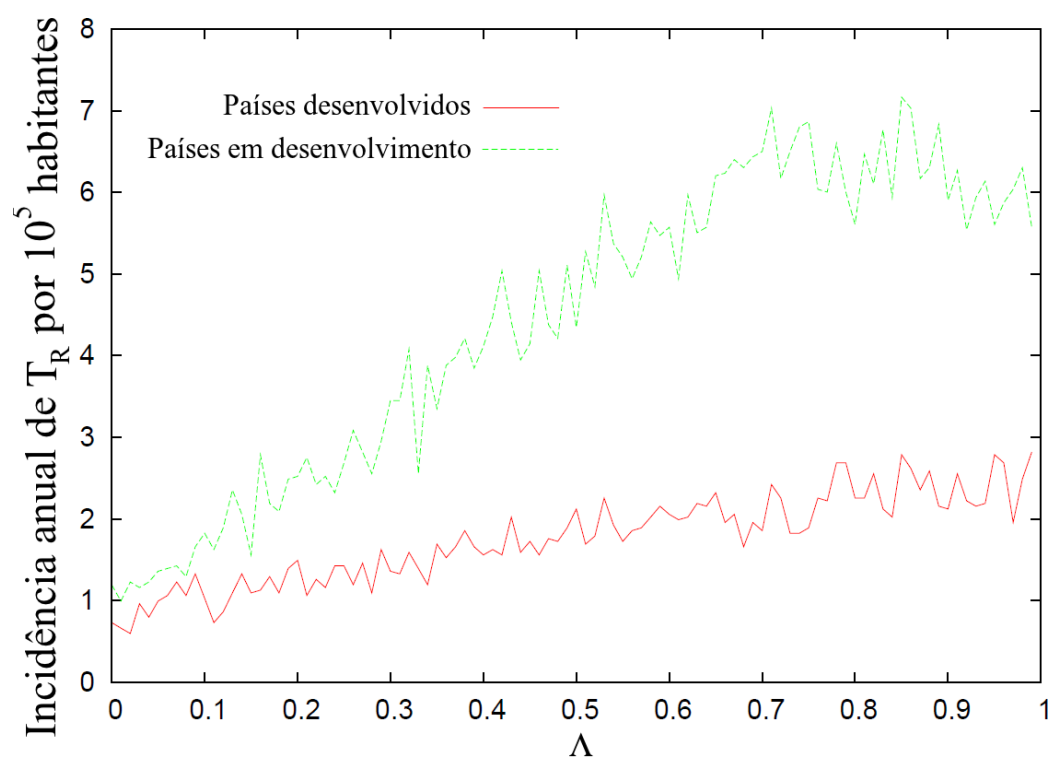

Figura 9.15: Casos $T_{R}$ em função de $\Lambda$ para países desenvolvidos $(\phi=95 \%, r=1 / 10)$ e em desenvolvimento $(\phi=1 / 2, r=1 / 2)$. Parâmetros: $\sigma=1 / 5, \delta=4 / 5, n_{T}=3 / 5$ e $n_{L}=1 / 10$.

$\left(L_{S}\right)$, latente com o tipo $R$ da bactéria $\left(L_{R}\right)$ e, tuberculose ativa com o tipo $S\left(T_{S}\right)$ e tipo $R\left(T_{R}\right)$ da bactéria. Essa simulação numérica permitiu lidar com o problema com mais refinamento que modelos já existentes baseados em equações diferenciais além de ser validada pela reprodução de resultados já conhecidos na literatura.

Simulações para diferentes regimes de tratamento foram testados. Estes diferentes regimes mostraram como tratamentos ineficientes podem criar condições para a emergência de resistência à droga. Também mostramos como a localidade e nãolocalidade (interações locais ou globais) interferem no modelo, resultando em predomínio de diferentes compartimentos na população. Uma vez que o modelo tem estrutura espacial, os diferentes padrões de disseminação de TB podem ser visualizados a qualquer momento da evolução do sistema.

Há várias possibilidades para estender o modelo aqui apresentado. Uma modificação direta, seria incluir um estado de coinfecção da tuberculose. Dessa forma, indivíduos poderiam ser infectados com os tipos $S$ e $R$ da bactéria simultaneamente, o que gera um novo estado $T_{S R}$. Uma segunda modificação possível consideraria mudanças na topologia das redes nas quais os indivíduos estão dispostos. Poderíamos estudar a disseminação da tuberculose em que os contatos entre os indivíduos seriam, por exemplo, em redes do tipo mundo pequeno ou livre de escala [117]. 
Uma variação mais sofisticada desse trabalho estaria focado na emergência de resistência a drogas através do desenvolvimento de um modelo intra-hospedeiro. O estado de cada indivíduo não seria definido por transições relacionadas a certas probabilidades, mas ao número e tipo de patógenos que ele possui. No caso da tuberculose, estados latentes e infecciosos seriam determinados pela quantidade de patógenos em cada um dos indivíduos.

Apresentamos também a exploração do espaço de parâmetros. As simulações mostram a dependência do número de indivíduos infectantes em cenários de países desenvolvidos e em desenvolvimento. Mesmo investimentos pequenos são suficientes para reduzir consideravelmente o número de indivíduos infectantes. Porém, como a quimioprofilaxia possui eficácias diferentes para os dois tipos de linhagens $(R$ e $S)$, não eliminando o tipo $R$, ocorre um aumento do número de indivíduos latentes com tipo $R$ com aumento do número de indivíduos sob tratamento. Este efeito é mais evidente em países em desenvolvimento do que naqueles com nível maior de desenvolvimento. 


\section{Capítulo}

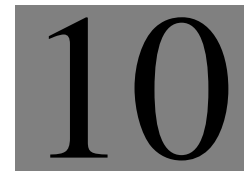

\section{Conclusão}

A elaboração de um modelo que reproduz resultados de determinado sistema é de fundamental importância quando o objetivo é compreender os mecanismo que levam esse sistema a ter um determinado comportamento. Graças à modelagem, é possível fazer previsões permitindo um controle maior dos processo envolvidos. Além disso, podem revelar comportamentos padrões e até mesmo relacionar diferentes áreas do conhecimento em um mesmo formalismo. Aplicações de um mesmo modelo em diferentes contextos podem agregar uma única teoria fundamental, revelando aspectos simples e singulares da natureza.

Modelos generalizados e seus parâmetros de generalização possibilitam o ajuste dos dados. Tais parâmetros podem ter significados intimamente relacionados aos mecanismos do problema estudado. Em modelos de uma espécie, mostramos que o parâmetro de generalização $\tilde{q}$ do modelo de Richards pode ser relacionado com a estrutura fractal das ramificações sanguíneas. Ao atribuir este significado empírico à $\tilde{q}$, relacionamos o comportamento da curva de crescimento com princípios anatômicos que regem o crescimento dos seres vivos.

A remoção ou inserção de indivíduos de uma população pode ser modelada a partir de uma taxa extrínseca de crescimento. Esta taxa é responsável por provocar transições entre sobrevivência e extinção da população. O caso da extinção é particularmente interessante quando buscamos eliminar células de tumores. A partir de um modelo microscópico é possível obter uma interpretação microscópica do parâmetro de generalização do modelo de Richards. Isso possibilita caracterizar curvas de crescimento de tumores de acordo com suas características físicas. Nesse contexto, podemos utilizar conceitos de transição de fase e expoentes críticos de forma 
a obter grandezas relevantes em protocolos de tratamento de tumores.

A relação da taxa extrínseca de crescimento com a capacidade de suporte permite considerar toda influência externa como uma modificação no ambiente, provocando um aumento ou diminuição na população máxima. Algumas particularidades são reveladas com esse resultado. O modelo de Gompertz por exemplo, é o único que pode incorporar totalmente a taxa extrínseca de crescimento na capacidade de suporte. Nesse caso, tanto o estado estacionário quanto a evolução do sistema são idênticos se olhamos para o problema sob a perspectiva da retirada de indivíduos da população ou simplesmente de uma limitação do ambiente. Ao considerar as taxas intrínseca e extrínseca dependentes do tempos é possível abordar modelos de dinâmica de duas espécies assim como modelos estocásticos, em que o ruído é um fator relevante.

Usando a função de escala apropriada, todos os modelos considerados podem ser escritos como um modelo linear simples. Até mesmo quando uma taxa extrínseca de crescimento é incluída nos modelos, o colapso de dados permanece. Esta taxa extrínseca pode representar a aproximação de campo médio da interação entre espécies. Assim, podemos inferir que o colapso de dados é válido para modelos com múltiplas espécies. Ao considerar também esta taxa como um termo de estocasticidade nos modelos, como um ruído aditivo ou multiplicativo, conjecturamos que os modelos estocásticos também apresentam colapso de dados.

No modelo de Lotka-Volterra competitivo, podemos obter os diferentes regimes ecológicos, i.e. neutralismo, comensalismo, amensalismo, competição, predação e mutualismo a partir dos parâmetros de interação $\epsilon_{1}$ e $\epsilon_{2}$. Tais regimes podem ser classificados de acordo com o produto desses parâmetros. Se este termo se anula, pelo menos uma das espécies se torna independente da outra. Se $\epsilon_{1} \epsilon_{2}>0$, tem-se mutualismo (ambos positivos) ou competição (ambos negativos). Para $\epsilon_{1} \epsilon_{2}<0$, temse a predação. O nível coletivo é obtido a partir da estabilidade da solução de estado estacionário, de onde se obtém três fases: a extinção de uma espécie $\left(\epsilon_{i}<-1\right)$, a coexistência de espécies e uma fase proibida $\left(\epsilon_{2}>1 / \epsilon_{1}\right)$. Embora o modelo estudado tenha sido considerado em outros casos isolados, esse estudo revela um aspecto mais geral de um conjunto de equações matemáticas simples, que representam cenários ecológicos muito ricos que podem ser descritos analiticamente. Este formalismo pode ser aplicado para modelar tratamento de câncer a partir de vírus replicantes. As 
soluções analíticas obtidas podem fornecer informações a respeito da população de células cancerosas no tempo transiente, possibilitando uma melhora no planejamento do tratamento.

Assim como os modelos de uma espécie, os de duas espécies podem ser generalizados usando o modelo de crescimento tipo Richards. A generalização do modelo de Lotka-Volterra competitivo modifica as soluções do estado estacionário nos diferentes regimes ecológicos abrangendo um número maior de possíveis situações permitindo uma descrição mais realista dos regimes ecológicos envolvendo duas espécies. Nesse caso geral, dependendo do valor do parâmetro de generalização $\tilde{q}$, não existe coexistência no regime de competição e pode haver extinção de uma das espécies no regime de mutualismo. No regime de predação, a extinção do predador é possível de acontecer, desde que que a condição inicial do sistema seja favorável à presa. Ainda neste regime, é possível fazer uma distinção entre predação forte ou fraca. Além disso, a magnitude de $\tilde{q}$ regula a sensibilidade das espécies aos parâmetros de interação $\epsilon_{1}$ e $\epsilon_{2}$, tornando-as mais sensíveis quanto maior o valor do módulo de $\tilde{q}$.

O formalismo de equações diferenciais pode ser usado para modelar a dinâmica de transmissão de doenças. Soluções analíticas de modelos de uma e duas espécies são as mesmas quando consideramos modelos de disseminação de doenças. Ao considerar o efeito de reforço, o modelo de disseminação da dengue para dois sorotipos permite obter as curvas de epidemia de sua forma hemorrágica. Esses casos estão mais associados às internações devido a sua severidade. O conhecimento prévio do comportamento dessas epidemias, pode possibilitar políticas públicas de saúde mais intensas de combate ao vetor e possibilitar um planejamento do número de leitos em hospitais para suprir a demanda de internações.

Abordagens que não utilizam equações diferenciais ordinárias são interessantes pois permitem a enxergar o problema sob diferentes aspectos e entender mecanismos antes ocultos. Uma abordagem diferente em modelos de doenças transmitidas por vetores é feita utilizando teoria de probabilidades. Nessa abordagem leva-se em conta o número de vezes em que o vetor se alimenta (picadas). A analogia feita entre a dinâmica de transmissão e o sorteio de bolas de uma urna, revela ser um problema que apesar de parecer simples, é muito rico, relacionando geometria multidimensional com conceitos probabilidade e estatística. Aqui, o número de indivíduos 
está relacionado à dimensionalidade da hiper-pirâmide de Pascal enquanto que o número picadas tem relação com a camada dessa hiper-pirâmide. Os elementos dessa hiper-pirâmide: vértices, arestas, faces, etc. relaciona-se com o número de microestados para um dado número de infectados. Um aspecto geral encontrado para esse problema surgiu ao fazermos o colapso das curvas de número médio de indivíduos infectados.

A implementação de um modelo baseado em agentes da disseminação da tuberculose permitiu o estudo da emergência de resistência à droga devido ao uso de antibióticos. O modelo é baseado nas interações entre indivíduos dispostos nos sítios de uma rede quadrada. Diferentemente dos modelos baseados em equações diferenciais, a estrutura espacial é levada em conta neste modelo. Esse estudo permitiu lidar com o problema com mais refinamento que modelos existentes. Simulações para diferentes regimes de tratamento foram testados. Estes diferentes regimes mostraram como tratamentos ineficientes podem criar condições para a emergência de resistência à droga. Uma vez que o modelo permite trabalhar com a localização dos indivíduos, mostramos como a localidade e não-localidade (interações locais ou globais) interferem no modelo, resultando em predomínio de diferentes estágios da doença na população. As simulações também mostram a dependência do número de indivíduos infectantes em cenários de países desenvolvidos e em desenvolvimento. Nestas é mostrado que investimentos pequenos são suficientes para reduzir consideravelmente o número de indivíduos infectantes.

Para finalizar, é interessante enfatizar que foi a obtenção de uma solução analítica para o modelo de crescimento de Richards com coeficientes dependentes do tempo que possibilitou o desenvolvimento de grande parte dos resultados desta tese. 


\section{Capítulo}

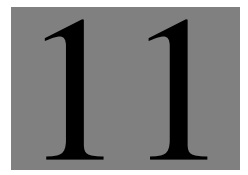

\section{Perspectivas}

Experimentos com crescimento de tecido tumorais devem ser realizados de forma a verificar a interpretação microscópica do parâmetro $\tilde{q}$. Para diferentes tipos de tumores, o parâmetro $\tilde{q}$ deve ser capaz de ajustar as curvas de crescimento. Propomos também experimentos de irradiação desse tumores, verificando as condições em que a extinção das células cancerosas ocorrem. Confrontando em seguida com os resultados analíticos das transições sobrevivência/extinção obtidas no Cap. 3.

Colocando bactérias para crescer em um ambiente controlado ao retirar uma proporção fixa dessas bactérias em determinados intervalos de tempo, poderemos verificar a relação entre a capacidade de suporte e a taxa extrínseca de crescimento conforme proposto no Cap. 3.

Para o modelo generalizado de Lotka-Volterra competitivo nos limitamos aos casos em que os parâmetros $q_{1}$ e $q_{2}$ são iguais. Um estudo considerando esses parâmetros diferentes deve ser realizado de forma a considerar diferenças nos crescimentos das espécies e com isso obter novas situações nos regimes ecológicos. A extinção mútua que ocorre nesse modelo deve ser explorada mais profundamente uma vez que pode estar relacionada ao efeito Allee. Este efeito estabelece um limiar de número de indivíduos abaixo do qual a espécie se extingue.

Para o modelo de disseminação da dengue com dois sorotipos, ainda são necessários alguns estudos quanto aos parâmetros da simulação. Há uma forte dependência, em termos quantitativos, do número total de vetores e hospedeiros do sistema. Possíveis simplificações do modelo de forma a obter soluções analíticas do estado estacionário, assim como o cálculo da taxa básica re reprodução $\left(R_{0}\right)$, 
definida como o número de infecções secundárias produzidas por cada indivíduo infectado. O valor dessa taxa permite prever a emergência ou não da epidemia em função dos parâmetros. Outra possível modificação no modelo seria considerar a população de mosquitos variável ao longo do ano. Esse fenômeno é observado na natureza e está relacionado aos períodos de chuva e mudanças de temperatura. É possível também estudar métodos de controle da doença propondo a erradicação dos mosquitos a partir de uma taxa extrínseca de crescimento conforme estudos dos Cap. 3. Ainda como método de erradicação da dengue, podemos incluir o efeito da bactéria Wolbachia proposto recentemente como forma de controle da doença [118]. Essa bactéria estimula no mosquito as defesas contra o vírus. Como isso acontece ainda permanece um mistério - Talvez por ação competitiva da bactéria por recursos orgânicos, talvez porque a bactéria de alguma forma incentiva a maturação do sistema imune do mosquito. O importante é que esses mosquitos infectados são mais resistentes à infecção pelo vírus da dengue. Além disso, quando fêmeas saudáveis são fecundadas por machos infectados, todos os ovos morrem. Quando uma fêmea contaminada pela bactéria Wolbachia é fecundada por um macho todos os filhotes já nascem contaminados pela bactéria e resistentes ao vírus da dengue. O efeito da bactéria na população de mosquitos poderia ser reproduzido incluindo no modelo uma taxa intrínseca de crescimento dos mosquitos dependente do tempo.

$\mathrm{Na}$ abordagem probabilística da disseminação da dengue, simulações com valores maiores de número de indivíduos precisam ser realizadas. A relação entre o cálculo do valor médio de infectados $(\bar{x})$ e o ajuste da curva desse valor médio em função do número de picadas $b$ ainda precisa ser obtido. Algumas modificações ainda podem ser feitas ao considerar "pesos" ao microestados e dessa forma mimetizar uma mistura não homogênea entre vetores e hospedeiros. Por exemplo, ao atribuir um peso maior aos microestados em que menos indivíduos são infectados, simulamos uma concentração de mosquitos em uma dada região. No caso em que esses pesos são os mesmos para todas as contagens de microestados, temos a situação de mistura homogênea entre vetores e hospedeiros.

No trabalho de disseminação da tuberculose, há várias possibilidades para estender o modelo aqui apresentado. Uma modificação direta, seria incluir um estado de coinfecção de tuberculose. Nesta extensão, indivíduos poderiam ser infectados 
com os tipos $S$ e $R$ da bactéria simultaneamente, o que gera um novo estado $T_{S R}$. Uma segunda modificação possível consideraria mudanças na topologia das redes nas quais os indivíduos estão dispostos. Poderíamos estudar a disseminação da tuberculose quando os contatos entre os indivíduos fossem, por exemplo, em redes do tipo mundo pequeno ou livre de escala. Uma variação mais sofisticada desse trabalho estaria focado na emergência de resistência a drogas através do desenvolvimento de um modelo intra-hospedeiro. Em outras palavras, o estado de cada indivíduo não seria definido por transições relacionadas a certas probabilidades, mas ao número e tipo de patógenos que ele possui. No caso da tuberculose, a diferença entre os estados latente e infeccioso passam a ser determinados pela quantidade de patógenos em cada um dos indivíduos. 


\section{Referências}

[1] N. T. J. Bailey, The Mathematical Theory of Infectious Diseases and its Applications. London: Charles Griffin \& Co., London., 1975. 2

[2] J. D. Murray, Mathematical biology I: an introduction. Springer, New York, 2002. 2, 10, 18, 43, 44, 48, 50, 62, 103

[3] T. Malthus, An Essay on the Principle of Population, as it Affects the Future Improvement of Society. 1798. 2

[4] F. J. Richards, "A flexible growth functions for empirical use," Journal of Experimental Botany, vol. 10, pp. 290-300, 1959. 3, 11, 36, 59

[5] H. von Foerster, P. M. Mora, e L. W. Amiot, "Doomsday: Friday, 13 november, a.d. 2026," Science, vol. 132, pp. 1291-1295, 1960. 9, 35

[6] W. E. Boyce e R. C. DiPrima, Elementary Differential Equation and Boundary Value Problem. Wiley \& Sons, New York, 2009. 10, 18

[7] E. W. Montroll, Fluctuation phenomena, ch. On an enriched collection of stochastic processes, pp. 61-205. Elsevier Science Ltd, 1979. 11

[8] C. Tsallis, "Possible generalization of Boltzmann-Gibbs statistics," Journal of Statistical Physics, vol. 52, pp. 479-487, 1988. 12, 149

[9] C. Tsallis, "What are the numbers experiments provide?," Química Nova, vol. 17 , no. 6 , pp. $468-471,1994.12,149$

[10] R. S. González, Difusão anômala: transic̃ão entre os regimes localizado e estendido na caminhada do turista unidimensional. PhD thesis, 2009. 12 
[11] G. B. West, J. H. Brown, e B. J. Enquist, "A general model for the origin of allometric scaling laws in biology," Science, vol. 276, pp. 122-126, 1997. 12, 14

[12] G. B. West, J. H. Brown, e B. J. Enquist, "A general model for ontogenetic growth," Nature, vol. 413, pp. 628-631, 2001. 12, 14

[13] G. B. West, J. H. Brown, e B. J. Enquist, "Life's universal scaling law," Physics today, pp. 36-42, 2004. 12

[14] M. E. Turner, E. L. Bradley, K. A. Kirk, e K. M. Pruitt, "A theory of growth," Mathematical Biosciences, vol. 29, pp. 367-373, 1976. 14, 36

[15] A. Tsoularis e J. Wallace, "Analysis of logistic growth models," Mathematical Biosciences, vol. 179, pp. 21-55, May 2002. 15, 37

[16] L. Norton, R. Simon, H. D. Brereton, e A. E. Bogden, "Predicting the course of gompertzian growth," Nature, vol. 264, pp. 542-545, 1976. 17, 19

[17] J. A. González e I. Rondón, "Cancer and nonextensive statistics," Physica A, vol. 369, pp. 645-654, 2006. 17

[18] A. dOnofrio, U. Ledzewicz, H. Maurer, e H. Schättlerd, "On optimal delivery of combination therapy for tumors," Mathematical Biosciences, vol. 222(1), pp. 13-26, 2009. 17

[19] B.-Q. Ai, X.-J. Wang, G.-T. Liu, e L.-G. Liu, "Correlated noise in a logistic growth model," Physical Review E, vol. 67, p. 022903, 2003. 17, 30

[20] S. A. Menchón e C. A. Condat, "Cancer growth: Predictions of a realistic model," Physical Review E, vol. 78, p. 022901, 2008. 17

[21] P. P. Delsanto, A. Romano, M. Scalerandi, , e G. P. Pescarmona, "Analysis of a phase transition from tumor growth to latency," Physical Review E, vol. 62, p. $25472554,2000.17$

[22] B. C. T. Cabella, A. S. Martinez, e F. Ribeiro, "Data collapse, scaling functions, and analytical solutions of generalized growth models," Physical Review $E$, vol. 83, p. 061902, 2011. xv, 17, 25, 34, 35, 38, 54 
[23] B. C. T. Cabella, F. Ribeiro, e A. S. Martinez, "Effective carrying capacity and analytical solution of a particular case of the richards-like two-species population dynamics model," Physica A, vol. 391, p. 12811286, 2012. xv, xviii, 17, 28, 62, 70, 71

[24] A. K. Laird, S. A. Tyler, e A. Barton, "Dynamics of normal growth," Growth, vol. 29, pp. 233-248, 1965. 19

[25] Z. Bajzer, S. Vuk-Pavlovic, e M. Huzac, A survey of models for tumor-immune system dynamics. Birkhauser, Boston, 1996. 19

[26] M. H. Zwietering, I. Jongenburger, F. M. Rombouts, e K. V. T. Riet, "Modeling of the bacterial growth curve," Applied and Environmental Microbiology, vol. 56, pp. 1875-1881, 1990. 19

[27] B. Gompertz, "On the nature of the function expressive of the law of human mortality, and on a new mode of determining the value of life contingencies," Philosophical Transactions of the Royal Society of London, vol. 115, pp. 513585, 1825. 19

[28] Z. Bajzer, "Gompertzian growth as a self-similar and allometric process," Growth Development 6 Aging, vol. 63, pp. 3-11, 1999. 19

[29] E. S. D. Hart e Z. Agur, "The growth law of primary breast cancer as inferred from mammography screening trials data," British Journal of Cancer, vol. 78, pp. 382-387, 1998. 19

[30] P. F. Verhult, "Notice sur la loi que la population poursuit dans son accroissement," Correspondances Mathematiques et Physiques, vol. 10, pp. 113-121, 1838. 19

[31] V. P. Collins, R. K. Loeffler, e H. Tivey, "Observations on growth rtes of human tumors," The American Journal of Roentgenology, Radium Therapy, and Nuclear Medicine, vol. 76, pp. 988-1000, 1956. 19

[32] H. E. Skipper, F. M. S. Jr., e W. S. Wilcox, "Experimental evaluation of potential anticancer agents. xii. on the criteria and kinetics associated with 
"curability"of experimental leukemia," Cancer Chemotherapy Reports, vol. 35, pp. 1-111, 1964. 19

[33] W. S. Wilcox, D. P. Griswold, W. R. L. Jr., F. M. S. Jr., e H. E. Skipper, "Experimental evaluation of potenital anticancer agents. xvii. kinetics of growth and regression after treatment of certain solid tumors," Cancer Chemotherapy Reports, vol. 47, pp. 27-39, 1965. 19

[34] M. Duchatellier e L. Israel, "Growth fraction, resistance, schedule-doubling time relationship sequential versus simultaneous combinations, as evaluated by a mathematical model of response to chemotherapy," European Journal of Cancer, vol. 7, pp. 545-549, 1971. 19

[35] M. H. Zwietering, J. C. deWit, e S. Notermans, "Application of predictive microbiology to estimate the number of bacillus cereus in pasteurised milk at the point of consumption," International Journal of Food Microbiology, vol. 30, pp. 55-70, 1996. 19

[36] J. Crown, "High dose chemotherapy of metastatic breast cancer: the end of the beginning?," British Journal of Cancer, vol. 75, pp. 467-469, 1997. 19

[37] M. W. Retsky, R. H. Wardwell, D. E. Swartzendruber, e D. L. Headley, "Prospective computerized simulation of breast cancer: Comparison of computer predictions with nine sets of biological and clinical data," Cancer Research, vol. 47, pp. 4982-4987, 1987. 19

[38] M. W. Retsky, D. E. Swartzendruber, R. H. Wardwell, P. Bame, e V. Petrosky, "A gompertzian model of human breast cancer growth," Cancer Research, vol. 49, pp. 6443-6444, 1989. 19

[39] L. Norton, "Correspondence re: Larry norton, a gompertzian model of human breast cancer growth," Cancer Research, vol. 49, p. 6444, 1989. 19, 23

[40] G. G. Steel e L. F. Lamerton, "The growth rate of human tumours," British Journal of Cancer, vol. 20, pp. 74-86, 1966. 19 
[41] G. A. G.G. Steel e A. Herwich, The Biological Basis of Radiotherapy. Elsevier, Amsterdam, 1989. 19

[42] G. Steel, Basic Clinical Radiobiology. Edward Arnold Publisher, London, 2002. 19

[43] P. W. Sullivan e S. E. Salmon, "Kinetics of tumor growth and regression in igg multiple myeloma," The Journal of Clinical Investigation, vol. 51, pp. 16971708, 1972. 19

[44] L. Norton, "A gompertzian model of human breast cancer growth," Cancer Research, vol. 48, pp. 7067-7071, 1988. 19, 23

[45] T. K. C.P. Calderon, "Modeling tumor growth," Mathematical Biosciences, vol. 103, pp. 97-114, 1991. 19

[46] S. Gilbert, Developmental Biology. Sinauer, Sunderland, 1991. 20

[47] M. A. Castro, G. Schwartsmanna, E. A. Bernard, e J. C. Moreira, "Phenotype modulation of cellular uv-sensitivity," Cancer Letters, vol. 45, pp. 65-72, 1999. 20

[48] R. K. D. Drasdo e J. S. McCaskill, "Monte carlo approach to tissue-cell populations," Physical Review E, vol. 52, pp. 6635-6657, 1995. 20

[49] S. M. C. M. Strigini, "Wingless gradient formation in the drosophila wing," Current Biology, vol. 10, pp. 293-300, 2000. 20

[50] M. Milán e S. M. Cohen, "Notch signaling is not sufficient to define the affinity boundary between dorsal and ventral compartments," Mollecular Cell, vol. 4, pp. 1073-1078, 1999. 20

[51] L. M. Franks, Introduction to the Cellular and Molecular Biology of Cancer. Oxford University Press, New York, 1990. 20

[52] P. Waliszewski, M. Molski, e J. Konarski, "On the holistic approach in cellular and cancer biology: nonlinearity, complexity and quasideterminism of dynamic cellular network," Journal of Surgical Oncology, vol. 68, pp. 70-78, 1998. 20 
[53] P. Waliszewski, M. Molski, e J. Konarski, "Self-similarity, collectivity and evolution of fractal dynamics during retinoid-induced differentiation of cancer cell population," Fractals, vol. 7, pp. 139-149, 1999. 20

[54] P. Waliszewski, J. Konarski, e M. Molski, "On the modification of fractal self-space during cell differentiation or tumor progression," Fractals, vol. 8, pp. 195-203, 2000. 20

[55] P. Waliszewski, M. Molski, e J. Konarski, "On the relationship between fractal geometry of space and time in which a cellular system exists and dynamics of gene expression," Acta Biochimica Polonica, vol. 48, pp. 209-220, 2001. 20

[56] W. Isaeva, E. V. Puschina, e Y. A. Karetin, "The quasi-fractal structure of fish brain neurons," Russian Journal of Marine Biology, vol. 30, pp. 127-134, 2004. 20

[57] J. Pastor, A. Bru, I. Fernaud, C. Berenguer, M. J. Fernaud, e S. Melle, "Fractal dimension and temporal evolution of neurons," Anales de Física / Real Sociedad Española de Física, vol. 10, pp. 1-2, 1998. 20

[58] M. Molski e J. Konarski, "Tumor growth in the space-time temporal fractal dimension," Chaos, Solitons 85 Fractals, vol. 36, pp. 811-818, 2008. 20

[59] J. C. M. Mombach, N. Lemke, B. E. J. Bodmann, e M. A. P. Idiart, "A meanfield theory of cellular growth," Europhysics Letters, vol. 59, pp. 923-928, 2002. 20,30

[60] J. C. M. Mombach, N. Lemke, B. E. J. Bodmann, e M. A. P. Idiart, "A meanfield theory of cellular growth," Europhysics Letters, vol. 60, p. 489, 2002. 20

[61] T. Wheldon, Mathematical Models in Cancer Research. Adam Hilger, Bristol, 1988. 23,24

[62] L. Norton e R. Simon, "Tumor size, sensitivity to therapy, and design of treatment schedules," Cancer Treatment Reports, vol. 61, pp. 1307-1317, 1977. 23 
[63] L. Norton e R. Simon, "The norton-simon hypothesis revisited," Cancer Treatment Reports, vol. 70, pp. 163-169, 1986. 23

[64] H. E. Stanley, Introduction to Phase Transitions and Critical Phenomena. 1971. 26

[65] H. Calisto e M. Bologna, "Exact probability distribution for the BernoulliMalthus-Verhulst model driven by a multiplicative colored noise," Physical Review E, vol. 75, p. 050103(R), 2007. 29

[66] G. Aquino, M. Bologna, e H. Calisto, "An exact analytical solution for generalized growth models driven by a Markovian dichotomic noise," Europhysics Letters, vol. 89, p. 50012, 2010. 29

[67] B. C. T. Cabella, F. Ribeiro, e A. S. Martinez, "Full analytical solution and complete phase diagram analysis of the verhulst-like two-species population dynamics model," arXiv:1010.3361v2 [q-bio.PE], 2011. xv, xvi, xvii, 29, 47, $51,52,55,57$

[68] E. W. Montroll, "Social dynamics and the quantifying of social forces," Proceedings of the National Academy of Sciences U. S. A., vol. 75, pp. 4633-4637, 1978. 30,36

[69] R. Zygadlo, "Verhulst-type kinetics driven by white shot noise: Exact solution by direct averaging," Physical Review E, vol. 47, pp. 106-117, 1993. 30

[70] R. Zygadlo, "Relaxation and stationary properties of a nonlinear system driven by white shot noise: An exactly solvable model," Physical Review E, vol. 47, pp. 4067-4075, 1993. 30

[71] R. Mannella, C. J. Lambert, N. G. Stocks, e P. V. E. McClintock, "Relaxation of nonlinear systems driven by colored noise: An exact result," Physical Review $A$, vol. 41, pp. 3016-3020, 1990. 30

[72] A. A. Dubkov e B. Spagnolo, "Verhulst model with levy white noise excitation," The European Physical Journal B, vol. 65, pp. 361-367, 2008. 30 
[73] P. Ball, Critical Mass: How One Thing Leads to Another. Farrar, Straus and Giroux, 2004. 33

[74] S. M. Bhattacharjee e F. Seno, "A measure of data collapse for scaling," Journal of physics A: mathematical and general, vol. 34, pp. 6375-6380, 2001. 33

[75] H. E. Stanley, "Scaling, universality and renormalization: three pillars of modern critical phenomena," Reviews of modern physics, vol. 71, p. S358, 1999. 33

[76] A.-L. Barabasi e H. E. Stanley, Fractal concepts in surface growth. Cambridge University Press, 1995. 33

[77] D. Strzalka e F. Grabowski, "Towards possible $q$-generalizations of the malthus and verhulst growth models," Physica A, vol. 387, pp. 2511-2518, 2008. 36

[78] A. S. Martinez, R. S. González, e C. A. S. Terçariol, "Continuous growth models in terms of generalized logarithm and exponential functions," Physica $A$, vol. 387 , no. 23 , pp. 5679-5687, 2008. 36, 59

[79] A. S. Martinez, R. S. González, e A. L. Espíndola, "Generalized exponential function and discrete growth models," Physica A, vol. 388, pp. 2922-2930, 2009. 36,59

[80] M. A. Nowak, R. M. Anderson, A. R. McLean, T. F. Wolfs, J. Goudsmit, e R. M. May, "Antigenic diversity thresholds and the development of aids," Science, vol. 254, pp. 963-969, 1991. 43, 57

[81] L. Edelstein-Keshet, Mathematical models in biology. SIAM, May 2005. 44, 62

[82] N. S. Goel, S. C. Maitra, e E. W. Montroll, "On the Volterra and other nonlinear models of interacting populations," Reviews of modern physics, vol. 43, pp. 232-276, 1971. 46

[83] K. W. Dorschner, S. F. Fox, M. S. Keener, e R. D. Eikenbary, "Lotka-volterra competition revisited: The importance of intrinsic rates of increase to the unstable equilibrium," Oikos, vol. 48, pp. 55-61, 1987. 46 
[84] J. Hofbauer e K. Sigmund, The theory of evolution and dynamical systems: mathematical aspects of selection. Cambridge University Press, Cambridge, 1988. 46

[85] A. Hastings, "Transients: the key to long-term ecological understanding?," Trends in Ecology and Evolution, vol. 19 (1), 2004. 56

[86] S. Gavrilets e A. Hastings, "Intermittency and transient chaos from simple frequency- dependen selection," Proceedings of the Royal Society B: Biological Sciences, vol. 261, p. 233238, 1995. 56

[87] Y. Lai e R. Winslow, "Geometric-properties of the chaotic saddle responsible for supertransients in spatiotemporal chaotic systems.," Physical Review Letters, vol. 74, p. 52085211, 1995. 56

[88] Y. Lai, "Persistence of supertransients of spatiotemporal chaotic dynamicalsystems in noisy environment.," Physics Letters A, vol. 200, p. 418422, 1995. 56

[89] Y. Lai, "Unpredictability of the asymptotic attractors in phasecoupled oscillators.," Physical Review, vol. 51, p. 29022908, 1995. 56

[90] L. F. Cavalieri e H. Kocak, "Intermittent transition between order and chaos in an insect pest population.," Journal of Theoretical Biology, vol. 175, p. 231234, 1995. 56

[91] M. Harrison, "Dynamical mechanism for coexistence of dispersing species.," Journal of Theoretical Biology, vol. 213, p. 5372, 2001. 56

[92] V. Kaitala, "Dynamic complexities in host-parasitoid interaction.," Journal of Theoretical Biology, vol. 197, p. 331341, 1999. 56

[93] A. L. de Espíndola, C. T. Bauch, B. C. T. Cabella, e A. S. Martinez, "An agent-based computational model of the spread of tuberculosis," Journal of Statistical Mechanics: Theory and Experiment, p. P05003, 2011. xx, xxi, xxii, $56,104,106,112,113,114,115,116,117,118,119,120$ 
[94] D. Wodarz, "Viruses as antitumor weapons: defining conditions for tumor remission.," Cancer Research, vol. 61(8), pp. 3501-3507, 2001. 57

[95] A. S. Novozhilov, F. S. Berezovskaya, E. V. Koonin, e G. P. Karev, "Mathematical modeling of tumor therapy with oncolytic viruses: regimes with complete tumor elimination within the framework of deterministic models," Biology Direct, vol. 1:6, 2006. 58

[96] P. Turchin, Complex Population Dynamics - A Theoretical/Empirical Synthesis. Princeton University Press, 2003. 80

[97] W. H. Organization, "Dengue." http://www.who.int/topics/dengue/en/. 83, 84

[98] S. de Estado da Saúde de São Paulo, "Boletim epidemiológico paulista." http://www.cve.saude.sp.gov.br/agencia/bepa20.htm, 2005. 83

[99] R. J. S. Pontes, A. L. D. Fabbro, G. de Melo Rocha, R. C. Santiago, L. T. M. F. A. A. M. C. Silva, V. D. O. Garotti, e J. M. P. Pint, "Epidemia de dengue em ribeirão preto, sp, brasil: nota prévia," Revista de Saúde Pública, vol. 25, 1991. 84

[100] A. L. Dal-Fabbro, A. D. C. Passos, e E. M. S. Rodrigues, "Dengue control in Ribeira ao Preto," Caderno de Saúde Pública, vol. 14, 1998. 84

[101] E. C. Holmes, L. M. Bartley, e G. P. Garnett, Emerging Infections. Academic Press, 1998. xix, 85, 86

[102] W. H. Organization, "Tuberculosis." http://www.who.int/topics/tuberculosis/en/, July 2009. 103

[103] B. R. Bloom e C. J. L. Murray, "Tuberculosis: commentary on a reemergent killer," Science, vol. 257, pp. 1055-1064, 1992. 103

[104] S. M. Blower e J. L. Gerberding, "Understanding, predicting and controlling the emergence of drug-resistant tuberculosis: a theoretical framework," Journal of Molecular Medicine, vol. 76, pp. 624-636, 1998. 103, 104, 105, 111 
[105] S. M. Blower, A. R. Mclean, T. C. Porco, P. M. Small, P. C. Hopewell, M. A. Sanchez, e A. R. Moss, "The intrinsic transmission dynamics of tuberculosis epidemics," Nature Medicine, vol. 8, no. 1, pp. 815-821, 1995. 103, 104, 105

[106] P. M. S. S. M. Blower e P. Hopewell, "Control strategies for tuberculosis epidemics: new models for old problems," Science, vol. 273, pp. 497-500, 1996. 103, 104, 105

[107] S. M. Blower, T. C. P. T., e T. Lietman, Tuberculosis: the evolution of antibiotic resistance and the design of epidemic control strategies. Mathematical Models in Medical and Health Sciences. Eds Horn, Simonett, Webb. Vanderbilt University Press, 1998. 103, 104, 105

[108] S. C. Fu, "Modelling epidemic spread using cellular automata," Master's thesis, The Univesity of Western Australia, Department of Computer Science and Software Enginnering, 2002. 104

[109] A. L. Espíndola, Modelos Computacionais Baseados em Agentes Aplicados á Migrac̃ão Interna. $\mathrm{PhD}$ thesis, Instituto de Física, Universidade Federal Fluminense, 2006. 105

[110] J. J. Silveira, A. L. Espíndola, e T. J. P. Penna, "An agent-based model to rural-urban migration analysis," Physica A, vol. 364, pp. 445-456, 2006. 105

[111] A. L. Espíndola, T. J. P. Penna, e J. J. Silveira, "Rural-urban migration in d-dimensional lattices," International Journal of Modern Physics C, vol. 16, no. 12 , pp. 1831-1840, 2005. 105

[112] A. L. Espíndola, J. J. Silveira, e T. J. P. Penna, "A harris-todaro agent-based model to rural-urban migration," Brazilian Journal of Physics, vol. 36, no. 3A, pp. 610-613, 2006. 105

[113] D. Alves, V. J. Haas, e A. Caliri, "The predictive power of r0 in an epidemic probabilistic system.," Journal of Biological Physics, vol. 29, pp. 63-75, 2003. 107 
[114] L. H. Schimdt, "The emergence of isoniazid-sensitive bacilli in monkeys inoculated with isoniazid-resistant strains.," Trans. 17th Conference on Chemotherapy of Tuberculosis - VA Armed Forces, p. 264, 1958. 107

[115] D. J. Austin, K. G. Kristinsson, e R. M. Anderson, "The transmission dynamics of antibiotic-resistant bacteria: the relationship between resistance in commensal organisms and antibiotic consumption," Proceedings of the Royal Society B: Biological Sciences, vol. 264, pp. 1629-1638, 1997. 110

[116] D. J. Austin, K. G. Kristinsson, e R. Anderson., "The relationship between the volume of antimicrobial consumption in human communities and the frequency of resistance," Proceedings of the National Academy of Sciences, vol. 96, pp. 1152-1156, 2007. 110

[117] A. Barabasi, Linked: how everything is connected to everything else and what it means for science, business and everyday life. New York: Peguin Group, 2002. 126

[118] A. A. Hoffman, B. L. Montgomery, J. Popovici, I. Iturbe-Ormaetxe, P. H. Johnson, F. Muzzi, M. Greenfield, M. Durkan, Y. S. Leong, Y. Dong, H. Cook, J. Axford, A. G. Callahan, N. Kenny, C. Omodei, E. A. McGraw, P. A. Ryan, S. A. Ritchie, M. Turelli, e S. L. ONeill, "Successful establishment of wolbachia in aedes populations to suppress dengue transmission," Nature, vol. 476, p. $454457,2011.134$

[119] L. Nivanen, A. L. M. A, e Q. A. Wang, "Generalized algebra within a nonextensive statistics," Rep. Math. Phys., vol. 52, pp. 437-444, Dec 2003. 152

[120] N. Kalogeropoulos, "Algebra and calculus for tsallis thermo-statistics," Physica A, vol. 356, pp. 408-418, 2005. 152

[121] E. P. Borges, "A possible deformed algebra and calculus inspired in nonextensive thermostatistics," Physica A, vol. 340, pp. 95-101, 2004. 152 


\section{Apêndice}

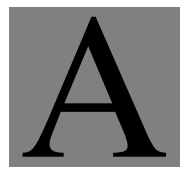

\section{Generalização das funções logaritmo e exponencial}

Neste capítulo apresentamos várias generalizações das funções logarítmica e exponencial, propostas nos mais variados contextos da ciência. Utilizamos argumentos totalmente geométricos, apresentamos uma generalização dessas funções similar à obtida no contexto da termodinâmica não-extensiva [8, 9].

Baseado em argumentos da termodinâmica não-extensiva [8], C. Tsallis propôs uma generalização das funções logarítmica e exponencial [9]. Esta generalização não é unívoca.

Considere a família de funções $f_{\tilde{q}}(t): \mathbb{R}_{+}^{*} \rightarrow \mathbb{R}, \tilde{q} \in \mathbb{R}:$

$$
f_{\tilde{q}}(t)=\frac{1}{t^{1-\tilde{q}}} .
$$

Note que para $\tilde{q}<1$, a família de funções acima corresponde a hipérboles assimétricas, sendo simétrica em relação à bissetriz do primeiro quadrante apenas para $\tilde{q}=0$. Por outro lado, para $\tilde{q}>1$, a Eq. A.1 representa leis de potência, enquanto que para $\tilde{q}=1$ obtém-se a função constante $f_{1}(t)=1$. Nestes dois últimos casos, a Eq. A.1 não diverge em $t=0$, permitindo acrescentar a origem no domínio da função. A Fig. A.1 mostra graficamente os diversos comportamentos da Eq. A.1 para alguns valores do parâmetro $\tilde{q}$. Note-se que $f_{\tilde{q}}(1)=1, \forall \tilde{q} \in \mathbb{R}$.

É interessante notar que a função inversa de $f_{\tilde{q}}(t)$ é $f_{\tilde{q}^{\prime}}(t)$, com $\tilde{q}^{\prime}=\tilde{q} /(\tilde{q}-1)$. Este fato pode ser observado graficamente na Fig. A.1. Note-se que os gráficos das funções $f_{3}(t)$ e $f_{3 / 2}(t)$ apresentam uma simetria de espelhamento em torno da bissetriz do primeiro quadrante $\left[f_{2}(t)\right]$, que é característica de funções inversas. O 
mesmo pode ser observado para os gráficos de $f_{1 / 2}(t)$ e $f_{-1}(t)$.

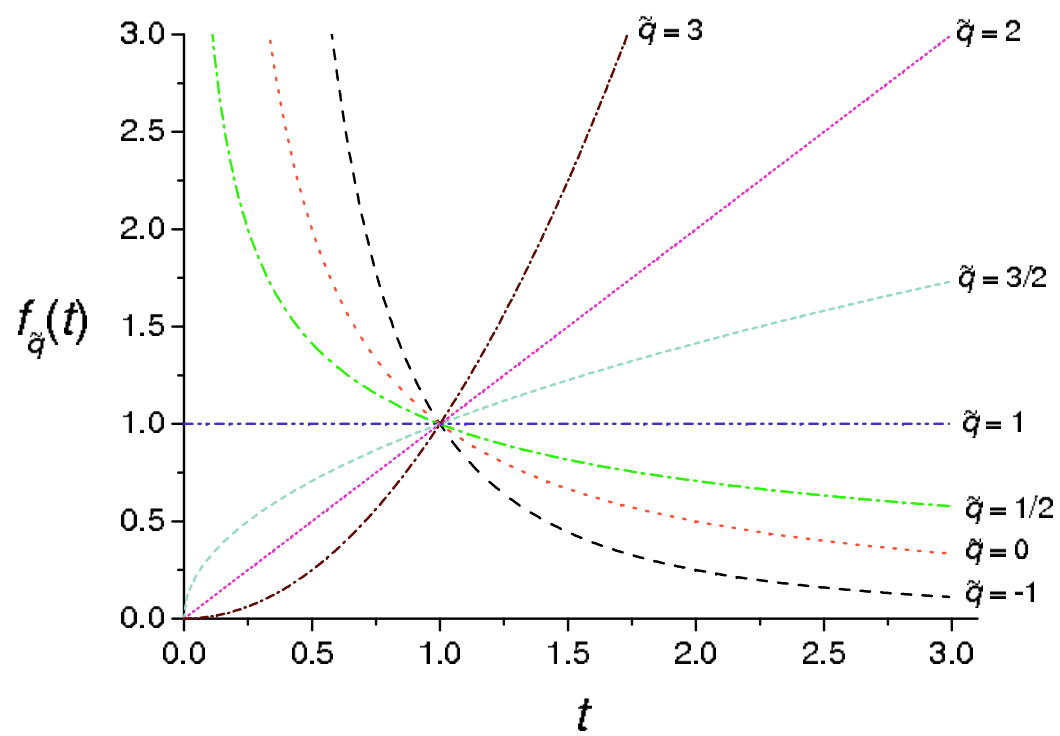

Figura A.1: Comportamento hiperbólico $(\tilde{q}<1)$, constante $(\tilde{q}=1)$ e lei de potência $(\tilde{q}>1)$ da função $f_{\tilde{q}}(t)=t^{\tilde{q}-1}$ (Eq. A.1) para diversos valores de $\tilde{q}$. Note-se que para $\tilde{q}=2$ (função linear) ocorre uma mudança de concavidade nas leis de potência.

\section{A.1 Função logaritmo generalizada}

A função logaritmo natural generalizada (ou simplesmente $\tilde{q}$-logaritmo), $\ln _{\tilde{q}}(x)$, $x>0$, pode ser interpretada geometricamente como a área abaixo da curva da Eq. A.1 no intervalo $[1, x]$ :

$$
\ln _{\tilde{q}}(x)=\int_{1}^{x} \frac{\mathrm{d} t}{t^{1-\tilde{q}}}=\lim _{\tilde{q}^{\prime} \rightarrow \tilde{q}} \frac{x^{\tilde{q}^{\prime}}-1}{\tilde{q}^{\prime}}= \begin{cases}\frac{x^{\tilde{q}}-1}{\tilde{q}}, & \text { se } \tilde{q} \neq 0 \\ \ln x, & \text { se } \tilde{q}=0 .\end{cases}
$$

É importante não confundir esta função com o logaritmo de base $\tilde{q}\left[\log _{\tilde{q}}(x)\right]$. Esta é uma generalização da definição da função logaritmo natural, que é obtida como caso particular para $\tilde{q}=0$. Devido à definição (Eq. A.2), a área é considerada negativa para $0<x<1$ e positiva para $x>1$, independentemente do valor de $\tilde{q}$. Além disso, para $x=1$, a área é nula, mantendo a propriedade do logaritmo tradicional: $\log _{\tilde{q}} 1=0$. A Fig. A.2 mostra o comportamento da Eq. A.2 para alguns valores de $\tilde{q}$. 


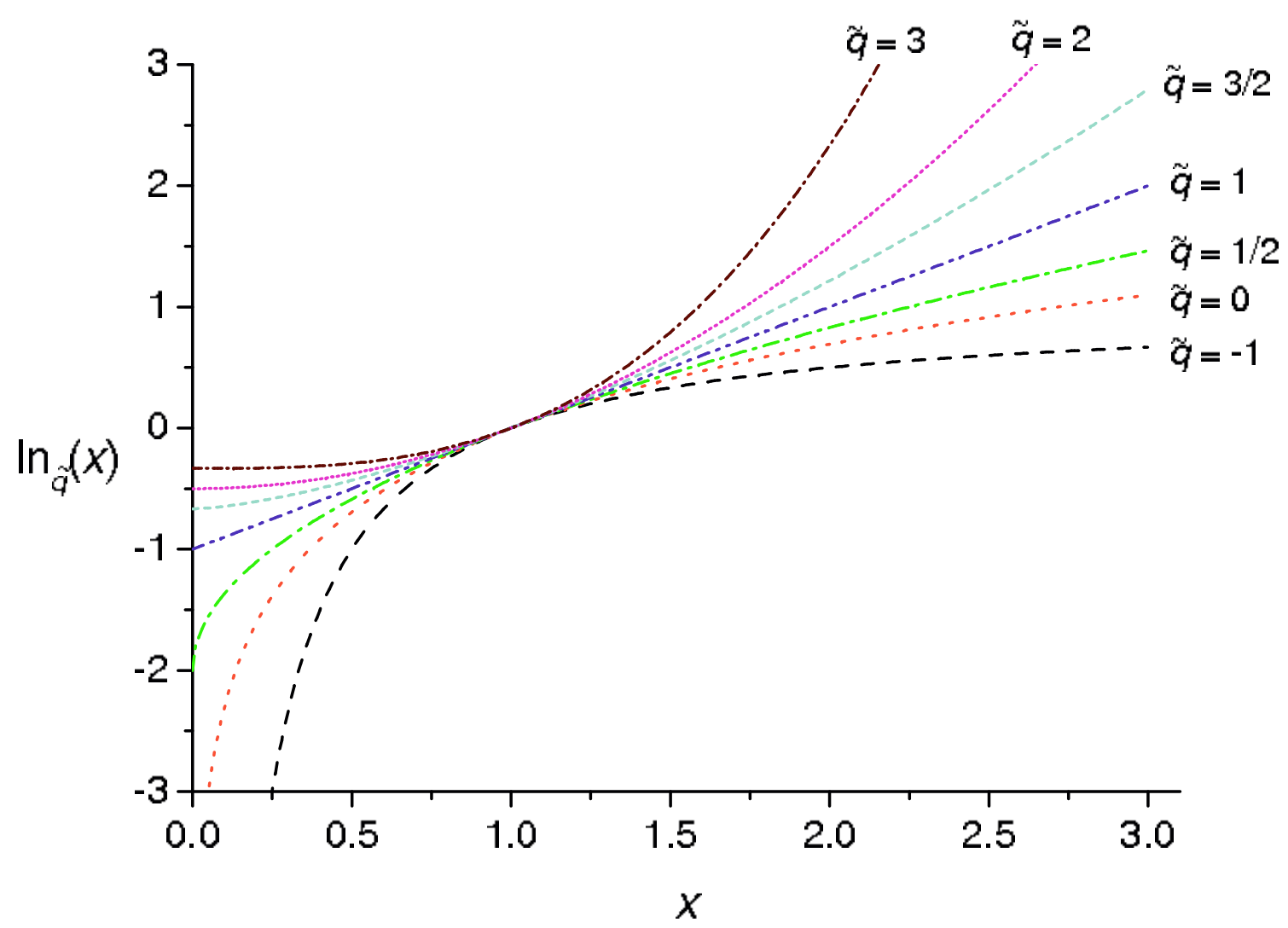

Figura A.2: Comportamento da função q̃-logarítmica (Eq. A.2) para alguns valores de $\tilde{q}$.

A imagem da função $\tilde{q}$-logaritmo é obtida tomando-se os limites $x \rightarrow 0^{+}$e $x \rightarrow$ $+\infty$, para os casos $\tilde{q}<0$ e $\tilde{q}>0$, respectivamente. Assim, verifica-se que:

$$
\operatorname{Im}\left[\ln _{\tilde{q}}(x)\right]=\left\{\begin{array}{ccc}
(-\infty,-1 / \tilde{q}) & \text { se } & \tilde{q}<0 \\
\mathbb{R} & \text { se } & \tilde{q}=0 \\
(1 / \tilde{q},+\infty) & \text { se } & \tilde{q}>0
\end{array}\right.
$$

Dados uma deformação $\alpha \neq 0$ e um fator de escala $\beta \neq 0$, pode-se encontrar a seguinte propriedade do $\tilde{q}$-logaritmo:

$$
\ln _{\tilde{q}}\left(\beta x^{\alpha}\right)=\frac{\left(\beta x^{\alpha}\right)^{\tilde{q}}-1}{\tilde{q}}=\alpha\left[\frac{\left(\beta^{1 / \alpha} x\right)^{\alpha \tilde{q}}-1}{\alpha \tilde{q}}\right]=\alpha \ln _{\alpha \tilde{q}}\left(\beta^{1 / \alpha} x\right) .
$$

Para $\alpha=-1$, temos que:

$$
\ln _{\tilde{q}}\left(\frac{\beta}{x}\right)=-\ln _{-\tilde{q}}\left(\frac{x}{\beta}\right)
$$


É interessante notar que a Eq. A.5 apresenta duas simetrias: uma aritmética (inversão aditiva) e outra geométrica (inversão multiplicativa). Para o caso particular de $\beta=1$, temos:

$$
\ln _{\tilde{q}}\left(x^{-1}\right)=-\ln _{-\tilde{q}}(x)
$$

Assim, $\forall x>0, \ln _{\tilde{q}}\left(x^{-1}\right)=-\ln _{-\tilde{q}}(x)$ se, e somente se, $\tilde{q}=0$. Este resultado mostra que a função q̃-logaritmo se comporta como função logarítmica apenas no limite $\tilde{q} \rightarrow 0$.

Aqui utilizamos a mesma representação das Refs. [119, 120] $(\tilde{q}=a=k)$ ao invés da representação tradicional $(\tilde{q}=1-q)$ utilizada na Ref. [121] porque a primeira evidencia melhor a simetria exposta na Eq. A.5.

\section{A.2 Função exponencial generalizada}

A partir das Eqs. A.2 e A.3, temos que a função q̃-logaritmo é bijetora e, portanto, admite inversão. Geometricamente, isso corresponde a determinar o limite superior do intervalo $[0, y]$ para o qual a área sob a curva da Eq. A.1 é igual a $x$, isto é, $\ln _{\tilde{q}}(y)=x$. À função inversa do $\tilde{q}$-logaritmo dá-se o nome de função exponencial generalizada (ou simplesmente $\tilde{q}$-exponencial), $\exp _{\tilde{q}}(x)$. Devido às propriedades das funções inversas, e pela definição acima, $\exp _{\tilde{q}}(x)=y$, então, $\exp _{\tilde{q}}\left[\ln _{\tilde{q}}(y)\right]=y=$ $\ln _{\tilde{q}}\left[\exp _{\tilde{q}}(y)\right]$. Analiticamente, a função $\tilde{q}$-exponencial é dada por:

$$
\begin{aligned}
\exp _{\tilde{q}}(x) & = \begin{cases}\lim _{\tilde{q}^{\prime} \rightarrow \tilde{q}}\left[1+\tilde{q}^{\prime} x\right]^{1 / \tilde{q}^{\prime}} & , \text { se } \tilde{q} x \geq-1 \\
0 & , \text { caso contrário }\end{cases} \\
& =\lim _{\tilde{q}^{\prime} \rightarrow \tilde{q}}\left[1+\tilde{q}^{\prime} x\right]_{+}^{1 / \tilde{q}^{\prime}},
\end{aligned}
$$

onde o uso do operador

$$
[a]_{+}=\max (a, 0)
$$

é necessário, uma vez que $\exp _{\tilde{q}}(x)$ não é real se $\tilde{q} x<-1$. A função $\tilde{q}$-exponencial é estritamente não-negativa, $\exp _{\tilde{q}}(x) \geq 0$, e $\exp _{\tilde{q}}(0)=1$, para qualquer valor de $\tilde{q}$. A Fig. A.3 mostra o comportamento da Eq. A.7 para alguns valores de $\tilde{q}$.

Dado $\alpha \neq 0$, obtém-se para a função q̃-exponencial uma relação similar àquela 


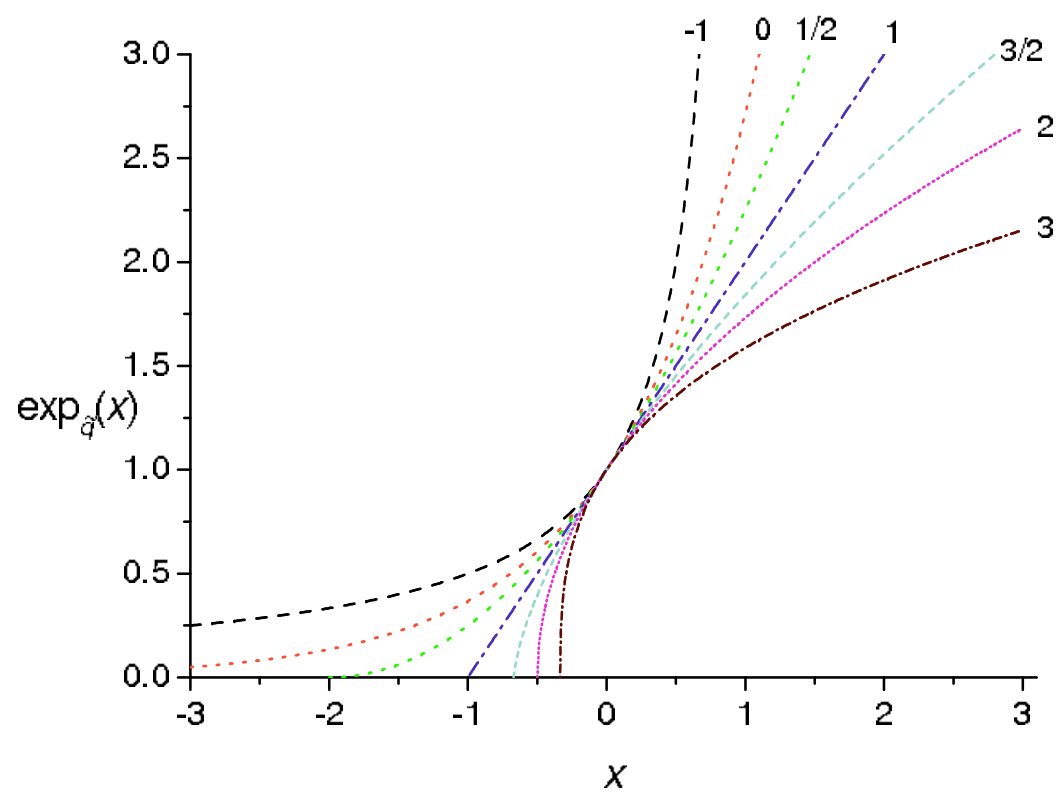

Figura A.3: Comportamento da função $\tilde{q}$-exponencial (Eq A.7) para alguns valores de $\tilde{q}$.

expressa na Eq. A.4:

$$
\left[\exp _{\tilde{q}}(x)\right]^{\alpha}=(1+\tilde{q} x)^{\alpha / \tilde{q}}=\left[1+\left(\frac{\tilde{q}}{\alpha}\right) \alpha x\right]^{\alpha / \tilde{q}}=\exp _{\tilde{q} / \alpha}(\alpha x) .
$$

Em particular, se $\alpha=-1$, temos:

$$
\left[\exp _{\tilde{q}}(x)\right]^{-1}=\exp _{-\tilde{q}}(-x)
$$

Assim, $\forall x>0,\left[\exp _{\tilde{q}}(x)\right]^{-1}=\exp _{\tilde{q}}(-x)$ se, e somente se, $\tilde{q}=0$. Este resultado mostra que a função $\tilde{q}$-exponencial se comporta como função exponencial apenas no limite $\tilde{q} \rightarrow 0$. 